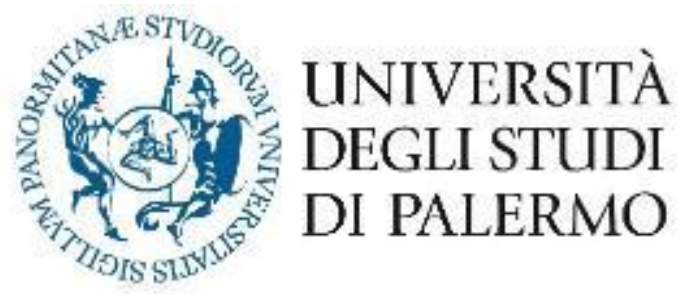

Dottorato in

'Frutticoltura Mediterranea'

Dipartimento di

Scienze Agrarie, Alimentari e Forestali

AGR/13 - Chimica agraria

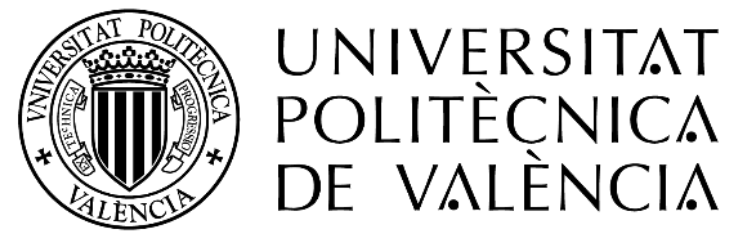

Doctorado en

'Recursos y Tecnologías Agrícolas'

Departamento de

Ecosistemas Agroforestales

Malherbologia

\title{
EFFECTS OF DIFFERENT WEED CONTROL PRACTICES ON SOIL QUALITY IN MEDITERRANEAN CROPS
}

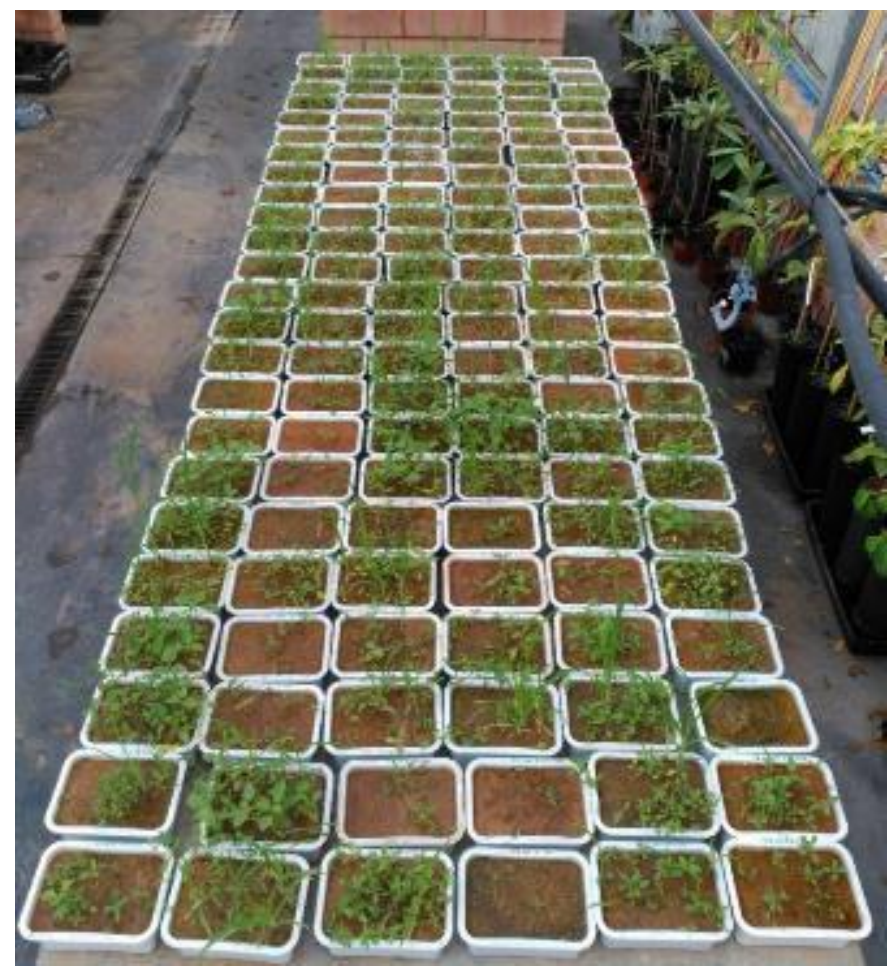

PhD STUDENT

MARTINA ODDO

TUTOR

PROF. ERISTANNA PALAZZOLO
COORDINATOR

PROF. MARIA ANTONIETTA GERMANÀ

CO-TUTORS

PROF. MERCEDES VERDEGUER SANCHO

DR. VITO ARMANDO LAUDICINA 





\section{Abstract: Effects of different weed control practices on soil quality in} mediterranean crops

This research approaches the question of weed control sustainability, from the point of view of soil quality maintenance and enhancing.

A big choice of practices and products for weed control are available nowadays, but the actual definition of "sustainable practice" not always considers soil fertility. Soil processes timescale is wider than the productive, commercial and legislative ones. Also the definition of survey protocols is a process slower than the evolution of weed control methods.

The faster reaction in the soil ecosystem after an external pressure is given by the organisms living in it, and the microbial community is finally the most effective agent in nutrient recycling processes.

In this investigation, the same soil analysis protocol was applied on soil samples exposed to different weed management and control methods. Using soil quality indexes and bioindicators, soil properties variations after the different weed control treatments were compared. Soil carbon pool and how microbial community recycles was surveyed. A standard protocol to both find variations in long-term soil quality and survey the short-term impact of weed control practices on soil biological processes was defined.

Weed management practices can interact with the nutrients recycling processes performed by the microorganisms living in the soil. These processes have a central role in maintaining soil fertility, one of the most important resources for agriculture.

Three weed management practices were compared: the use of synthetic (oxyfluorfen) or natural (essential oils and aqueous extracts) herbicides and two mechanical methods (tillage and mulching).

Soil fertility was monitored measuring soil physical-chemical values and elaborating soil quality indexes and bioindicators. 


\section{Riassunto: Effetti di diverse tecniche di gestione delle erbe infestanti dei coltivi mediterranei sulla qualità del suolo}

Questa ricerca si occupa di un ramo della sostenibilità ambientale del controllo delle arvensi infestanti, dal punto di vista del mantenimento e del miglioramento della qualità del suolo. Oggi è disponibile sul mercato una vasta gamma di prodotti e di tecniche, ma la stessa definizione di "pratica sostenibile" non sempre tiene in considerazione la fertilità del suolo. I processi che avvengono nel suolo hanno infatti scale temporali più ampie rispetto a quelli produttivi, commerciali e legislativi. Anche la definizione dei protocolli di indagine è un processo più lento rispetto all'evoluzione commerciale dei metodi di controllo delle infestanti. In seguito ad una pressione esterna, la parte dell'ecosistema suolo che reagisce più velocemente sono gli organismi che in esso vivono, e la comunità microbica è in definitiva l'operatore più efficace nel riciclare i nutrienti del suolo.

In questo lavoro gli effetti sul suolo di alcune pratiche di gestione delle infestanti sono stati testati con un protocollo di analisi del suolo standardizzato. Si sono confrontate le variazioni delle proprietà del suolo dopo i diversi trattamenti di controllo delle infestanti.

In particolare è stato monitorato il Carbon pool del suolo e come la comunità microbica del suolo lo ricicla. È stato definito un protocollo standard che permette di valutare l'impatto delle pratiche di controllo delle infestanti sia sulle variazioni a lungo termine nella qualità del suolo, sia quelle a breve termine sui processi biologici.

L'ipotesi di base è che la gestione delle infestanti possa interagire con i processi di riciclaggio dei nutrienti che avvengono ad opera dei microrganismi che vivono nel terreno. Questi processi hanno un ruolo centrale nel mantenimento della fertilità del suolo, una delle risorse più importanti per l'agricoltura. Sotto particolare attenzione sono le pratiche di gestioni delle infestanti dei frutteti: l'uso di erbicidi sintetici (oxyfluorfene), di erbicidi naturali (oli essenziali ed estratti acquosi) e due metodi meccanici (aratura e pacciamatura). La fertilità del terreno è stata monitorata misurando variabili chimico-fisiche del suolo ed elaborando indici di qualità e bioindicatori. 


\section{Resumen: Efectos de diferentes prácticas de control de arvenses sobre la calidad del suelo en cultivos mediterráneos}

Esta investigación aborda la cuestión de la sostenibilidad del control de las plantas arvenses, desde el punto de vista del mantenimiento y mejora de la calidad del suelo.

Una gran variedad de prácticas y productos para el control de las arvenses están disponibles hoy en día, pero la definición real de "práctica sostenible" no siempre considera la fertilidad del suelo. La escala de tiempo de los procesos del suelo es más amplia que los procesos productivos, comerciales y legislativos. También la definición de protocolos para la investigación es un proceso más lento que la evolución comercial de los métodos de control de malas hierbas.

La reacción más rápida en el ecosistema del suelo después de una presión externa es dada por los organismos que viven en ella, y la comunidad microbiana es el agente más eficaz en los procesos de reciclaje de nutrientes.

En esta investigación se aplicó el mismo protocolo de análisis de suelo en muestras de suelo expuestas a diferentes métodos de manejo y control de arvenses. Utilizando índices de calidad del suelo y bioindicadores, se compararon las variaciones de propiedades del suelo después de los diferentes tratamientos de control de arvenses. En particular se estudiaron la reserva de carbono en el suelo y la forma en que la comunidad microbiana recicla. Se definió un protocolo estándar para encontrar variaciones en la calidad del suelo a largo plazo y para analizar el impacto a corto plazo de las prácticas de control de arvenses en los procesos biológicos del suelo.

Las prácticas de manejo de malas hierbas pueden interactuar con los procesos de reciclaje de nutrientes realizados por los microorganismos que viven en el suelo. Estos procesos tienen un papel central en el mantenimiento de la fertilidad del suelo, uno de los recursos más importantes para la agricultura.

Se compararon las prácticas de manejo de arvenses de frutales: el uso de herbicidas sintéticos (oxyfluorfen) o naturales (aceites esenciales y extractos acuosos) y dos métodos mecánicos (labranza y mulching).

Se monitoreó la fertilidad del suelo midiendo los valores físico-químicos del suelo y elaborando índices de calidad del suelo y bioindicadores. 


\section{Resum: Efectes de diferents pràctiques de control d'arvenses sobre la qualitat del sòl en cultures mediterrànies}

Aquesta investigació aborda la qüestió de la sostenibilitat del control de les plantes arvenses, des del punt de vista del manteniment i millora de la qualitat del sòl.

Una gran varietat de pràctiques i productes per al control de les arvenses estan disponibles avui en dia, però la definició real de "pràctica sostenible" no sempre considera la fertilitat del sòl. L'escala de temps dels processos del sòl és més àmplia que els processos productius, comercials i legislatius. També la definició de protocols per a la investigació és un procés més lent que l'evolució comercial dels mètodes de control de males herbes.

La reacció més ràpida en l'ecosistema del sòl després d'una pressió externa és donada pels organismes que hi viuen, i la comunitat microbiana és l'agent més eficaç en els processos de reciclatge de nutrients.

En aquesta investigació es va aplicar el mateix protocol d'anàlisi de sòl en mostres de sòl exposades a diferents mètodes de maneig i control d'arvenses. Utilitzant índexs de qualitat del sòl i bioindicadors, es van comparar les variacions de propietats del sòl després dels diferents tractaments de control d'arvenses. En particular es van estudiar la reserva de carboni en el sòl i la forma en què la comunitat microbiana el recicla. Es va definir un protocol estàndard per trobar variacions en la qualitat del sòl a llarg termini i per analitzar l'impacte a curt termini de les pràctiques de control d'arvenses en els processos biològics del sòl.

Les pràctiques de maneig de males herbes poden interactuar amb els processos de reciclatge de nutrients realitzats pels microorganismes que viuen a terra. Aquests processos tenen un paper central en el manteniment de la fertilitat del sòl, un dels recursos més importants per a l'agricultura.

Es van comparar les pràctiques de maneig d'arvenses de fruiters: l'ús d'herbicides sintètics (oxyfluorfè) o naturals (olis essencials i extractes aquosos) i dos mètodes mecànics (conreu i mulching).

Es va monitorejar la fertilitat del sòl mesurant els valors fisicoquímics del sòl i elaborant índexs de qualitat del sòl i bioindicadors. 


\section{Index}

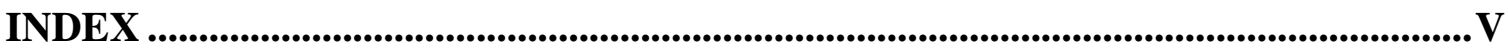

1 INTRODUCTION AND OBJECTIVES...............................................................1

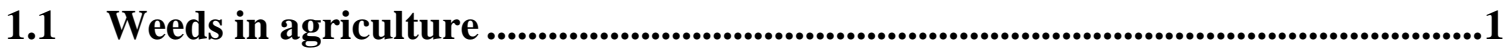

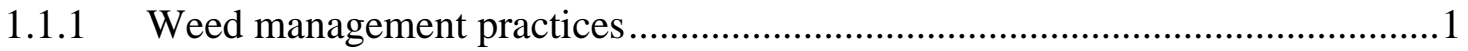

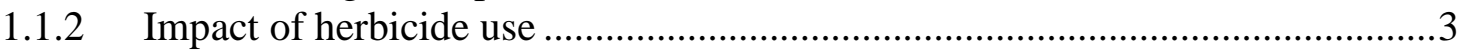

1.1.3 European legislation on plant protection products .........................................

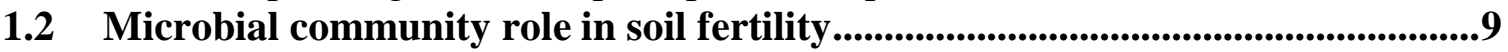

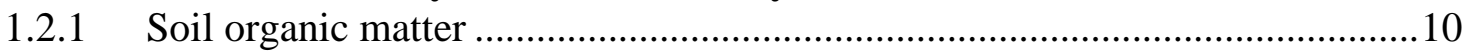

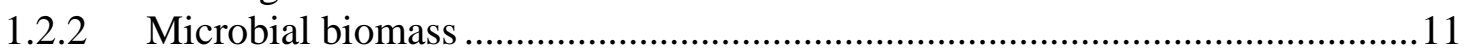

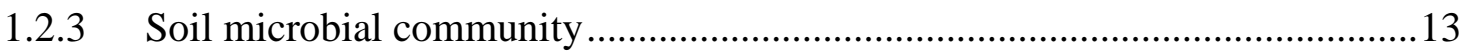

1.3 Weed control methods studied in this work .............................................................15

1.3.1 Natural herbicides: essential oils (EOs), aqueous extracts (AEs) and carvacrol

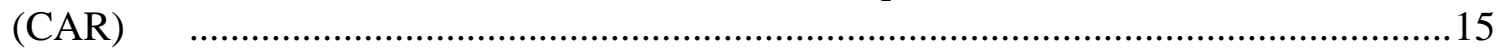

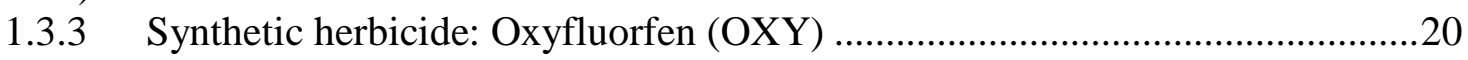

1.3.4 Physical management techniques: tillage and mulching ...............................23

1.4 Objectives ..........................................................................................................................24

2 MATERIALS AND METHODS ......................................................................26

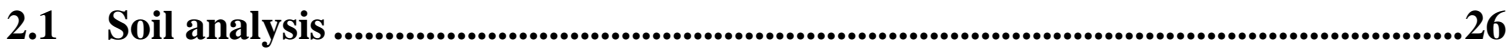

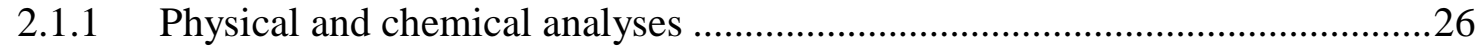

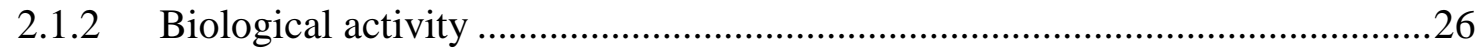

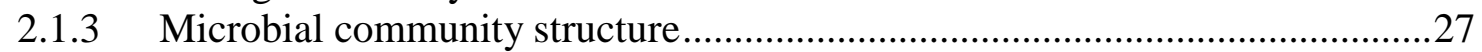

2.2 Materials and methods used in testing natural and synthetic herbicides .........29

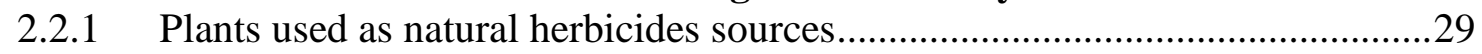

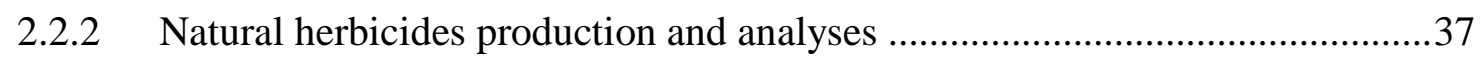

2.2.3 Preliminary soil tests and experimental conditions .......................................42

2.2.4 Experiment one: short and medium-term response of soil microorganisms to essential oils with phytotoxic potential extracted from mediterranean plants .............45

2.2.5 Experiment two: medium term response of soil microorganisms to aqueous extracts with phytotoxic potential extracted from mediterranean plants..........................48

2.2.6 Experiment three: short, medium and long-term response of soil

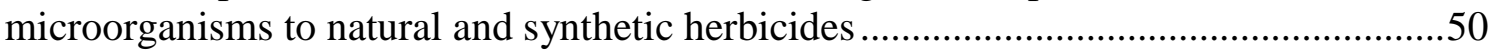

2.3 Materials and methods used in study of physical practices..................................55

2.3.1 Experiment four: long-term comparison between tillage and mulching effects

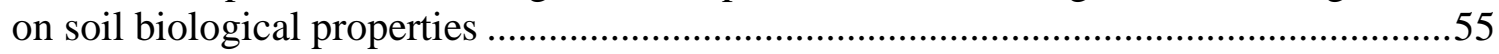

$3 \quad$ RESULTS AND DISCUSSION .............................................................................58

3.1 Essential oils composition and main chemical components properties ................58

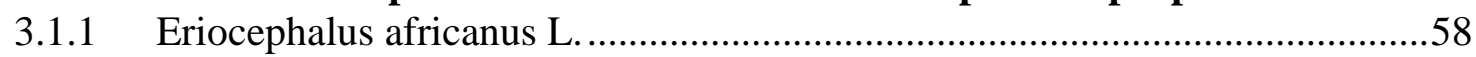

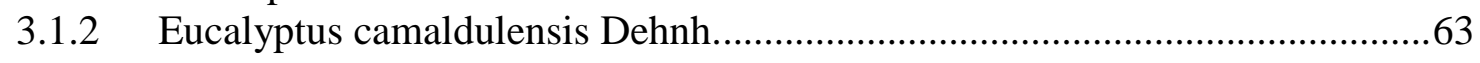

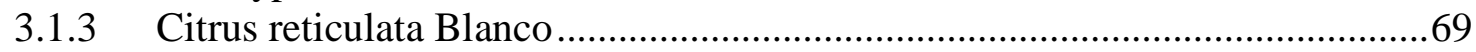

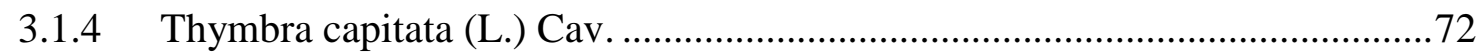

3.2 Experiment one: short and medium-term response of soil microorganisms to essential oils with phytotoxic potential extracted from mediterranean plants ...............74

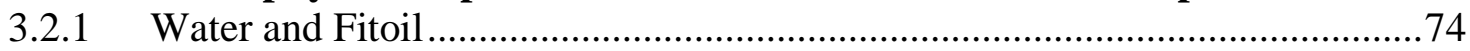

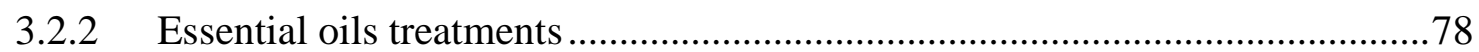


3.3 Experiment two: medium-term response of soil microorganisms to aqueous extracts with phytotoxic potential extracted from mediterranean plants .....................108

3.4 Experiment three: short, medium and long-term response of soil microorganisms to natural and synthetic herbicides ..........................................112

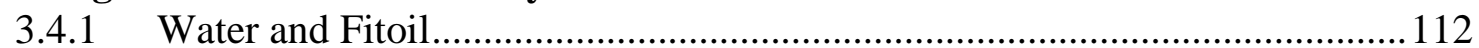

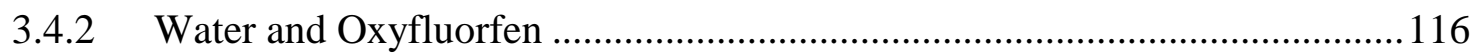

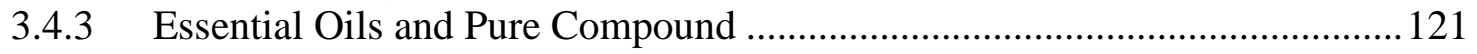

3.5 Experiment four: long-term comparison between tillage and mulching effects on soil biological properties .........................................................................................................140

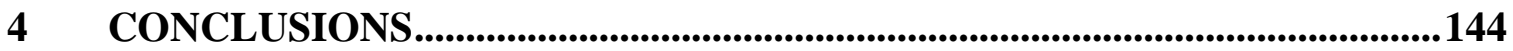

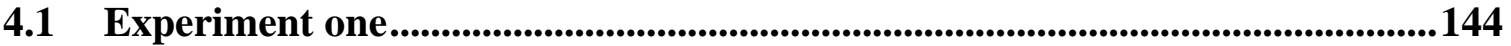

4.2 Experiment two ............................................................................................................145

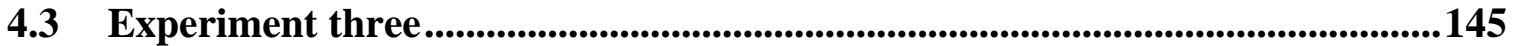

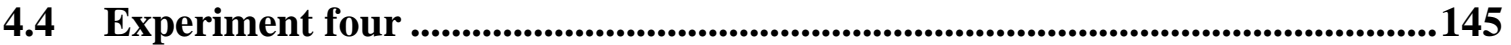

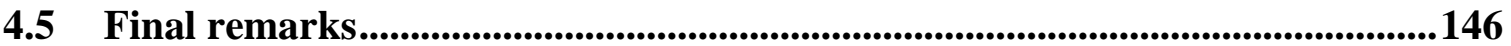

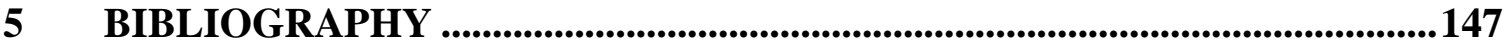




\section{Tables index}

Table 1: Reasons why farmers are reluctant to use non-chemical methods for weed control instead of herbicides....

Table 2: Reasons why European farmers will have to adopt more non-chemical weed control methods

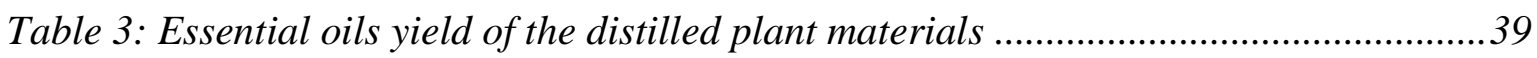

Table 4: Main chemical and physical properties of the soil used for the first experiment..45

Table 5: Volumes of essential oils applied and codes used in the first experiment .............47

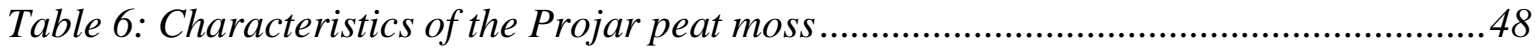

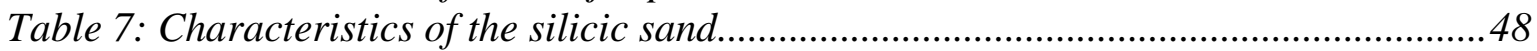

Table 8:Volumes of essential oils, pure compound and synthetic herbicide applied in the

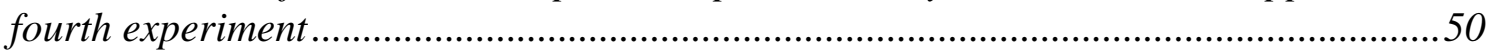

Table 9: Physical properties of the soil used in the fourth experiment.................................51

Table 10: Groups of chemical compounds (\%) found in the essential oils ..........................58

Table 11: Chemical composition of E. Africanus Essential Oil used in the first experiment

60

Table 12: Chemical composition of E. africanus Essential Oil used in the third experiment

Table 14: Chemical composition of C. limon Essential Oil .............................................68

Table 15: Chemical composition of C. reticulata Essential Oil .......................................... 70

Table 16: Chemical composition of T. capitata Essential Oil used in the experiment one .73

Table 17: Chemical composition of T. capitata Essential Oil used in the experiment three

Table 18: Pairwise mean comparison between the chemical, biochemical and microbiological parameters at the same sampling day after 15, 30, 90 and 120 days since WAT and FIT treatments application

Table 19: Principal Component Matrix .78

Table 20: Fisher's $F$ values of the chemical, biochemical and microbiological parameters calculated by two-way ANOVA (type and concentration of essential oil as factors) after 15, 30, 90 and 120 days since EOs treatments application...

Table 21: Significant ( $*, P<0.05$; **, $P<0.01$; ***, $P<0.001$; n.s, not significant) mean differences of soil biochemical properties among treatments concentrations determined after 15, 30, 90 and 120 days since FIT and ERI treatments application....

Table 22: Significant ( $*, P<0.05$; **, $P<0.01$; ***, $P<0.001$; n.s, not significant) mean differences of soil microbial community bioindicators among treatments concentrations determined after 15, 30, 90 and 120 days since FIT and ERI treatments application....84

Table 23: Significant ( $*, P<0.05 ; * *, P<0.01 ; * * *, P<0.001$; n.s, not significant) mean differences of soil biochemical properties among treatments concentrations determined after 15, 30, 90 and 120 days since FIT and EUC treatments application .87

Table 24: Significant (*, $P<0.05$; **, $P<0.01$; ***, $P<0.001$; n.s, not significant) mean differences of soil microbial community bioindicators among treatments concentrations determined after 15, 30, 90 and 120 days since FIT and EUC treatments application.. 89

Table 25: Significant ( $*, P<0.05 ; * *, P<0.01$; ***, $P<0.001$; n.s, not significant) mean differences of soil biochemical properties among treatments concentrations determined after 15, 30, 90 and 120 days since FIT and LEM treatments application....

Table 26: Significant ( $*, P<0.05$; **, $P<0.01$; ***, $P<0.001$; n.s, not significant) mean differences of soil microbial community bioindicators among treatments concentrations determined after 15, 30, 90 and 120 days since FIT and LEM treatments application..95 
Table 27: Significant (*, $P<0.05$; **, $P<0.01$; ***, $P<0.001$; n.s, not significant) mean differences of soil biochemical properties among treatments concentrations determined after 15, 30, 90 and 120 days since FIT and TCP treatments application. 98

Table 28: Significant (*, $P<0.05$; **, $P<0.01 ; * * *, P<0.001 ; n . s$, not significant) mean differences of soil microbial community bioindicators among treatments concentrations determined after 15, 30, 90 and 120 days since FIT and TAN treatments application 100

Table 29: Significant ( $*, P<0.05 ; * *, P<0.01 ; * * *, P<0.001 ; n . s$, not significant) mean differences of soil biochemical properties among treatments concentrations determined after 15, 30, 90 and 120 days since FIT and TCP treatments application. 103

Table 30: Significant ( $*, P<0.05$; **, $P<0.01$; ***, $P<0.001$; n.s, not significant) mean differences of soil microbial community bioindicators among treatments concentrations determined after 15, 30, 90 and 120 days since FIT and TCP treatments application 105

Table 31: Chemical variables of experiment two substrate after the aqueous extracts treatments.... 108

Table 32: Fisher's F values of the substrate chemical, biochemical and microbiological variables calculated by one-way ANOVA after (aqueous extract treatment as factors) determined 120 days after AEs application.....

Table 33: Significant (*, $P<0.05$; **, $P<0.01 ; * * *, P<0.001 ; n . s$, not significant) mean differences of chemical, biochemical and microbiological variables among aqueous extracts treatments determined 120 days after AEs application .................................. 110

Table 34: Pairwise mean comparison between the chemical, biochemical and microbiological parameters at the same sampling day after 30, 60, 120 and 180 days since WAT and OXY treatments application. .116

Table 35: Principal Component Matrix. 121

Table 36: Significant (*, $P<0.05$; **, $P<0.01$; ***, $P<0.001$; n.s, not significant) Fisher's $F$ values of the chemical, biochemical and microbiological parameters calculated by oneway ANOVA (concentration of essential oil as factors) after 30, 60, 120 and 180 days since TCP and CAR treatments application.

Table 37: Significant (*, $P<0.05$; **, $P<0.01$; ***, $P<0.001$; n.s, not significant) mean differences of biochemical variables among concentrations determined at each repetition 30, 60, 120 and 180 days after TCP and CAR treatments application. 123

Table 38: Significant (*, P<0.05; **, $P<0.01$; ***, $P<0.001$; n.s, not significant) mean differences of fatty acids bioindicators among concentrations determined at each repetition 30, 60, 120 and 180 days after TCP and CAR treatments application ........ 129

Table 39: Significant (*, $P<0.05$; **, $P<0.01$; ***, $P<0.001$; n.s, not significant) mean differences of weeds variables among concentrations determined at each repetition 30, 60, 120 and 180 days after TCP and CAR treatments application.

Table 40: Significant (*, $P<0.05$; **, $P<0.01$; ***, $P<0.001$; n.s, not significant) mean differences of soil variables among concentrations determined at each repetition 30, 60, 120 and 180 days after FIT and ERI treatments application. 135

Table 41: Fisher's $F$ values of the chemical, biochemical and microbiological parameters calculated by one-way ANOVA (physical practice as factors) at the two sampling depths (0-20 and 20-40 cm) in the four experimental plots.

Table 42: Mean differences and significance chemical, biochemical and microbiological parameters determined at the two sampling depths $(0-20$ and $20-40 \mathrm{~cm})$ in the four experimental plots. 141 


\section{Figure index}

Figure 1: Map of the herbicide consumption per agricultural land area unit in Europe.....4 Figure 2: Maps of the fungicide consumption per agricultural land area unit in Europe....4

Figure 3: Chronological increase in herbicide resistant weeds globally ..............................5

Figure 4: Map of the abundance of resistant weeds in the World .......................................6

Figure 5: Map of the abundance of resistant weeds in Europe ..............................................6

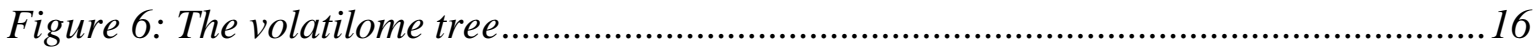

Figure 7: Flow diagram of primary and secondary metabolism for formation of secondary

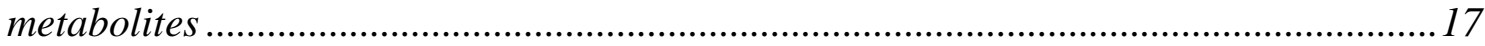

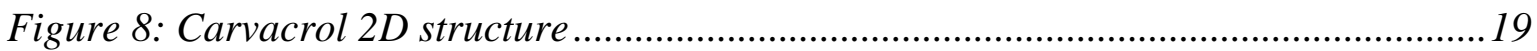

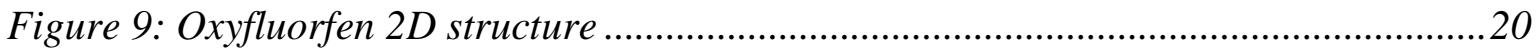

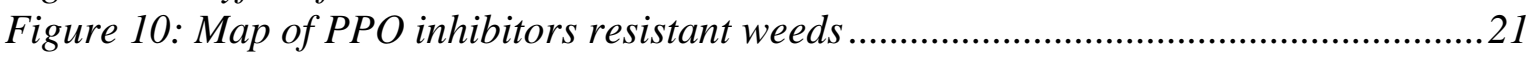

Figure 11: Oxyfluorfen report on EU Pesticides database ...............................................22

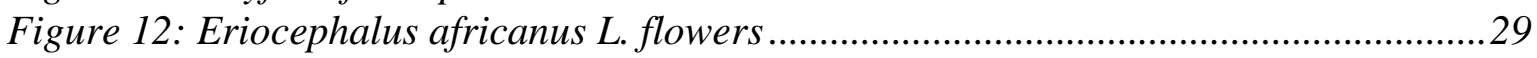

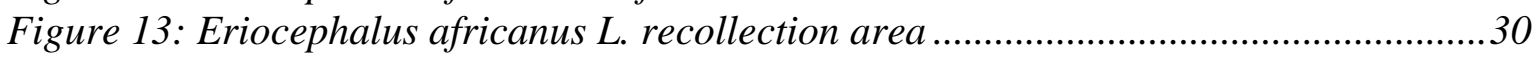

Figure 14: Eucalyptus camaldulensis Dehnh. leaves, flowers and fruits ...........................31

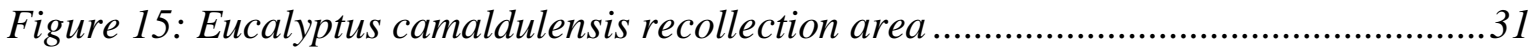

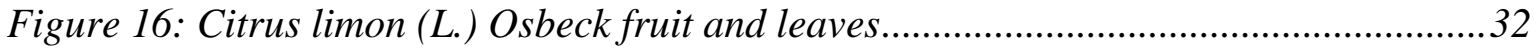

Figure 17: Citrus limon (L.) Osbeck leaves recollection area ..............................................

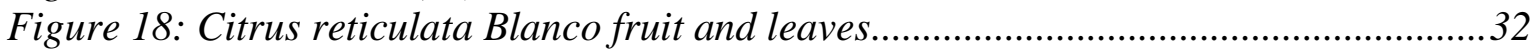

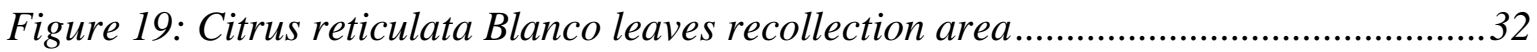

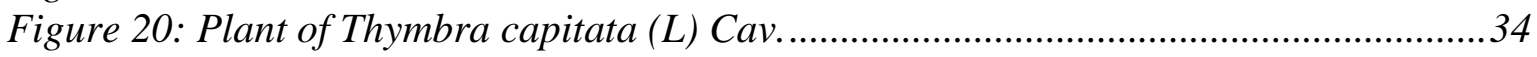

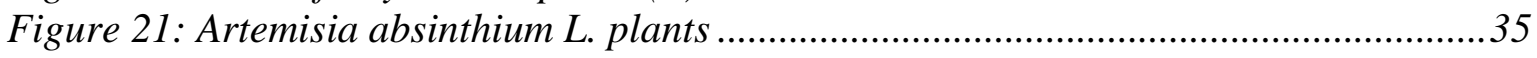

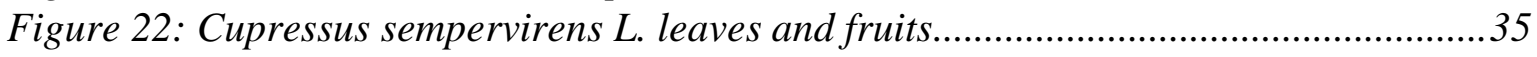

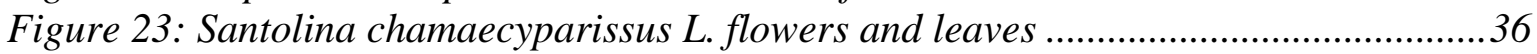

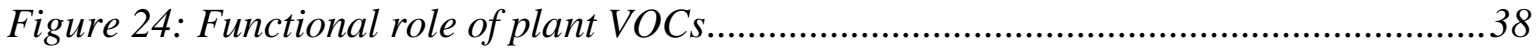

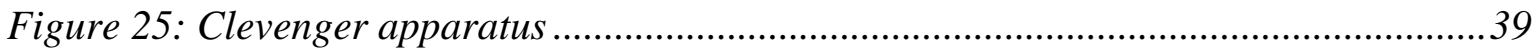

Figure 26: Water Holding Capacity evaluation method 1 .................................................43

Figure 27: Water Holding Capacity evaluation method 2 ...................................................43

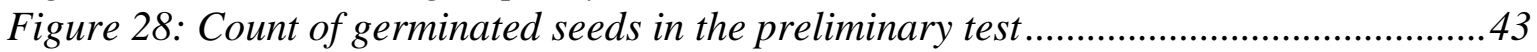

Figure 29: Localization of the experimental greenhouse ...................................................4

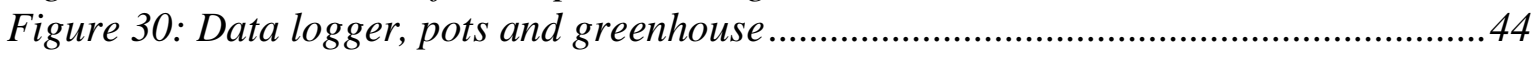

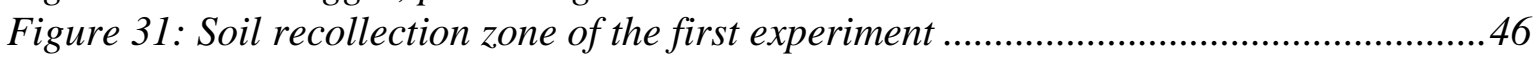

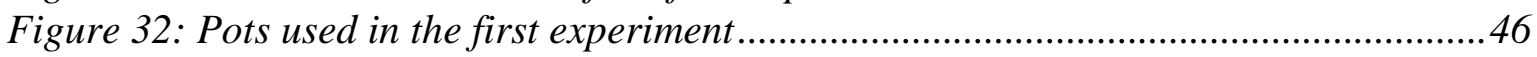

Figure 33: Soil recollection zone of the third experiment .................................................51

Figure 34: Experiment three containers: before, during and after the treatment application

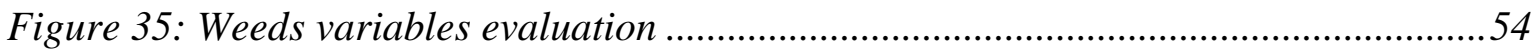

Figure 36: Experimental plots of the third experiment and physical practices details .......57

Figure 37: Biochemical soil variables determined at days 15, 30, 90 and 120 in the fitoil

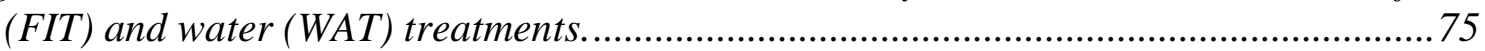

Figure 38: Microbial community structure determined at days 15, 30, 90 and 120 in the fitoil

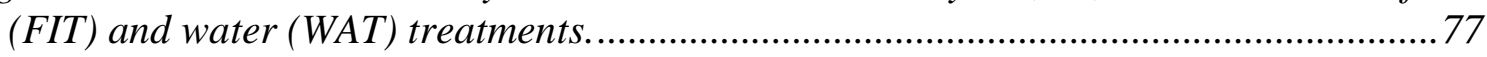

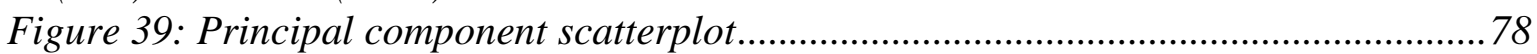

Figure 40: Biochemical soil variables determined at days 15, 30, 90 and 120 in the FIT (fitoil) and ERI (Eriocephalus africanus) treatments at different concentration $(C 1, C 2$ and $C 4$ are, respectively, 1,2 and $4 \mathrm{~mL}$ of essential oil per litre of water) 82 
Figure 41: Microbial community structure determined at days 15, 30, 90 and 120 in the FIT (fitoil) and ERI (Eriocephalus africanus) treatments at different concentration (C1, C2 and $C 4$ are, respectively, 1,2 and $4 \mathrm{~mL}$ of essential oil per litre of water)....................8 86

Figure 42: Biochemical soil variables determined at days 15, 30, 90 and 120 in the FIT (fitoil) and EUC (Eucalyptus camaldulensis) treatments at different concentration (C1, $C 2$ and $C 4$ are, respectively, 1,2 and $4 \mathrm{~mL}$ of essential oil per litre of water) ...............8

Figure 43: Microbial community structure determined at days 15, 30, 90 and 120 in the FIT (fitoil) and EUC (Eucalyptus camaldulensis) treatments at different concentration (C1, $C 2$ and $C 4$ are, respectively, 1,2 and $4 \mathrm{~mL}$ of essential oil per litre of water) ...............92

Figure 44: Biochemical soil variables determined at days 15, 30, 90 and 120 in the FIT (fitoil) and LEM (Citrus limon) treatments at different concentration $(C 1, C 2$ and $C 4$ are, respectively, 1,2 and $4 \mathrm{~mL}$ of essential oil per litre of water) ....................................9. 94

Figure 45: Microbial community structure determined at days 15, 30, 90 and 120 in the FIT (fitoil) and LEM (Citrus limon) treatments at different concentration $(C 1, C 2$ and C4 are, respectively, 1,2 and $4 \mathrm{~mL}$ of essential oil per litre of water) ......................................97

Figure 46: Biochemical soil variables determined at days 15, 30, 90 and 120 in the FIT (fitoil) and TAN (Citrus reticulata) treatments at different concentration (C1, C2 and C4 are, respectively, 1,2 and $4 \mathrm{~mL}$ of essential oil per litre of water)

Figure 47: Microbial community structure determined at days 15, 30, 90 and 120 in the FIT (fitoil) and TAN (Citrus reticulata) treatments at different concentration (C1, C2 and C4 are, respectively, 1,2 and $4 \mathrm{~mL}$ of essential oil per litre of water).............................. 102

Figure 48: Biochemical soil variables determined at days 15, 30, 90 and 120 in the FIT (fitoil) and TCP (Thymbra capitata) treatments at different concentration (C1, C2 and C4 are, respectively, 1,2 and $4 \mathrm{~mL}$ of essential oil per litre of water) ......................... 104

Figure 49: Microbial community structure determined at days 15, 30, 90 and 120 in the FIT (fitoil) and TCP (Thymbra capitata) treatments at different concentration (C1, C2 and $C 4$ are, respectively, 1,2 and $4 \mathrm{~mL}$ of essential oil per litre of water).......................... 107

Figure 50: Soil variables determined 120 days after aqueous extracts (AE) treatments. 111

Figure 51: Biochemical soil variables determined at days 30, 60, 120 and 180 in the fitoil (FIT) and water (WAT) treatments....................................................................... 112

Figure 52: Microbial community structure determined at days determined at days 30, 60, 120 and 180 in the fitoil (FIT) and water (WAT) treatments ..................................... 114

Figure 53: Weeds variables determined at days 30, 60, 120 and 180 in the fitoil (FIT) and water (WAT) treatments.

Figure 54: Biochemical soil variables and microbial community structure determined at days 30, 60, 120 and 180 in the oxyfluorfen (OXY) and water (WAT) treatments. ......119

Figure 55: Weeds variables determined at days 30, 60, 120 and 180 in the oxyfluorfen (OXY) and water (WAT) treatments.

Figure 56: Principal Components scatterplots ............................................................. 121

Figure 57: Biochemical soil variables determined at days 30, 60, 120 and 180 in the TCP (Thymbra capitata EO) and CAR (carvacrol) treatments at different concentration $(C 2$, $C 4$ and $C 8$ are, respectively, 2, 4 and $8 \mathrm{~mL}$ of essential oil per litre of water) ............. 126

Figure 58: Microbial community structure determined at days 30, 60, 120 and 180 in the TCP (Thymbra capitata EO) and CAR (carvacrol) treatments at different concentration (C2, C4 and C8 are, respectively, 2,4 and $8 \mathrm{~mL}$ of essential oil per litre of water) ..... 132

Figure 59: Weeds variables determined at days 30, 60, 120 and 180 in the TCP (Thymbra capitata $E O)$ and $C A R$ (carvacrol) treatments at different concentration $(C 2, C 4$ and $C 8$ are, respectively, 2,4 and $8 \mathrm{~mL}$ of essential oil per litre of water)....... 134 
Figure 60: Biochemical soil variables determined at days 30, 60, 120 and 180 in the FIT (fitoil) and ERI (Eriocephalus africanus) treatments at different concentration (C2, C4 and C8 are, respectively, 2, 4 and $8 \mathrm{~mL}$ of essential oil per litre of water)

Figure 61: Microbial community structure determined at days 30, 60, 120 and 180 in the FIT (fitoil) and ERI (Eriocephalus africanus) treatments at different concentration (C2, $C 4$ and $C 8$ are, respectively, 2,4 and $8 \mathrm{~mL}$ of essential oil per litre of water) 138

Figure 62: Weeds variables determined at days 30, 60, 120 and 180 in the FIT (fitoil) and ERI (Eriocephalus africanus) treatments at different concentration $(C 2, C 4$ and $C 8$ are, respectively, 2,4 and $8 \mathrm{~mL}$ of essential oil per litre of water)

Figure 63: Soil properties measured at the two sampling depths in the four experimental plots. 143 



\section{Introduction and objectives}

Weed management is currently an unavoidable activity in agriculture, independently from the production typology. Weeds are also undesired in natural, farmed and recreational green areas.

Even if the target of these techniques is usually a grass, every kind of management can affect soil microbiota and consequently soil biologic fertility.

Soil fertility is a very important natural resource whose renewability has a key role in crop production. To survey and enhance it is the most effective way to support crop production sustainability.

\subsection{Weeds in agriculture}

It was stated that direct yield losses caused by pathogens, animals, and weeds, are responsible for losses ranging between 20 and $40 \%$ of global agricultural productivity, harder is to evaluate the true costs of crop losses to consumers, public health, societies, environments, economic fabrics and farmers (Savary et al. 2012). Comparing loss due to weeds with the one caused to other pests, it results that 'overall, weeds produced the highest potential loss $(34 \%)$ with animal pests and pathogens being less important (losses of $18 \%$ and $16 \%)^{\prime}$. When no weed control practices are applied potential yield can decrease from the 50 to the $80 \%$ (Oerke \& Dehne 2004; Oerke 2006).

Herbicides accounted for $46 \%$ of global pesticide sales in 2005 , with insecticides $(26 \%)$ and fungicides (23\%) accounting for smaller proportions of the $\$ 33,600$ million total spend (Agrow 2006).

\subsubsection{Weed management practices}

Weed control practices can be classified in several ways, including by weed control spectrum, labelled crop usage, chemical families, mode of action, application timing and/or method etc... In scientific and legal fields, nowadays, two categorical classifications are used: one related to time (prevention, control and eradication) and other to techniques (physical, chemical and biological). Each single weed management practice can be classified according to both categories (Monaco et. al 2002).

The time categorization refers to the colonization stage of the weed population on the field. Preventive methods consist in avoiding any weed propagule incoming in the orchard to control the weed before the establishment of a population. All the equipment must be kept 
clean and the growth of weeds in the neighbourhood controlled too. All the material and the seeds must be controlled and, if it is possible, certified.

Control consists in limiting the consequences of weed infestations on crop growth and yield, modifying the agroecosystem to promote mostly the target crop and/or stressing the weed population. It is easy to understand that a healthy crop can compete a weed invasion better than a stressed one. Some good practices in cultural weed control practices are: follow soil test recommendations for fertilizer and lime; - select a crop variety compatible with the environment, plant in the right time; - control all plant diseases regularly; - use mature compost or organic amendments.

Eradication is much more difficult than prevention or control, consisting in the total elimination of all living plants, propagules and seeds from the soil superficial layer.

As previously mentioned, the second classification divides weed management techniques among physical, chemical and biological.

Physical techniques either destroy weeds or make the environment less favourable for seed germination and weed survival. Among physical techniques, the mechanical ones are the oldest in agriculture, including hand-pulling, tillage, hoeing, mowing, ploughing, disking, cultivating, and digging. Such practices are traditionally used, sometimes even abused increasing the organic matter mineralization by weathering. Moreover, often equipment and work force are required, increasing operating expenses (Jabran et al. 2015). Mulching using inert materials (straw, wood chips, gravel, plastic, etc.) can be considered a mechanical control mean since it uses a physical barrier to block light and impede weed growth. Other physical techniques based on temperature and drought are solarisation and flaming.

Chemical herbicides can be defined as crop-protecting chemicals used to kill weedy plants or interrupt normal plant growth. Herbicides offer a convenient, economical, and effective way to help manage weeds. They allow to plant fields with less tillage and earlier planting dates. Without herbicide use, no-till agriculture loses efficiency and short-term productivity. However, herbicide use also carries risks that include environmental, ecological, and human health effects. Herbicides may not be a necessity on some farms or landscape settings, but without the use of chemical weed control, mechanical and cultural control methods become that much more important.

Biological weed control involves the use of other living organisms, such as insects, diseases, or livestock, for the management of certain weeds. Also, the use of organic materials interfering weed growth can be considered biological control methods. Herbivores such as sheep and goats can provide successful control of some common pasture weeds. 
Mulching using organic material having the potential to release inhibitory (allelopathic) chemicals into the soil environment that inhibit weed seedling growth is another recently studied technique.

Research continues in this area of weed management. In theory, biological control is well suited for an integrated weed management program. However, the limitations of biological control are that it is a long-term undertaking, its effects are neither immediate nor always adequate. Only certain weeds, insects and controlled diseases are potential candidates, and not enough ecological studies to draw a sustainable model have been performed on them.

During last decade, aside the synthetic herbicides, new natural origin chemical herbicides gained interest both in scientific and commercial field (Hatcher \& Melander 2003; Flamini 2012).

\subsubsection{Impact of herbicide use}

Farmers have preferred synthetic herbicides during the last decades for their easy use, large number of weed species controlled and fast and long-lasting effect. On the other hand, they could affect the ecosystems, pollute groundwater and the environment, and affect human and animal health. The overuse of synthetic herbicides can also promote the apparition of resistant weeds. There are many kinds of herbicides from which to choose and many factors decide when, where, and how a specific herbicide can be used most effectively. It is extremely important to understand both the benefits and disadvantages associated with chemical weed control before selecting the proper practice for each orchard.

More than $97 \%$ of food samples evaluated by the European Food Safety Authority (EFSA) hold pesticide residue levels that fall within legal limits, with just under $55 \%$ of samples free of detectable traces of these chemicals. The findings are part of EFSA's 2013 annual report on pesticide residues in food, which includes the results for almost 81,000 food samples from 27 EU Member States, Iceland and Norway (EFSA 2014).

The European Union Council, in the aim to protect the citizens, regulates use and commercialization of pesticides in order to reduce the risks and impacts of them on people's health and the environment. There are two important regulations: the Regulation (EC) No $1107 / 2009$ of the European Parliament concerning the placing of plant protection products on the market, which repeals Council Directives 79/117/EEC and 91/414/EEC and the Directive 2009/128/EC of the European Parliament and of the Council of 21 October 2009 
establishing a framework for Community action to achieve the sustainable use of pesticides (European Commission 2016).
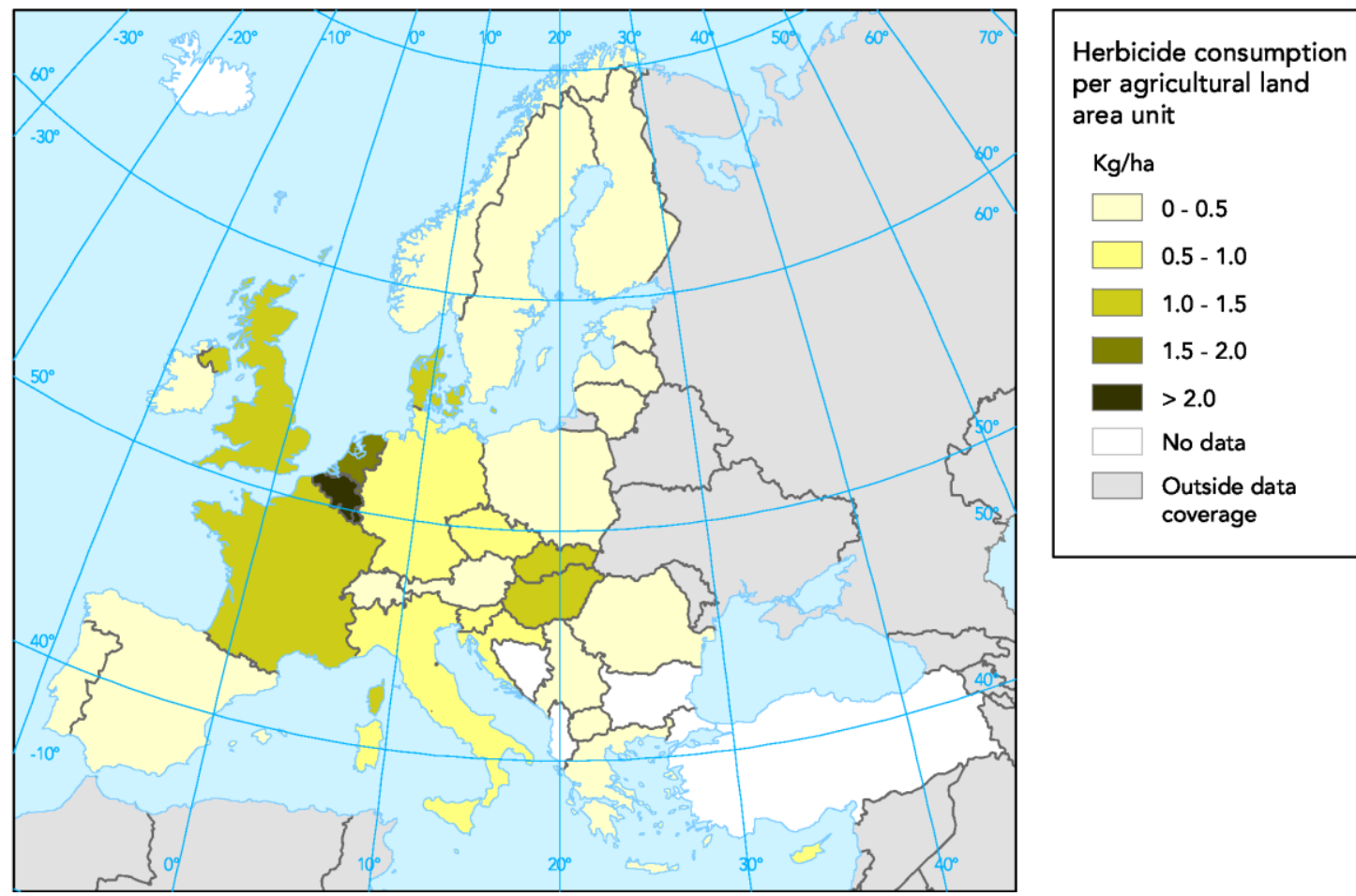

Figure 1: Map of the herbicide consumption per agricultural land area unit in Europe. (EEA 2012)

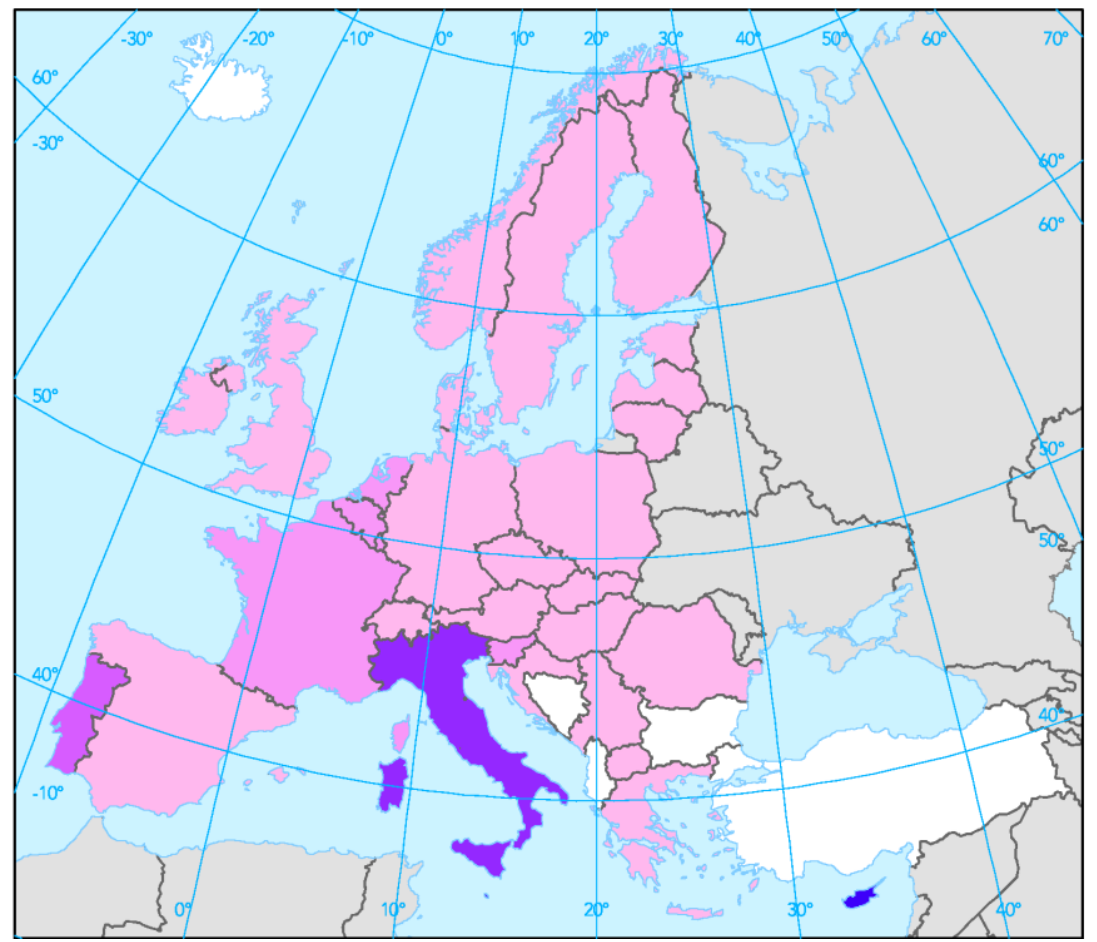

\section{Fungicide consumption} per agricultural land area unit

$\mathrm{Kg} / \mathrm{ha}$

$\square 0-1$

$1-2$

$2-3$

$3-4$

$>4$

No data

Outside data coverage

Figure 2: Maps of the fungicide consumption per agricultural land area unit in Europe. (EEA 2012) 


\subsubsection{Herbicide-resistant weeds}

The most renowned organizations for weed study are the European Weed Research society in E.U. (EWSR, 2016) and Weed Science in U.S.A (Heap 2017), furnishing updated opensource databases containing many data on weeds and herbicides. Since 1975 the number of resistant weeds registered globally increased dramatically, reaching 481records in 2017 (figure 3). According to the database, there are 30resistant weeds registered in Italy and 37 in Spain, in figures 3,4 and 5 are reported three charts produced interrogating the site geoportal.

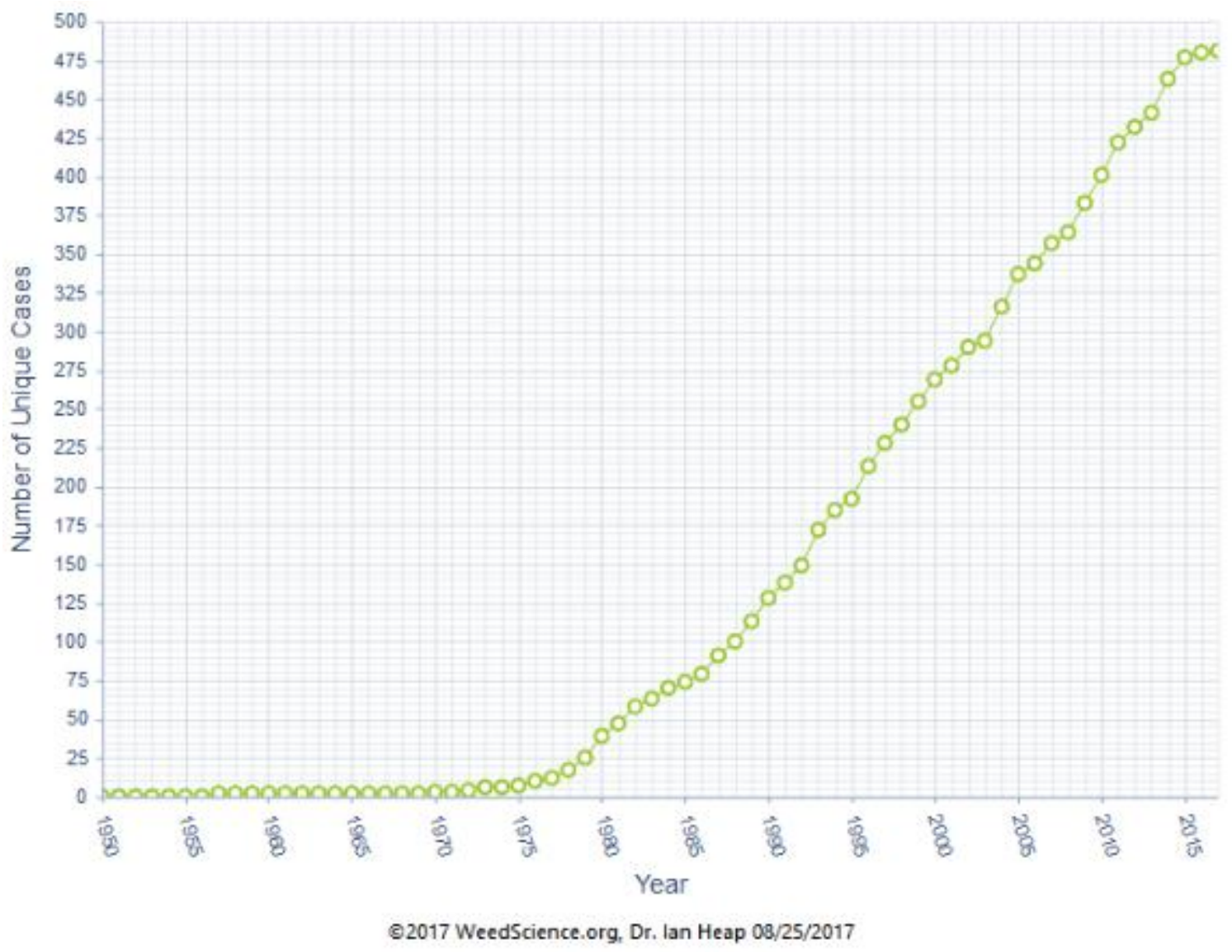

Figure 3: Chronological increase in herbicide resistant weeds globally (Heap 2017) 


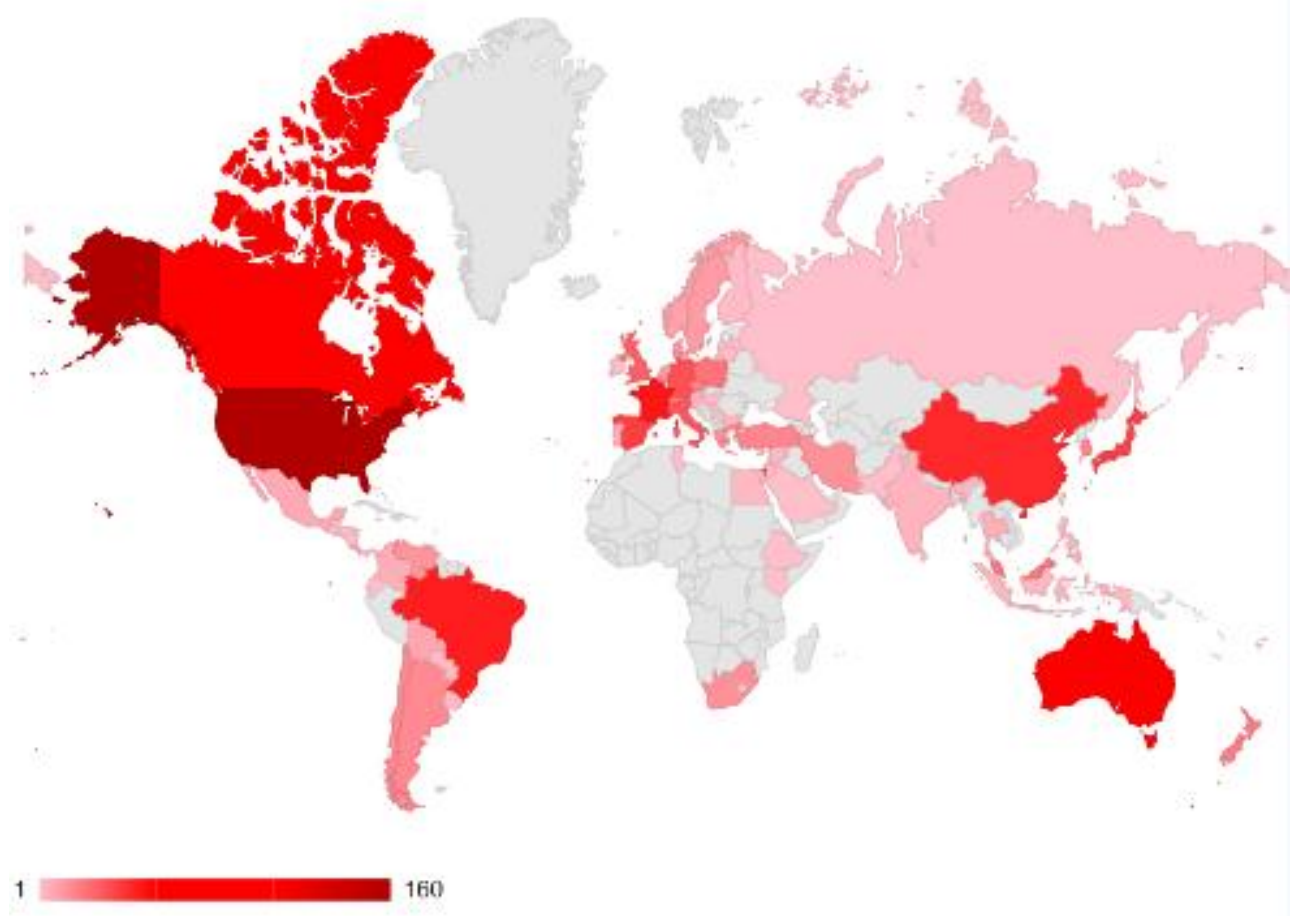

Figure 4: Map of the abundance of resistant weeds in the World (Heap 2017)

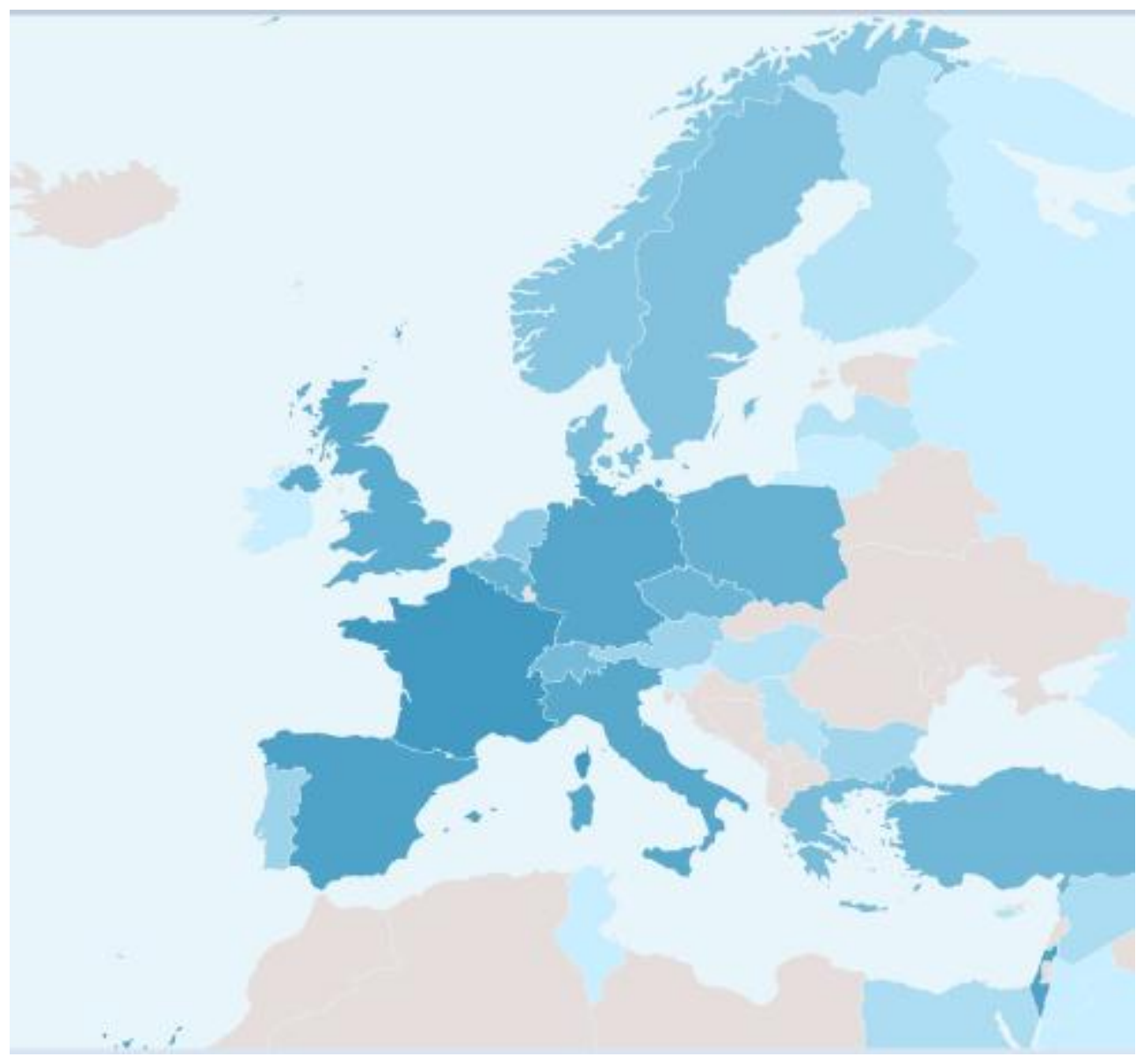

Figure 5: Map of the abundance of resistant weeds in Europe (Heap 2017) 


\subsubsection{European legislation on plant protection products}

The EU defines: 'Integrated Pest Management (IPM) means careful consideration of all available plant protection methods and subsequent integration of appropriate measures that discourage the development of populations of harmful organisms and keep the use of plant protection products and other forms of intervention to levels that are economically and ecologically justified and reduce or minimize risks to human health and the environment' (Moss 2010).

Integrated Weed Management (IWM) can be considered one part of IPM, and has been described as the application of many alternative weed control measures, which include cultural, genetic, mechanical, biological and chemical means of weed control (Swanton and Weise 1991).

Natural origin chemical herbicides are expected to be a good compromise between easy use and low environmental impact, because application method and the commercial presentation are the same of synthetic one. Essential Oils (EOs) and Aqueous Extracts (AEs) mixtures are generally harmless for human health and their herbicide efficiency is proved even more mainly by their use in organic farming. Nevertheless, few studies focus on the effects of essential oils soil application on microbial community.

While synthetic herbicides are considered the main means of weed control in many countries, there is increasing recognition that their use will have to be integrated with greater use of non-chemical methods (table1 and 2).

Table 1: Reasons why farmers are reluctant to use non-chemical methods for weed control instead of herbicides

\begin{tabular}{ll}
\hline 1 & More complex to manage, time constraints \\
2 & Less effective than herbicides \\
3 & Control levels more variable \\
4 & More expensive than herbicides \\
5 & Control levels less predictable \\
6 & No compensation following control failure \\
7 & May not reduce the need for herbicides \\
8 & Little visible evidence of success \\
9 & Riskier, to consultant as well as farmer \\
10 & Less return for supplier of herbicides \\
11 & May have adverse environmental effects \\
12 & Harder manual effort \\
\hline Moss 2010)
\end{tabular}


Oddo M. - Effects of different weed control practices on soil quality in mediterranean crops

Table 2: Reasons why European farmers will have to adopt more non-chemical weed control methods

1 Fewer herbicides available due to past European Union (EU) regulatory actions, and lack of new modes of action.

2 Increasing resistance, especially in grass-weeds such as Alopecurus myosuroides Huds. (blackgrass) and Lolium spp.

3 New EU regulatory actions requiring farmers to adopt Integrated Pest Management (IPM).

(Moss 2010)

The traces of pesticides leave in treated crops are called "residues". The maximum residue level (MRL) is the highest level of a pesticide residue that is legally tolerated in or on food or feed when pesticides are applied correctly. The amounts of residues found in food must be safe for consumers and must be as low as possible. The European Commission fixes MRLs for all food and animal feed. The MRLs for all crops and all pesticides can be found in the MRL database on the Commission website (European Commission 2017). 


\subsection{Microbial community role in soil fertility}

Over the last few years, several studies have been conducted to define soil quality and find the most proper indicators for its proper evaluation. These studies highlighted that soil quality is a relative concept, since it depends mainly on the use which the soil is destined to. In fact, the Soil Science Society of America Ad Hoc Committee on Soil Health (Karlen et al. 1997) defined soil quality as "the ability of a specific soil to function within the limits of a natural or anthropic ecosystem to support the productivity of plants and animals, maintain and improve the quality of water and air and support human health and human habitation.". This soil quality definition can be considered as the most comprehensive one because it simultaneously evaluates the three basic aspects of soil characteristics: biological productivity, soil interaction with other environmental compartments and plant and animal health, man included. According to (Huising et al. 2016), soil functions refer to the seven key functions of soil in the global ecosystem as:

1. Biomass production, including in agriculture and forestry;

2. Storing, filtering and transforming nutrients, substances, and water;

3. Biodiversity pool, such as habitats, species and genes;

4. Physical and cultural environment for humans and human activities;

5. Source of raw materials;

6. Acting as carbon pool;

7. Archive of geological and archaeological heritage.

One of the main properties of an ecosystem is its productivity, the amount of biomass produced in a determined area during a period. The primary producers are autotrophic organisms, which produce the primary productivity from the ecosystem base. Biomass production by Heterotrophic organisms consuming autotrophies is called secondary productivity. A given ecosystem can have a very high total or biological productivity, however, if decomposers decompose organic matter at the same rapidity with which it is formed, net primary productivity will be low (Doran \& Zeiss 2000; Manzoni et al. 2012).

Moreover, if we associate with the concept of "soil quality" to that of "soil health", the quality of a soil is closely related to the purpose it is intended for. A "healthy" soil may be unsuitable for a certain use but still be healthy. For example, soils at early stages of development and in extreme conditions have low biodiversity and low potential productivity, but this is a natural stage of soil evolution that is considered to be a healthy soil, but not suitable for agricultural production (Sparling 1997; Andrén et al. 1999; Muscolo et al. 2015). 
By referring to the primary productivity of a soil, we can use the term "fertility" instead of "quality".

Soil natural fertility is an inherent quality of the soil, determined and developed during the pedogenetic processes. Climate change and human activities have been named as the main causes of soil fertility loss, i.e. factors capable of triggering degradation processes of arid, semiarid and sub-humid lands that lead to desertification (UNCED, 1992). Agricultural management is one of the most significant anthropogenic activities that greatly alter soil quality (van Diepeningen et al. 2006; Anderson \& Domsch 2010).

Since different plants have different needs and optimal growth conditions, there is not a comprehensive concept of soil fertility. In fact, it is conditioned by all those environmental, physical and chemical factors linked to plant nutrition, and is intimately linked to the soil organic matter (SOM) through biological activity of microorganisms.

Three complementary soil fertility types can be distinguished. Physical fertility refers to those soil physical characteristics resulting by weathering processes on the original lithological material. Chemical fertility refers essentially to the soil's ability to make nutrients available for plant growth. Biological fertility refers to that fertility that is closely related to the presence and activity of the living organisms of the soil. Biological fertility depends on the quantity and quality of organic residues, microbial biomass levels and various environmental parameters such as humidity, temperature, aeration, etc.

Attempts to make an overall assessment of soil fertility are complex, as this, as previously described, is a very broad concept. For this reason, several studies have been conducted over the last few years in the aim to identify indicators of the physical, chemical and biological quality of the soil. Unlike soil quality indicators, considered "static" because they only detect long-term changes, biochemical indicators are considered "dynamic" because they are particularly sensitive to reporting changes in the state of the soil ecosystem in the short term. Among the most used biochemical parameters as soil quality indicators, microbial biomass, an estimate of its potential activity and its structure are of great importance (Paz-Ferreiro \& Fu 2016).

Soil microbial properties are reported to be more sensitive than physical and chemical properties in detecting changes in soil quality (Doran et al. 1996; Nannipieri et al. 2003).

\subsubsection{Soil organic matter}

Soil organic matter (SOM) is the heterogeneous and extremely complex mixture of all living and non-living organic materials of plant and animal origin, included in soil under any 
form (excluding macroflora, macrofauna and mesofauna). While standing for a small part (0.1-10\%) of the solid phase, plays a key role in defining soil quality. In addition, over the last few years, SOM has attributed a central role to global warming, fulfilling the role of carbon sink and source (Laudicina et al. 2012).

SOM amount not only depends on the quantity and quality of organic materials in the soil, but also on the particular orientation and relative speed of the humification and mineralization processes to which these materials are subjected to, as on abiotic factors influencing soil biota equilibria (Fontaine et al. 2003; Guenet et al. 2010).

SOM is a nutrient and energetic substrate for soil organisms and a source of nutrients for plants, regulates water retention; influences xenobiotics biodegradability, persistence and reactivity; and contributes to limiting erosion phenomena by stabilizing soil physical structure. Ultimately, SOM plays a cross-role in soil ecology as it can influence soil physical, chemical and biological properties, the set of which is the soil fertility. Therefore, being SOM correlated with many aspects of productivity and sustainability of agro-ecosystems and environmental conservation is considered to be the best chemical soil quality indicator (Smith \& Smith 2000, 2009).

Soil biota, a small, labile but crucial fraction of soil organic matter, is the driving force behind energy transfers and nutrient transformations in soils, thus playing a major role in soil fertility and resiliency (Badalucco et al. 2010).

\subsubsection{Microbial biomass}

By microbial biomass is meant the living fraction of the organic matter of the soil, excluding plant roots and organisms larger than $510^{3} \mu \mathrm{m}^{3}$ (Ladd \& Paul 1981). Microbial biomass is a key component of soil fertility and plays an irreplaceable role, in the absence of which the soil would simply become an inert mechanical support (Lynch 1987; Foster 1988; Bradford et al. 2002; Laudicina et al. 2013).

Microbial Biomass Carbon (MBC) accounts for approximately 1-5\% of total organic C, while Microbial Biomass Nitrogen (MBN) ranges from 2 to $6 \%$ of total organic nitrogen. It is mainly (> 50\%) concentrated in the first 20 centimetres of soil. The MBC in the soil varies from 100 to $>1000 \mathrm{mg} \mathrm{C} \mathrm{kg-1.} \mathrm{It} \mathrm{is} \mathrm{considered} \mathrm{a} \mathrm{good} \mathrm{indicator} \mathrm{since,} \mathrm{having} \mathrm{a} \mathrm{very} \mathrm{short}$ turnover ( $<1$ year), responds fairly quickly to conditions of stress / disturbance of the soil (Abdul \& Grohmann 2012; Novara et al. 2014). On the other hand, however, being a very dynamic property, its timely determination does not provide any indication of the quality of the organic substance. For these reasons, it is necessary to monitor it over time (at least 
seasonal). The immobilized chemical elements in the microbial cell, although constituting a negligible percentage of the total contained in the soil, have remarkable nutritional significance since the cellular compounds to which they belong are the most easily degradable compound, hence the most readily available, to ensure proper refuelling of nutrients for plant growth.

Microbial soil biomass with its biological activity contributes to maintaining soil fertility and the conditions of habitability and nutrition suitable for plant growth (Nannipieri et al. 2003).

Among the functions of remarkable environmental value carried out by microbial organisms of microbial biomass we find the mineralization of the organic substance and the consequent release of soluble forms of nutrients available for the mineral nutrition of plants, biological fixation of nitrogen by nitrogenous organisms, degradation Xenobiotics and the biological control of pathogens (thanks to the allelopathic substances produced by indigenous populations as a defence reaction). Jenkinson \& Ladd (1977) described the microbial soil biomass as "the eye of the needle through which all organic matter must pass as it is broken down into simple inorganic components, including water, carbon dioxide, nitrate, phosphate and sulphate, that the plants can use again".

Microbial activity refers to the vastness of the activities of soil microorganisms and is of crucial importance for biogeochemical cycles. It is regulated by several factors: oxygen, nutrients and water availability, temperature, $\mathrm{pH}$, etc. Microbial activity can be determined in the field or in the laboratory. In the laboratory, being conducted under standard temperature and humidity conditions, microbial activity refers to "potential microbial activity" and not actual, but allows to compare soils in different geographic areas and different environmental and management conditions.

To determine the potential microbial activity several methods have been proposed, including soil respiration (SR), i.e. the amount of $\mathrm{CO}_{2}$ emitted by soil under standard conditions. SR is a measure of the total metabolic activity of soil microorganisms under aerobic conditions. This biochemical soil bioindicator gives indications about $\mathrm{C}$ availability for soil microorganisms, or the decomposition of soil organic matter. Since the decomposition is a process governed by soil microorganisms, the emitted $\mathrm{CO}_{2}$ volume is commonly called microbial respiration or heterotrophic breathing.

SR is a very sensitive parameter of the biotic fraction of the soil ecosystem. It responds promptly to disturbance factors such as temperature, humidity, irrigation, soil processing, addition of organic fertilizers and fertilizers, etc. 
Although the validity of biochemical parameters as soil quality indicators is widely acknowledged, it should be emphasized that the determination of a single biochemical or microbiological parameter cannot be used as an index of the microbiological activity of the soil, which is the result of various metabolic processes and multiple enzymatic activities.

To this end, it is necessary to use more parameters to be representative of the main microbial processes in the soil. In some cases, it may also be useful to determine some simple indexes such as the metabolic quotient $(\mathbf{q C O} 2)$.

\subsubsection{Soil microbial community}

Soil functionality not only depends on soil microbial community activity, but also on its structure. Bacteria, Archea and Fungi are the most important soil inhabitants, in addition to these, Protozoa, Animals (especially Nematodes) and Chromalveolata (in particular algae and actinomicetae) also play a prominent role (Schloter et al. 2003; Gardner et al. 2011; Hinojosa et al. 2016).

Assessing soil microbial community biodiversity can be determinant to understand soil ecosystem. One of the assumptions ecosystem ecology is the principle of emerging properties (McIntosh 1981; Pickett et al. 1989), according to which there is a positive correlation between the number of ecological niches simultaneously present in an ecosystem (functional diversity of populations) and its Resistance to external perturbations.

It has been hypothesized that similarly, in the soil ecosystem, a reduction in microbial community functional or taxonomic diversity may have adverse effects on the soil's resistance to external disturbances (Andrén et al. 1999).

In fact, as reported by Bengtsson (1998) on the importance of taxonomic diversity, it does not have a specific function in ecosystems, but high a-diversity (specific redundancy) increases the likelihood of vicariousness between taxonomically distant organisms with similar ecological value and overlapping niche (functional redundancy).

Soils with high biodiversity microbial communities can thus easily absorb environmental disturbances and perform functions and services in ecosystems when human needs or environmental conditions change.

The large number of microorganisms living in some soils (estimated an average of $10^{9}$ bacteria, $10^{7}$ actinomycetes, $10^{6}$ fungi, $10^{4}$ algae, $10^{5}$ protozoans per gram of soil), their high diversity (estimated on average 4000 different genomes per gram of soil), the difficulty of cultivating them in laboratory and the problems associated to the proper placement of different species of microorganisms, obstacles investigations. So researchers have developed 
methods for assessing biodiversity based on microbial communities rather than on different species (Pankhurst 1997; Bradford et al. 2002; Coleman \& Whitman 2005; Dirilgen et al. 2016).

Some of these methods include microbial community structure analysis based on i) extracting and amplifying DNA extracted from the soil or ii) extraction and characterization of the fatty acids of the phospholipids (FAs) of the cell membrane.

Membrane composition is species-specific (Cavalier-Smith 1987, 2002), and during vital phases it is modified by biological feedbacks in adaptation to the external stress. For example, the decrease in environmental temperature causes the production by the Golgi apparatus of fatty acids with relatively more saturated phospholipids, to maintain membrane fluidity. For the same reason, all cryogenic organisms possess, in proportion, few unsaturated membrane phospholipids. Based on this assumption it can be stated that the cell membrane is a diagnostic character of both the identity and the state of health or stress of an organism (Olsson 1999; Feng \& Simpson 2009; Wixon \& Balser 2013) . 


\subsection{Weed control methods studied in this work}

\subsubsection{Natural herbicides: essential oils (EOs), aqueous extracts (AEs) and carvacrol (CAR)}

Allelochemicals are secondary metabolites produced by living organisms to interact (either positively or negatively) with other individuals or species. Allelopathy plays a major role in regulating population abundance of co-existing plants, insects, fungi and microbes in ecological communities. In a classical sense, allelopathy refers to the in vivo plant-plant interactions that occur through specific chemical compounds (allelochemicals) produced and released by plants, both in natural and agricultural ecosystems. However, recently allelopathy definition has been enlarged to include all plant metabolites exerting effects on other plants.

Volatile Organic Compounds (VOCs, figure 6) plays the mayor role in plant communication, many biochemical pathways are involved in VOCs production. Chemically, VOCs, as shown in figure 7, belong to the large group of terpenoids (homo-, mono-, di-, sesquiterpenoids), fatty acid derived C6- volatiles and derivatives, phenylpropanoid aromatic compounds (like methyl salicylate, MeSA, and indole), as well as certain alkanes, alkenes, alcohols, esters, aldehydes, and ketones (Maffei 2010).

The use of plant extracts with negative allelopathic interactions (phytotoxic effects) against weeds is widely worldwide studied (Reigosa et al. 2006; Bhadoria 2011). In this work, two kind of plant extracts have been tested: aqueous extracts (AEs) and essential oils (EOs). Other research groups (Dudai et al. 1999; Reigosa \& Pazos-Malvido 2007; Reigosa-Roger \& Sánchez-Moreiras 2009; Graña 2015) study the effects and mechanism of action of natural pure compounds (PCs) on model plants (mainly Arabidopsis thaliana). 


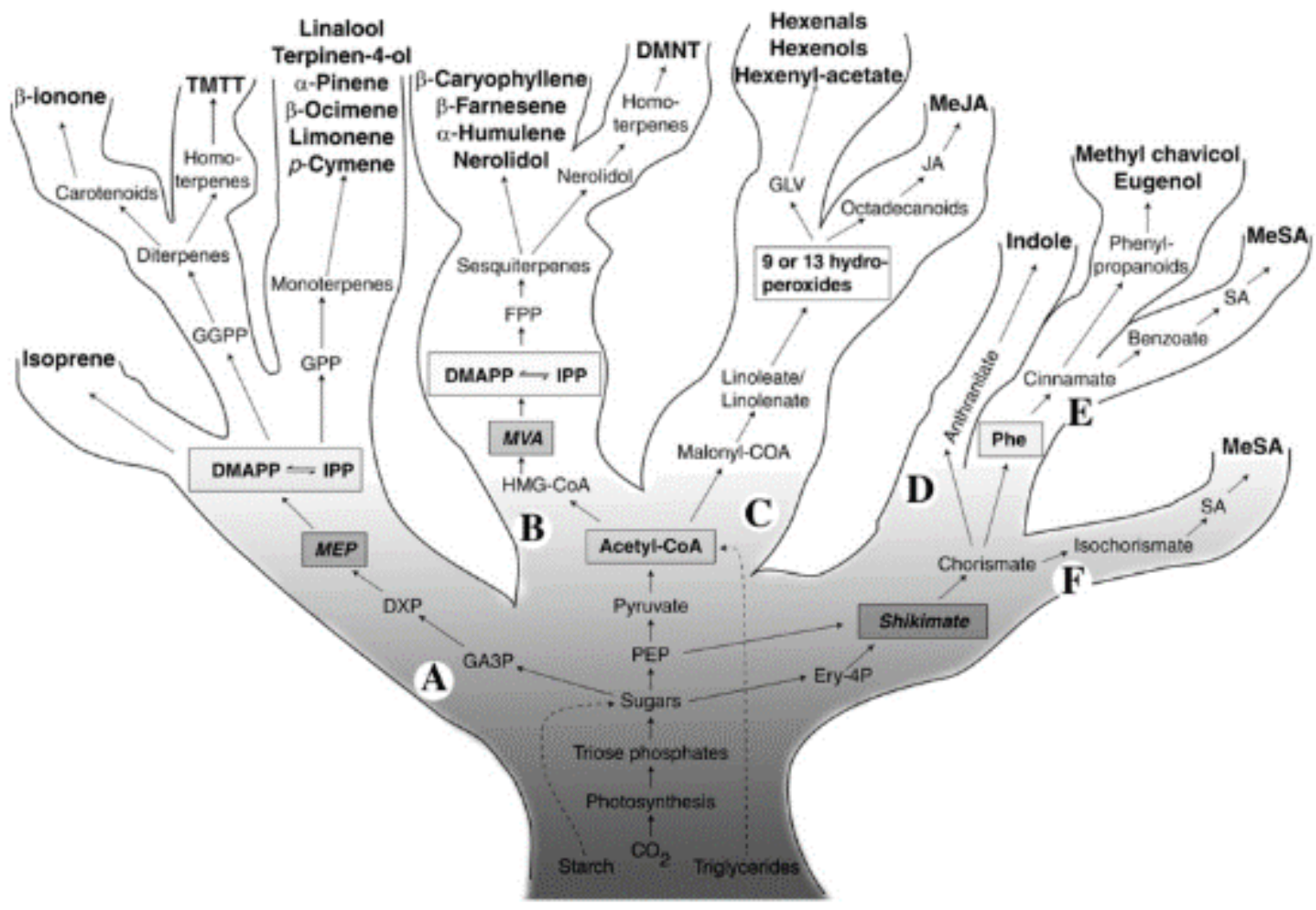

Figure 6: The volatilome tree

Branch (A) VOCs are produced by different biochemical pathways. The MEP pathways give rise to the formation of monoterpenes and diterpenes. The latter are precursors of the homoterpene TMTT and of the caroteoid-derived $\beta$-ionone. Isoprene is generated from DMAPP. Branch $(B)$ sesquiterpenoids are generated by FPP derived from the cytosolic MVA pathway. The homoterpene DMTT derives from the sesquiterpene nerolidol. Branch $(C)$ oxylipins generate from fatty acids which are cleaved into GLVs and JA derivatives. Branch $(D)$ the volatile indoles generate from anthranilate. Branch $(E)$ aromatic VOCs such as eugenol derive from phelylpropanoids, whereas MeSA derived from SA generated from benzoic acid. Branch $(F)$ alternatively, $M e S A$ can be formed by methylation of $S A$ deriving from isochorismate.

(Maffei, 2010). 


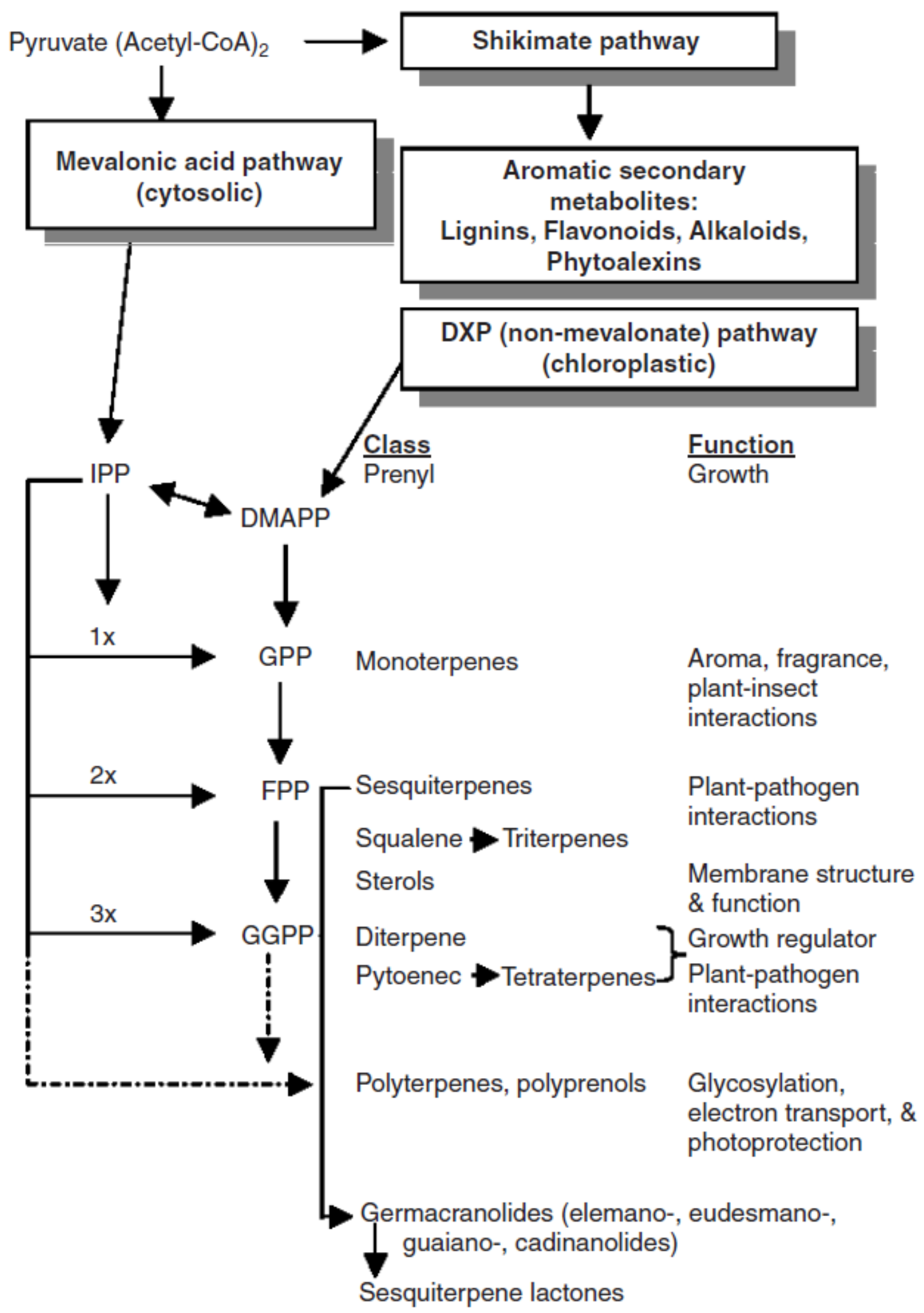

Figure 7: Flow diagram of primary and secondary metabolism for formation of secondary metabolites Isoprenoid biosynthesis proceeds either via the mevalonate pathway (cytosolic) or via the non-mevalonate (1-deoxy-D-xylulose-5-phosphate [DXP]) pathway for plastidic isoprenoids. IPP, isopropyl pyrophosphate; GGPP, pyrophosphate; GPP, geranyl pyrophosphate; FPP, farnesyl pyrophosphate; DMAPP, dimethylallyl pyrophosphate; $1 x, 2 x$, and $3 x$ indicate the number of IPP units added. (Da Silva et al. 2005). 


\subsubsection{Essential oils (EOs)}

Essential oils (EOs, also called volatile or ethereal oils), are very complex natural mixtures of lipophilic substances, as terpenoids, aromatic compounds, oxydes, ethers, alcohols, esters, aldehydes and ketones, at different concentrations. They are extracted by hydrodistillation from plant tissues, mainly aerial parts (flowers, leaves or fruits). The EOs are aromatic, characterized by a pungent odour, limpid and differently coloured, soluble in organic solvents with lower density than water (Palazzolo et al. 2013). EOs showed herbicide effects both in scientific studies and commercial formulations.

Over the last decade, especially thanks to the EU's push towards IPM, the interest in pesticide activity of EOs has grown in both scientific and technical fields. However, published studies relate to very specific applications, such as the effect on targeted microorganisms or weeds.

Given the great amount of specialized bibliography available, today it is possible to have a more ecological approach that takes into account both the effects on plants and the microbial community of the soil in which they live and with which they interact.Synowiec et al. (2017) affirmed that in the agrophytocenosis of a crop field, the application of EOs will have a selective effect that is species-specific. Moreover, the phytotoxic effects of EOs under field conditions will most probably be changed by weather and soil conditions (such as soil biological activity or soil sorption capacity) and may therefore differ from those observed under petri dish conditions.

Commercial herbicide essential oils mixtures have usually a wide action range and short action time. All contain additives and wetting agents to fix the active compound in the 0-5 cm soil layer, avoid oil evaporation and chemical degradation (Verdeguer 2011).

\subsubsection{Aqueous extracts (AEs)}

Water soluble plant secondary metabolites are recognised to have allelopathic effects on seedlings growth depending on both the concentration levels and the plant parts from which the aqueous extract was derived (Aryakia et al. 2015).

One advantage in using AEs compared to EOs is the easier production of the extracts. Once produced aqueous extracts can be frozen or lyophilized. Lyophilization is a very interesting solution for commercial purposes, because of the easier packaging and moving, as for the possibility to control the treatment concentration by weighting the lyophilised powder. 


\subsubsection{Pure compound, Carvacrol (CAR)}

One of the first studies about the use of this compound separated from plant essential oil as herbicide is Dudai et al. (1999), reporting in vitro inhibition against germination of wheat and Amaranthus seeds. Synowiec et al. (2017) also reported several studies about its use as herbicide and pesticide, both as single compound and in synergy with other pure compounds.

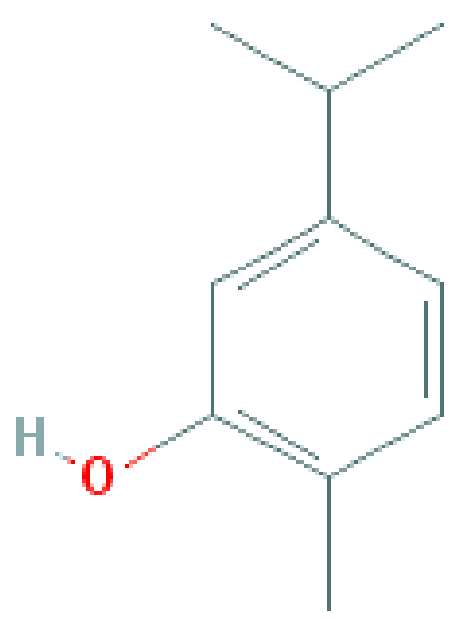

Figure 8: Carvacrol 2D structure (Kim et al. 2016) 


\subsubsection{Synthetic herbicide: Oxyfluorfen (OXY)}

As explained in paragraph 1.1.1, synthetic or chemical herbicides are the most widely used tools for weed control. In this thesis oxyfluorfen (figure 9) was chosen as synthetic herbicide to study because is one of the most used herbicides in citrus and fruit orchards in the Valencian Community.

Oxyfluorfen is a broad spectrum pre-emergent herbicide, its IUPAC name is 2-chloro-1(3-ethoxy-4-nitrophenoxy)-4-(trifluoromethyl)benzene, and the molecular formula is $\mathrm{C}_{15} \mathrm{H}_{11} \mathrm{ClF}_{3} \mathrm{NO}^{4}$ (figure 9). Belongs to the group of the Protoporphyrinogen Oxidase (PPO) Inhibitors: Diphenyl-ether, N-Phenylphthalimide, and Aryl Triazinone. PPO or protox is a key enzyme in the chlorophyll/heme biosynthetic pathway.

PPO inhibitors herbicides have a contact action and cause leaf burn, desiccation, growth inhibition, and ultimately cell death (Sanyal \& Shrestha 2008). Its wide use caused the selection of resistant weeds across the planet (figure 10).

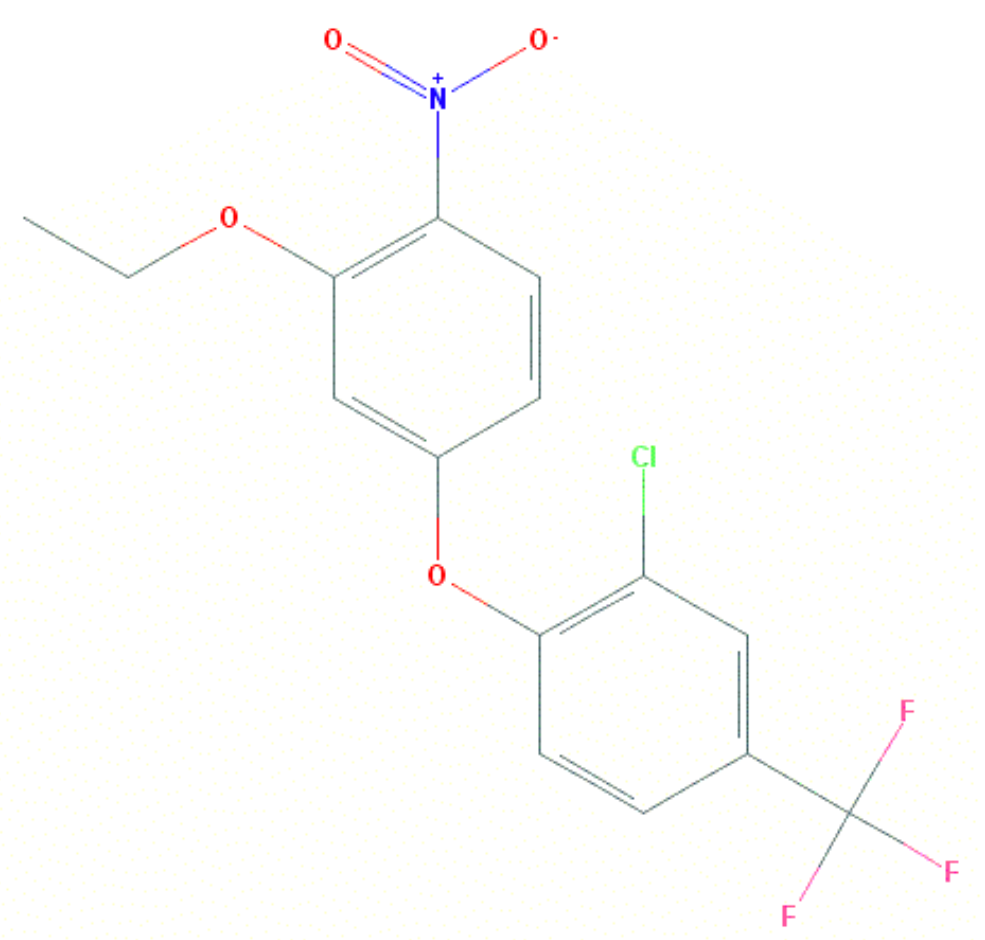

Figure 9: Oxyfluorfen 2D structure

(Kim et al. 2016) 
Its use in Europe were discussed in 2011 and approved until 2021, with modification regarding maximum residues levels allowed in foods (figure 11). Its effects are not limited to plant growth: it is dangerous for water environments, also several studies on animals and persons reports various levels of toxicity after both acute and chronical exposition to Oxyfluorfen (Kim et al. 2016).

\section{E (PPO INHIBITORS) RESISTANT CASES GLOBALLY}
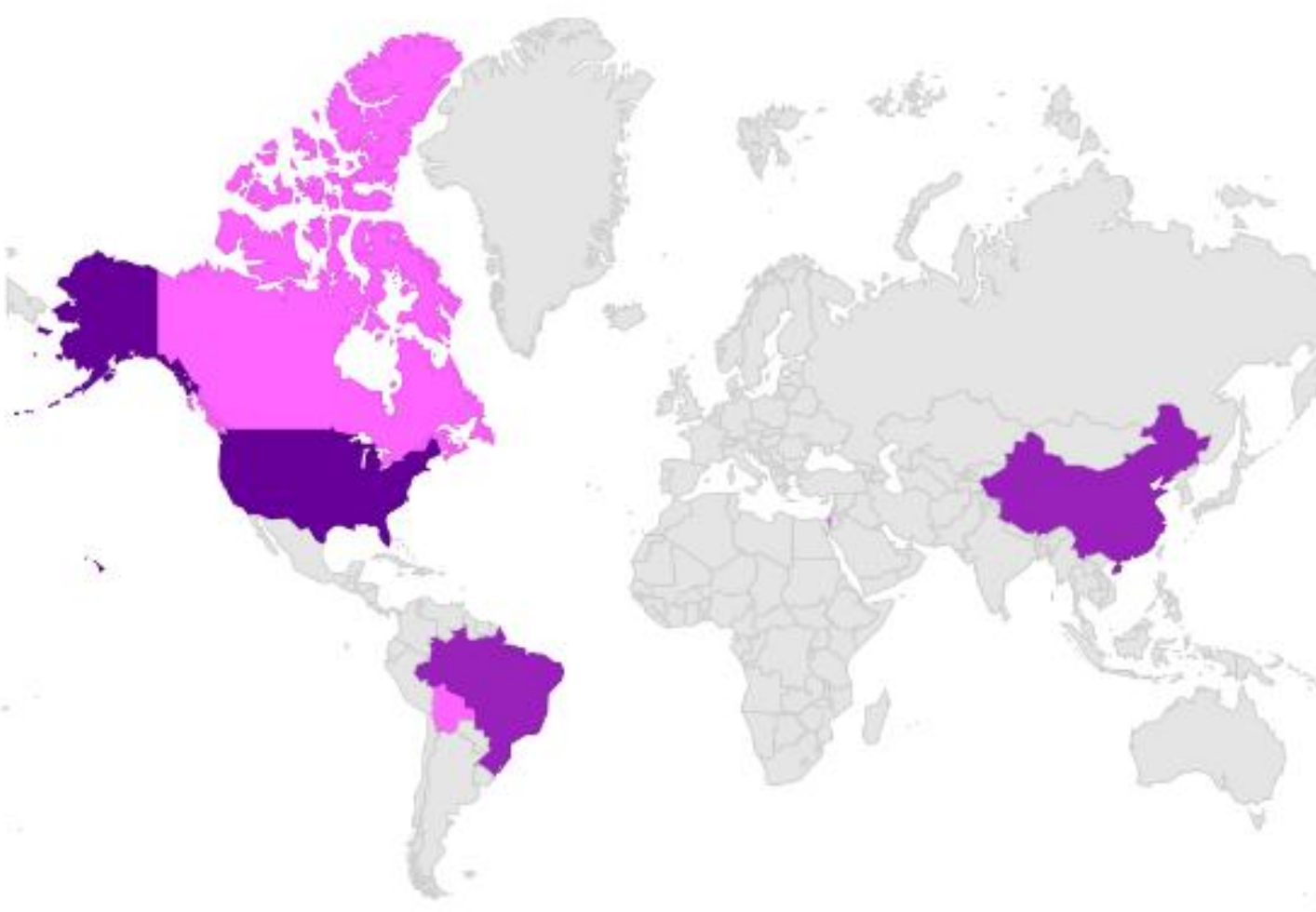
4

Figure 10: Map of PPO inhibitors resistant weeds

(Heap 2017) 
Oddo M. - Effects of different weed control practices on soil quality in mediterranean crops

\section{Oxyfluorfen Approved}

\begin{tabular}{|c|c|c|c|}
\hline Legislation & $\begin{array}{l}\text { Reg. (EU) } \\
2017 / 359 \longleftarrow, \\
\text { Reg. (EU) No } \\
798 / 2011 \square\end{array}$ & $\begin{array}{l}\text { Old } \\
\text { Legislation }\end{array}$ & 2008/934/EC 凹 \\
\hline $\begin{array}{l}\text { Date of } \\
\text { approval }\end{array}$ & $01 / 01 / 2012$ & $\begin{array}{l}\text { Expiration } \\
\text { of approval }\end{array}$ & $31 / 12 / 2021$ \\
\hline RMS & ES & $\begin{array}{l}\text { Risk } \\
\text { Assessment }\end{array}$ & EFSA $\square$ \\
\hline Category & $\mathrm{HB}$ & $\begin{array}{l}\text { Review } \\
\text { Report }\end{array}$ & $\begin{array}{l}\text { 固 Review } \\
\text { report } 2017 \\
\text { 固 Oxyfluorfen } \\
\text { RR Sep } \\
\text { 2011.pdf }\end{array}$ \\
\hline Type & $\begin{array}{l}\text { Candidate for } \\
\text { Substitution } \\
\text { (CfS) }\end{array}$ & CfS - criteria & two PBT criteria \\
\hline
\end{tabular}

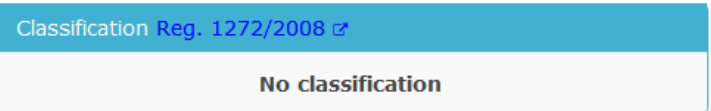

\section{Toxicological information}

\begin{tabular}{|c|c|c|c|}
\hline \multicolumn{2}{|c|}{ Reference values } & Source & Remark \\
\hline ADI & 0,003 & EFSA 10 & \\
\hline ARfD & 0,3 & EFSA 10 & \\
\hline AOEL & 0,013 & EFSA 10 & \\
\hline \multicolumn{4}{|l|}{ Other } \\
\hline \multicolumn{4}{|c|}{$\begin{array}{l}\text { Where no units are shown, the ADI and AOEL are expressed in } \mathrm{mg} / \mathrm{kg} \\
\text { bw per day. The ARfD is expressed in } \mathrm{mg} / \mathrm{kg} \text { bw. }\end{array}$} \\
\hline
\end{tabular}

Authorisation at national level

\begin{tabular}{|l|l|} 
Authorised in & In progress for
\end{tabular}

$B G, C Y, E L, E S, F R, H R, H U$,

IE, IT, MT, PL, PT, RO

EU - Maximum Residue Levels (Reg. (EC) No 396/2005) (MRLs)

\begin{tabular}{|l|l|}
\hline Legislation & Annexes \\
\hline Reg. (EC) No $149 / 2008 \llbracket$ & Oxyfluorfen \\
\hline & Annex IIIA \\
\hline
\end{tabular}

\section{Legend}

\begin{tabular}{l|l|l|l} 
RMS:Rapporteur Member State & Co-RMS:Co-Rapporteur Member State & ADI:Acceptable daily intake & ARfD:Acute reference dose
\end{tabular} AOEL:Acceptable operator exposure level

Figure 11: Oxyfluorfen report on EU Pesticides database

(European Commission 2017) 


\subsubsection{Physical management techniques: tillage and mulching}

\subsubsection{Tillage}

Laudicina et al., (2014) demonstrated that reduced tillage is regarded as one of the most effective conservation agricultural practices to decrease $\mathrm{CO}_{2}$ emissions from soil and sequester $\mathrm{C}$ into it. On the other hand, conventional tillage causes an increase in soil respiration, although many authors noted that such an increase usually occurs for few days after machine operations (Malik et al. 2012, Griffiths et al. 2013). However, Luo et al. (2010) highlighted that the role of no-tillage management in sequestrating $\mathrm{C}$ is greatly regulated by cropping systems. Tillage requires extra soil turn-over, so it can disturb soil structure and deplete soil fertility (Jabran et al. 2015) There are many reports on the dynamics of microbial parameters in soils after different rates of tillage intensities (Laudicina et al. 2011, 2015; Novara et al. 2014). Consequently, it is important to empathize on both quantity and timing of tillage management to avoid fertility loss.

\subsubsection{Mulching}

Mulching consists in cover the soil with artificial or organic materials to avoid weeds growth, water and nutrients loss. Plastic mulches are usually applied to suppress soil evaporation in many arid and semi-arid regions. As a special surface cover, plastic mulch evidently affects the surface albedo and prevents vapours exchange between the land surface and the atmosphere (Yang et al. 2012).In comparison with conventional management, the use of plastic mulches could reduce soil $\mathrm{CO}_{2}$ emissions by approximately $100 \mathrm{~g} \mathrm{C} \mathrm{m}^{-2}$ year ${ }^{-1}$ in agricultural lands in arid and/or semi-arid areas (LI et al. 2011), the effect on nitrogen emissions is debating (Berger et al. 2013).

Mulching using organic materials, in particular allelopathic plants residues, is an even more studied practice, used mainly in organic agriculture. Although, due to the variability in time and action mechanisms of allelochemicals release and decomposition, the practical application of this weed control method is still limited (Bond 2002; Zeng et al. 2008; Chinchilla Albundio 2015; Cheng \& Cheng 2015). 


\subsection{Objectives}

As alternative to the traditional synthetic herbicides, natural herbicides are being developed, based on allelopathic substances (allelochemicals) obtained from plants or microorganisms (Dance 2008; McGuire \& Treseder 2010; Inderjit et al. 2011; Wang et al. 2011; Weston \& Mathesius 2013), and some of them are already available on the market (Muzell Trezzi et al. 2016). Natural herbicides, despite having similar mode of application, are more respectful with the environment than the synthetic ones, having less persistence and different mode of action, avoiding the apparition of weed resistant biotypes.

Two mechanical practices are also considered more sustainable than the use of synthetic herbicides. The first is the mechanical removal of weeds (tillage), an effective traditional practice, well adapted to the large-scale agriculture. If abused it can negatively affect soil quality interfering with nutrients mineralization processes. Mulching (to apply a layer of material on the soil); reduces weed growth mainly by obstructing and shadowing. Cover material can have natural origins or be manufactured, very modern materials are the geotextiles dedicated for weed control. As wide is the range of materials used for mulching, as various can be the effects on soil microbiota.

This research plan focuses on the short, medium and long-term evolution of the main soil quality indexes under the impact of different weed management practices, to shine a light on their environmental sustainability.

For the achievement of this main objective, 4 experiments were established.

- Experiment one: short and medium-term response of soil microorganisms to essential oils with phytotoxic potential extracted from mediterranean plants

- Experiment two: medium term response of soil microorganisms to aqueous extracts with phytotoxic potential extracted from mediterranean plants

- Experiment three: short, medium and long-term response of soil microorganisms to natural and synthetic herbicides

- Experiment four: long-term comparison between tillage and mulching effects on soil biological properties

Experiments number one, two and three investigated the effects that the use of natural products, essential oils (EOs), aqueous extracts (AEs) and pure compounds (PCs) contained in essential oils, caused on short, medium and long-term in soil biochemical and biological equilibria. A very commonly used active compound of synthetic herbicides: oxyfluorfen (OXY) was selected as synthetic herbicide to compare with in the third experiment. 
All these 3 treatments can be considered preventive practices, targeting weeds during seedlings during early germination phase. OXY is a strictly chemical management technique, while AEs, Eos and PCs can be considered both chemical and biological.

On the other hand, the long-term effect in the soil microorganism community caused by two commonly used physical management techniques: tillage (T) and mulching (M) was also studied. According to time classification (chapter 1.1.1), performed tillage was a very effective eradicating method; mulching consisted in a preventive inert geotextile.

Chemical, biochemical and biological soil quality indexes were analysed in sampled soils. The indexes were used to evidence if and how weed management practices impact on soil fertility. 


\section{Materials and methods}

\subsection{Soil analysis}

Soil samples were air-dried at $23^{\circ} \mathrm{C}$, sieved at $2 \mathrm{~mm}$ and stored in sealed polyethylene bags at $4{ }^{\circ} \mathrm{C}$ prior to biochemical analyses that were carried out within ten days in the Dep. of Agricultural, Food and Forest Sciences of the University of Palermo Agrochemistry laboratories.

Soil chemical analyses were carried out on air-dried subsamples, while soil biochemical analyses on remoistened to 50\% of water holding capacity (WHC) subsamples, preincubated at room temperature for 7 days and then analysed for its soil biochemical properties.

If not specified, used methods are the standard ones suggested by the Italian Ministry for Agroforestry Politics (MiPAF, 2004, 2002, 1999)

\subsubsection{Physical and chemical analyses}

Soil texture (sand, 2-0.02 mm; silt, 0.02-0.002 mm; clay, <0.002 mm) was determined by pipette method after shaking soil samples for $2 \mathrm{~h}$ and using sodium hexametaphosphate (Gee \& Or 2002).

Soil $\mathrm{pH}$ was measured in distilled water (actual acidity) using a soil/solution ratio of 1:2.5 $\left(\mathrm{w} \mathrm{v}^{-1}\right)$ and a glass membrane electrode.

The electrical conductivity was measured in a 1:5 soil/water ratio mixture (50 g soil and $250 \mathrm{ml}$ water) after 1-h end-over-end shaking. The $\mathrm{EC}_{1: 5}$ was converted to the $\mathrm{EC}$ of a saturated paste $(\mathrm{EC})$ using the following equation: $\mathrm{EC}=(14.0-0.13 \times$ clay $\%) \times \mathrm{EC}_{1: 5}$ (Hazelton \& Murphy 2007).

Soil total organic C (TOC) and total N (TN) contents of pulverised soil samples were determined by oxidation with $\mathrm{K}_{2} \mathrm{Cr}_{2} \mathrm{O}_{7}$ in presence of sulphuric acid $\left(\mathrm{H}_{2} \mathrm{SO}_{4}\right)$ (Walkley \& Black 1934) and the Kjeldahl method, respectively (MiPAF 1999).

The content of total carbonates was determined by the gasvolumetric method using the Dietrich-Fruehling calcimeter (Williams 1949).

\subsubsection{Biological activity}

Microbial biomass C (MBC) and N (MBN) were determined by the fumigation-extraction method (Brookes et al. 1985; Vance et al. 1987). 
Moist (50\% WHC) soil aliquots were fumigated with alcohol-free chloroform in vacuum desiccators for $24 \mathrm{~h}$ in the dark. After removing the chloroform by repeated (at least six) evacuations, the soil samples were extracted with $0.5 \mathrm{M} \mathrm{K}_{2} \mathrm{SO}_{4}\left(4 \mathrm{~K}_{2} \mathrm{SO}_{4}: 1 \mathrm{~g}\right.$ soil, $\left.\mathrm{v} \mathrm{w}^{-1}\right)$ for $30 \mathrm{~min}$ on a horizontal shaker $(200 \mathrm{rpm})$. Unfumigated soil samples were similarly extracted and used as controls. All soil extracts were filtered through Whatman 42 paper (nominal pore size $2.5 \mu \mathrm{m}$ ) and then analysed for organic $\mathrm{C}$ by acid dichromate oxidation and for total $\mathrm{N}$ by Kjeldhal.

Microbial biomass $\mathrm{C}$ and $\mathrm{N}$ were estimated as the difference between the organic $\mathrm{C}$ and total $\mathrm{N}$ extracted from fumigated and unfumigated samples, respectively, multiplied by a $\mathrm{k}$ $\mathrm{EC}$ of 2.64 for $\mathrm{MBC}$ and by a $\mathrm{k} \mathrm{EN}$ of 2.22 for MBN.

Microbial quotient was calculated as the percentage of TOC present as MBC.

SR was determined by measuring the evolved $\mathrm{CO}_{2}$ during 3 days of soil incubation. Briefly, $10 \mathrm{~g}$ of soil at $50 \%$ of WHC (8.45 g air-dried) was placed in a 120-mL glass jar at $22^{\circ} \mathrm{C}$, and the cumulatively produced $\mathrm{CO}_{2}$ was determined by a gas chromatograph equipped with a thermal conductivity detector after 3 days of incubation. The $\mathrm{CO}_{2}$ evolved was measured by sampling an aliquot of gas from the bottles by using a syringe and injecting it into a gas-chromatograph (Trace GC, Thermo Electron) equipped with a thermal conductivity detector (TCD).

Metabolic quotient (qCO2) was calculated as $\mathrm{mg} \mathrm{CO}_{2}-\mathrm{C} \mathrm{g}^{-1} \mathrm{MBC} \mathrm{h}^{-1}\left[\left(\mathrm{mg} \mathrm{CO}_{2}-\mathrm{C}\right.\right.$ cumulated in $240 \mathrm{~h}$ (10 days) $\mathrm{kg}^{-1}$ soil $) / 240 \mathrm{~h} \mathrm{~g}^{-1} \mathrm{MBC} \mathrm{kg}^{-1}$ soil].

\subsubsection{Microbial community structure}

Fatty acids (FAs) were extracted from soils and analysed according to the modified Bligh and Dyer method (Wu et al. 2009).

The fatty acids were detected on a gas chromatograph (Thermo Scientific FOCUS ${ }^{\text {TM }}$ GC) equipped with a flame ionization detector and a fused-silica capillary column Mega-10 (50 m x 0.32 mm I.D.; film thickness $0.25 \mu \mathrm{m})$.

The GC temperature progression was: initial isotherm at $115^{\circ} \mathrm{C}$ for 5 minutes, increase at a rate of $1.5^{\circ} \mathrm{C}$ per minute from 115 to $230^{\circ} \mathrm{C}$, and final isotherm at $230^{\circ} \mathrm{C}$ for 2 minutes. Both injection port and detector were set up at $250^{\circ} \mathrm{C}$ and helium at $1 \mathrm{~mL} \mathrm{~min}^{-1}$ in a constant flow mode was used as carrier. The injected volume was $1 \mu \mathrm{L}$ in a splitless mode. Nonadecanoic acid methyl ester (19:0; cat no. N-5377, Sigma-Aldrich Co.) was used as an internal standard for quantification of the fatty acid methyl esters. The identification of the peaks was based on comparison of retention times to known standards (Supelco Bacterial 
Acid Methyl Esters mix cat no. 47080-U and Supelco 37 Component FAME mix cat no. 47885-U).

The relative abundance of detected FAs was expressed as fatty acids nanomoles for each gram of dry soil. Fatty acids with less than 14 carbon atoms or more than 20 carbon atoms were excluded as considered originating from non-microbial sources (Laudicina et al. 2011). The FAs i15:0, a15:0, 15:0, i16:0, i17:0, 17:0, cy17:0, 18:1 $\omega 7$, cy19:0 were used to represent bacterial biomass and compared to the total microbial FAs amount (Bac\%) while 18:2 $\omega 6,9$ for fungal biomass (Fun\%) (Laudicina et al. 2011). The FAs i15:0, a15:0, i16:0, i17:0 were

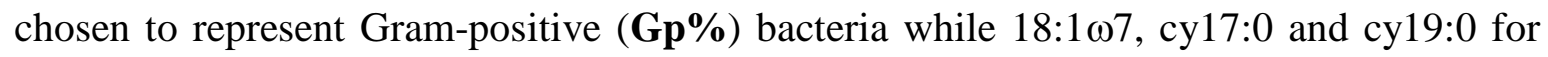

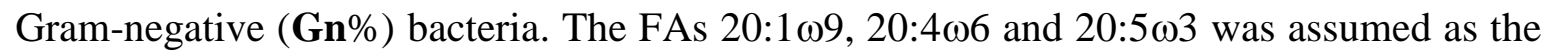
measure of soil mesofauna biovolume (Mes\%, microinvertebrates between $0.1 \mathrm{~mm}$ and 2 $\mathrm{mm}$ in size living in the soil or in a leaf litter layer on the soil surface, Laudicina et al. 2011). 


\subsection{Materials and methods used in testing natural and synthetic herbicides}

\subsubsection{Plants used as natural herbicides sources}

\subsubsection{Eriocephalus africanus L. (ERI EO)}

Eriocephalus africanus L. (figure 12) is a perennial bushy shrub commonly named Cape Snow Bush for its white flowers and fruits. Belongs to family Asteraceae, is endemic from the mediterranean shrublands of South Africa (the Fynbos of the Cape region) and naturalized in the Mediterranean region. It is traditionally used in culinary and to treat dermal and gastrointestinal infections, as antipyretic and analgesic on mammals and as antimicrobial in food preservation (Salie et al. 1996; Amabeoku et al. 2000; Viljoen et al. 2006). Recent studies (Asita \& Mokhobo 2013) investigated the use of a plant smoke condensate obtained from plant of the same genus (E. punctulatus) as alternative to pesticides use on stored products. Its extracts have been studied for their antioxidant properties (Catarino et al. 2015) and phytotoxicity (Verdeguer et al. 2009).

Of particular interest are the EO extracted from E. africanus populations in which the most abundant compound is artemisia ketone (Merle et al. 2007), as the one source of used plant material. It is located at $39^{\circ} 30^{\prime} 34^{\prime \prime} \mathrm{N}$ and $0^{\circ} 25^{\prime} 25.34^{\prime \prime} \mathrm{W}$, cultivated in a green roundabout in Burjassot district, (Valencia, Spain, Figure 13).

ERI EOs was used in two experiments, branches in vegetative state was collected during spring 2014 and 2016 (see table 3) and processed as described in chapter 2.2.2 before to perform the first and the third experiment.

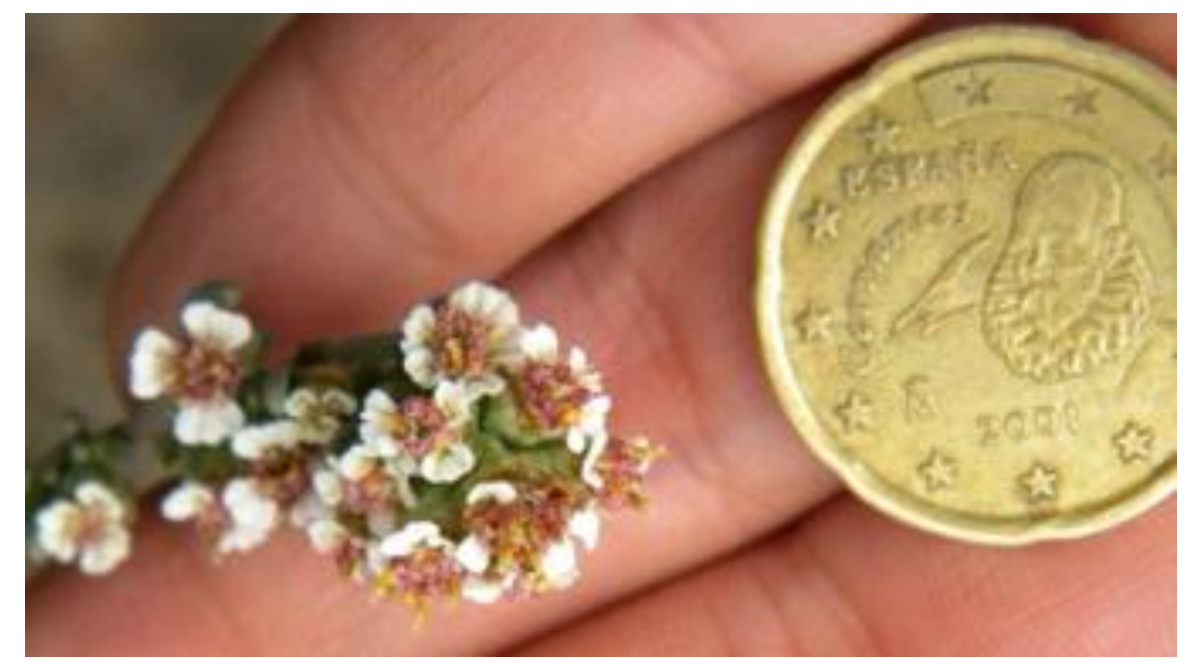

Figure 12: Eriocephalus africanus L. flowers 


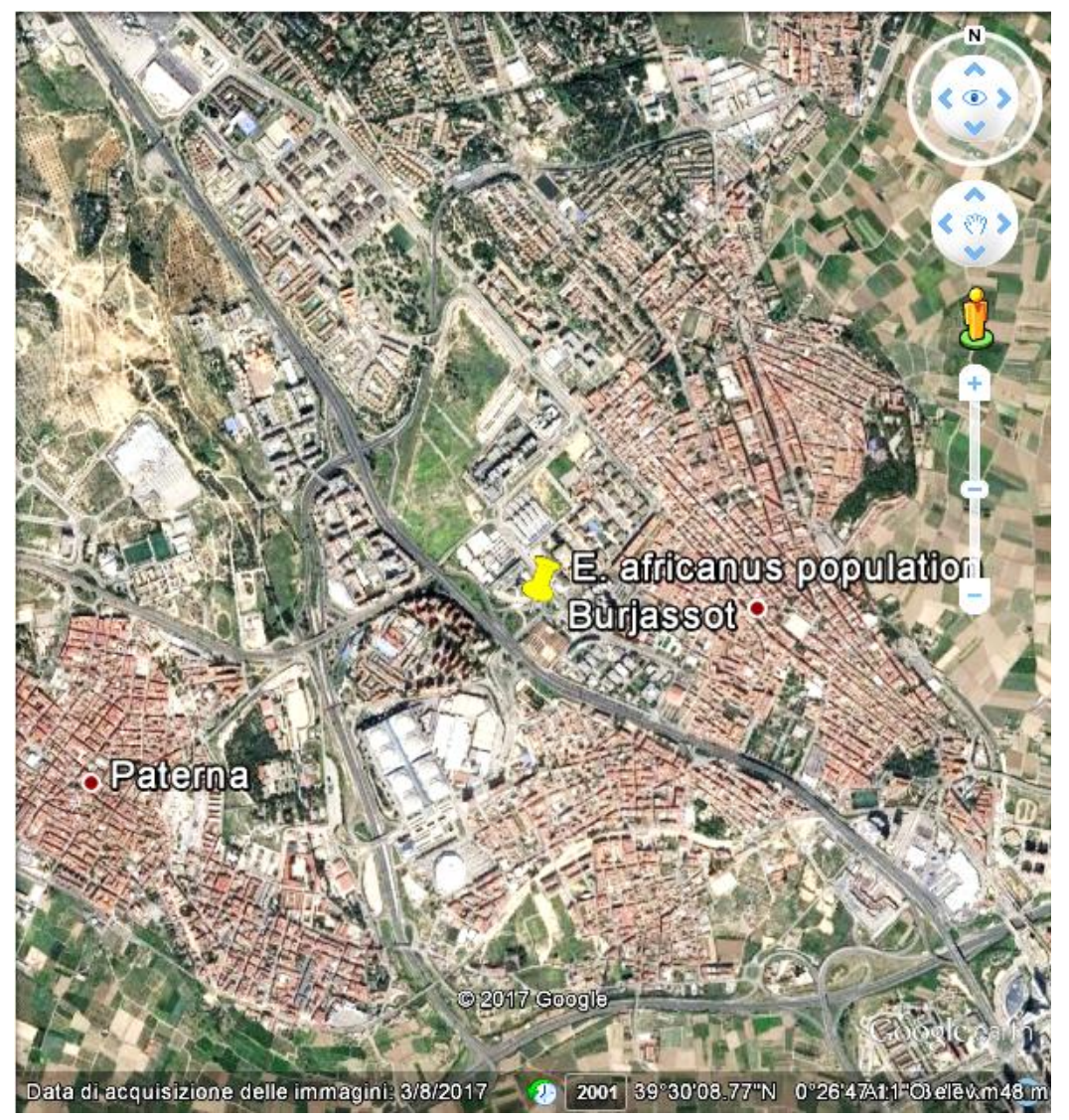

Figure 13: Eriocephalus africanus L. recollection area

In a green roundabout motorway junction in the Burjasot district (Valencia,

Spain), near the University of Valencia

\subsubsection{Eucalyptus camaldulensis Dehnh. (EUC EO and AE)}

Eucalyptus camaldulensis Dehnh. (figure 14) is a tree from Myrtaceae, once only growing in Australia and Oceania, nowadays is worldly used as biomass source and for decorative purposes. Eucalyptus species are a well-known source of allelopathic substances (Verdeguer et al. 2009; De Freitas Duarte et al. 2012; Chu et al. 2014). Several studies have been carried out as well, concerning its use as antimicrobial or flavouring agent in pharmaceutical and food industries (Kalemba \& Kunicka 2003; Ponce et al. 2003; Solórzano-Santos \& MirandaNovales 2012; Liakos et al. 2014).

The use of EOs extracted from Eucalyptus as pesticide is not approved in European Union. Default Maximum Residue Levels are defined as $0.01 \mathrm{mg} \mathrm{Kg}^{-1}$ according to Art 18(1)(b)Reg. (EC) No 396/2005(European Commission 2017).

Stems in vegetative state was collected during April and July 2014 in the Rio Turia urban Park (Valencia, Spain, figure 15) and processed as described in chapter 2.2.2.1 to extract EUC EO for the first experiment, and in chapter 2.2.2.2 to produce ERI AE for the second experiment. 


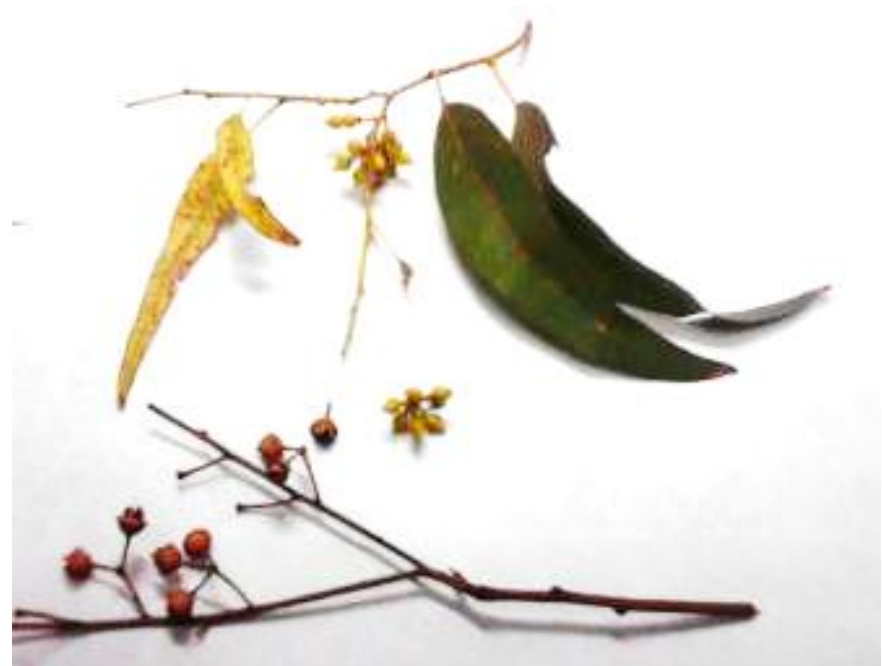

Figure 14: Eucalyptus camaldulensis Dehnh. leaves, flowers and fruits

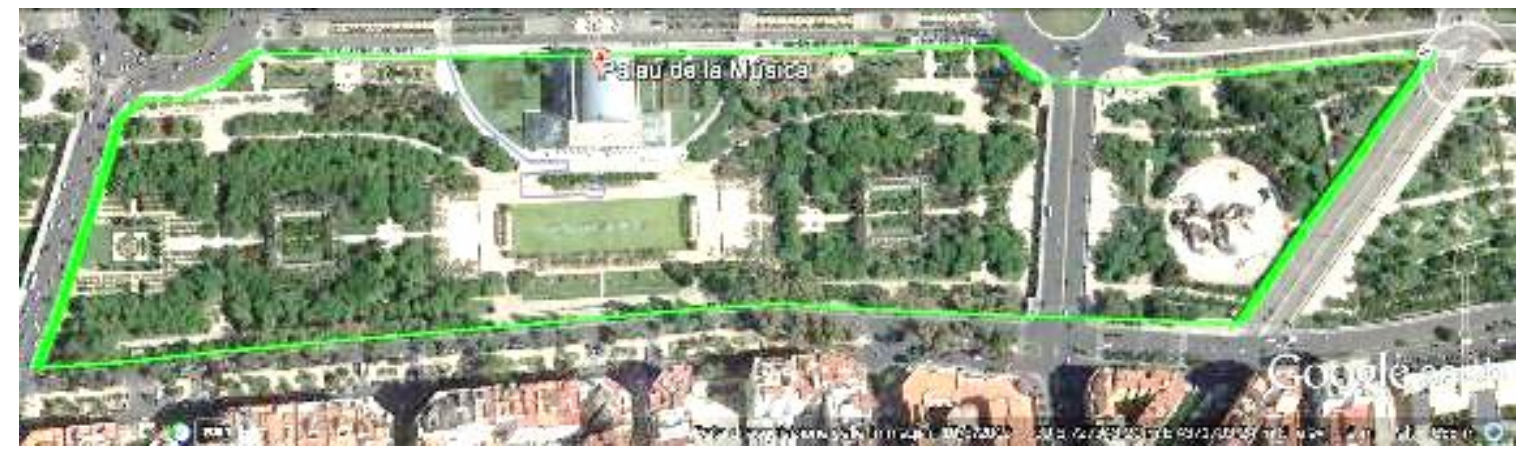

Figure 15: Eucalyptus camaldulensis recollection area

Within the Urban Park of Rio Turia, in the area adjacent to Palau de la Música in Valencia (Spain)

\subsubsection{Citrus limon (L.) Osbeck (LEM EO)}

Juices and extracts from Citrus limon (L.) Osbeck (the lemon, figure 16), are traditionally used to preserve food from oxidation and contamination (Settanni et al. 2012), it is also used in medicine (Palazzolo et al. 2013; Langeveld et al. 2014).

Limonene is the major chemical compound of most of citrus oils, belongs to the volatile fraction of the EO. and has documented antibacterial properties (Palazzolo et al. 2013). It was demonstrated to have allelochemical activity on respiratory parameters of isolated mitochondria and to be very toxic to the germination and growth of other plants (Reigosa et al. 2006). In vitro germination tests classified limonene as the $9^{\text {th }}$ among the 10 top phytotoxic monoterpenes out of 27 studied by De Martino et al. (2010).

On June 2014 stems in vegetative state were collected in an experimental lemon orchard located inside the Valencian Institute for Agronomic Investigations (IVIA, figure 17). LEM EO was distilled as described in chapter 2.2.2.1. 


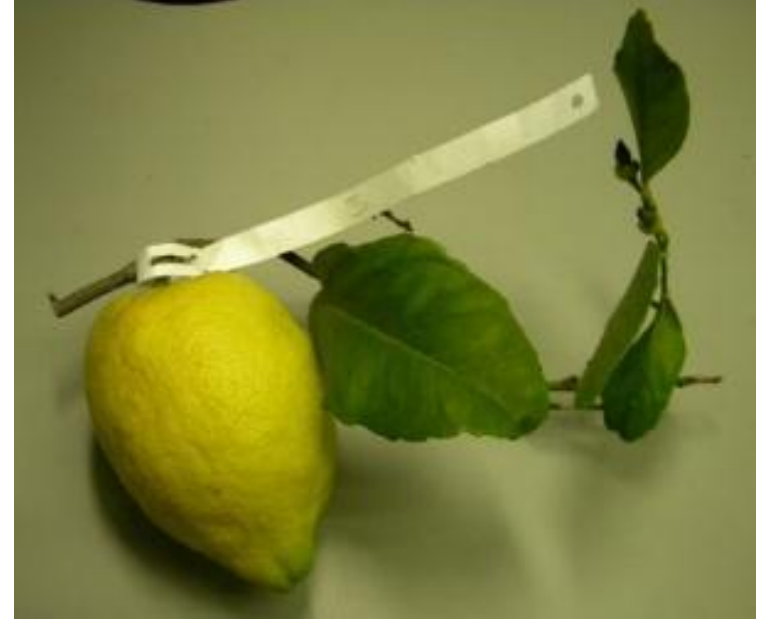

Figure 16: Citrus limon (L.) Osbeck fruit and leaves

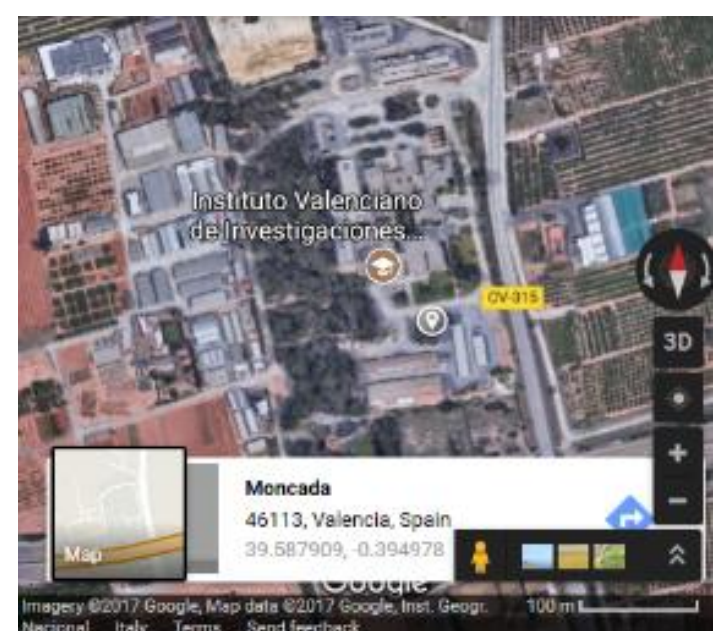

Figure 17: Citrus limon (L.) Osbeck leaves recollection area

IVIA, Instituto Valenciano Investigacion Agraria

\subsubsection{Citrus reticulata Blanco (TAN EO)}

Citrus reticulata Blanco var. 'Clemenules' (the tangerine, figure 18) produces allelopathic compounds that can be used against foodborne pathogens and for medical purposes (Settanni et al. 2012; Palazzolo et al. 2013; Raut \& Karuppayil 2014).

Sabinene is a discriminant metabolite to identify the chemo-cultivar which 'Clemenules' tangerine variety belongs to (Merle et al. 2004). Karp et al.in 1982 evidenced that sabinene is an essential precursor of thujone-like compounds, a typical volatile allelochemicals according to Zeng et al., 2008. Another important component of tangerine EOs is citral, a mixture of geranial and neral (Palazzolo et al. 2013). It is used to confer lemon flavour to food, perfumes and soaps, and it is largely used also in pharmaceutical and chemical industry (Kim et al. 2016).

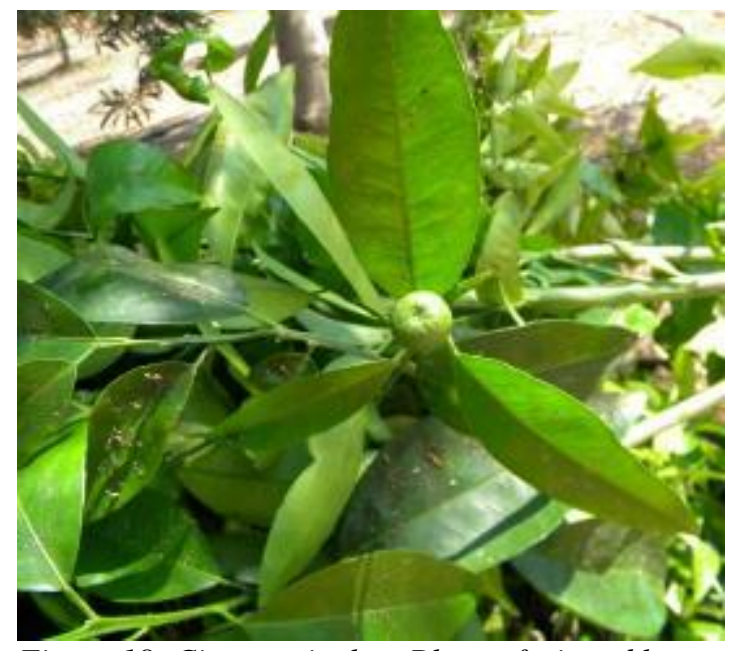

Figure 18: Citrus reticulata Blanco fruit and leaves

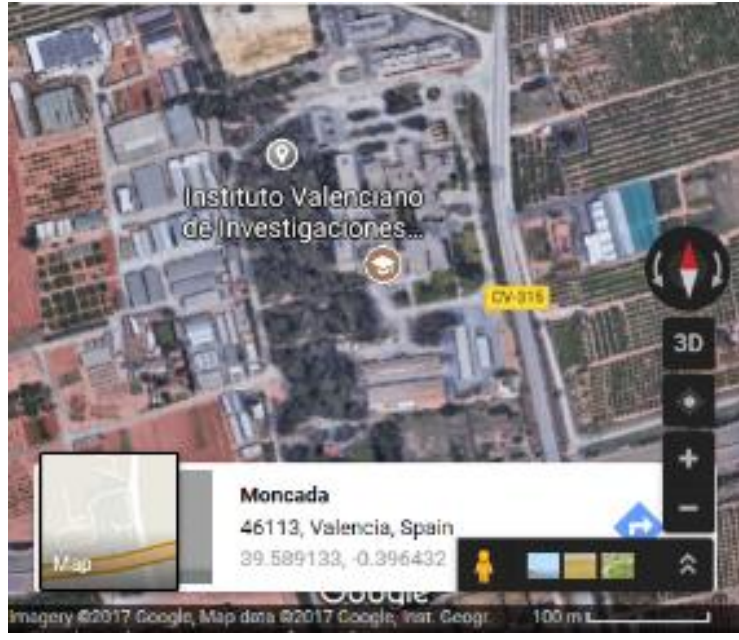

Figure 19: Citrus reticulata Blanco leaves recollection area

IVIA, Instituto Valenciano Investigacion Agraria 
One of the first studies about the herbicide use of this isolated compound was carried out by Dudai et al. (1999), who demonstrated its inhibitory effect on the in-vitro germination of wheat and Amaranthus seeds.

Tangerine stems in vegetative state were collected during May 2014 in an experimental lemon orchard located inside the Valencian Institute for Agronomic Investigations (IVIA, figure 17). TAN EO was distilled as described in chapter 2.2.2.1.

\subsubsection{Thymbra capitata (L.) Cav. (TCP EO)}

Thymbra capitata (L.) Cav. (figure 20) is a compact, woody perennial bush. As many Lamiaceae, is traditionally used as spice in Europe with the common name thyme. TCP EO herbicidal activity has been recently studied (García Plasencia 2014; Chinchilla Albundio 2015), and many studies report its antimicrobial effects, both in agriculture and for human purposes (Cosentino et al. 1999; Tabti et al. 2014; Raut \& Karuppayil 2014). It was also demonstrated that the presence of a natural population of thyme can affect soil microbiota (Papatheodorou et al. 2002).

Its EO contains mainly thymol and carvacrol, that negatively interact with many living organisms, even pests and weeds (Koul et al. 2008; Regnault-Roger et al. 2012), human pathogens (Dutta et al. 2007) and phytopathogens (Behdani et al. 2012; Tabti et al. 2014). Thyme EOs have been recently studied for weed control, antimicrobial effects and because affect soil microbiota. One of the main compound of thyme EOs, i.e. carvacrol, is well known to have anti-germinative effect (see chapter 1.4.1.3).

TCP EOs was used in the first and the third experiment. EO used in the first experiment was obtained from plants of Thymbra capitata (L.) Cav. located in the municipality of Carmona (Seville), collected during July 2012 in flowering state and processed as described in chapter 2.2.2.1 (García Plasencia 2014). EO used in the third experiment was bought in 2016 from the distillation factory Bordas Chinchurreta of Sevilla. 


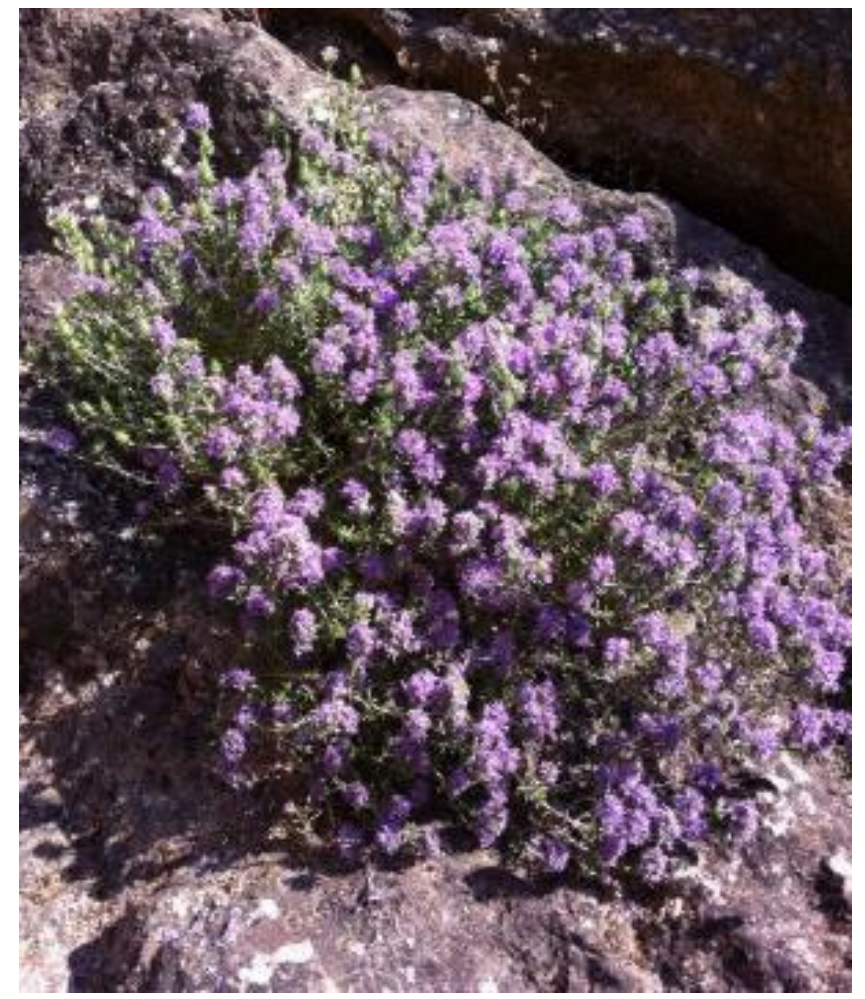

Figure 20: Plant of Thymbra capitata (L) Cav.

\subsubsection{Artemisia absinthium L. (ART AE)}

Artemisia absinthium L., the famous ingredient of the spirit absinthe (figure 20), is an herbaceous perennial plant native to temperate regions of Eurasia and Northern Africa, widely naturalized in Canada and the northern United States.

Artemisia genus characteristic secondary metabolite artemisinin, according to Knudsmark Jessing et al. (2014), allelopathically protects the plant from insects and other herbivores, as well as pathogens and competing plant species. Also arbusculin-A from Artemisia spp. is responsible for many of the allelopathic effects of that plant (Reigosa et al. 2006).

Used plant material was collected in the fields of Calamocha (Teurel, Spain) during spring 2014 and processed as described in chapter 2.2.2 to produce ART AE. 


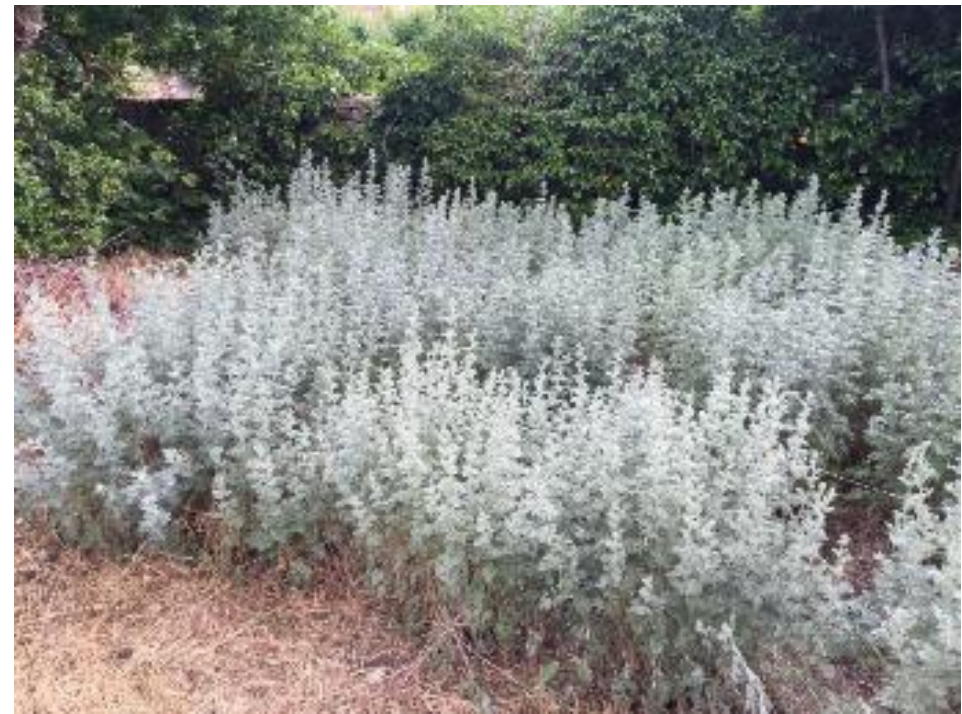

Figure 21: Artemisia absinthium L. plants

\subsubsection{Cupressus sempervirens L. (CUP AE)}

The extracts of Cupressus sempervirens L., the Mediterranean cypress (figure 21), have been tested against common foodborne pathogens in order to determine their antimicrobial activity before and after their incorporation into several films (Blázquez 2014).

Allelopathic effects of Cupressaceae species growing with a cover crop, are studied in landscape engineering for soil stabilization and recreational green areas management (Aliloo 2012).

Recent in vitro tests (M'barek 2016) showed wide phytotoxic effects of $C$. sempervirens extracts on seedlings germination and growth.

Used plant material was collected from trees situated in the Rio Turia urban park (Valencia, Spain) during spring 2014 and CUP AE extracted as described in chapter 2.2.2.2.

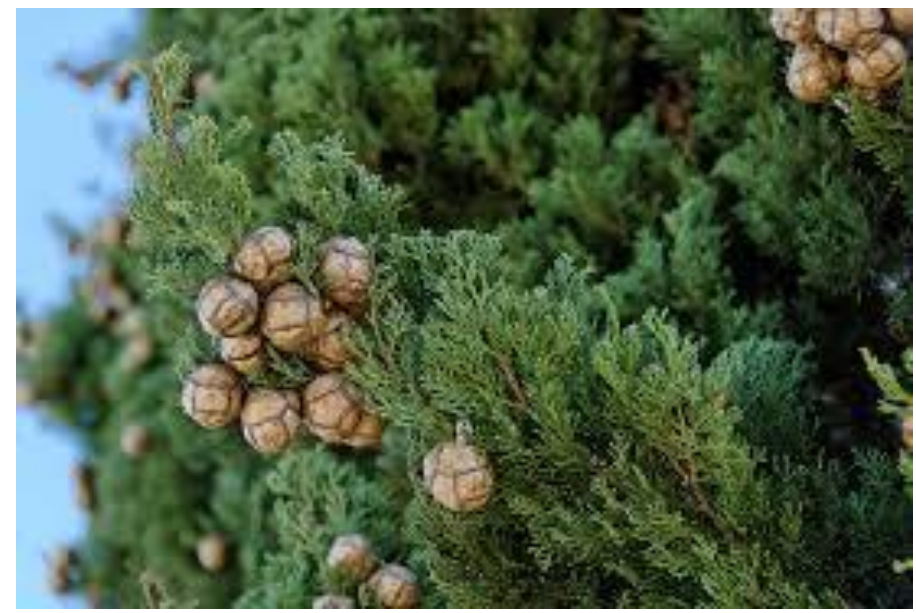

Figure 22: Cupressus sempervirens L. leaves and fruits 


\subsubsection{Santolina chamaecyparissus L. (SAN AE)}

Santolina chamaecyparissus L., of the family of Asteraceae is a strongly flavoured small evergreen shrub (figure 23). The natural extracts from Santolina spp. are widely studied as microbicide for pharmaceutical, phytopharmaceutical and industrial applications (Da Silva et al. 2005; Raut \& Karuppayil 2014; El Asbahani et al. 2015), as well for the potential use of its EOs as a fumigant against plant pests (Seo et al. 2014).

The plant material used for this trial was collected in the fields of Picassent (Valencia, Spain) from plants in flowering state during spring 2014. SAN AE was extracted as described in chapter 2.2.2.2.

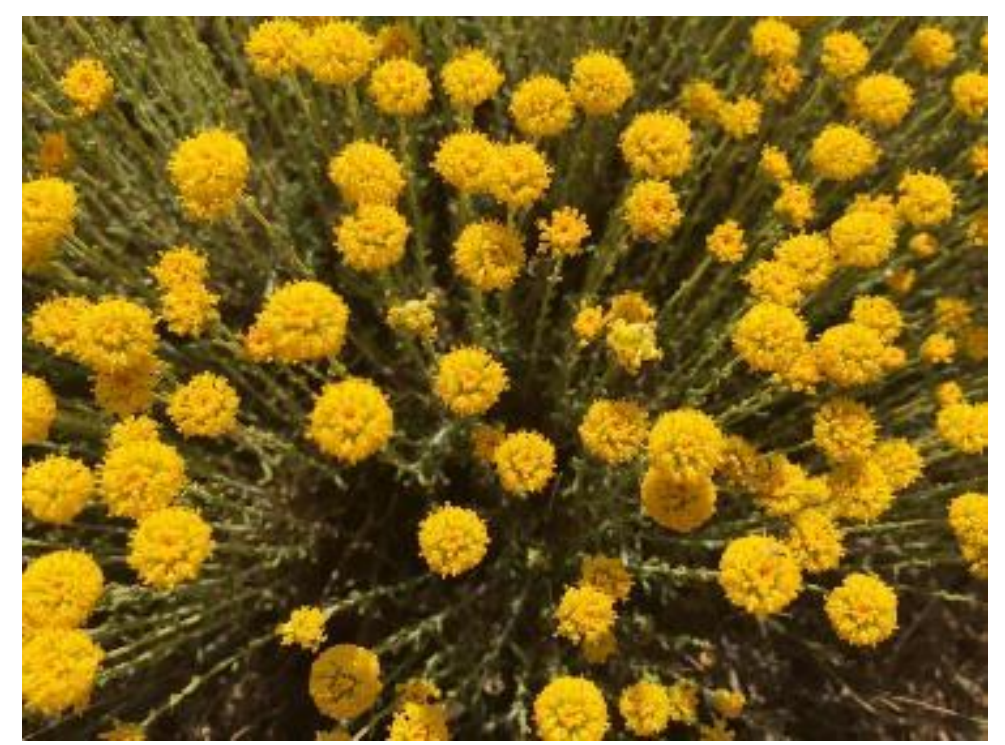

Figure 23: Santolina chamaecyparissus L. flowers and leaves 


\subsubsection{Natural herbicides production and analyses}

All the extracts were produced from homogeneous plant material. Small branches were collected from at least five different plants of the same population, to avoid a single plant physiological state influence essential oils chemical composition. To choose when to recollect the plant material, the days following meteorological conditions different from the seasonal mean was discarded. Similarly, material from wounded or infected plants, as branches having parasites or malformations, was not collected, because it is widely recognized (Maffei 2010) that plant can rapidly change tissues VOCs content to maintain homeostasis against biotic and abiotic stress (see figure 24).

Collected branches were stored in plastic bags, perforated to avoid mycotic colonization, transported to the Instituto Agroforestal Mediterraneo phytochemistry laboratory and stored at $5^{\circ} \mathrm{C}$. Mature and healthy leaves were manually selected and processed to produce the extracts for further uses within 7 days from harvest. 


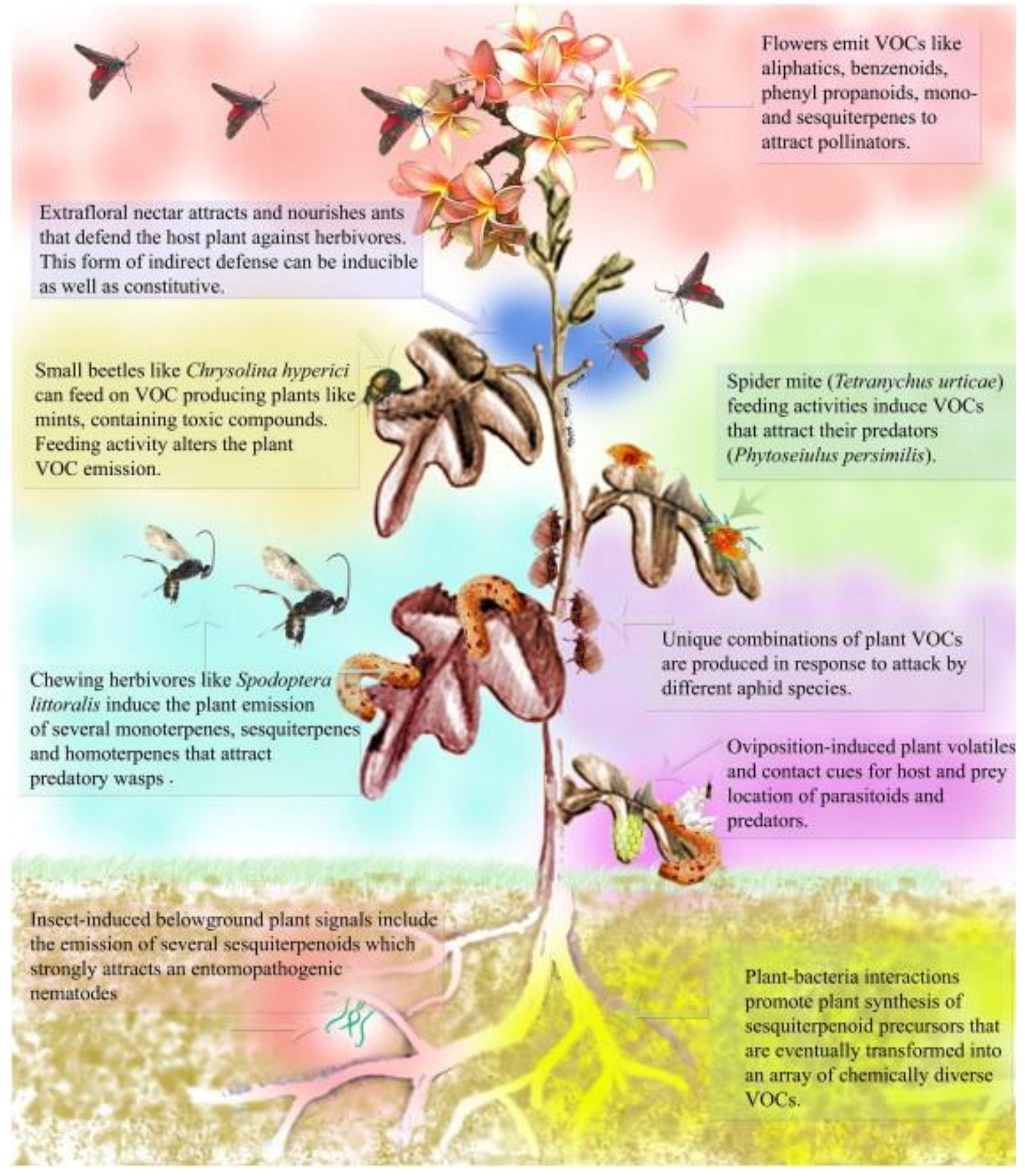

Figure 24: Functional role of plant VOCs

Plants emit a wide array of volatile compounds for pollinator's attraction and in response to biotic and abiotic stress. Flowers emit compounds belonging to several major classes of VOCs to attract pollinators. Extrafloral nectaries attract both ants and butterflies and their activation is inducible by insect herbivory. Several beetles, such as Chrysomela menthastri and C. hyperici, feed on aromatic plants despite their toxic compounds and induce increased VOC plant emissions. Aphids feeding on plants trigger the emission of several monoterpenes and homoterpenes. Sucking herbivore like spider mites induce VOC emissions that attract their predators. Chewing herbivores like Spodoptera littoralis induce the plant emission of several monoterpenes, sesquiterpenes and homoterpenes that attract predatory wasps. Oviposition-induced plant volatiles and contact cues for host and prey location of parasitoids and predators. Insect-induced belowground plant signals include the emission of several sesquiterpenoids which strongly attracts an entomopathogenic nematodes. Plant-bacteria interactions promote plant synthesis of sesquiterpenoid precursors that are eventually transformed into an array of chemically diverse VOCs.

(Maffei 2010) 


\subsubsection{Essential oils}

\section{Extraction}

The aerial plant parts were collected and the fresh material hydrodistilled using a Clevenger apparatus for three to five hours to obtain the essential oils.

A weighted quantity of plant material was inserted in a 2 L round flask and covered by demineralised water. Flask was connected to the Clevenger apparatus (figure 25) and heated on a heating mantle; the condenser of the apparatus was maintained at $20^{\circ} \mathrm{C}$ by an electronic recirculating chiller.

Kinetic energy of the water in the flask acts on plants tissues extracting the oils, which are dragged along the steam flow to the condenser. Here vapours returned liquids are collected in the graduated receiving tube, excess water goes back into the flask and the essential oil remains floating in the tube. When observing the graduated tube oil volume does not increase for 30 minutes, the assembly was cooled, the water from the distillate receiving tube removed and oil collected in a sterile vial. Obtained essential oils underwent a dehydration process by sodium sulphate, and then vials were sealed and stored at $4^{\circ} \mathrm{C}$ in dark conditions.

Each plant essential oil yield was repetitively measured distilling $100 \mathrm{~g}$ of plant material and expressed in $\mathrm{v} \mathrm{w}^{-1}$ (volume of oil obtained in $\mathrm{ml}$ per $100 \mathrm{~g}$ of plant material), results are listed in table 3.

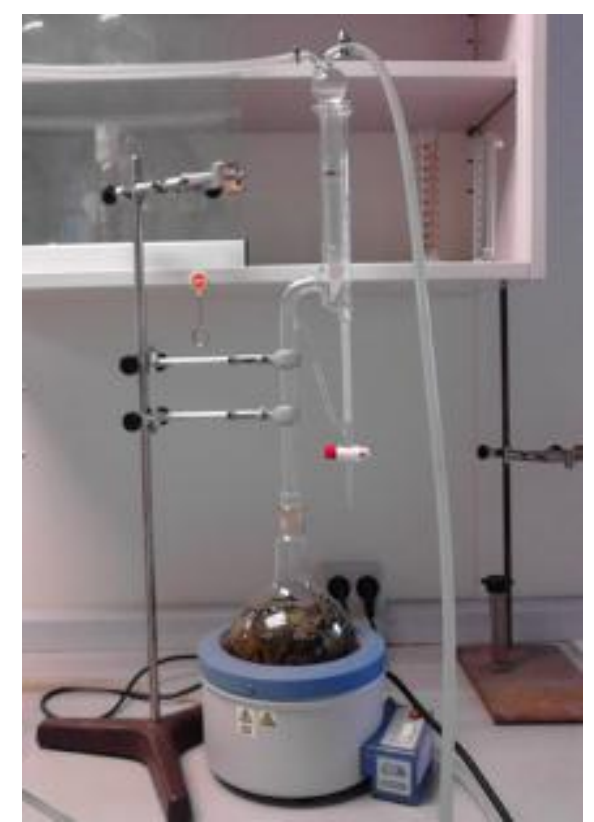

Figure 25: Clevenger apparatus
Table 3: Essential oils yield of the distilled plant materials

\begin{tabular}{lll}
\hline Plant & Recollection period & Yield \\
\hline C. limon & jun-14 & $0.45 \%$ \\
C. reticulata & may-14 & $0.46 \%$ \\
E. africanus & apr-14 & $1.00 \%$ \\
& mar-16 & $0.92 \%$ \\
& apr-16 & $0.65 \%$ \\
E. camaldulensis & apr-14 & $0.26 \%$ \\
& jul-14 & $0.44 \%$ \\
T capitata & jul-12 & $2.71 \%$ \\
\hline Reported results are means \pm standard deviations $(n=3)$
\end{tabular}




\section{Analyses}

To analyse essential oils chemical composition a $10 \%$ dilution in hexane of each oil was prepared. Quantitative composition was analysed by gas-chromatography (GC) and qualitative by mass spectrometry (MS).

For quantitative analysis was used a Clarus 500 GC (Perkin-Elmer Inc., Wellesley, PA) gas chromatograph equipped with an FID detector and fused silica capillary column ZB5MS (30 m x 0.25 mm i.d. x $0.25 \mu \mathrm{m}$ film thickness; Phenomenex Inc., Torrance, CA). The injection volume was $1 \mu \mathrm{l}$. The $\mathrm{GC}$ oven temperature was held at $60^{\circ} \mathrm{C}$ for 5 min and then programmed at a rate of $3^{\circ} \mathrm{C} \min ^{-1}$ to $180^{\circ} \mathrm{C}$; when reached, temperature was raised to $280^{\circ}$ $\mathrm{C}$ at $20^{\circ} \mathrm{C} \mathrm{m^{-1 }}$ and maintained at $280^{\circ} \mathrm{C}$ for $10 \mathrm{~min}$. Helium was the carrier gas $(1.2 \mathrm{ml}$ $\min ^{-1}$ ). Injector and detector temperatures were set at $250^{\circ} \mathrm{C}$. The percentage composition of the sample was computed from GC peak areas by means of the software Total Chrom 6.2 (Perkin-Elmer Inc.).

Identification of the compounds was performed using a Clarus 500 GC-MS (Perkin-Elmer Inc.) with the same capillary column, carrier and operating conditions above described for GC-FID analysis. Detection was performed in the EI mode (ionization energy, $70 \mathrm{eV}$ ) and ionization source temperature was set at $200^{\circ} \mathrm{C}$. MS spectra acquisition was done in full scan mode (mass range $\mathrm{m} / \mathrm{z} 40-500$ ). The total ion chromatograms and mass spectra were processed with the software Turbomass 5.4 (Perkin-Elmer Inc.). The sample components were identified by comparison of their mass spectra with those of computer library (NIST Mass Spectral Search Program for the NISTIEPAINIH mass Spectral Library, version 2.0, build 4/2005) and available data in the literature.

To help the identification of the chemical compounds, together with the oil samples a C7C30 saturated alkanes standard mix (Supelco 49451-U by Sigma Aldrich) was analysed using the same chromatographer programs. After obtaining the retention times of each of the components of the essential oil, expressed in minutes, the Kovats Retention index (RI) was determined from the following formula: $\mathrm{RI}=100 *\left(\mathrm{n}^{\circ} \mathrm{C} \mathrm{HC}_{\mathrm{n}-1}+\left[\left(\log \mathrm{RT} \mathrm{X}-\log \mathrm{RT} \mathrm{HC}_{\mathrm{n}-}\right.\right.\right.$ 1) $\left.\left.\times\left(\log \mathrm{RT}_{\mathrm{HC}} \mathrm{n}_{\mathrm{1}}-\log \mathrm{RT} \mathrm{HC}_{\mathrm{n}-1}\right)\right]\right)^{-1}$

Beeing:

- $\mathrm{n}^{\circ} \mathrm{C} \mathrm{HC}_{\mathrm{n}-1}$ : carbon numbers of the hydrocarbon prior to the compound.

- RT X: compound retention time.

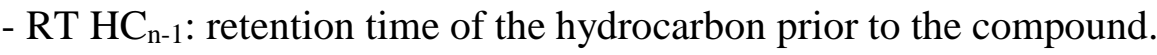

- $\mathrm{RT} \mathrm{HC}_{\mathrm{n}+1}$ : retention time of the hydrocarbon subsequent to the compound. 


\subsubsection{Aqueous extracts}

\section{Extraction}

Aqueous extracts were prepared applying the aqueous decoction method described by Pérez et al. (2002). 20g of leaves was macerated in $200 \mathrm{~mL}$ of distilled water, heated at 80 ${ }^{\circ} \mathrm{C}$ for 15 minutes, and then filtered with $50 \mathrm{~g} \mathrm{~m}^{-2}$ filter paper. Thereafter, leaves were submitted to a second extraction process, by immersion in $100 \mathrm{~mL}$ of distilled water at $80^{\circ} \mathrm{C}$ for 15 minutes, and filtered again. Both obtained extracts were mixed in a big container to homogenise the chemical contents, and then frozen at $-25^{\circ} \mathrm{C}$ until use to avoid compound decomposition. 


\subsubsection{Preliminary soil tests and experimental conditions}

Before mounting the greenhouse experiments, many soil samples were collected from different tangerine orchards, with the goal to test the germination potential of the endemic seedbank. Some soil appeared treated with synthetic herbicides and was discarded. The remaining samples were further tested as described in this paragraph.

To obtain statistically homogeneous experimental pots, it is indispensable to mix and sieve the soil to perform a pot experiment. Experimental pots also need to be adequate for the experiment duration time (short time $=$ smaller pots; long time $=$ bigger and very resistant pots).It is also important to find a compromise between volume of pots and the sieve to use. In microbiological field the standard is to use a 4-mm sieve; while in weed studies usually only the stones are removed before filling the pots, to maintain the original soil seedbank.

The smaller quantity of soil to obtain homogeneous samples for microbiological analysis is $500 \mathrm{~g}$ of humid soil, incubated in a pot with a minimum height of $5 \mathrm{~cm}$.

Another difference is if the focus is on the plant or on the soil: in the first case is needed to give water to the plants every time it needs, while for microbiological studies is better to maintain the $50-60 \%$ of soil water holding capacity.

\subsubsection{Water Holding Capacity}

Two types of water holding capacity (WHC) evaluation were performed to plan the total volume of treatment to apply avoiding its loss by percolation trough pots drainage holes.

1) $50 \mathrm{~g}$ of air dried soil, sift at $1 \mathrm{~cm}$ was mixed with water in a baker glass, then it was filtered for two hours in quantitative filter paper (figure 26).

Than the weight of the filter paper with the soil and of the wet filter paper alone was measured.

2) Five plastic pots were filled with $250 \mathrm{~g}$ ( $7 \mathrm{~cm}$ height) of dry soil, sift at 1 and $0.5 \mathrm{~cm}$, the holes of the pots was previously occluded by using filter paper $\left(70 \mathrm{~g} \mathrm{~m}^{-2}\right)$.

Than the pots was collocated in a tray, water was slowly added to the tray, reaching the upper level of the soil during 4 hours (fig. 27). Water was removed, pot weight was measured again after 30 minutes.

Water Holding Capacity was calculated as grams of water in grams of soil. 


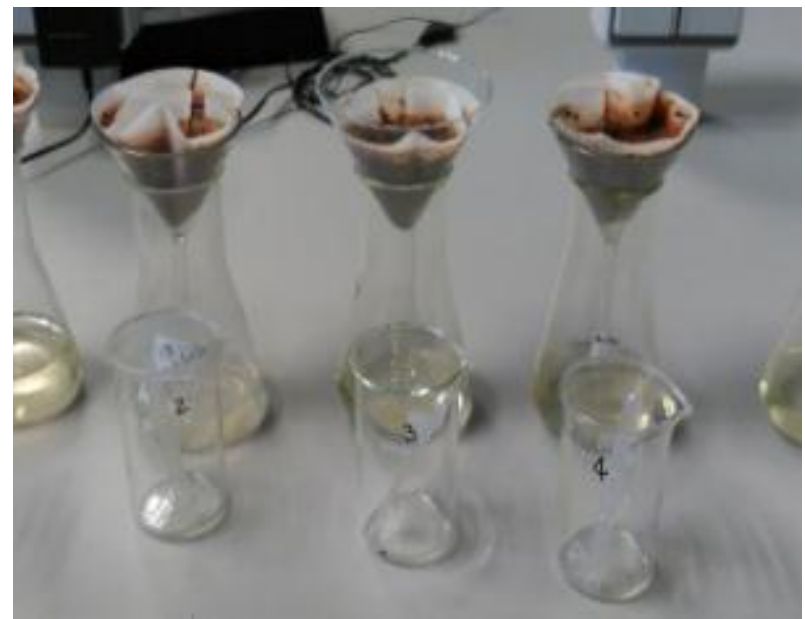

Figure 26: Water Holding Capacity evaluation method 1

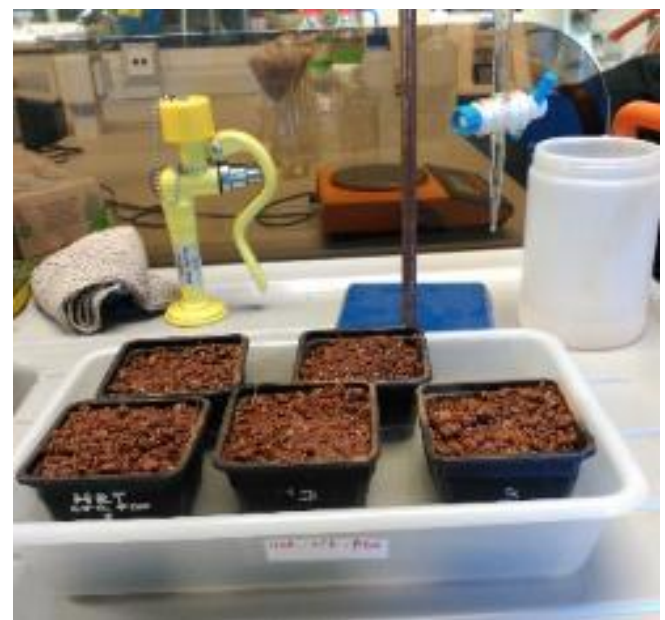

Figure 27: Water Holding Capacity evaluation method 2

\subsubsection{Germination test}

All the pots used for the WHC were incubated in greenhouse for 15 days. Water content and number of germinated seeds were surveyed. The soil with the healthiest endemic seedbank (having high germinative potential and the desired biodiversity), was chosen to perform the greenhouse experiments. In figure 28 the graph representing the endemic seedbank potential germination of the soil used in the fourth experiment.

Monitoring weeds growth, pot weight and given water (to evaluate evaporation and seedbank health), it was possible to enhance in-vivo chemical herbicide testing experimental protocols. In fact, in-vivo experiments are usually performed on artificial substrates, easier to manage than soils.

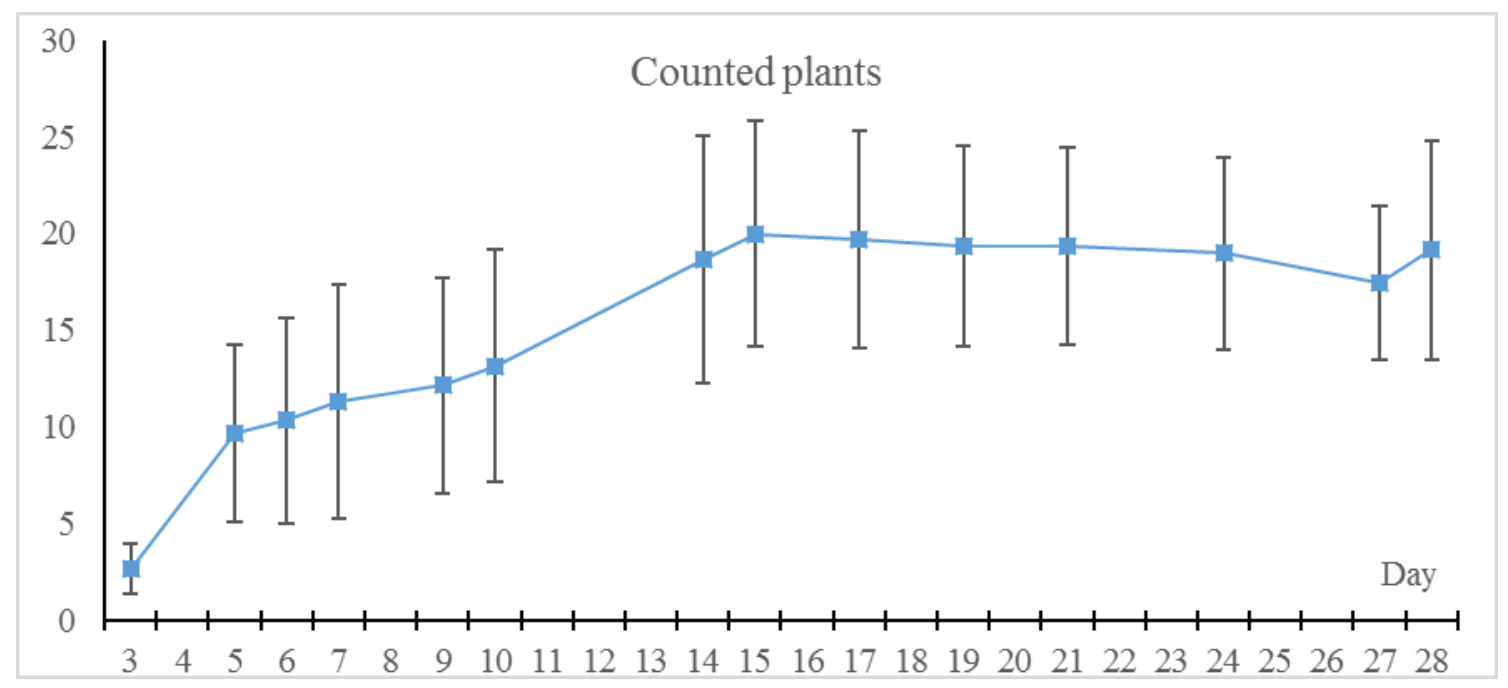

Figure 28: Count of germinated seeds in the preliminary test

Reported data are means $(N=5)$, bars are standard deviation 


\subsubsection{Greenhouse localization and conditions}

The experiments were performed in the greenhouse n. 8 of the building 5Pin the Universitat Politècnica de València-Campus de Vera; situated at 39²9'00.5"N; 0²0'29.7"W (figure 29). Environmental variables were monitored during the experiments using an HOBO U23 Pro v2 temperature and relative humidity data logger (figure 30).

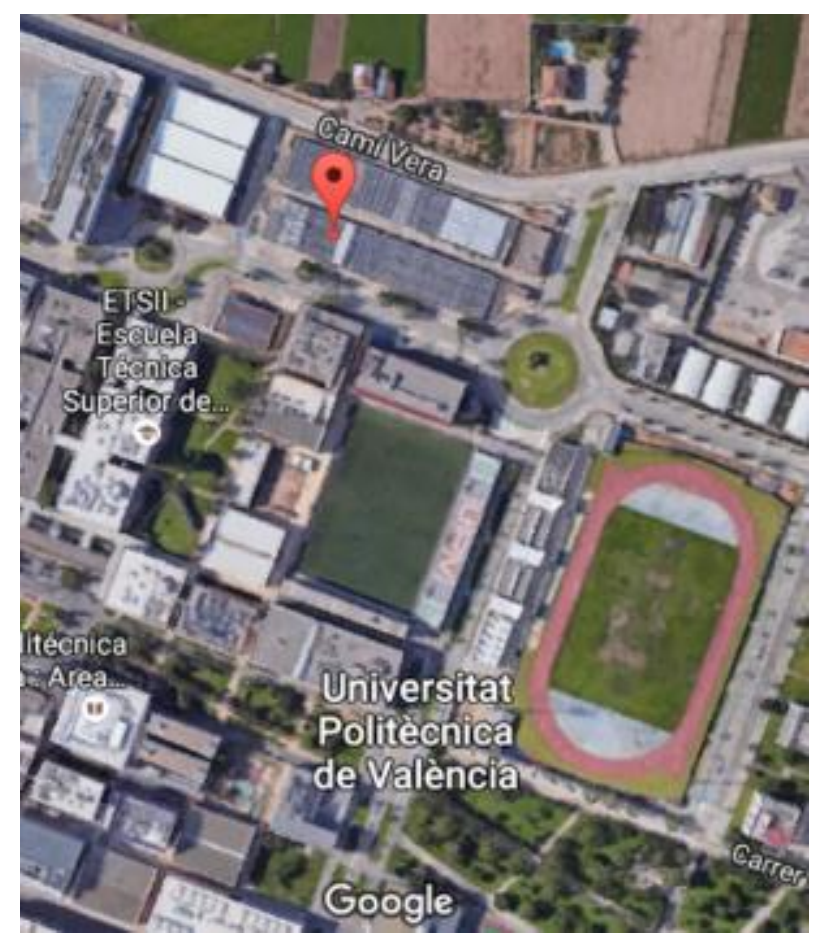

Figure 29: Localization of the experimental greenhouse

Inside the Campus De Vera (UPV), Camino de Vera, s/n 46022, Valencia, Spain

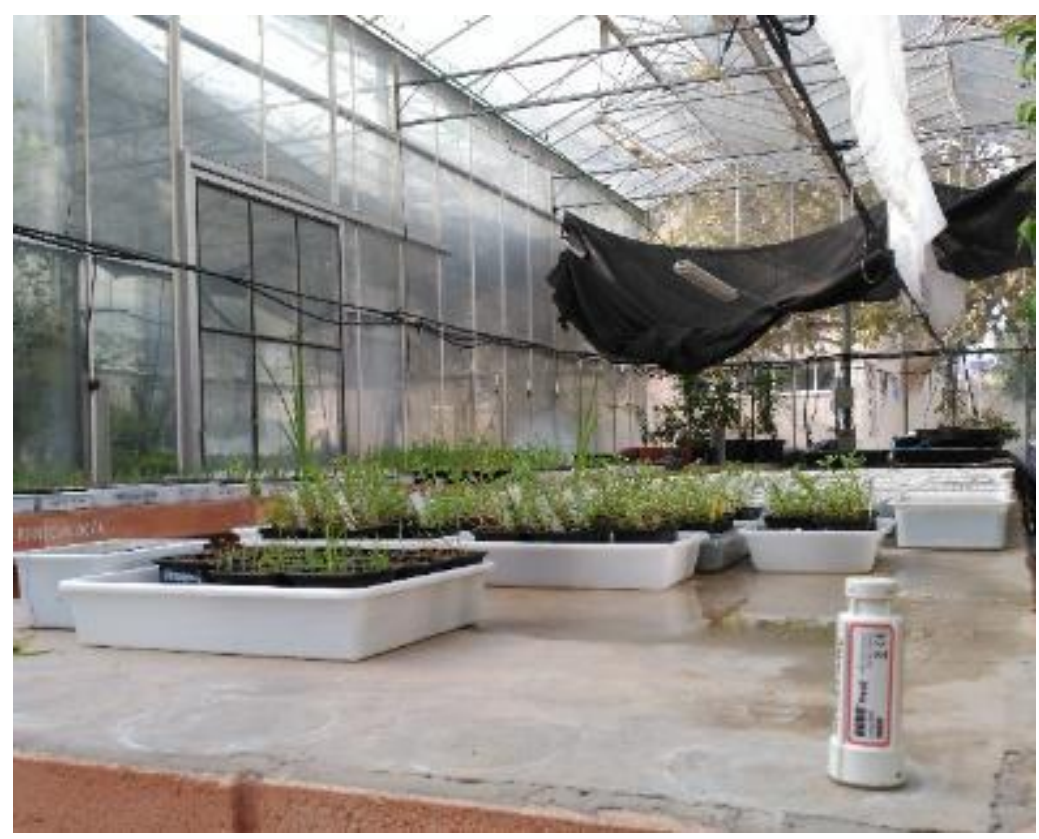

Figure 30: Data logger, pots and greenhouse 


\subsubsection{Experiment one: short and medium-term response of soil microorganisms to} essential oils with phytotoxic potential extracted from mediterranean plants

Topsoil $(0-10 \mathrm{~cm})$ was collected in the inter row zone of a tangerine orchard $\left(39^{\circ} 46^{\prime} 28^{\prime \prime}\right.$ N; 0¹6'5" O, Vall D’Uixó, Spain, see figure 31).

The main chemical and physical soil properties are listed in table 4.

Table 4: Main chemical and physical properties of the soil used for the first experiment

\begin{tabular}{ll}
\hline Soil properties & \\
\hline Water holding capacity (WHC) & $43 \%$ \\
\hline Clay & $1.2 \%$ \\
Silt & $4.9 \%$ \\
Sand & $93.9 \%$ \\
\hline $\mathrm{pH}$ & 7.5 \\
\hline Electrical Conductivity (EC) & $1.5 \mathrm{dS} \mathrm{m}^{-1}$ \\
\hline Total N (TN) & $1.7 \mathrm{~g} \mathrm{~kg}^{-1}$ \\
\hline Total organic Carbon (TOC) & $10.5 \mathrm{~g} \mathrm{~kg}^{-1}$ \\
\hline Total carbonates & $12.3 \%$ \\
\hline
\end{tabular}

To homogenize the soil and eliminate the bigger stones, soil was sift using a $1 \mathrm{~cm}$ sieve. Experiment started in August and lasted until November 2014. In 204 plastic pots $(10 \mathrm{~cm}$ $\varnothing ; 15 \mathrm{~cm}$ height, see figure 32) drainage holes were occluded with filter paper to avoid substrate loss, and then pots were filled with $560 \mathrm{~g}$ of soil. The soil in each pot was brought to 2-3 of its water holding capacity and left to reach the equilibrium overnight.

Then, 15 emulsions (5 essential oils x 3 oil volumes), each containing $1 \mathrm{~mL}(\mathrm{C} 1), 2 \mathrm{~mL}$ (C2) or $4 \mathrm{~mL}(\mathrm{C} 4)$ of one essential oil, $1 \mathrm{~mL}$ of organic emulsifier (Agrobiotec's Fitoil ${ }^{\circledR}$ ) and tap water up to $1 \mathrm{~L}$ were prepared. The control emulsion (FIT) held only Fitoil and tap water. Twelve pots (4 sampling days, 3 pots per day) received only water (WAT treatment) to verify Fitoil effects. Treatments were applied by direct pulverization on the soil surface in a volume equivalent to $33 \%$ of the soil WHC. The final concentrations of added EOs (table 5) were $0.143 \mu \mathrm{L}(\mathrm{C} 1), 0.286 \mu \mathrm{L}(\mathrm{C} 2)$ and $0.571 \mu \mathrm{L} \mathrm{g}^{-1}$ soil (C4).

After the addition of EO emulsions, pots were incubated in a greenhouse for 120 days at controlled conditions. During the incubation water loss by evaporation was reintegrated using tap water so that the soil was maintained at $50 \%$ of its WHC by monitoring the weight of pots and eventually adding the required amount of water. Such control was carried out two times a week. On days 15, 60, 90 and 120 since the beginning of incubation, three pots per treatment were destructively sampled, air dried, sieved in a polyethylene bag and moved in the Agrochemistry laboratories of the Università degli Studi di Palermo for soil analyses (see paragraph 2.1). 


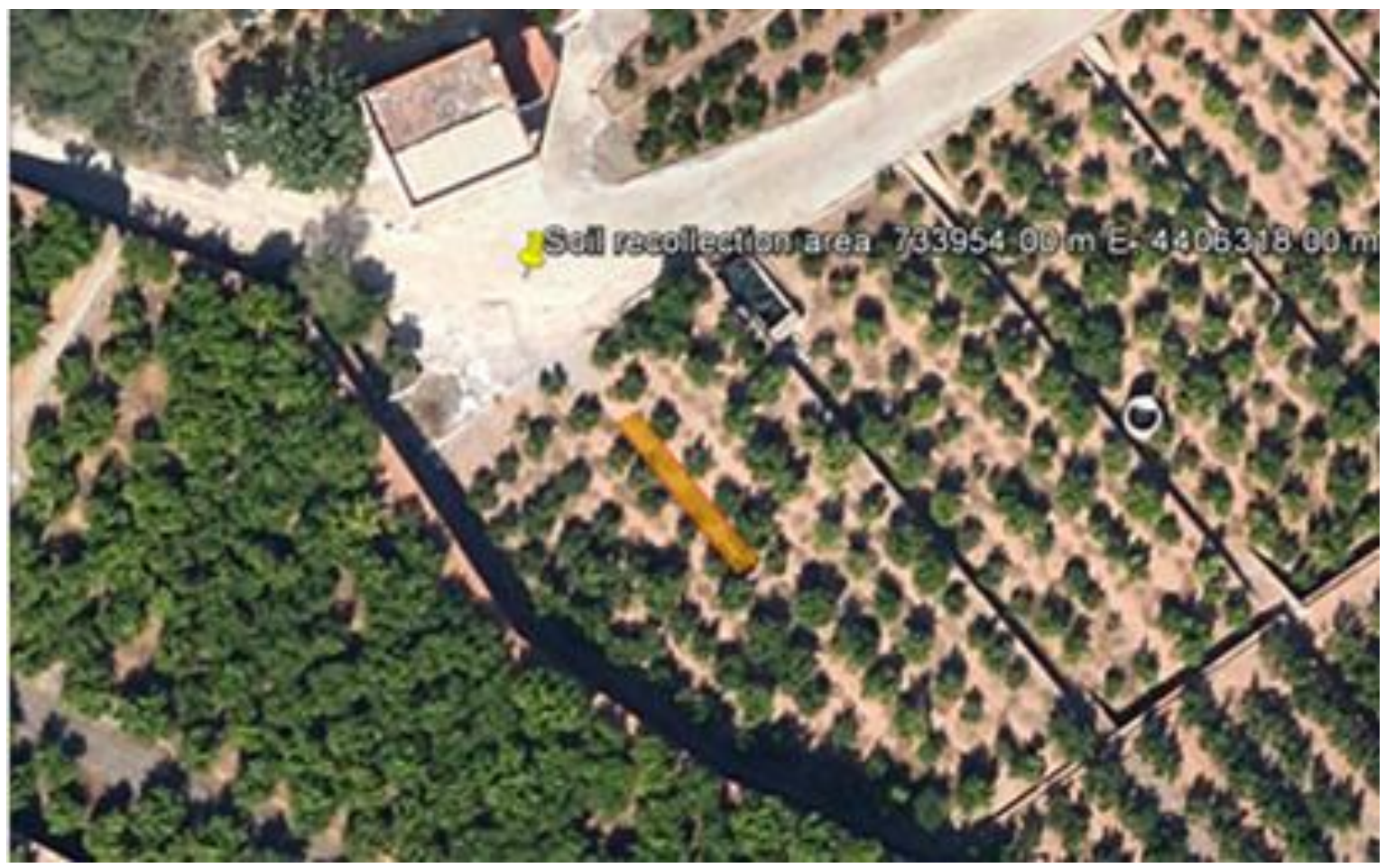

Figure 31: Soil recollection zone of the first experiment

The tangerine orchard belongs to an organic cooperative (Heliotec) situated in the zone of Nules (Valencia, Spain)
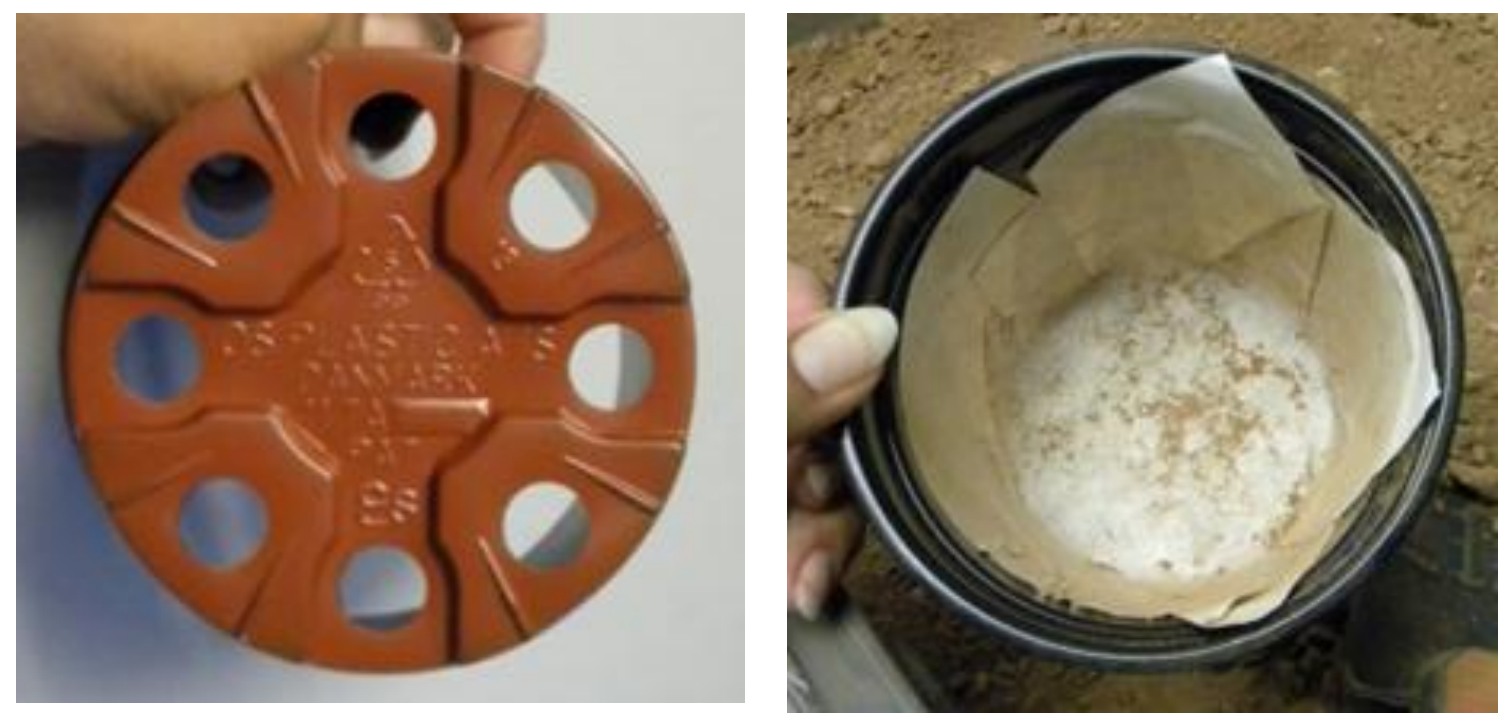

Figure 32: Pots used in the first experiment 
Table 5: Volumes of essential oils applied and codes used in the first experiment

\begin{tabular}{|c|c|c|c|c|}
\hline Source plant & Concentration of EO emulsion & $\mu \mathrm{L}$ EO pot ${ }^{-1}$ & 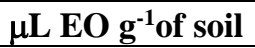 & Code \\
\hline \multirow[t]{3}{*}{ C. reticulata } & $1 \mathrm{~mL} \mathrm{~L}^{-1}$ & 80 & 0.143 & TAN C1 \\
\hline & $2 \mathrm{~mL} \mathrm{~L}^{-1}$ & 160 & 0.286 & TAN C2 \\
\hline & $4 \mathrm{~mL} \mathrm{~L}^{-1}$ & 320 & 0.571 & TAN C4 \\
\hline \multirow[t]{3}{*}{ C. limon } & $1 \mathrm{~mL} \mathrm{~L}^{-1}$ & 80 & 0.143 & LEM C1 \\
\hline & $2 \mathrm{~mL} \mathrm{~L}^{-1}$ & 160 & 0.286 & LEM C2 \\
\hline & $4 \mathrm{~mL} \mathrm{~L}^{-1}$ & 320 & 0.571 & LEM C4 \\
\hline \multirow[t]{3}{*}{ E. camaldulensis } & $1 \mathrm{~mL} \mathrm{~L}^{-1}$ & 80 & 0.143 & EUC C1 \\
\hline & $2 \mathrm{~mL} \mathrm{~L}^{-1}$ & 160 & 0.286 & EUC C2 \\
\hline & $4 \mathrm{~mL} \mathrm{~L}^{-1}$ & 320 & 0.571 & EUC C4 \\
\hline \multirow[t]{3}{*}{ E. africanus } & $1 \mathrm{~mL} \mathrm{~L}^{-1}$ & 80 & 0.143 & ERI C1 \\
\hline & $2 \mathrm{~mL} \mathrm{~L}^{-1}$ & 160 & 0.286 & ERI C2 \\
\hline & $4 \mathrm{~mL} \mathrm{~L}^{-1}$ & 320 & 0.571 & ERI C4 \\
\hline \multirow[t]{3}{*}{ T. capitata } & $1 \mathrm{~mL} \mathrm{~L}^{-1}$ & 80 & 0.143 & TCP C1 \\
\hline & $2 \mathrm{~mL} \mathrm{~L}^{-1}$ & 160 & 0.286 & TCP C2 \\
\hline & $4 \mathrm{~mL} \mathrm{~L}^{-1}$ & 320 & 0.571 & TCP C4 \\
\hline
\end{tabular}

Treatment codes and mode of application explained in the text

\subsubsection{Statistical analysis}

Before performing parametric statistical analyses, normal distribution and variance homogeneity of the data were checked by Kolmogorov-Smirnoff goodness-of-fit and Levene's tests, respectively.

Statistical analysis was performed using Statgraphics Centurion version 15.0 (Statpoint Inc., USA, 2005).

A preliminary principal component analysis (PCA) was performed to assess the separation among treatments. PCA was carried out using correlation matrix on standardised soil properties, with each variable having a zero mean and unit variance, no rotation was applied, water treatment data was not included in the PCA (Laudicina et al. 2009). As the principal component influencing dependent variables variances was the sampling day, to better understand the effects of the treatments we opted for a two-way ANOVA, performed singly for 4 incubation times (i.e. 15, 30, 90, 120 days) in which the first factor became EO type, with the levels ERI, EUC, LEM, TAN, TCP, while the second factor was the concentration (Fitoil control, C1, C2 and C4).

Than the one-way ANOVA (followed by Tukey post hoc test at $\mathrm{P}<0.05$ ) was used to compare each EOs concentration with the fitoil control, considered as concentration zero (C0). Studied dependent variables were $\mathrm{C}_{\mathrm{ext}}, \mathrm{MBC}, \mathrm{SR}, \mathrm{qCO}_{2}, \mathrm{FAs}, \mathrm{Bac} \%$, Fun\%, $\mathrm{Gp} \%$, Gn\%, Gp_Gn, F_B and Mes\%. 


\subsubsection{Experiment two: medium term response of soil microorganisms to aqueous extracts with phytotoxic potential extracted from mediterranean plants}

Poa аппиа $L$. is a widespread weed. In recreation green areas it can produce consistent losses, since use of synthetic herbicide is forbidden in such sensible places for human health. During 2014 the UPV study group performed a pot experiment on a golf course artificial substrate, testing the phytotoxic effects of four plants water extracts (AEs) on P. annua germination and growth, in table 6 the main chemical and physical properties of used substrate are listed.

The substrate was a mix of $90 \%$ silicic sand and 10\% brown peat moss (table 6 and 7), percentages in weight.

\begin{tabular}{ll} 
Table 6: Characteristics of the Projar peat moss \\
\hline Product: & $\begin{array}{l}\text { Baltic brown sphagnum } \\
\text { peat moss }\end{array}$ \\
Basic component: & Sphagnum fuscum peat \\
Decomposition degree: & H2-H6 (Von Post) \\
Structure / fraction: & $0-40 \mathrm{~cm}$ \\
pH: & $3.4-3.8$ \\
E.C.: & $0.6 \mathrm{mS} \mathrm{cm}^{-1}$ \\
Available water & $55 \%$ \\
Air volume & $36 \%$ \\
Water volume & $57 \%$ \\
Water retention & $4.8 \mathrm{~g} \mathrm{~g}^{-1}$ \\
Porosity & $93 \%$ \\
Humidity & $45 \%$ \\
Density & $117 \mathrm{Kg} \mathrm{m}^{-3}$ \\
\hline
\end{tabular}

Table 7: Characteristics of the silicic sand

\begin{tabular}{ll}
\hline \multicolumn{2}{c}{ Texture } \\
\hline Sieve & Retained \% \\
\hline 710 & 7.39 \\
630 & 10.52 \\
500 & 10.87 \\
315 & 29.48 \\
250 & 14.3 \\
160 & 15.37 \\
80 & 10.62 \\
\hline & Chemical analysis \\
\hline $\mathrm{SiO}_{2}$ & $98.90 \%$ \\
$\mathrm{TiO}_{2}$ & $0.042 \%$ \\
$\mathrm{Al}_{2} \mathrm{O}_{3}$ & $0.45 \%$ \\
$\mathrm{Fe}_{2} \mathrm{O}_{3}$ & $0.095 \%$ \\
$\mathrm{CaO}_{2} \mathrm{O}$ & $0.20 \%$ \\
$\mathrm{Na}_{2} \mathrm{O}$ & $0.012 \%$ \\
$\mathrm{~K}_{2} \mathrm{O}$ & $0.18 \%$ \\
$\mathrm{pH}$ in $\mathrm{H}_{2} \mathrm{O}$ & 8.91 \\
$\mathrm{pH}$ in $\mathrm{KCl}$ & 8.58 \\
$\mathrm{E} . \mathrm{C} \cdot 1: 5\left(\mathrm{dS} \mathrm{m}{ }^{-1}\right)$ & 0.22 \\
\hline
\end{tabular}

30 plastic pots $\left(\mathrm{h}=10.5 \mathrm{~cm} ; \varnothing_{\max }=12.5 \mathrm{~cm} ; \varnothing_{\min }=8.5 \mathrm{~cm}\right)$ were filled using $0.5 \mathrm{~L}$ of artificial substrate. In 25 pots were sown 100 P. annua seeds, 5 pots were left unsown constituting a control. Pots were lead to $50 \% \mathrm{WHC}$, then four groups of five sown pots were treated with WEs of Eucalyptus camaldulensis Dehnh. (EUC), Santolina chamaecyparissus L. (SAN), Artemisia absynthium L. (ART) and Cupressus sempervirens L. (CUP), the remaining 10 pots (five sown and five unsown) was treated with water (CTR and UNS). Treatments were sprayed on the pots in a proportion of $1 \mathrm{~L} \mathrm{~m}^{-2}$ during five days, then watered with $50 \mathrm{~mL}$ tap water each two day. P. annua germination and growth were monitored during 
120 days after the treatment. After 120 days, three random pots for each treatment were destructively sampled and soil fertility bioindicators analysed (see paragraph 2.1).

\subsubsection{Statistical analysis}

Before performing parametric statistical analyses, normal distribution and variance homogeneity of the data were checked by Kolmogorov-Smirnoff goodness-of-fit and Levene's tests, respectively.

Statistical analysis was performed using Statgraphics Centurion version 15.0 (Statpoint Inc., USA, 2005).

One-way ANOVA with repetitions, followed by Tukey post hoc test was used to compare control and treatment means at $\mathrm{P}<0.05$, with treatments as independent variable. ANOVA was repeated two times: with the whole dataset and excluding the UNS values.

Studied dependent variables was: FAs, BAC\%, FUN\%, Gp\%, Gn\%, Gp_Gn, F_B, Mes\%, $\mathrm{pH}, \mathrm{EC}, \mathrm{C}_{\mathrm{ext}}, \mathrm{TOC}, \mathrm{N}_{\mathrm{tot}}, \mathrm{MBC}, \mathrm{SR}, \mathrm{qCO}_{2}$. 


\subsubsection{Experiment three: short, medium and long-term response of soil microorganisms to natural and synthetic herbicides}

The goal of this experiment was to increase and complete the information of the experiment number one. Rectangular plastic food containers were chosen instead to use commercial pots. Used containers were closed on the bottom to avoid treatment loss by percolation; a small amount of drainage material (perlite) was distributed under the soil to impede the evolution of anaerobic conditions. Bigger containers have been used to increase sample homogeneity; additionally, soil (always coming from a tangerine orchard) was sift at $4 \mathrm{~mm}$ instead $1 \mathrm{~cm}$.

Table 8:Volumes of essential oils, pure compound and synthetic herbicide applied in the fourth experiment

\begin{tabular}{lcccc}
\hline Treatment & Concentration & $\boldsymbol{\mu L}$ compound pot $^{\mathbf{1}}$ & $\boldsymbol{\mu} \mathbf{L}$ product $\mathbf{~}^{\mathbf{1}}$ of soil & Code \\
\hline E. africanus & $2 \mathrm{~mL} \mathrm{~L}^{-1}$ & 372 & 0.372 & ERI C2 \\
& $4 \mathrm{~mL} \mathrm{~L}^{-1}$ & 744 & 0.744 & ERI C4 \\
\hline T. capitata & $8 \mathrm{~mL} \mathrm{~L}^{-1}$ & 1488 & 1.488 & ERI C8 \\
& $2 \mathrm{~mL} \mathrm{~L}^{-1}$ & 372 & 0.372 & TCP C2 \\
& $4 \mathrm{~mL} \mathrm{~L}^{-1}$ & 744 & 0.744 & TCP C4 \\
\hline Carvacrol & $8 \mathrm{~mL} \mathrm{~L}^{-1}$ & 1488 & 1.488 & TCP C8 \\
& $1.44 \mathrm{~mL} \mathrm{~L}^{-1}$ & 268 & 0.268 & CAR C2 \\
& $2.88 \mathrm{~mL} \mathrm{~L}^{-1}$ & 536 & 0.536 & CAR C4 \\
\hline Oxyfluorfen & $5.76 \mathrm{~mL} \mathrm{~L}^{-1}$ & 1071 & 1.071 & CAR C8 \\
\hline Fitoil & $0.54 \mathrm{~mL} \mathrm{~L}^{-1}$ & 8.4 & 0.84 & OXY \\
\hline $\mathrm{H}_{2} \mathrm{O}$ & $1 \mathrm{~mL} \mathrm{~L}^{-1}$ & 186 & 0.186 & FIT \\
\hline
\end{tabular}

Treatment codes and mode of application explained in the text

The EOs of E. africanus EO (ERI) and T. capitata EO. (TCP), which in the first experiment had shown the strongest effects on soil bioindicators were tested again. The emulsions were prepared as previously described, increasing concentrations at $2(\mathrm{C} 2), 4(\mathrm{C} 4)$ and $8(\mathrm{C} 8) \mathrm{mL} \mathrm{L}^{-1}$.

The most abundant pure compound of thyme EO, carvacrol (CAR), has also been tested (as emulsion with Fitoil as emulsifier) at the three volumes contained in TCP EO treatments, considering its content in the used T. capitata EO $(72.3 \%$, v/v).

Used carvacrol was a commercial product, W224502 Sigma-Aldrich Carvacrol.

Oxyfluorfen (OXY), a widely used pre-emergence synthetic herbicide, was set as a positive control. It has been dissolved in water and dosed as suggested by commercial instructions for citrus orchards: $4 \mathrm{Lha}^{-1}$ corresponding to 8.4 microliters in $210 \mathrm{~cm}^{2}$. Lainco's Fenfen (Register number 23.917) was the commercial oxyfluorfen-based $\left(24 \% \mathrm{w} \mathrm{v}^{-1}\right)$ herbicide used in the experiment. Fenfen is a selective herbicide against annual weeds in pre- or early post- 
emergence, with a long residual activity. Two control treatments have been performed, respectively with water (WAT) and with an emulsion of water and Fitoil (FIT) (table 8).

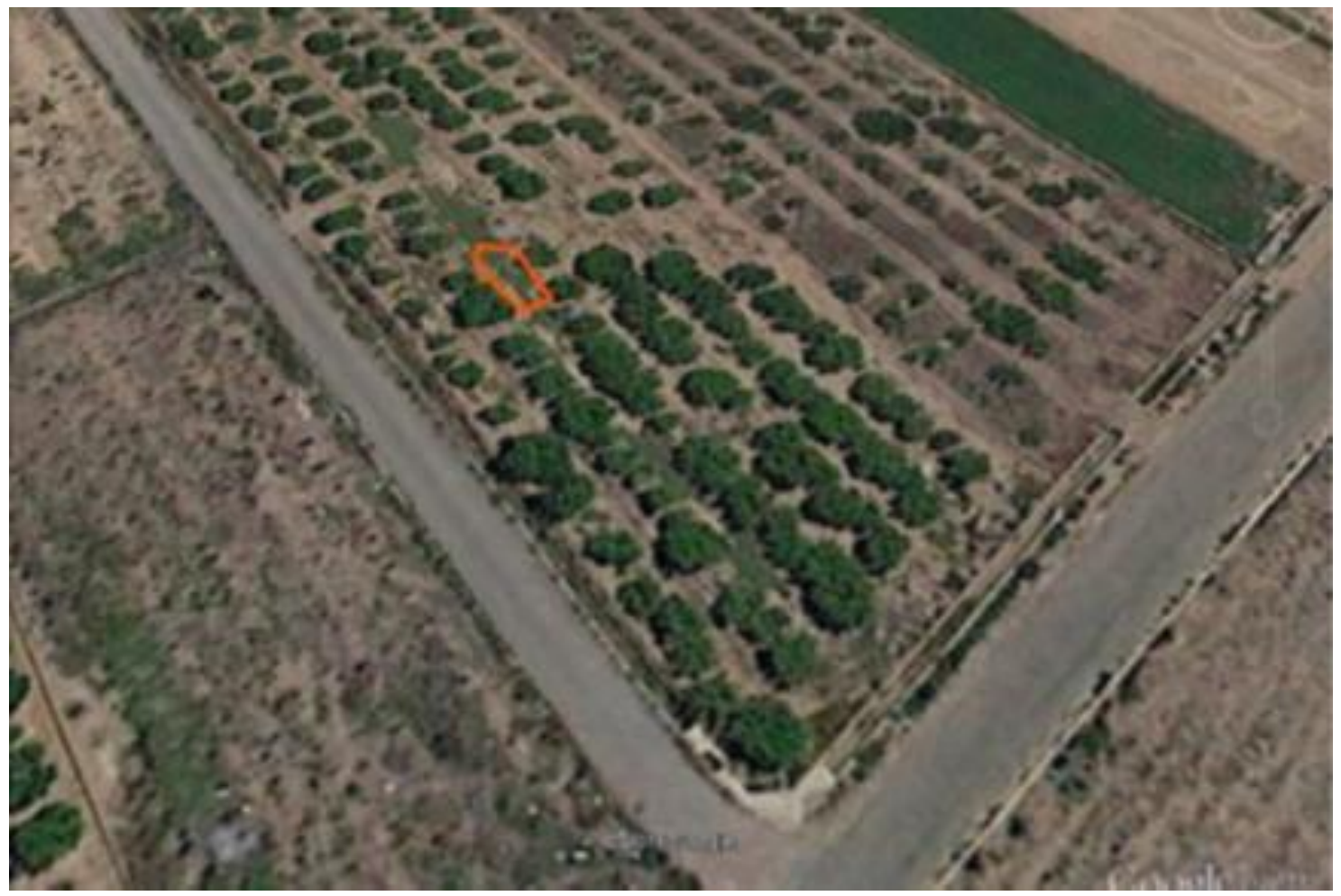

Figure 33: Soil recollection zone of the third experiment Puçol, comunitat Valenciana

Table 9: Physical properties of the soil used in the fourth experiment

\begin{tabular}{ll}
\hline Soil properties & \\
\hline Clay & $21.85 \%$ \\
Silt & $47.55 \%$ \\
Sand & $30.60 \%$ \\
\hline
\end{tabular}

Experimental design was set to monitor soil bioindicators and weed development during 6 months, the experiment lasted since 22August 2016 to22 February 2017.

Topsoil $(0-5 \mathrm{~cm})$ collected from the organic tangerine orchard situated at the coordinates $39^{\circ} 37^{\prime} 24.46 " \mathrm{~N} \quad 0^{\circ} 17^{\prime} 25.89 " \mathrm{~W}$, in the zone of Puçol, comunitat Valenciana (figure 33). Soil was sifted contextually with the recollection, using a plastic net having $1 \mathrm{~cm}$ holes, then air dried in laboratory conditions $\left(23^{\circ} \mathrm{C}\right)$ for one week and then sift again at $4 \mathrm{~mm}$. One hundred-fortyfour containers were filled with $45 \mathrm{~g}$ of Gramoflor (2-6 cm texture) Premium perlite (corresponding to $2.5 \mathrm{~cm}$ height) covered by $1 \mathrm{~kg}$ soil $(5 \mathrm{~cm}$ height), soil was lead to $66 \%$ WHC by adding $373 \mathrm{~mL}$ of tap water. Than using a manual sprayer, treatments were 
applied by direct pulverization on the soil, the actual amount of treatment reaching the soil surface was controlled by weighting (see figure 34 ).

Treated containers were incubated at greenhouse conditions and watered every two days. On days $30,60,120$ and 180 since the beginning of incubation, three containers per treatment were destructively sampled for soil analyses (see paragraph 2.1).

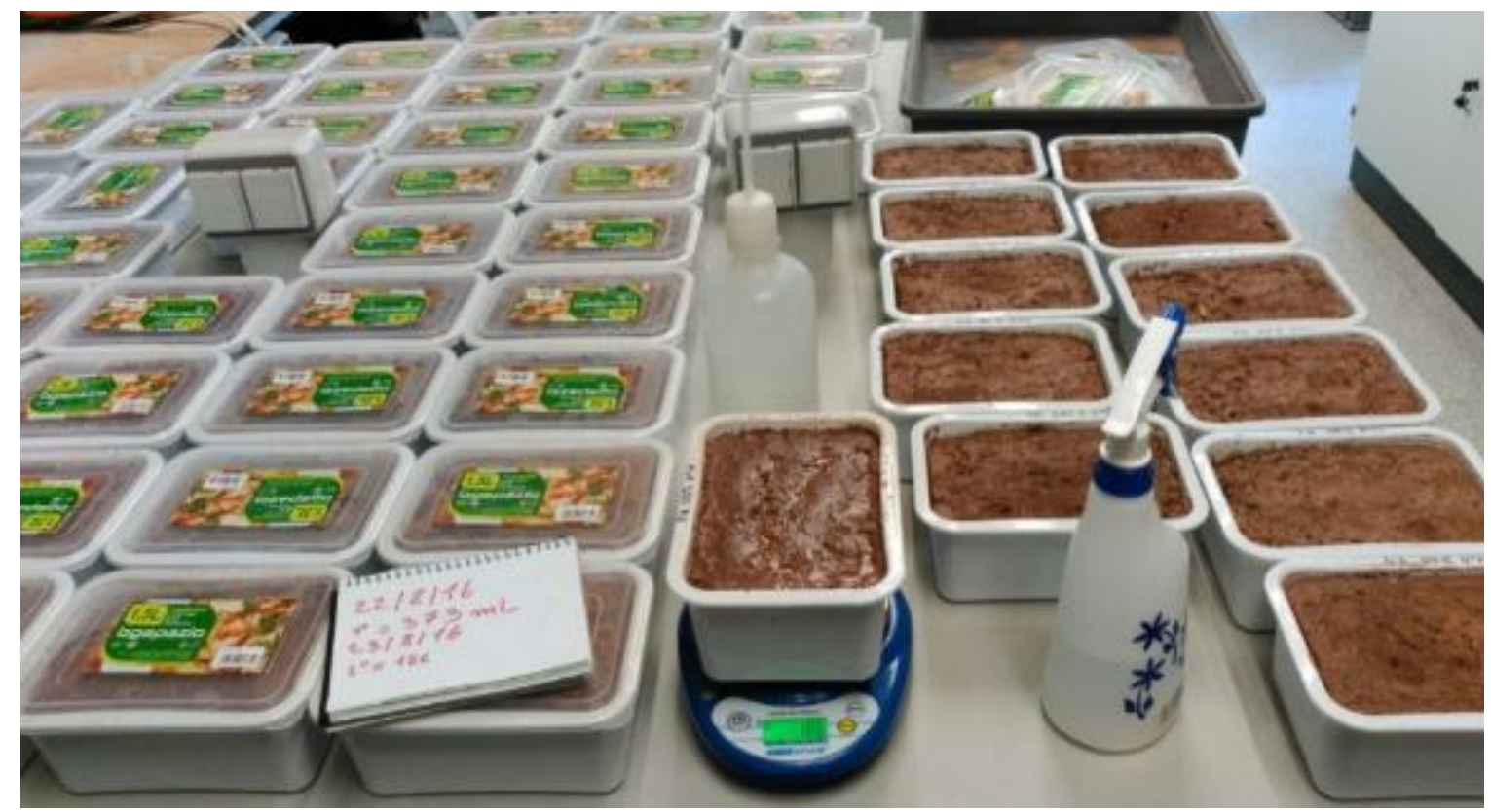

Figure 34: Experiment three containers: before, during and after the treatment application

\subsubsection{Germination and growth monitoring}

At every sampling day, two pictures were taken for each container for further analysis by using MedCalc Digimizer software (version 4.6.1; MedCalc software, Ostend, Belgium) to obtain weeds vertical growth (figure $35 \mathrm{~A}$ ) and canopy (figure $35 \mathrm{~B}$ ).

All the aerial parts of the plants were collected and sorted by identified taxon, for each identified taxonomical group, the number of specimens, (figure $35 \mathrm{C}$ ). the fresh and the dry weight was registered. Plants was dried by oven desiccation, at $40^{\circ} \mathrm{C}$ temperature during one week before to measure the dry weights.

\subsubsection{Statistical analysis}

Data were checked for normality and homogeneity as previously reported in paragraph 2.3.3.1; and a preliminary principal component analysis (PCA) was also performed. 
As the principal component influencing dependent variables variances was the sampling day, to better understand the effects of the treatments we opted for a one-way ANOVA performed singly for 4 incubation times (i.e. 30, 60, 120 and 180 days) and for 3 treatments (with the levels ERI, TCP and CAR) in which the factor is the concentration (Fitoil control, $\mathrm{C} 2, \mathrm{C} 4$ and C8). Tukey post hoc test was used to compare treatment means at $\mathrm{P}<0.05$.

Student t-test (pairwise mean comparisons) was performed between OXY vs WAT and TCP vs CAR.

Studied dependent variables was: $\mathrm{C}_{\mathrm{ext}}, \mathrm{MBC}, \mathrm{SR}, \mathrm{qCO}_{2}, \mathrm{FAs}, \mathrm{Bac} \%$, Fun $\%$, Gp\%, Gn\%, Gp_Gn, F_B, Mes\%, Count, Fresh w. and Dry w.

$\mathbf{A}$

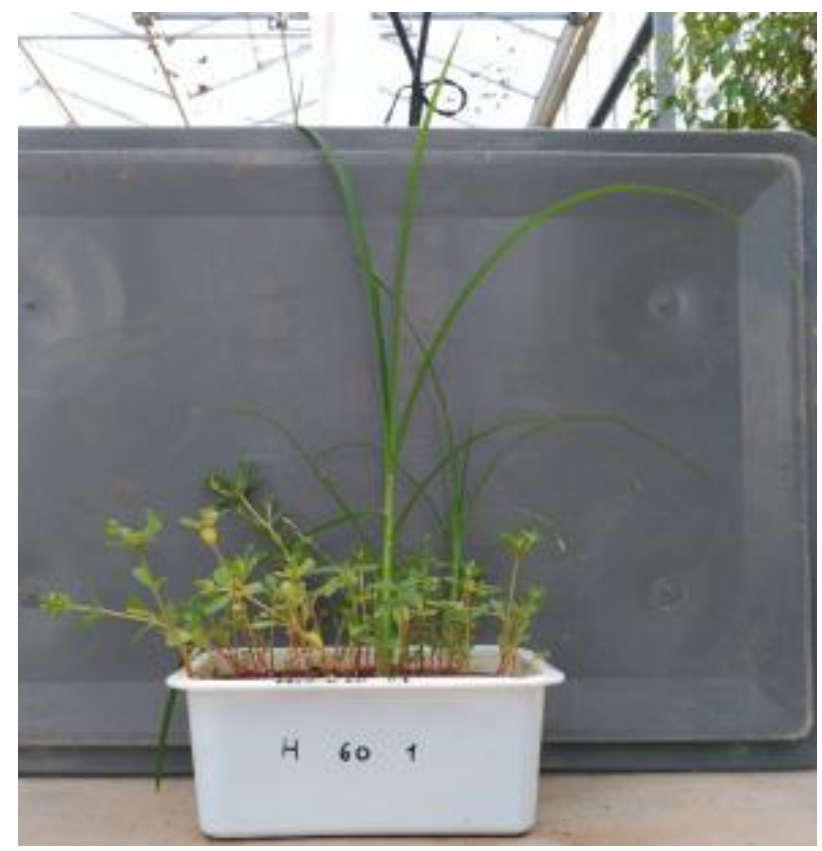

B

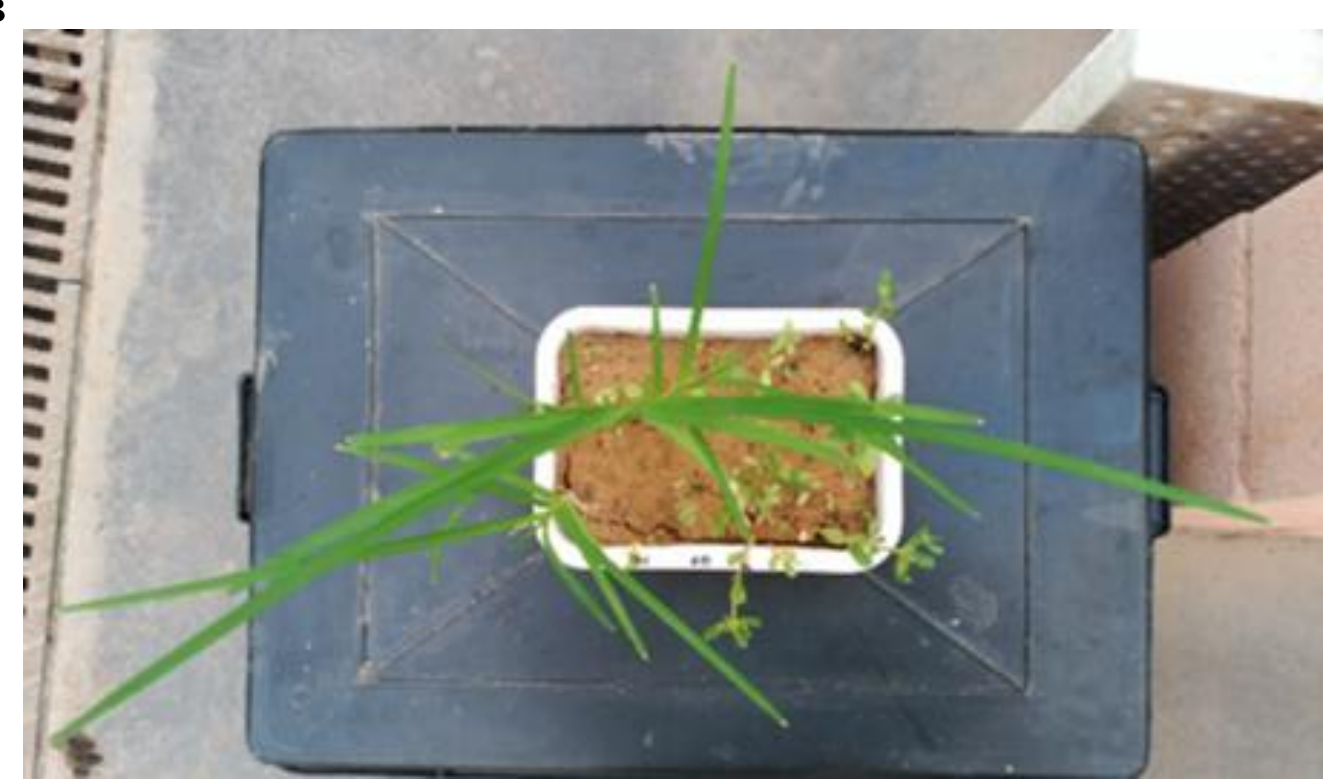


Oddo M. - Effects of different weed control practices on soil quality in mediterranean crops

C

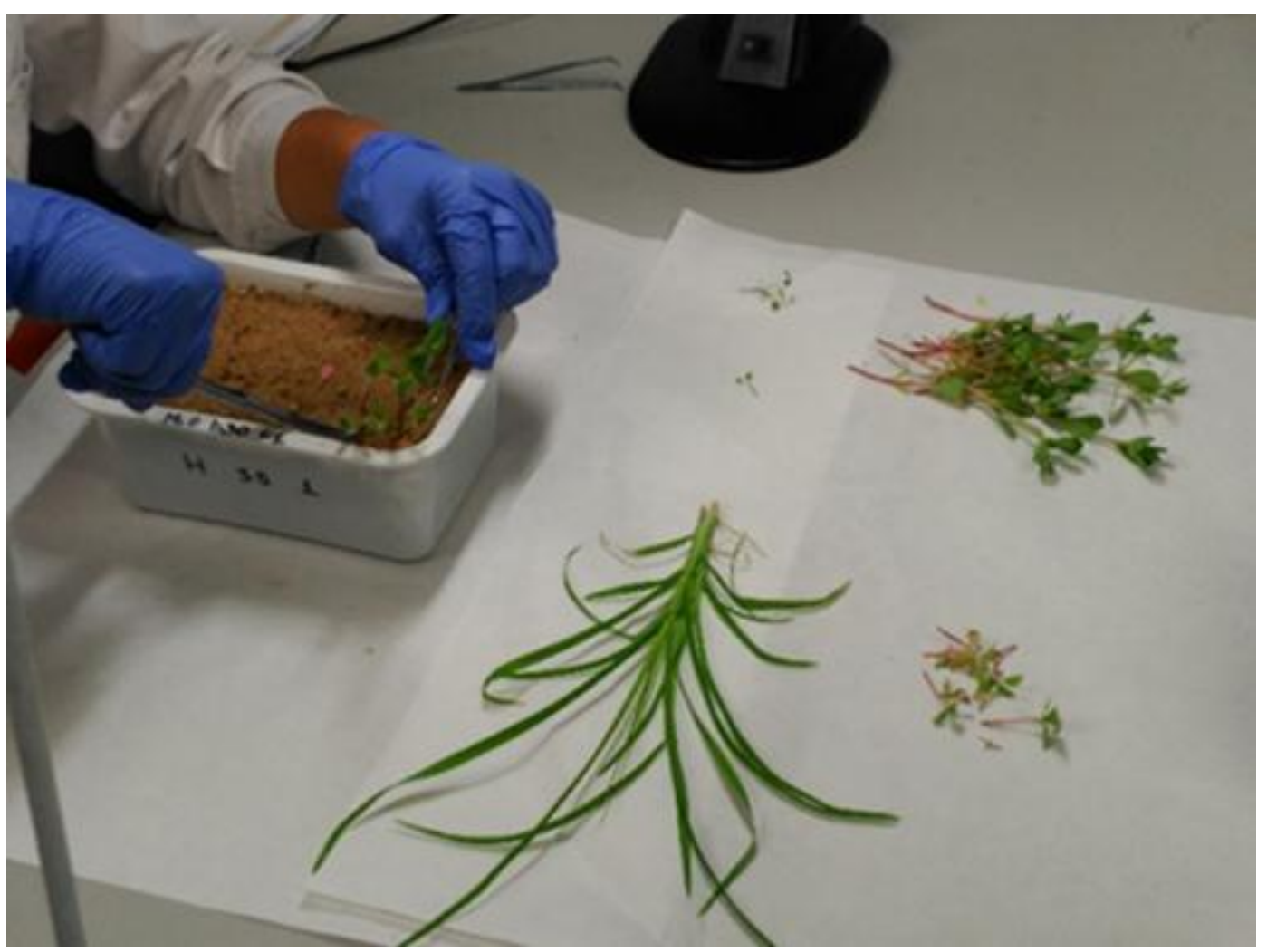

Figure 35: Weeds variables evaluation

elongation $(A)$; canopy $(B)$; germination, plant aerial parts count, fresh weight and dry weight $(C)$. 


\subsection{Materials and methods used in study of physical practices}

\subsubsection{Experiment four: long-term comparison between tillage and mulching effects on soil biological properties}

The aim of this work was to investigate the long-term effect of rotary tillage and mulching with a plastic geotextile on soil total and extractable organic carbon (EOC and TOC, respectively), microbial biomass carbon (MBC), soil respiration and microbial community structure by phospholipid fatty acids.

Soil used for this experiment was located in Petrosino (TP, Sicily, 37 $42^{\prime} 22.60^{\prime \prime} \mathrm{N}$; $12^{\circ} 30^{\prime} 20.32^{\prime \prime} \mathrm{E}$, figure 35). Since 2001, a tangerine orchard was split in four treatments by obtaining a $10 \mathrm{~m}$ length and $20 \mathrm{~m}$ width plot per treatment. In each plot weed management consisted in one of the following combinations: tillage during 15 years (T15), mulching (with geotextiles, figure 36) during 15 years (M15), tillage for 7 years followed by 8 years of mulching (T7M8) and 7 years of mulching followed by 8 of tillage (M7T8).

Rotary tillage was applied two-three times per year (March or April, June, October) and regarded the first $10 \mathrm{~cm}$ of soil. On April 2015 three soil samples at two different sampling depths $(0-20$ and $20-40 \mathrm{~cm})$ were collected per plot. Each treatment was replicated three times in the field. Soil samples were air-dried and sieved at $2 \mathrm{~mm}$ to be analysed as described in paragraph 2.1 .

\section{Statistical analysis}

Data were checked for normality and homogeneity as previously reported in paragraph

\subsubsection{1}

One-way ANOVA with repetitions was performed singly for each deepness (i.e. 0-20 and $20-40 \mathrm{~cm}$ ) having the weed management practice as independent variable.

The studied dependent variables were: $\mathrm{C}_{\mathrm{ext}}, \mathrm{MBC}, \mathrm{SR}, \mathrm{qCO}_{2}, \mathrm{FAs}, \mathrm{Bac} \%$, Fun $\%, \mathrm{Gp} \%$, Gn\%, Gp_Gn, F_B and Mes\%. 
A

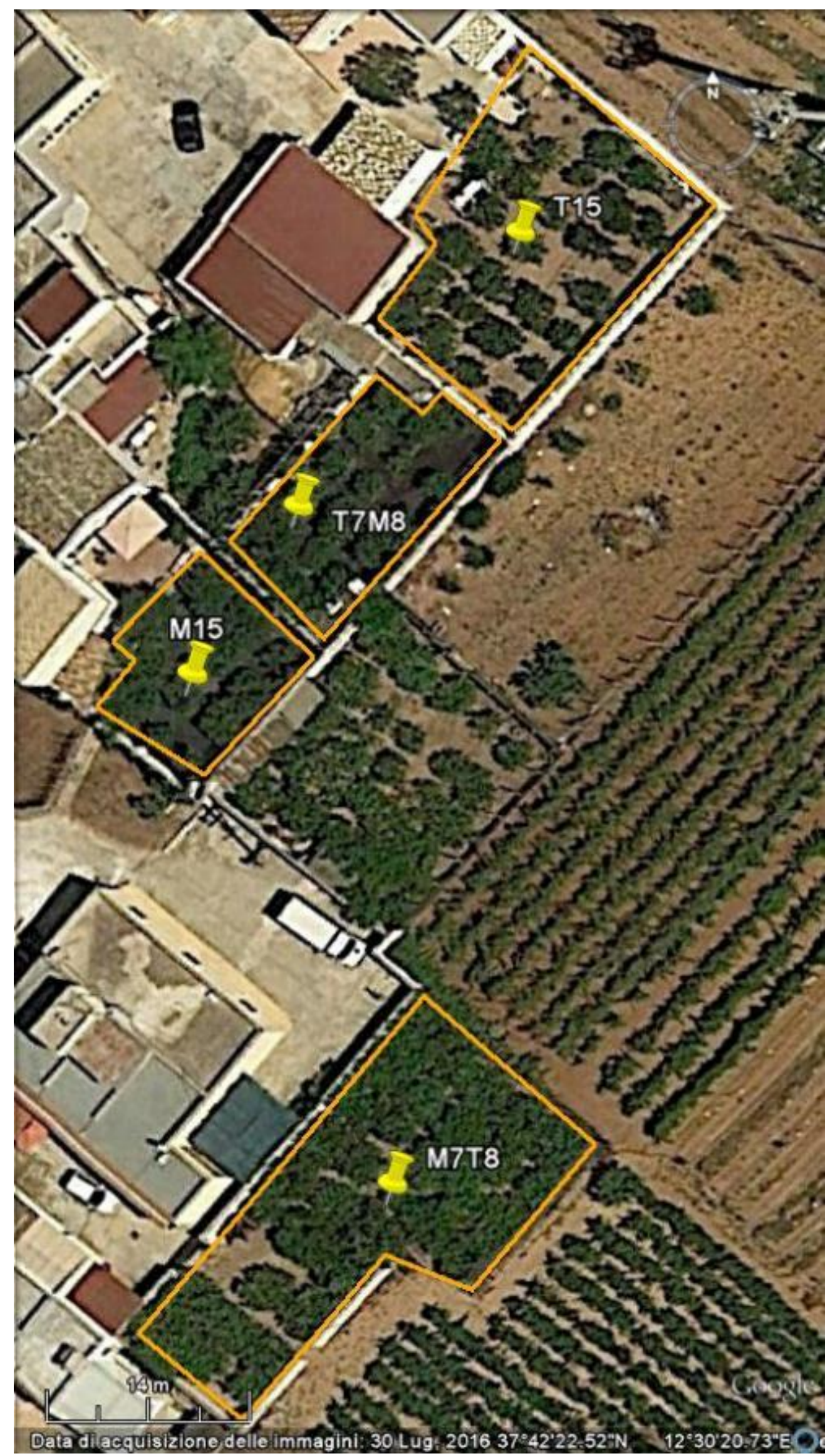


B

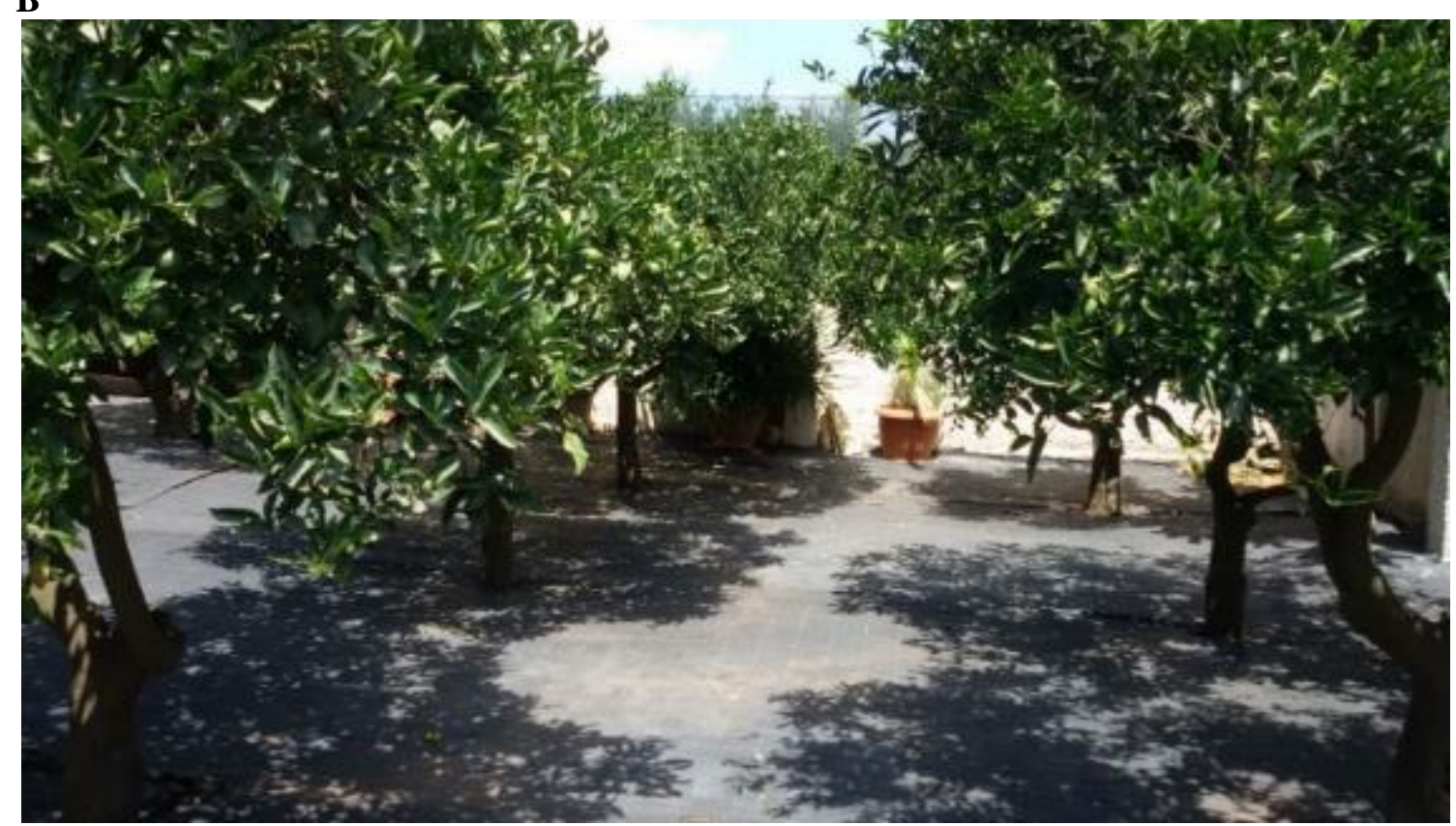

$\mathbf{C}$

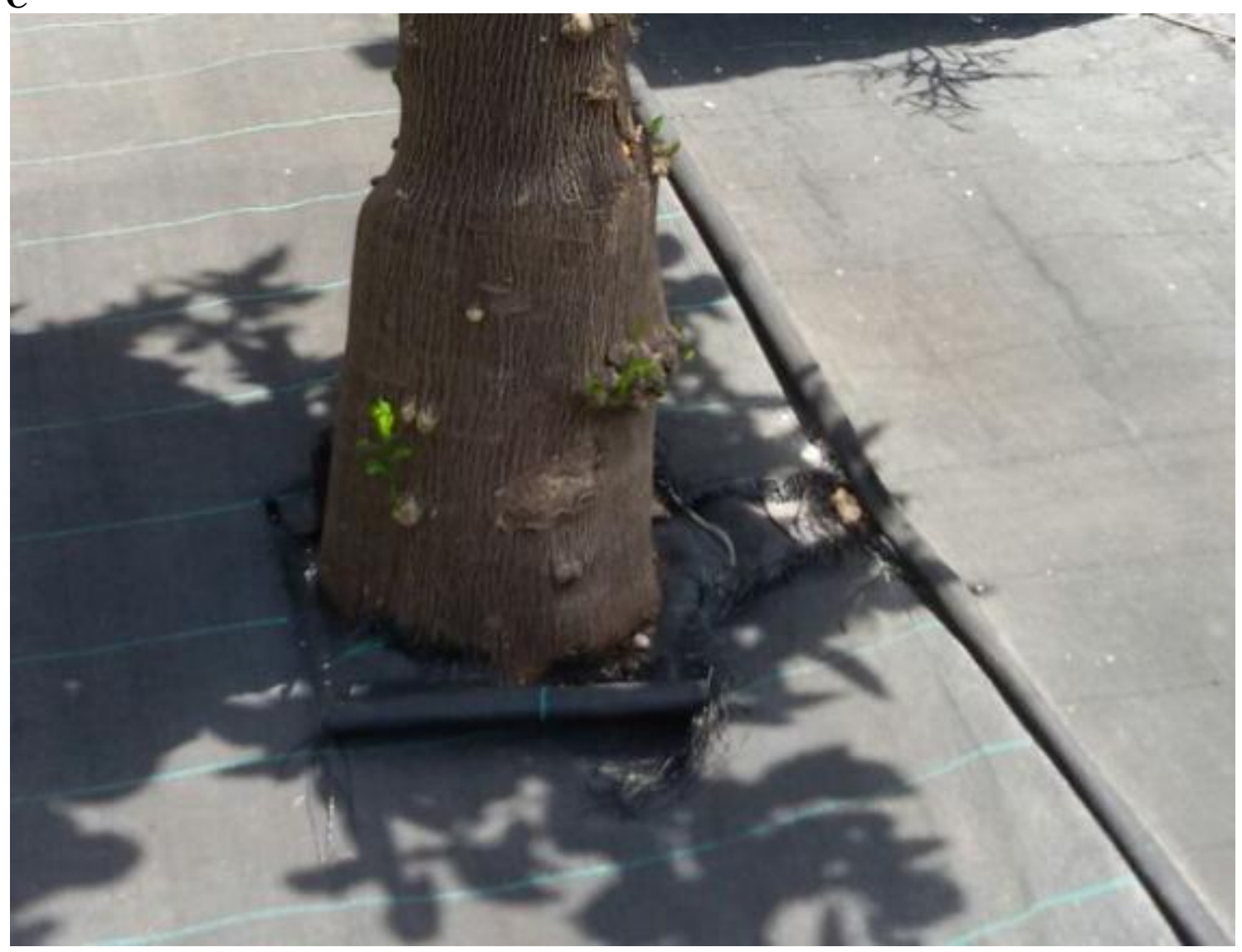

Figure 36: Experimental plots of the third experiment and physical practices details

A) Soil recollection area; $B)$ Mulched plot; C) Geotextile use detail 


\section{Results and discussion}

\subsection{Essential oils composition and main chemical components properties}

The chemical composition of used EOs is resumed in table 10.

Table 10: Groups of chemical compounds (\%) found in the essential oils

\begin{tabular}{l|ccccccc}
\hline $\begin{array}{l}\text { EOs Chemical } \\
\text { compounds }\end{array}$ & ERI 2014 & ERI 2016 & EUC 2014 & LEM 2014 & TAN 2014 & TCP 2014 & TCP 2016 \\
\hline Monoterpene & $5.98 \%$ & $2.68 \%$ & $34.66 \%$ & $59.11 \%$ & $65.24 \%$ & $3.25 \%$ & $22.54 \%$ \\
hydrocarbons & $(3)$ & $(5)$ & $(13)$ & $(12)$ & $(17)$ & $(11)$ & $(9)$ \\
Oxygenated & $66.07 \%$ & $69.39 \%$ & $38.61 \%$ & $34.95 \%$ & $32.30 \%$ & $93.97 \%$ & 73.98 \\
Monoterpenes & $(18)$ & $(11)$ & $(19)$ & $(17)$ & $(13)$ & $(10)$ & $(6)$ \\
Sesquiterpene & $0.60 \%$ & $3.93 \%$ & $0.83 \%$ & $3.15 \%$ & $1.66 \%$ & $2.17 \%$ & $3.14 \%$ \\
hydrocarbons & $(3)$ & $(4)$ & $(2)$ & $(7)$ & $(4)$ & $(3)$ & $(1)$ \\
Oxygenated & $21.35 \%$ & $19.88 \%$ & $21.82 \%$ & $0 \%$ & $0 \%$ & $0.53 \%$ & $0.14 \%$ \\
sesquiterpenes & $(12)$ & $(6)$ & $(8)$ & $(0)$ & $(0)$ & $(1)$ & $(1)$ \\
Total identified & $94.00 \%$ & $98.06 \%$ & $95.92 \%$ & $97.21 \%$ & $99.20 \%$ & $99.32 \%$ & $99.88 \%$ \\
& $(36)$ & $(26)$ & $(42)$ & $(36)$ & $(34)$ & $(25)$ & $(17)$ \\
\hline
\end{tabular}

EOs extracted by hydrodistillation from fresh and mature leaves of Eriocephalus africanus L. (ERI), Eucalyptus camaldulensis Dehnh. (EUC), Citrus limon (L.) Osbeck var. 'Eureka' (LEM), Citrus reticulata Blanco var. 'Clemenules' (TAN) and Thymbra capitata (L.) Cav. (TCP). 2014 and 2016 refers to the year of the analyses. The number of chemical compounds for each group are reported in parenthesis.

\subsubsection{Eriocephalus africanus $\mathbf{L}$.}

Essential oils extracted from Eriocephalus africanus L. leaves was used in the experiments number one and three.

\subsubsection{Composition of the E.O. used in the experiment one}

The major compounds, for both their number and their abundance are the oxygenated monoterpenes (66.07\%, 18 identified compounds), inside them artemisia ketone is the most abundant (57.54\%) and yomogi alcohol is the fourth in order of abundance (3.59\%). The $21.35 \%$ of identified compounds belongs to the oxygenated sesquiterpenes (12 identified compounds) and intermedeol is the most abundant of this group (10.54\%). 3 monoterpene hydrocarbons (5.98\%) and 3 sesquiterpene hydrocarbons (0.60) was also identified. In the first group, $\alpha$-Pinene is the third compound in order of abundance (3.78\%).

\subsubsection{Composition of the EO used in the experiment three}

E. africanus E.O. distilled in 2016 contains more oxygenated monoterpenes $(69.39 \%, 11$ identified compounds) than the 2014 one. Artemisia ketone is still the most abundant oxygenated monoterpene $(54.18 \%)$, while the second of this group is no more yomogi alcohol, but linalool (8.25\%), that is the third for abundance in the oil. 
Oxygenated sesquiterpene is the second group for abundance, the main compounds behind this group are intermedeol $(9.16 \%)$ and linalyl anthranilate $(7.36 \%)$, while intermedeol was not detected in this EO.

Not oxygenated hydrocarbons amount respectively to $3.93 \%$ the sesquiterpenes (4 compounds) and to $2.98 \%$ the monoterpene (5 compounds). 
Oddo M. - Effects of different weed control practices on soil quality in mediterranean crops

Table 11: Chemical composition of E. Africanus Essential Oil used in the first experiment

\begin{tabular}{|c|c|c|}
\hline Compound & $\mathbf{R I}$ & $\%$ \\
\hline Monoterpene hydrocarbons & & 5.98 \\
\hline$\alpha$-Pinene & 937 & 3.78 \\
\hline$\beta$-Pinene & 979 & 1.47 \\
\hline p-Cymene & 1026 & 0.73 \\
\hline Oxygenated monoterpenes & & 66.07 \\
\hline 1-Octen-3-ol & 982 & $\mathrm{t}$ \\
\hline Yomogi alcohol & 997 & 3.59 \\
\hline Eucalyptol & 1034 & 0.07 \\
\hline Artemisia ketone & 1065 & 57.54 \\
\hline Artemisia alcohol & 1083 & 1.13 \\
\hline$\alpha$-Campholenal & 1128 & 0.27 \\
\hline Nopinone & 1139 & $\mathrm{t}$ \\
\hline trans-Pinocarveol & 1142 & 1.28 \\
\hline Isoamyl angelate & 1151 & 0.04 \\
\hline Pinocarvone & 1164 & 1.47 \\
\hline cis-Pinocamphone & 1176 & $\mathrm{t}$ \\
\hline Terpinen-4-ol & 1180 & $\mathrm{t}$ \\
\hline Artemisia ketone isomer & 1187 & 0.21 \\
\hline Myrtenal & 1193 & 0.26 \\
\hline Myrtenol & 1195 & 0.21 \\
\hline trans-Carveol & 1219 & $\mathrm{t}$ \\
\hline Carvone & 1244 & $\mathrm{t}$ \\
\hline Thymol & 1297 & $\mathrm{t}$ \\
\hline Sesquiterpene hydrocarbons & & 0.60 \\
\hline$\alpha$-Copaene & 1368 & 0.17 \\
\hline$\beta$-Caryophyllene & 1416 & 0.43 \\
\hline allo-Aromadendrene & 1457 & $\mathrm{t}$ \\
\hline Oxygenated sesquiterpenes & & 21.35 \\
\hline Anisylacetone & 1495 & $\mathrm{t}$ \\
\hline Kessane & 1526 & 1.47 \\
\hline Liguloxide & 1534 & 2.08 \\
\hline Spathulenol & 1575 & 1.32 \\
\hline Caryophyllene oxide & 1580 & 1.04 \\
\hline Viridiflorol & 1590 & 0.11 \\
\hline$\gamma$-Eudesmol & 1632 & 2.26 \\
\hline $\begin{array}{l}\text { Caryophylla-4(12),8(13)- } \\
\text { dien-5-ol }\end{array}$ & 1637 & 0.89 \\
\hline epi- $\alpha$-Muurolol & 1646 & 1.28 \\
\hline$\beta$ - Eudesmol & 1653 & 0.14 \\
\hline$\alpha$-Eudesmol & 1656 & 0.22 \\
\hline Intermedeol & 1667 & 10.54 \\
\hline 35 compounds identified & & 94.00 \\
\hline
\end{tabular}

Chemical compounds grouped by phytochemical groups and listed in order of elution in the HP-I column. RI, Kovats retention index relative to $C 8$ C32 n-alkanes on the HP-1 column. Peak area percentages are calculated in GC on apolar HP-1 column.

In italic, the compounds having abundance> $3 \%$.

$t$, traces $<0.01 \%$.
Table 12: Chemical composition of E. africanus Essential Oil used in the third experiment

\begin{tabular}{|c|c|c|}
\hline Compound & RI & $\%$ \\
\hline Monoterpene hydrocarbons & & 2.98 \\
\hline$\alpha$-Pinene & 939 & 1.58 \\
\hline$\beta$-Pinene & 983 & 0.59 \\
\hline$\rho$-Cymene & 1033 & 0.43 \\
\hline Limonene & 1037 & 0.16 \\
\hline cis-Ocimene & 1045 & 0.22 \\
\hline Oxygenated monoterpenes & & 69.39 \\
\hline 3-Octanone & 990 & 0.03 \\
\hline Yomogi alcohol & 1004 & 2.86 \\
\hline Eucalyptol & 1041 & 0.28 \\
\hline Artemisia ketone & 1073 & 54.18 \\
\hline Artemisia alcohol & 1090 & 0.79 \\
\hline Linalool & 1112 & 8.25 \\
\hline trans-Pinocarveol & 1153 & 0.81 \\
\hline Pinocarvone & 1174 & 1.08 \\
\hline Terpinen-4-ol & 1190 & 0.78 \\
\hline Artemisia ketone isomer & 1197 & 0.05 \\
\hline Myrtenal & 1206 & 0.28 \\
\hline Sesquiterpene hydrocarbons & & 3.93 \\
\hline$\beta$-Caryophyllene & 1425 & 0.94 \\
\hline Trans-beta-Farnesene & 1461 & 0.46 \\
\hline$\alpha$-Selinene & 1502 & 0.26 \\
\hline Caryophyllene & 1561 & 2.27 \\
\hline Oxygenated sesquiterpenes & & 19.88 \\
\hline Linalyl anthranilate & 1262 & 7.36 \\
\hline Isolongifolan-8-ol & 1545 & 1.83 \\
\hline Spathulenol & 1589 & 0.91 \\
\hline y-Eudesmol & 1646 & 1.82 \\
\hline epi- $\alpha$-Muurolol & 1659 & 0.68 \\
\hline Intermedeol & 1681 & 9.16 \\
\hline compounds identified & & 98.06 \\
\hline
\end{tabular}

Chemical compounds grouped by phytochemical groups and listed in order of elution in the HP-I column. RI, Kovats retention index relative to $C 8$ C32 n-alkanes on the HP-1 column. Peak area percentages are calculated in GC on apolar HP-I column.

In italic, the compounds having abundance > 3\%.

$t$, traces $<0.03 \%$. 


\subsubsection{Main chemical compounds properties}

Compound: Artemisia ketone

CAS number: 546-49-6

Molecular formula: $\mathrm{C}_{10} \mathrm{H}_{16} \mathrm{O}$

Molecular structure:

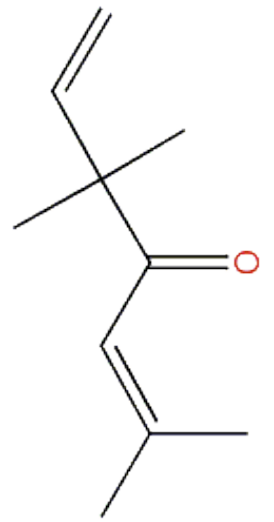

Other information:
Molecular Weight: $152.237 \mathrm{~g} \mathrm{~mol}^{-1}$

Synonym: 2,5,5-Trimethyl-2,6-heptadien-4-one

About the compound

Artemisia ketone is an irregular monoterpene, characteristic of the Anthemideae, derived from the biosynthetic route of Chrysanthemic acid (Njenga 2005). It is recognised as allelopathic compound in mediterranean biomes (Scognamiglio et al. 2013), to have phytotoxic properties against germinating seeds (Mann 2012), it was studied as insecticide for his acetylcholinesterase inhibitory activity (Seo et al. 2014) and is patented in arthropod repellents composition (US2015126437). Essential oils containing percentage of artemisia ketone similar to the used E. africanus essential oil were found to have antimicrobial particularly antibacterial effect (Rasooli et al. 2003). It is patented as pro-fragrances and as compound for insects repellents and attractants (Kim et al. 2016)

Odour Characteristic: Green, Herbal.

\section{Compound: Intermedeol}

CAS number: 6168-59-8

Molecular formula: $\mathrm{C}_{15} \mathrm{H}_{26} \mathrm{O}$

Molecular structure:

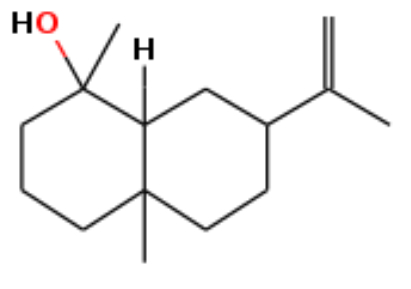

Molecular Weight: $222.372 \mathrm{~g} \mathrm{~mol}^{-1}$

Synonym: 5beta,10alpha-eudesm-11-en-4-ol

About the compound

As artemisia ketone, it is a common compound of the E.O.s obtained from the experimental population (Merle et al. 2007). Intermedeol is studied and patented for his insect and parasites repellence (Cantrell and Klun, 2011; Chen et al., 2008; Soares et al., 2010; Kim et al., 2016). It can have inhibitory effects on oral pathogens (Ocheng et al. 2015). Medical investigation focuses on its use against leukaemia (Jeong et al. 2002).

\section{Compound: $\alpha$ - and $\beta$ - Pinene}

CAS number: $80-56-8$

Molecular formula: $\mathrm{C}_{10} \mathrm{H}_{16}$

Molecular structure:

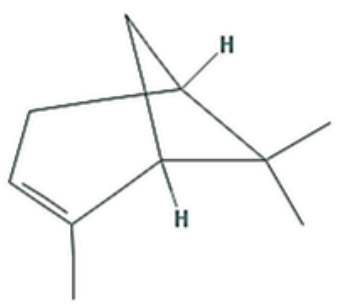

$\alpha$-pinene
Molecular Weight: $136.238 \mathrm{~g} \mathrm{~mol}^{-1}$

Synonym: 4,6,6-trimethylbicyclo[3.1.1]hept-3-ene About the compound

Pinene is a common compound of many essential oils. It is widely used both in chemical industry as solvent, both for human purposes (drugs, food additive, perfume, insect repellent, fungicides). Nevertheless, in even small doses it is allergenic, carcinogenic and toxic for human health, its use for human purposes is controlled by the authorities. For his well-known phytotoxic effect, it is under registration in the European Union Pesticide database (see other links).

Herranz et al. in 2006 reported that oils containing $\alpha$ and $\beta$-pinene have allelopathic effect on mediterranean herbaceous communities, selecting a sub-climacic vegetation. This study also 


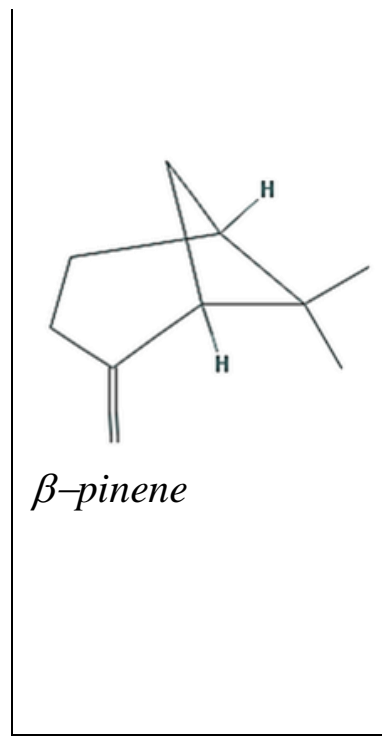

revealed $\alpha$ and $\beta$-pinene to have high persistence in soil samples. Also pinene is reported to be both allelopathic and phytotoxic in different Mediterranean biomes (Scognamiglio et al. 2013).

Ecologists tested on the field a model about an endogenous feedback regulation of soil metabolism, driven by $\alpha$ and $\beta$-pinene, that could play a role in inhibiting nitrification and increasing $\mathrm{CO}_{2}$ production in forest soil (Paavolainen et al. 1998). Also it causes soil community shift when applied on soil, being easily used as substrate by bacteria (Vokou et al. 2002). Plant pathology researchers focus on the use of this compound (compared with other essential oils compounds) to fight soil-borne pathogens (Kadoglidou et al. 2011). a-pinene have biological action on mitochondria that can affect the respiratory activity in intact tissues and its possible significance for seedling growth (Reigosa et al. 2006).

Other links: https://toxnet.nlm.nih.gov/cgi-bin/sis/search2/r?dbs+hsdb:@term+@rn+@ @rel+80-56-8 http://ec.europa.eu/food/plant/pesticides/eu-pesticides-

$\underline{\text { database/public/?event=activesubstance.detail\&language }=E N \& \text { selectedID }=877}$ https://echa.europa.eu/brief-profile/-/briefprofile/100.029.161

Other information: Odour Characteristic: pine or turpentine

\section{Compound: Yomogi alcohol}

CAS number: 247-474-7

Molecular formula: $\mathrm{C}_{10} \mathrm{H}_{18} \mathrm{O}$

Molecular structure:

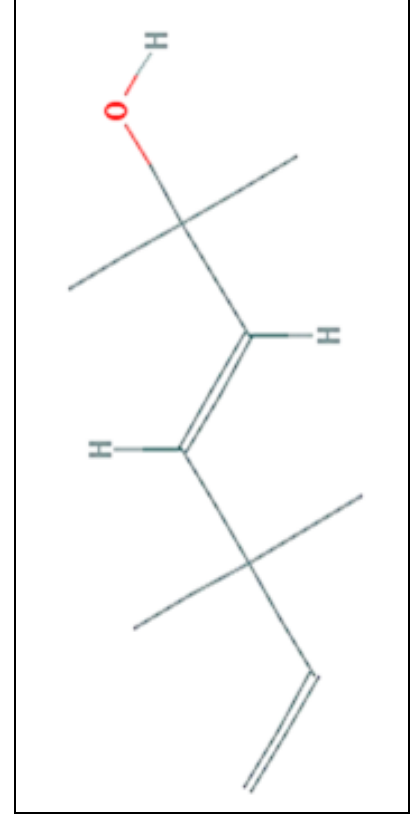

Molecular Weight: $154.253 \mathrm{~g} \mathrm{~mol}^{-1}$

Synonym: (3E)-2,5,5-trimethylhepta-3,6-dien-2-ol

About the compound

Yomogi alcohol derivates from the biosynthetic route of artemisia ketone and is characteristic of many Eriocephalus species (Njenga 2005) and of the population source of the plant material (Merle et al. 2007).

It is widely used in several commercial mixes patented for personal care, biocides, plant growth regulation, parasites and pest control (Kim et al. 2016). 


\section{Compound: Linalool}

CAS number: 78-70-6

Molecular formula: $\mathrm{C}_{10} \mathrm{H}_{18} \mathrm{O}$

Molecular structure:

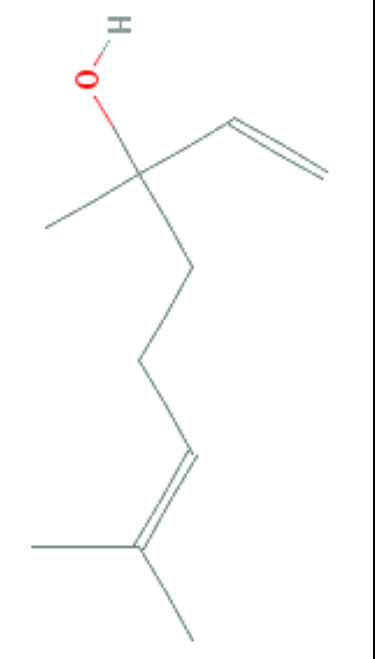

Molecular Weight:154.253 $\mathrm{g} \mathrm{mol}^{-1}$

Synonym: 3,7-dimethylocta-1,6-dien-3-ol

About the compound

This substance is manufactured and/or imported in the European

Economic Area in 1000 - 10000 tonnes per year. It is contained both in daily use articles, both in professional products, in formulation or re-packing. According to the classification provided by ECHA (European Chemical Agency) this substance causes serious eye irritation and may cause allergic skin reaction and irritations.

It is used as insecticide and repellent both in agrochemistry, both for veterinary and human products (Kim et al. 2016).

Other information: https://echa.europa.eu/brief-profile/-/briefprofile/100.001.032

\subsubsection{Eucalyptus camaldulensis Dehnh.}

In Eucalyptus camaldulensis Dehnh. essential oil the 42 identified compounds (95.92\%) are relatively distributed among oxygenated monoterpenes (19 compounds, 38.61\%), monoterpene hydrocarbons (13 compounds, 34.66\%) and oxygenated sesquiterpenes (8 compounds, $21.82 \%)$; while only two sesquiterpene hydrocarbons were detected $(0.83 \%)$.

The most abundant compound (28.34\%) is the monoterpene hydrocarbon p-cymene, followed by the oxygenated sesquiterpene spathulenol (17.99\%). Five oxygenated monoterpenes showed relatively high abundance $(>3 \%)$ in this oil: cryptone (14.12\%), 1,8cineole (eucalyptol, 6.99\%), p-menth-1-en-7-al (4.89\%), cumin aldehyde (4.11\%), terpinen-4-ol (3.45\%).

Carvacrol, an oxygenated monoterpene typical of Thymbra capitata (L.) Cav. EO was also detected, under significant concentration (1.30\%).

Its use ad pesticide is not approved in European Union, Maximum Residue Levels (MRLs) according to Art 18(1)(b) Reg 396/2005 are set to $0.01 \mathrm{mgkg}^{-1}$ (European Commission 2017). 
Oddo M. - Effects of different weed control practices on soil quality in mediterranean crops

Table 13: Chemical composition of E. camaldulensis Essential Oil

\begin{tabular}{|c|c|c|}
\hline Compound & $\mathbf{R I}$ & $\%$ \\
\hline Monoterpene hydrocarbons & & 34.66 \\
\hline$\alpha$-Thujene & 929 & 0.50 \\
\hline$\alpha$-Pinene & 937 & 1.58 \\
\hline Thuja-2,4 (10)-diene & 947 & 0.19 \\
\hline Sabinene & 975 & 0.14 \\
\hline$\beta$-Pinene & 980 & 1.12 \\
\hline Myrcene & 991 & 0.21 \\
\hline$\alpha$-Phellandrene & 1007 & 1.49 \\
\hline$\alpha$-Terpinene & 1019 & 0.28 \\
\hline p-Cymene & 1032 & 28.34 \\
\hline Limonene & 1033 & $\mathrm{t}$ \\
\hline$\gamma$-Terpinene & 1061 & 0.43 \\
\hline Terpinolene & 1086 & 0.12 \\
\hline p-Cymenene & 1090 & 0.26 \\
\hline Oxygenated Monoterpenes & & 38.61 \\
\hline Eucalyptol & 1037 & 6.99 \\
\hline Linalool & 1100 & 0.28 \\
\hline trans-Thujone & 1118 & 0.16 \\
\hline$\alpha$-Campholenal & 1128 & 0.20 \\
\hline trans-Pinocarveol & 1142 & 0.46 \\
\hline Pinocarvone & 1163 & 0.13 \\
\hline Terpinen-4-ol & 1183 & 3.45 \\
\hline Cryptone & 1192 & 14.12 \\
\hline$\alpha$-Terpineol & 1196 & 1.01 \\
\hline Verbenone & 1207 & 0.14 \\
\hline trans-Piperitol & 1209 & 0.25 \\
\hline m-Cumenol & 1229 & 0.06 \\
\hline Cumin aldehyde & 1246 & 4.11 \\
\hline Piperitone & 1255 & 0.23 \\
\hline p-Menth-1-en-7-al & 1280 & 4.89 \\
\hline$\alpha$-Terpinen-7-al & 1286 & 0.26 \\
\hline p-Cymen-7-ol & 1292 & 0.57 \\
\hline Carvacrol & 1300 & 1.30 \\
\hline 3-oxo-p-Menth-1-en-7-al & 1338 & $\mathrm{t}$ \\
\hline Sesquiterpene hydrocarbons & & 0.83 \\
\hline allo-Aromadendrene & 1457 & 0.35 \\
\hline Bicyclogermacrene & 1492 & 0.48 \\
\hline Oxygenated sesquiterpenes & & 21.82 \\
\hline Hedycaryol & 1548 & 0.40 \\
\hline Spathulenol & 1580 & 17.99 \\
\hline Viridiflorol & 1591 & 0.10 \\
\hline Ledol & 1600 & 0.18 \\
\hline Spathulenol isomer & 1605 & 0.47 \\
\hline Isospathulenol & 1631 & 1.14 \\
\hline$\beta$-Eudesmol & 1652 & 1.11 \\
\hline Isobicyclogermacrenal & 1727 & 0.43 \\
\hline 42 compounds identified & & 95.92 \\
\hline
\end{tabular}

Chemical compounds grouped by phytochemical groups and listed in order of elution in the HP-1 column. RI, Kovats retention index relative to $C 8-C 32$ n-alkanes on the HP-1 column. Peak area percentages are calculated in GC on apolar HP-1 column.

In italic, the compounds having abundance > $3 \%$. $t$, traces $<0.02 \%$. 


\subsubsection{Main chemical compounds properties}

\section{Compound: p-Cymene}

CAS number: 99-87-6

Molecular formula: $\mathrm{C}_{10} \mathrm{H}_{14}$

Molecular structure:

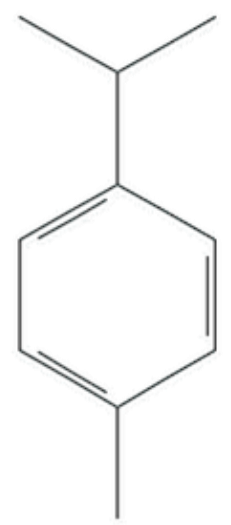

Molecular Weight: $134.222 \mathrm{~g} \mathrm{~mol}^{-1}$

Synonym: 1-methyl-4-propan-2-ylbenzene

About the compound

p-cymene is a very common volatile organic compound in plant extracts. In manufacturing, it is commonly used to formulate products for air spray, furnishing care, laundry, dishwashing and personal care. Has been tested in both agronomical and pharmaceutical studies (Kim et al. 2016). It can have toxic synergistic effects with other highly active compound (natural or synthetic), but there are no evidences about its toxicity for plants or animals (Nakatsu et al. 2000; Zeng et al. 2008; Langeveld et al. 2014; Seo et al. 2014). Probably for his wide diffusion in nature, both Gram-negative and positive bacteria are able to use it as nutritional substrate, with few limitations in oxidizing conditions. On the other hand, showed synergistic activity with thymol against fungi. Essential oils containing high quantities of this compound can increase soil bacterial biomass and respiration (Vokou et al. 2002; Tabassum \& Vidyasagar 2013). It has inhibitory activity against the enzyme acetylcholinesterase (Mann 2012).

\section{Compound: Spathulenol}

CAS number: 6750-60-3

Molecular formula: $\mathrm{C}_{15} \mathrm{H}_{24} \mathrm{O}$

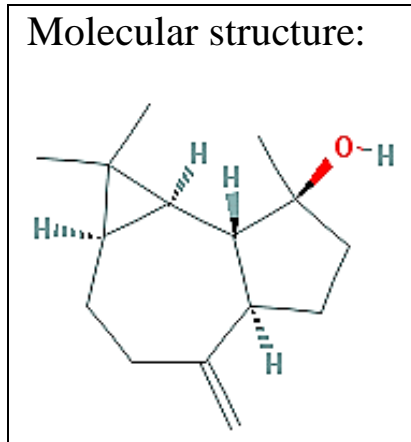

Molecular Weight: $220.356 \mathrm{~g} \mathrm{~mol}^{-1}$

Synonym: (1aR,4aR,7S,7aR,7bR)-1,1,7-trimethyl-4methylidene-decahydro-1H-cyclopropa[e]azulen-7-ol About the compound

It is characteristic of the eucalyptus population from which the plant material was collected; Eucalyptus camaldulensis Dehnh. EOs with high spathulenol contents are reported to inhibit weed germination (Verdeguer et al. 2009). Spathulenol is a compound with recognised pharmacological effects (Da Silva et al. 2005), has antimicrobial properties (Rahman et al. 2016) and was listed as "sesquiterpenoids allelochemicals" in Zeng et al., 2008. In several patents, it is a compound for human personal care and odour reduction. 
Compound: Eucalyptol

CAS number: 470-82-6

Molecular formula: $\mathrm{C}_{10} \mathrm{H}_{18} \mathrm{O}$

Molecular structure:

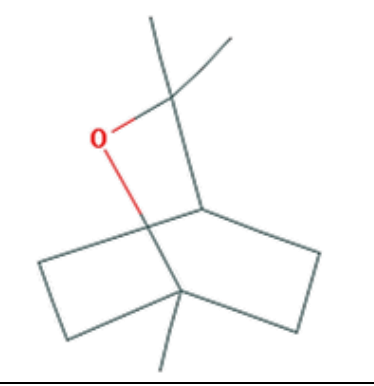

Molecular Weight: $154.253 \mathrm{~g} \mathrm{~mol}^{-1}$

Synonym: 1,8-cineole

About the compound

Taking the name from the plant, it is commonly used for a wide range of purposes, from food and drugs, to insect repellent, to industrial manufacturing (Kim et al. 2016). Recent studies on its herbicide effects revealed that the shape and structure of plant cells are affected by eucalyptol and similar volatile monoterpenes causes widen and shorten root cells, in addition to inducing nuclear abnormalities and increasing vacuole numbers (Cheng \& Cheng 2015).

Compound: p-menth-1-en-7-al

CAS number: 21391-98-0 Molecular formula: $\mathrm{C}_{10} \mathrm{H}_{16} \mathrm{O}$
Molecular Weight: $152.237 \mathrm{~g} \mathrm{~mol}^{-1}$

Synonym: Phellandral

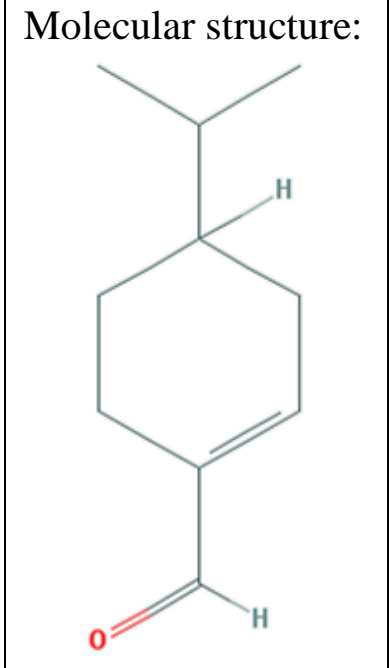

\section{About the compound}

It is used in medicine, personal care and as polymeric compound (Kim et al. 2016).

It is a common compound in E. camaldulensis EOs, and in particular of the population where plant material was collected (Verdeguer et al. 2009; Sliti et al. 2015).

\section{Compound: Cumin aldehyde}

CAS number: 122-03-2

Molecular Weight: $148.205 \mathrm{~g} \mathrm{~mol}^{-1}$

Molecular formula: $\mathrm{C}_{10} \mathrm{H}_{12} \mathrm{O}$

Molecular structure:

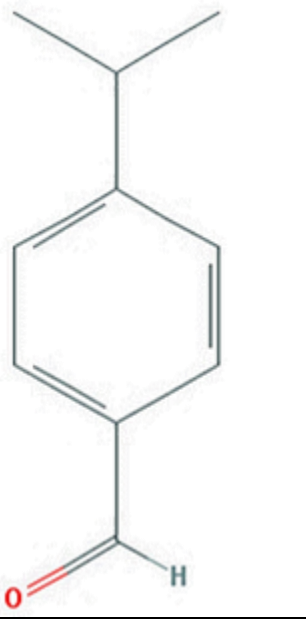

Other information: Flavour Profile: Acid, Green, Herb, Sharp
About the compound

Previously found in the population source of the plant material (Verdeguer et al. 2009).

Involved in xylene degradation (Kim et al. 2016).

It was found in the aqueous volatile fractions (AVFs, the water soluble volatile fractions produced together with the essential oils during the steam distillation process) of Eucalyptus species studied to have stronger inhibitory effects on germination and seedling growth of silverleaf nightshade (Solanum elaeagnifolium Cav.)(Zhang et al. 2014). Being soluble in water, in natural systems it is released to the soil from leaf leaching and litter decomposition, having phytotoxic activity (He et al. 2014). 


\section{Compound: Terpinen-4-ol}

CAS number: 562-74-3

Molecular formula: $\mathrm{C}_{10} \mathrm{H}_{18} \mathrm{O}$

Molecular structure:

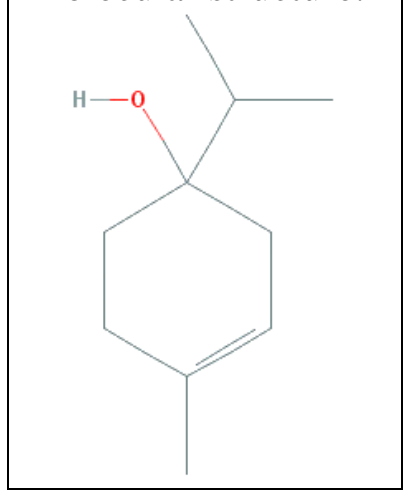

Molecular Weight: $154.253 \mathrm{~g} \mathrm{~mol}^{-1}$

Synonym: 4-Carvomenthenol About the compound

It is a common active compound in medicinal plants, being used for the bioactivity on: antiacetylcholinesterase; antiallergic; anti-asthma; antibacterial; antimicrobial; antiseptic; antitussive; bacteriostatic; diuretic; fungicide; herbicide; irritant; nematicide; pesticide; rhino irritant; spermicide; vulnerary (Da Silva et al. 2005; Kim et al. 2016).

\subsubsection{Citrus limon(L.) Osbeck}

In analysed Citrus limon (L.) Osbeck leaves essential oil, no oxygenated sesquiterpene has been found between the 36 (97.21\%) identified compounds (table 14).

Limonene $(30.14 \%), \beta$-pinene $(17.28 \%)$ and sabinene $(3.13 \%)$ are the most abundant monoterpene hydrocarbons that also constitute the bigger fraction of the oil (12 compounds, $59.11 \%$ ), followed by oxygenated monoterpenes (17 compounds, 34.95\%). This group includes the third, fourth, fifth and seventh compound in order of abundance (geranial, 11.91\%; neral, 9.30\%; neryl acetate, 3.90\% and geranyl acetate, 3.06\%).

A total of 7 sesquiterpene hydrocarbons $(3.15 \%)$ are also in the lemon leaves essential oil. 
Oddo M. - Effects of different weed control practices on soil quality in mediterranean crops

Table 14: Chemical composition of C. limon Essential Oil

\begin{tabular}{|c|c|c|}
\hline Compound & RI & $\%$ \\
\hline Monoterpene hydrocarbons & & 59.11 \\
\hline$\alpha$-Thujene & 928 & 0.06 \\
\hline$\alpha$-Pinene & 936 & 1.22 \\
\hline Camphene & 953 & 0.07 \\
\hline Sabinene & 976 & 3.13 \\
\hline$\beta$-Pinene & 982 & 17.28 \\
\hline Myrcene & 991 & 2.31 \\
\hline$\delta$-3-Carene & 1008 & 0.54 \\
\hline Limonene & 1037 & 30.14 \\
\hline cis-Ocimene & 1040 & 0.82 \\
\hline trans-Ocimene & 1051 & 2.85 \\
\hline$\gamma$-Terpinene & 1061 & 0.49 \\
\hline Terpinolene & 1085 & 0.20 \\
\hline Oxygenated Monoterpenes & & 34.95 \\
\hline 6-methyl-5-Hepten-2-one & 987 & $\mathrm{t}$ \\
\hline n-Octanal & 1004 & 0.07 \\
\hline Linalool & 1100 & 1.20 \\
\hline n-Nonanal & 1105 & 0.35 \\
\hline Citronellal & 1156 & 2.37 \\
\hline Terpinen-4-ol & 1180 & 0.01 \\
\hline$\alpha$-Terpineol & 1194 & 0.34 \\
\hline n-Decanal & 1206 & 0.09 \\
\hline Nerol & 1228 & 1.24 \\
\hline Neral & 1244 & 9.30 \\
\hline Geraniol & 1255 & 0.65 \\
\hline Geranial & 1275 & 11.91 \\
\hline Carvacrol & 1299 & 0.13 \\
\hline Citronellyl acetate & 1352 & 0.32 \\
\hline Neryl acetate & 1363 & 3.90 \\
\hline Geranyl acetate & 1382 & 3.06 \\
\hline Geranyl propanoate & 1470 & 0.01 \\
\hline Sesquiterpene hydrocarbons & & 3.15 \\
\hline$\beta$-Caryophyllene & 1417 & 1.55 \\
\hline$\alpha$-trans-Bergamotene & 1432 & 0.07 \\
\hline$\alpha$-Humulene & 1453 & 0.19 \\
\hline Bicyclogermacrene & 1491 & 0.45 \\
\hline$(\mathrm{E}, \mathrm{E})-\alpha$-Farnesene & 1504 & 0.68 \\
\hline$\beta$-Bisabolene & 1506 & 0.16 \\
\hline$\delta$-Amorphene & 1515 & 0.05 \\
\hline Oxygenated sesquiterpenes & & 0.00 \\
\hline
\end{tabular}

Chemical compounds grouped by phytochemical groups and listed in order of elution in the HP-1 column. RI, Kovats retention index relative to $C 8-$ C32 n-alkanes on the HP-1 column. Peak area percentages are calculated in GC on apolar HP-1 column.

In italic, the compounds having abundance> $3 \%$.

$t$, traces $<0.02 \%$. 


\subsubsection{Citrus reticulata Blanco}

As in lemon essential oil, also in tangerine one there are no oxygenated monoterpenes and a small percentage $(1.66 \%)$ of sesquiterpene hydrocarbons (table 15$)$

Among the 34 identified compounds (99.20\%), 17 are monoterpene hydrocarbons $(65.24 \%)$ and 13 oxygenated monoterpenes (32.30\%).

The monoterpene hydrocarbons sabinene and trans-ocimene, $\delta$-3-carene and myrcene are respectively the first, the third the fourth and the fifth most abundant compounds $(34.41 \%$; $6.46 \% ; 5.30 \%$ and $3.80 \%$ ). Oxygenate monoterpenes follows with linalool $(21.27 \%)$, terpinen-4-ol (3.38\%) and $\beta$-sinensal (3.26). 
Oddo M. - Effects of different weed control practices on soil quality in mediterranean crops

Table 15: Chemical composition of $C$. reticulata Essential Oil

\begin{tabular}{|c|c|c|}
\hline Compound & RI & $\%$ \\
\hline Monoterpene hydrocarbons & & 64.47 \\
\hline$\alpha$-Thujene & 929 & 0.34 \\
\hline$\alpha$-Pinene & 937 & 1.79 \\
\hline Camphene & 953 & 0.03 \\
\hline Sabinene & 980 & 34.41 \\
\hline$\beta$-Pinene & 982 & 2.20 \\
\hline Myrcene & 992 & 3.80 \\
\hline$\alpha$-Phellandrene & 1007 & 0.46 \\
\hline$\delta$-3-Carene & 1011 & 5.30 \\
\hline$\alpha$-Terpinene & 1019 & 1.23 \\
\hline$\rho$-Cymene & 1027 & 0.17 \\
\hline Limonene & 1033 & 3.69 \\
\hline$\beta$-Phellandrene & 1034 & 0.83 \\
\hline cis-Ocimene & 1040 & 0.21 \\
\hline trans-Ocimene & 1052 & 6.46 \\
\hline$\gamma$-Terpinene & 1062 & 2.07 \\
\hline Terpinolene & 1083 & 1.48 \\
\hline Oxygenated Monoterpenes & & 33.07 \\
\hline cis-Sabinene hydrate & 1073 & 0.77 \\
\hline Linalool & 1107 & 21.27 \\
\hline Citronellal & 1157 & 1.95 \\
\hline Terpinen-4-ol & 1183 & 3.38 \\
\hline$\alpha$-Terpineol & 1195 & 0.77 \\
\hline n-Decanal & 1208 & 0.02 \\
\hline Neral & 1240 & 0.20 \\
\hline Geranial & 1269 & 0.02 \\
\hline p-vinyl-Guaiacol & 1307 & $\mathrm{t}$ \\
\hline Methyl geranate & 1322 & 0.27 \\
\hline Geranyl acetate & 1379 & 0.17 \\
\hline (E)-Nerolidol & 1561 & 0.06 \\
\hline$\beta$-Sinensal & 1693 & 3.26 \\
\hline$\alpha$-Sinensal & 1750 & 0.93 \\
\hline Sesquiterpene hydrocarbons & & 1.66 \\
\hline$\beta$-Caryophyllene & 1416 & 0.87 \\
\hline trans- $\beta$-Farnesene & 1454 & 0.40 \\
\hline Bicyclogermacrene & 1491 & 0.25 \\
\hline$(\mathrm{E}, \mathrm{E})-\alpha$-Farnesene & 1503 & 0.14 \\
\hline Oxygenated sesquiterpenes & & 0.00 \\
\hline 34 compounds identified, $t<0.02$ & & 99.20 \\
\hline \multicolumn{3}{|c|}{$\begin{array}{l}\text { Chemical compounds grouped by phytochemical } \\
\text { groups and listed in order of elution in the HP-1 } \\
\text { column. RI, Kovats retention index relative to C } 8 \text { - } \\
\text { C32 } n \text {-alkanes on the HP- } 1 \text { column. Peak area } \\
\text { percentages are calculated in GC on apolar HP-1 } \\
\text { column. } \\
\text { In italic, the abundance bigger than } 3 \% \text {. } \\
t, \text { traces }<0.02 \% \text {. }\end{array}$} \\
\hline
\end{tabular}




\subsubsection{Main chemical compounds properties}

\section{Compound: Limonene}

CAS number: $138-86-3$

Molecular formula: $\mathrm{C}_{10} \mathrm{H}_{16}$
Molecular Weight: $136.238 \mathrm{~g} \mathrm{~mol}^{-1}$

Synonym: (+)-(R)-4-isopropenyl-1-methylcyclohexene About the compound

Limonene is the major chemical component of citrus oils, belongs to the volatile fraction of the E.O. and have documented antibacterial properties (Palazzolo et al. 2013).

In vitro germination tests classified limonene as the $9^{\text {th }}$ among the 10 top phytotoxic monoterpenes out of 27 studied by De Martino et al. (2010). It was demonstrated to have allelochemical activity on respiratory parameters of isolated mitochondria and to be very toxic to the germination and growth of other plants (Reigosa et al. 2006).

\section{Compound: Geranial and Neral}

CAS number: 5392-40-5

Molecular Weight: $152.237 \mathrm{~g} \mathrm{~mol}^{-1}$

Molecular formula: $\mathrm{C}_{10} \mathrm{H}_{16} \mathrm{O}$

Molecular structure:

Synonym: citral

About the compound

Citral (a mixture of geranial and neral) is commonly found in

Citrus EOs and reported to be used as food additive as lemon

flavour and also in perfume and soap production, also it is an important compound in pharmacology and biochemistry (Kim et al. 2016).

One of the first studies about the herbicidal use of this isolated compound was carried out by Dudai et al. (1999), who demonstrated its inhibitory effect on the in vitro germination of wheat and Amaranthus.

To be listed in the European Union pesticide database, it was studied as attractant, Maximum Residue Levels (MRLs) according to Art 18(1)(b) Reg 396/2005 are set to $0.01 \mathrm{mg} \mathrm{kg}^{-1}$ (European Commission 2017). 


\subsubsection{Thymbra capitata (L.) Cav.}

The composition of the obtained essential oils is characteristic of this species, with carvacrol as the major compound, although the amounts of this compound may range from $70-95 \%$ depending on the origin. The other identified compounds are usually common in the composition of this EO (Verdeguer, 2011; García Plasencia, 2013).

\subsubsection{Composition of the E.O. used in the experiment one}

Among the 25 compounds identified in the TCP EO used in the experiment one, the oxygenated monoterpene carvacrol resulted the $91.56 \%$ of oil composition. No other compound amounted to the $3 \%$ oil composition.

Oxygenated monoterpenes (10 compounds, 93.37\%) was followed by monoterpene hydrocarbons (11 compounds, 3.25\%), sesquiterpene hydrocarbons ( 3 compounds, $2.17 \%$ ) and oxygenated sesquiterpenes ( 1 compound, $0.053 \%$ ).

\subsubsection{Composition of the E.O. used in the experiment three}

17 chemical compounds were found in TCP EO analysed in 2016, constituting the $99.80 \%$ of oil composition (table 17). The most abundant was carvacrol (72.30\%), followed by $\rho$ cymene $(8.93 \%)$, $\gamma$-terpinene $(7.77 \%)$ and $\beta$-caryophyllene $(3.14 \%)$.

Monoterpene hydrocarbons have had the bigger number of identified compounds (9), representing the $22.54 \%$ of EO composition. Six compounds were oxygenated monoterpenes (including carvacrol), the most abundant oil fraction with $73.98 \%$ identified compounds. Only one sesquiterpene hydrocarbon (3.14\%) and one oxygenated monoterpene $(0.14 \%)$ was detected. 
Table 16: Chemical composition of T. capitata Essential Oil used in the experiment one

\begin{tabular}{|c|c|c|}
\hline Compound & RI & $\%$ \\
\hline Monoterpene hydrocarbons & & 3.25 \\
\hline$\alpha$-Thujene & 929 & 0.16 \\
\hline$\alpha$-Pinene & 937 & 0.08 \\
\hline$\beta$-Pinene & 979 & 0.03 \\
\hline Myrcene & 990 & 0.25 \\
\hline$\alpha$-Phellandrene & 1006 & 0.05 \\
\hline$\alpha$-Terpinene & 1018 & 0.26 \\
\hline$\rho$-Cymene & 1027 & 1.69 \\
\hline Limonene & 1032 & 0.05 \\
\hline$\beta$-Phellandrene & 1033 & 0.06 \\
\hline$\gamma$-Terpinene & 1061 & 0.56 \\
\hline$\delta$-Terpinene & 1086 & 0.06 \\
\hline Oxygenated Monoterpenes & & 93.37 \\
\hline 1-Octen-3-ol & 982 & 0.05 \\
\hline 3-Octanol & 998 & 0.01 \\
\hline cis-Sabinene hydrate & 1072 & 0.26 \\
\hline Linalool & 1100 & 0.64 \\
\hline Borneol & 1173 & 0.13 \\
\hline Terpinen-4-ol & 1181 & 0.67 \\
\hline$\alpha$-Terpineol & 1208 & 0.02 \\
\hline Thymol & 1293 & 0.03 \\
\hline Carvacrol & 1317 & 91.56 \\
\hline Eugenol & 1354 & 0.00 \\
\hline Sesquiterpene hydrocarbons & & 2.17 \\
\hline$\beta$-Caryophyllene & 1417 & 2.04 \\
\hline$\alpha$-Humulene & 1453 & 0.08 \\
\hline$\beta$-Bisabolene & 1506 & 0.05 \\
\hline Oxygenated sesquiterpenes & & $\mathbf{0 . 5 3}$ \\
\hline Caryophyllene oxide & 1578 & 0.53 \\
\hline compounds identified & & 99.32 \\
\hline
\end{tabular}

Chemical compounds grouped by phytochemical groups and listed in order of elution in the HP-I column. RI, Kovats retention index relative to $C 8-C 32$ n-alkanes on the HP-1 column. Peak area percentages are calculated in GC on apolar HP-1 column.

In italic the abundance bigger than $3 \%$.

$t$, traces $<0.02 \%$.
Table 17: Chemical composition of T. capitata Essential Oil used in the experiment three

\begin{tabular}{|c|c|c|}
\hline Compound & RI & $\%$ \\
\hline Monoterpene hydrocarbons & \multicolumn{2}{|c|}{22.54} \\
\hline$\alpha$-Tuyene & 931 & 0.89 \\
\hline$\alpha$-Pinene & 938 & 0.74 \\
\hline$\beta$-Pinene & 979 & 0.29 \\
\hline Mircene & 992 & 1.95 \\
\hline$\alpha$-Phellandrene & 1004 & 0.16 \\
\hline$\alpha$-Terpinene & 1018 & 1.61 \\
\hline$\rho$-Cymene & 1027 & 8.93 \\
\hline Limonene & 1031 & 0.20 \\
\hline$\gamma$-Terpinene & 1063 & 7.77 \\
\hline Oxygenated Monoterpenes & & 73.98 \\
\hline 1,8-Cineol & 1033 & 0.11 \\
\hline Linalool & 1100 & 0.77 \\
\hline Borneol & 1168 & 0.16 \\
\hline Terpinen-4-ol & 1178 & 0.37 \\
\hline Thymol & 1296 & 0.27 \\
\hline Carvacrol & 1312 & 72.3 \\
\hline Sesquiterpene hydrocarbons & & 3.14 \\
\hline$\beta$-Caryophyllene & 1420 & 3.14 \\
\hline Oxygenated sesquiterpenes & & 0.14 \\
\hline Caryophyllene oxide & 1583 & 0.14 \\
\hline compounds identified & & 99.80 \\
\hline
\end{tabular}

Chemical compounds grouped by phytochemical groups and listed in order of elution in the HP-1 column. RI, Kovats retention index relative to $C 8-C 32$ n-alkanes on the HP-1 column. Peak area percentages are calculated in GC on apolar HP-1 column. In italic the abundance bigger than $3 \%$.

\subsubsection{Main chemical compounds properties}

Carvacrol is the most common compound in the chemotype of the sampled population.

Its characteristics has been described in paragraph 1.4.1.3. 


\subsection{Experiment one: short and medium-term response of soil microorganisms to essential oils with phytotoxic potential extracted from mediterranean plants}

\subsubsection{Water and Fitoil}

\subsubsection{Biochemical soil properties}

As expected, extractable $C\left(\mathbf{C}_{\text {ext }}\right)$ was the least with only water throughout the whole incubation, where it started to decrease only at 90 days and halving compared to time zero at 120 days. On the other hand, the addition of only emulsifier (Fitoil), in comparison with water, always strongly increased the extractable carbon being $33.6 \%$ higher after the first 15 days and more than doubled at 120 days (135.2\%, figure 37, table 18$)$.

Table 18: Pairwise mean comparison between the chemical, biochemical and microbiological parameters at the same sampling day after 15,30,90 and 120 days since WAT and FIT treatments application

\begin{tabular}{|c|c|c|c|c|}
\hline & Day 15 & Day 30 & Day 90 & Day 120 \\
\hline $\mathrm{C}_{\mathrm{ext}}$ & $51.98 * *$ & $8.21 *$ & $52.92 * *$ & $46.34 * *$ \\
\hline $\mathrm{MBC}$ & n.s. & n.s. & n.s. & n.s. \\
\hline $\mathrm{CO}_{2}$ & n.s. & n.s. & n.s. & n.s. \\
\hline SR & n.s. & n.s. & n.s. & n.s. \\
\hline FAs & n.s. & n.s. & n.s. & $28.40 * *$ \\
\hline Вас\% & $8.16^{*}$ & n.s. & n.s. & n.s. \\
\hline Gp\% & $10.06 *$ & n.s. & n.s. & n.s. \\
\hline $\mathrm{Gn} \%$ & n.s. & n.s. & $33.60 * *$ & $75.12 * *$ \\
\hline Fun $\%$ & n.s. & n.s. & n.s. & $16.39 *$ \\
\hline F_B & n.s. & n.s. & n.s. & $18.30^{*}$ \\
\hline Gp_Gn & $8.91 *$ & n.s. & $13.38 *$ & $13.99 *$ \\
\hline Mes\% & n.s. & n.s. & n.s. & $7.97 *$ \\
\hline
\end{tabular}

Data obtained by student $t$-test $(n=3 ; *, P<0.05 ; * *, P<0.01 ; * * *, P<0.001 ;$ n.s, not significant) performed for each sampling day, WAT, (water treatment) and FIT (fitoil treatment) as independent variables.

$C_{\text {ext }}$, extractable organic carbon $\left(m g C \mathrm{~kg}^{-1}\right) ; M B C$, microbial biomass carbon $\left(\mathrm{mg} \mathrm{C} \mathrm{kg}^{-1}\right), \mathrm{SR}$, soil respiration ( $\mathrm{mg} \mathrm{CO}_{2}-\mathrm{C} \mathrm{kg}^{-1} \mathrm{~d}^{-1}$ ); FAs, microbial fatty acids (nmol g-1 soil); Bac\%, percentage of bacteria; Gp\% percentage of Gram-positive bacteria; Gn\% percentage of Gram-negative bacteria; Gp_Gn, Grampositive to gram negative ratio; Fun\%, percentage of fungi; $F \_B$, fungi to bacteria ratio; Mes\%, percentage of mesofauna.

With only water, as expected, soil respiration $(\mathbf{S R})$ more than doubled towards day 15 while more than halved at day 30 . Then, towards the end of incubation, soil respiration rate slowly came back to the start values. On the other hand, the addition of only Fitoil, compared to water, was not able to induce any significant soil respiration rata changing during the 120 days incubation (figure 37, table 18).

Soil microbial biomass C (MBC), with only water, increased by 20\% during the first 15 days of incubation and, thereafter, slowly and linearly decreased up to the end of incubation, when it halved compared to time zero. The addition of only Fitoil did not cause any significant MBC change in comparison with only water (figure 37, table 18). Given the previous trends of soil MBC and respiration with only water or Fitoil, the trend of specific 
respiration $\left(\mathbf{q C O}_{2}\right)$ throughout the whole incubation, which is the ratio of these latter two variables, was perfectly comparable to that of soil respiration (figure 37 , table 18).

$\boldsymbol{A}$

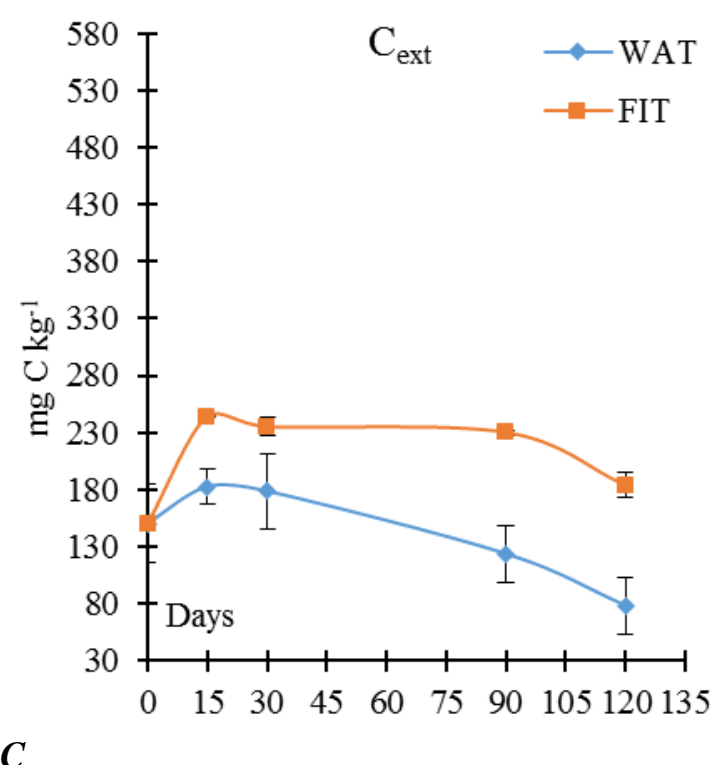

C

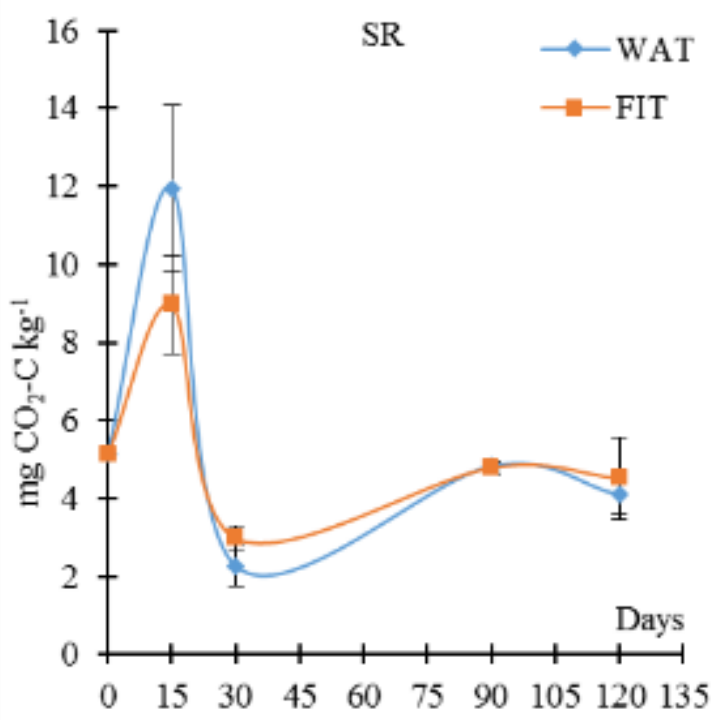

$\boldsymbol{B}$

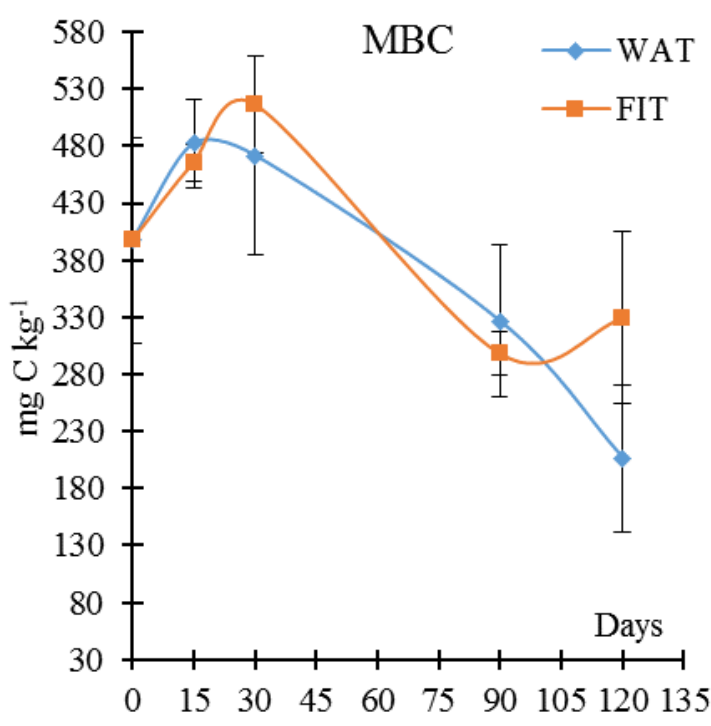

D

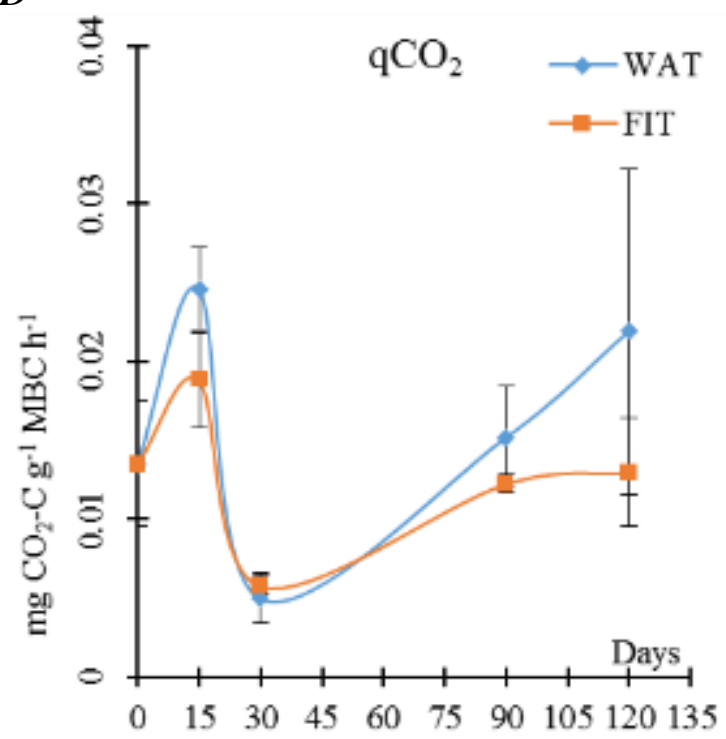

Figure 37: Biochemical soil variables determined at days 15, 30, 90 and 120 in the fitoil (FIT) and water (WAT) treatments.

A) $C_{\text {ext }}$, extractable organic carbon; B) $M B C$, microbial biomass carbon; C) $S R$, soil respiration; D) $q \mathrm{CO}_{2}$, metabolic quotient. Reported results are means of three samples, bars are standard deviations. 


\subsubsection{Microbial community structure}

The total amount of microbial FAs, increased during the first 30 days of incubation (according with MBC data), decreasing during the following time. Fitoil treatment positively (15.9+/-5.1\%) affects this variable on day 120 only (figure 38 a, table 19), inducing to suppose the use of Fitoil as carbon source by the new established microbial community.

Bacteria and fungi symmetrically evolved in both water and Fitoil treatments (figure 38 b), as consequently fungi to bacteria ratio done. During the first 30 days of incubation fungi growth and bacteria decreased of about 10\%. Later, on day 90 and 120, bacteria were about doubled compared with day 0 , while fungi decreased to about $1.4 \%$.

Bacteria bioindicator increased during time was due mainly to Gram-positive ones (figure $38 \mathrm{c}$, table 19) with a significant increase in the FIT treated soil on days 15 and 90. Also Gram-negative bacteria raised during time, with different rhythms in soil treated with water and Fitoil, being in the Fitoil treatment lower $(-7.4 \%+/-0.6 \%)$ on day 90 and higher on day $120(15.33 \%+/-2.8$; figure $43 \mathrm{c}$, table 19). In figure $43 \mathrm{~d}$ the Gram-positive to negative ratio confirms the middle-term (days 90 and 120) effect of Fitoil treatment on soil microbial community structure. 
$A$
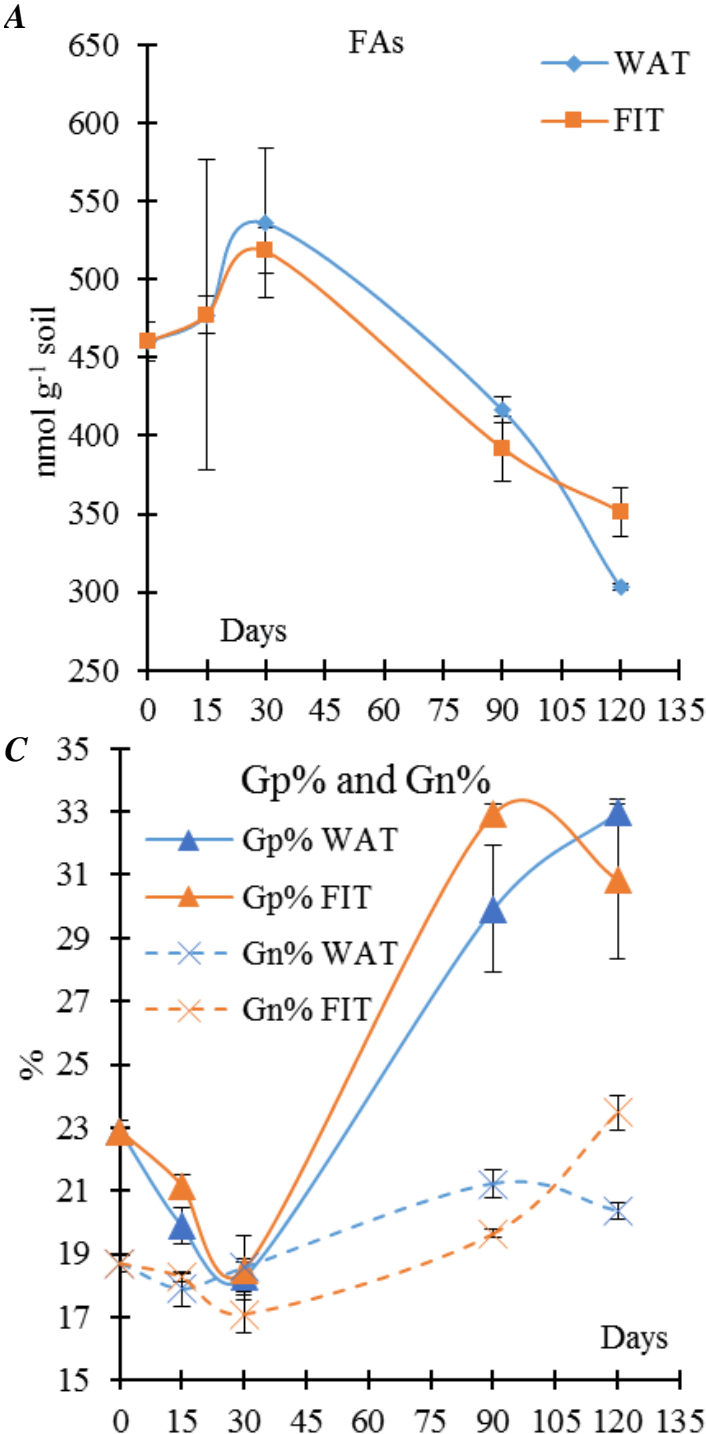

$\boldsymbol{E}$

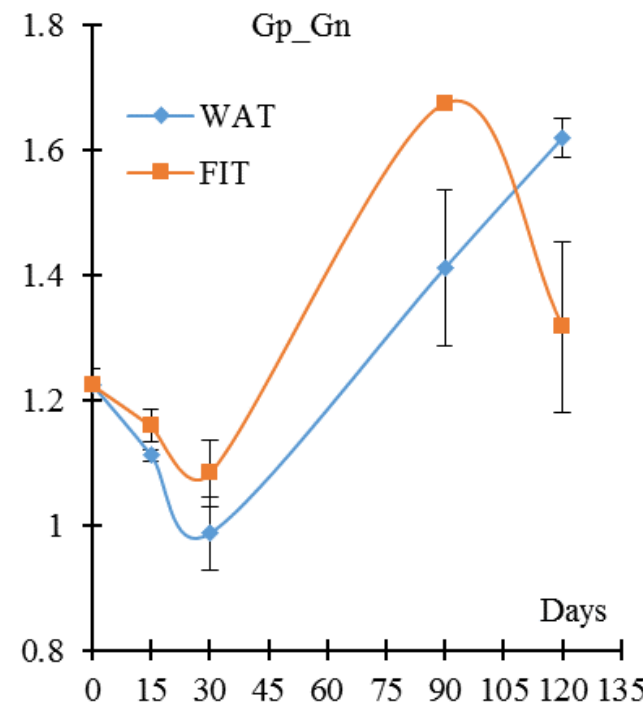

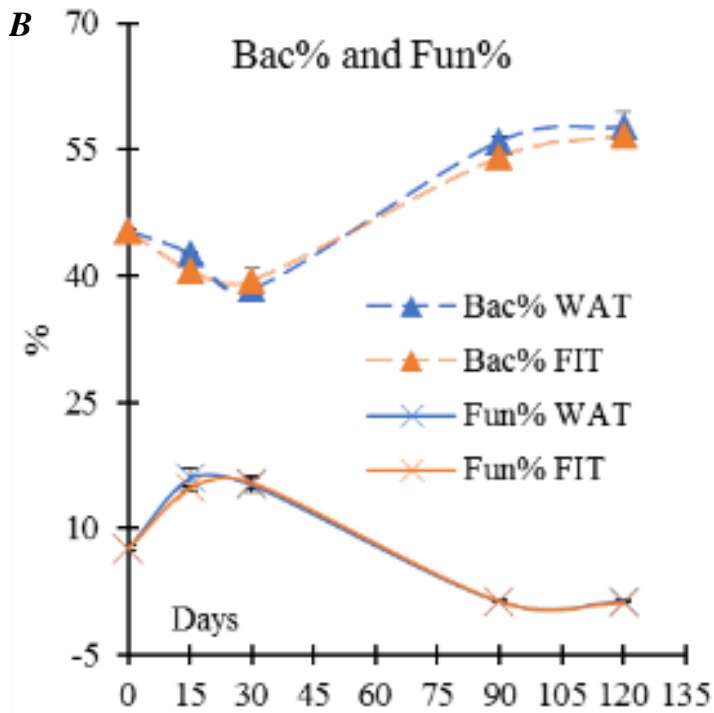

D 0.5 F B

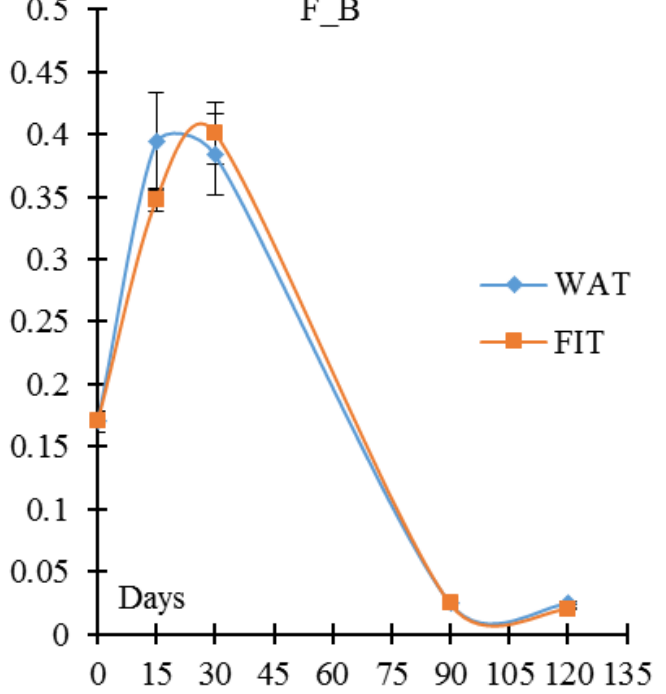

F 1.8 Mes\%

$\longrightarrow$ WAT

$\rightarrow$-FIT

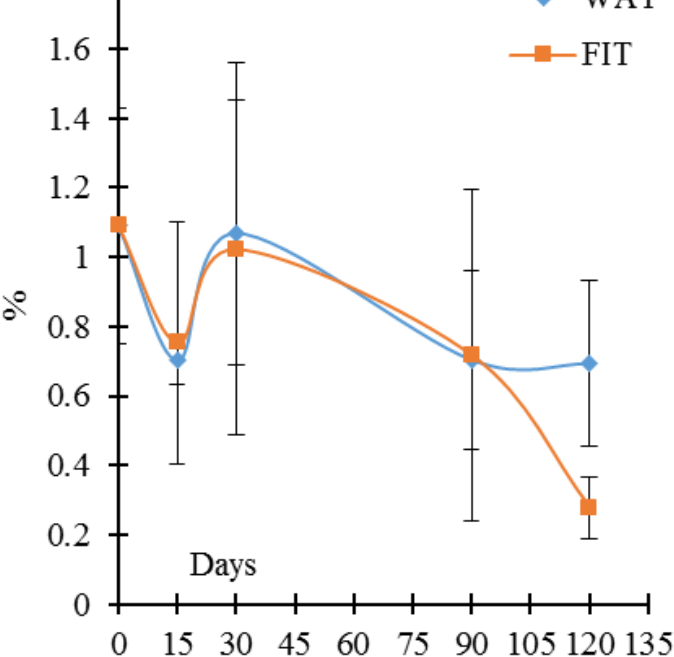

Figure 38: Microbial community structure determined at days 15, 30, 90 and 120 in the fitoil (FIT) and water (WAT) treatments.

A) FAs, microbial fatty acids; B) Bac\% and Fun\%, percentage of bacteria and fungi; C) Gp\% and Gn\%, percentage of Gram-positive and negative bacteria; D) $F_{-} B$, fungi to bacteria ratio; E) Gp_Gn, Grampositive to Gram-negative ratio; $F$ ) Mes\%, percentage of mesofauna. Reported results are means of three samples, bars are standard deviations. 


\subsubsection{Essential oils treatments}

As introduced in the materials and methods paragraph, the principal experimental factor influencing the variances of analysed soil properties (58.2\%) was the incubation time, affecting both quantitative and qualitative soil biomass bioindicators (table 21). Figure 39 shows the predominant role of PC1 in separating the short and the medium-term effects of EOs treatments.

$\frac{\text { Table 19: Principal Component Matrix }}{\text { PC1 }}$

\begin{tabular}{rrr}
$58.23 \%$ & $14.95 \%$ \\
\hline $\mathrm{C}_{\mathrm{ext}}$ & $\mathbf{- 0 . 7 8 3}$ & 0.197
\end{tabular}

$\begin{array}{lll}C_{\text {ext }} & \mathbf{- 0 . 7 8 3} & 0.197 \\ \text { MBC } & \mathbf{- 0 . 6 5 1} & 0.111\end{array}$

SR $\quad-0.207 \quad \mathbf{0 . 9 4 5}$

$\mathrm{qCO}_{2} \quad 0.155 \quad \mathbf{0 . 9 6 3}$

FAs $\quad \mathbf{- 0 . 7 9 3}-0.118$

$\begin{array}{lll}\mathrm{Bac} \% & \mathbf{0 . 9 8 0} & 0.113\end{array}$

$\begin{array}{lll}\mathrm{Gp} \% & \mathbf{0 . 9 7 3} & 0.090\end{array}$

Gn\% $\quad \mathbf{0 . 5 9 4} \quad 0.060$

Fungi\% $\quad \mathbf{- 0 . 9 7 4}-0.034$

F_B $\quad \mathbf{- 0 . 9 6 4}-0.104$

Gp_Gn $\quad \mathbf{0 . 8 1 0} \quad 0.070$

\begin{tabular}{lll}
$\mathrm{Mes} \%$ & $\mathbf{- 0 . 4 2 9}$ & -0.199 \\
\hline
\end{tabular}

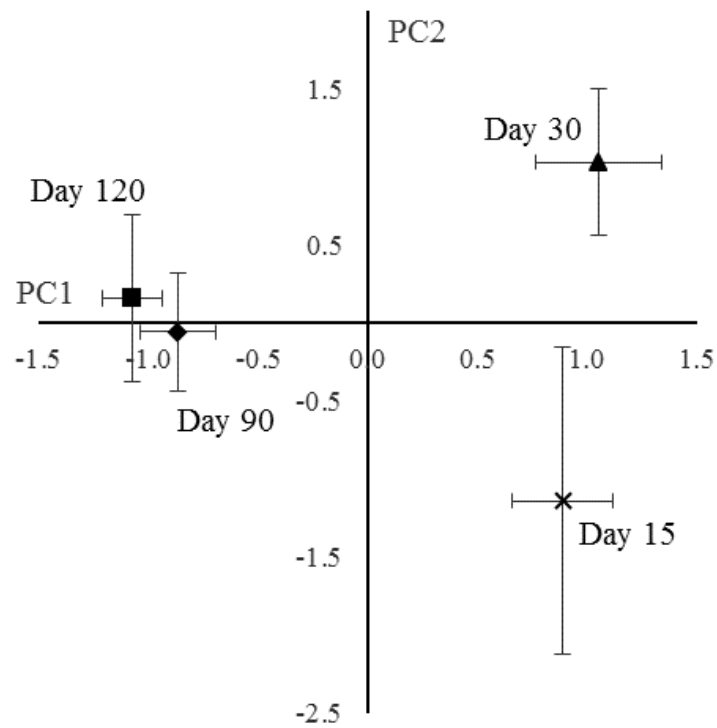

Figure 39: Principal component scatterplot

Showed data are means +/- standard deviations

The second component (vertical axe in figure 39) explicates only the $15 \%$ of variance, anyway determines a notable distance between the first two sampling times. Soil microbial community metabolisms indicators ( $\mathrm{SR}$ and $\mathrm{qCO}_{2}$, table 20), in fact, have had fast reactions to the EOs addiction during the first month after the treatments. Thereafter, soil microbial community reached a new metabolic equilibrium, and maintained it until the end of the experiment.

With addition of various EOs, carried out by Fitoil, all the variables $\mathrm{C}_{\text {ext }}, \mathrm{SR}, \mathrm{MBC}$ and $\mathrm{qCO}_{2}$, with very few exceptions, were significantly $(\mathrm{P}<0.05$ at least $)$ affected by any EO both type and concentration, regardless of incubation day (Table 20). As a general trend, for $\mathrm{C}_{\mathrm{ext}}$, the relative importance in affecting it, as indicated by the respective $\mathrm{F}$ values, was higher for EO x Conc during the first part of the incubation (day 15) whereas became clearly predominant for Conc for the rest of incubation. About SR, EO type slightly prevailed only at day 15 while its weight was comparable to that of EO concentration at 30 and 90 incubation days, but returned predominant again at the incubation end. It was more complex 
to follow in which proportion EO type and concentration affected soil MBC over incubation time: the two factors had comparable importance at days 15 and 30, and thereafter EO type became insignificant but only at day 120, whereas EO concentration did so only at day 90 . About $\mathrm{qCO}_{2}$, EO type affected it over time similarly to SR, while EO concentration significantly affected it only at days 30 and 90.

EO type have had a short-term effect on FAs bioindicators till day 30, then the concentration played the main role.

On day 30, Gram-positive bacteria was influenced by EO concentration, while Gn\% by EO type, consequently Bac\% resulted influenced by EO x Conc; on day 60, all the bacterial biomass bioindicators was influenced by EO type. Bac was affected mainly by EO type also on day 90, even if for $\mathrm{Gp} \%$ and $\mathrm{Gn} \%$ the $\mathrm{F}$ values was higher for conc. On last sampling day only concentration significantly affected Bac, and Conc have had the higher F values both for Gp and Gn \%.

Gp_Gn complex bioindicator undergoes more the effect of treatments concentrations than the EO type one, whom influence is higher on day 90.

Concentration is the main independent variable influencing fungi on day 15, 90 and 120, making way to EO type to be predominant on day 30 . The fungi to bacteria ratio follows the same trend.

Mesofauna was the dependent variable less influenced by treatments, especially by concentration on day 30 and 120 only.

Hereafter, describing with more detail how each EO affected the several soil bioindicators, we will focus on major effects only evidenced by the post-hoc multiple comparison (Tukey test) of between-subjects effects performed for each oil and sampling day. 
Oddo M. - Effects of different weed control practices on soil quality in mediterranean crops

Table 20: Fisher's $F$ values of the chemical, biochemical and microbiological parameters calculated by two-way ANOVA (type and concentration of essential oil as factors) after 15, 30, 90 and 120 days since EOs treatments application

\begin{tabular}{|c|c|c|c|c|c|}
\hline Dep. Var. & Ind. Var. & Day 15 & Day 30 & Day 90 & Day 120 \\
\hline \multirow[t]{3}{*}{$\mathrm{C}_{\text {ext }}$} & $\mathrm{EO}$ & $14.21 * * *$ & $3.05^{*}$ & $31.09 * * *$ & $2.69 *$ \\
\hline & Conc & $6.60 * * *$ & $6.56^{* *}$ & $54.65 * * *$ & $4.51 * *$ \\
\hline & EOxConc & $14.44 * * *$ & $7.47 * * *$ & $7.70 * * *$ & $2.15^{*}$ \\
\hline \multirow[t]{3}{*}{ MBC } & $\mathrm{EO}$ & $3.99 * *$ & $10.62 * * *$ & $9.90 * * *$ & n.s. \\
\hline & Conc & $4.46 * *$ & $25.44 * * *$ & n.s. & $3.72 *$ \\
\hline & EOxConc & $5.66 * * *$ & $5.21 * * *$ & $6.99 * * *$ & n.s. \\
\hline \multirow[t]{3}{*}{ SR } & EO & $12.56 * * *$ & $8.51 * * *$ & $7.16 * * *$ & $4.13 * *$ \\
\hline & Conc & $8.65 * * *$ & $7.81 * * *$ & $7.09 * * *$ & $2.87 *$ \\
\hline & EOxConc & $10.84 * * *$ & $17.66 * * *$ & $4.23 * * *$ & n.s. \\
\hline \multirow[t]{3}{*}{$\mathrm{qCO}_{2}$} & $\mathrm{EO}$ & $7.30 * * *$ & $6.21 * * *$ & $5.19 * *$ & $3.28 *$ \\
\hline & Conc & n.s. & $12.98 * * *$ & $3.14 *$ & n.s. \\
\hline & EOxConc & $10.21 * * *$ & $7.54 * * *$ & $4.77 * * *$ & n.s. \\
\hline \multirow[t]{3}{*}{ FAs } & $\mathrm{EO}$ & 8.14*** & $3.67 *$ & $8.34 * * *$ & $10.36 * * *$ \\
\hline & Conc & n.s. & n.s. & $9.47 * * *$ & $29.25 * * *$ \\
\hline & EOxConc & $7.03 * * *$ & n.s. & $4.43 * * *$ & $3.95 * * *$ \\
\hline \multirow[t]{3}{*}{ Вас\% } & $\mathrm{EO}$ & n.s. & $13.62 * * *$ & $6.32 * * *$ & n.s. \\
\hline & Conc & $2.98 *$ & n.s. & $3.52 *$ & $3.47 *$ \\
\hline & EOxConc & $4.53 * * *$ & $4.34 * * *$ & $3.09 * *$ & n.s. \\
\hline \multirow[t]{3}{*}{ Gp\% } & $\mathrm{EO}$ & $16.61 * * *$ & $8.71 * * *$ & $2.88 *$ & $8.31 * * *$ \\
\hline & Conc & $576.13 * * *$ & n.s. & n.s. & $13.10 * * *$ \\
\hline & EOxConc & $4.34 * * *$ & $2.75 * *$ & $12.07 * * *$ & $2.17 *$ \\
\hline \multirow[t]{3}{*}{ Gn\% } & $\mathrm{EO}$ & $9.75 * * *$ & $12.74 * * *$ & $7.15 * * *$ & $39.28 * * *$ \\
\hline & Conc & $3.97 *$ & $7.50 * * *$ & $39.09 * * *$ & $136.17 * * *$ \\
\hline & EOxConc & $5.18 * * *$ & $4.62 * * *$ & $34.23 * * *$ & $17.09 * * *$ \\
\hline \multirow[t]{3}{*}{ Gp_Gn } & $\mathrm{EO}$ & $6.96 * * *$ & $2.98^{*}$ & $3.73 *$ & $19.05 * * *$ \\
\hline & Conc & $9.12 * * *$ & $3.11 *$ & $18.01 * * *$ & $36.22 * * *$ \\
\hline & EOxConc & n.s. & n.s. & $30.57 * * *$ & $6.83 * * *$ \\
\hline \multirow[t]{3}{*}{ Fun\% } & $\mathrm{EO}$ & $14.48 * * *$ & $20.06 * * *$ & $2.69 *$ & n.s. \\
\hline & Conc & $39.72 * * *$ & $6.27 * *$ & $6.74 * * *$ & $17.96 * * *$ \\
\hline & EOxConc & $15.17 * * *$ & $12.91 * * *$ & 1.54n.s. & $2.29 *$ \\
\hline \multirow[t]{3}{*}{ F_B } & $\mathrm{EO}$ & $5.68 * *$ & $22.90 * * *$ & $3.13 *$ & 1.07n.s. \\
\hline & Conc & $24.35 * * *$ & n.s. & $6.44 * *$ & $17.35 * * *$ \\
\hline & EOxConc & $12.40 * * *$ & $11.59 * * *$ & n.s. & $2.14 *$ \\
\hline \multirow[t]{3}{*}{ Mes\% } & $\mathrm{EO}$ & n.s. & $3.53 *$ & n.s. & n.s. \\
\hline & Conc & n.s. & $5.01 * *$ & n.s. & $5.14 * *$ \\
\hline & EOxConc & n.s. & n.s. & n.s. & n.s. \\
\hline
\end{tabular}

Data obtained by two-way ANOVA with repetitions performed for each sampling day assuming EO type and concentration (Conc) in the emulsions as independent variables.

Concentrations C1, C2 and C4 are, respectively, 1,2 and $4 \mathrm{~mL}$ of essential oil per litre of water.

$C_{\text {ext }}$, extractable organic carbon $\left(\mathrm{mg} C \mathrm{~kg}^{-1}\right) ; \mathrm{MBC}$, microbial biomass carbon $\left(\mathrm{mg} \mathrm{C} \mathrm{kg}^{-1}\right)$, SR, soil respiration ( $\mathrm{mg} \mathrm{CO}_{2}-\mathrm{C} \mathrm{kg}^{-1} \mathrm{~d}^{-1}$ ); FAs, microbial fatty acids (nmol $\mathrm{g}^{-1}$ soil); Bac\%, percentage of bacteria; Gp\% percentage of Gram-positive bacteria; Gn\% percentage of Gram-negative bacteria; Gp_Gn, Grampositive to Gram-negative ratio; Fun\%, percentage of fungi; $F \_B$, fungi to bacteria ratio; Mes\%, percentage of mesofauna.

*, $P<0.05$; **, $P<0.01$; ***, $P<0.001$; n.s, not significant. In bold the higher values of the day. 


\subsubsection{ERI}

ERI EO affected organic carbon distribution ( $\mathrm{C}_{\mathrm{ext}}$ and $\left.\mathrm{MBC}\right)$ only after 90 days of incubation (table 20).

There is a notable effect of concentration: ERI C4 treated soils compared with ERI C1, on days 90 and 120, developed higher $\mathrm{C}_{\text {ext }}$ and lower $\mathrm{MBC}$, with bigger differences on day 90 (fig 40 a and b, table 21).

Table 21: Significant ( $*, P<0.05 ; * *, P<0.01 ; * * *, P<0.001$; n.s, not significant) mean differences of soil biochemical properties among treatments concentrations determined after 15, 30, 90 and 120 days since FIT and ERI treatments application

\begin{tabular}{lc|cccc}
\hline Dep. Var. & Ind. Var. & Day15 & Day30 & Day90 & Day120 \\
\hline Cext & FIT - C1 & n.s. & n.s. & $78.74^{* *}$ & $29.97^{* *}$ \\
MBC & C1 - C4 & n.s. & n.s. & $-56.83^{*}$ & $-30.77^{* *}$ \\
& FIT - C1 & n.s. & n.s. & $68.7^{* *}$ & n.s. \\
& C1 - C2 & n.s. & n.s. & $187^{*}$ & n.s. \\
SR & C1 - C4 & n.s. & n.s. & $192.13^{*}$ & n.s. \\
& FIT - C2 & n.s. & $1.44^{*}$ & n.s. & n.s. \\
& FIT - C4 & n.s. & $-2.70^{* *}$ & n.s. & n.s. \\
& C1 - C2 & n.s. & $1.64^{*}$ & n.s. & n.s. \\
& C1 - C4 & n.s. & $-2.50^{* *}$ & n.s. & n.s. \\
qCO2 & C2 - C4 & $2.25^{*}$ & $-4.14^{* * *}$ & n.s. & n.s. \\
& FIT - C4 & n.s. & $-0.01^{* *}$ & n.s. & n.s. \\
& C4 - C1 & n.s. & $0.01^{*}$ & n.s. & n.s. \\
\hline
\end{tabular}

Data obtained by Tukey post-hoc test ( $n=3)$ performed for each sampling day $(15,30,90$ and 120$)$ assuming concentration (FIT, C1, C2, C4) as independent variable. FIT, Fitoil treated soils. ERI, E. africanus EO

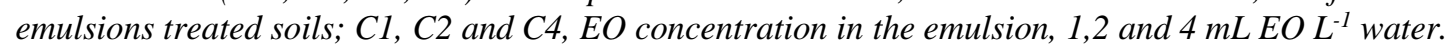
$C_{e x t}$, extractable organic carbon; $M B C$, microbial biomass carbon; $S R$, soil respiration; $q \mathrm{CO}_{2}$, metabolic quotient.

Soil metabolism ( $\mathrm{SR}$ and $\mathrm{qCO}_{2}$ ) showed a slight short-term reaction (it vanished since day 90) to ERI EO treatments only in the concentrations 2 and 4 (figures $40 \mathrm{c}$ and d, tables 20 and 21). The first different reaction to the concentrations appears on day 15 in SR only, when the higher concentration (C4) caused a significant decrease in soil respiration if compared with the medium one $(\mathrm{C} 2)$ but not with the $\mathrm{C} 1$ or the Fitoil treatment. On day 30 also the difference in respiration between $\mathrm{C} 1$ and $\mathrm{C} 2$ becomes significant, but the effect of $\mathrm{C} 2$ and $\mathrm{C} 4$ was inverted, reaching $\mathrm{C} 2$ the lower values of all the ERI treatments. The $\mathrm{C}_{2}$ treatment have had the same respiration volume and efficiency of the Fitoil control since this day. Since this day $\mathrm{CO}_{2}$ production in $\mathrm{C} 4$ treated soils remained higher than FIT until day 90 , when was matched by the other treatments. These changes are reflected by the metabolic quotient, which changed only on day 30, having $\mathrm{C} 4$ the stronger positive effect compared to the control and to the other concentrations. Again, C2 has on day 30 the lower value and $\mathrm{C} 1$ the same of FIT, than all the treatments conformed to the same values. 
$\boldsymbol{A}$

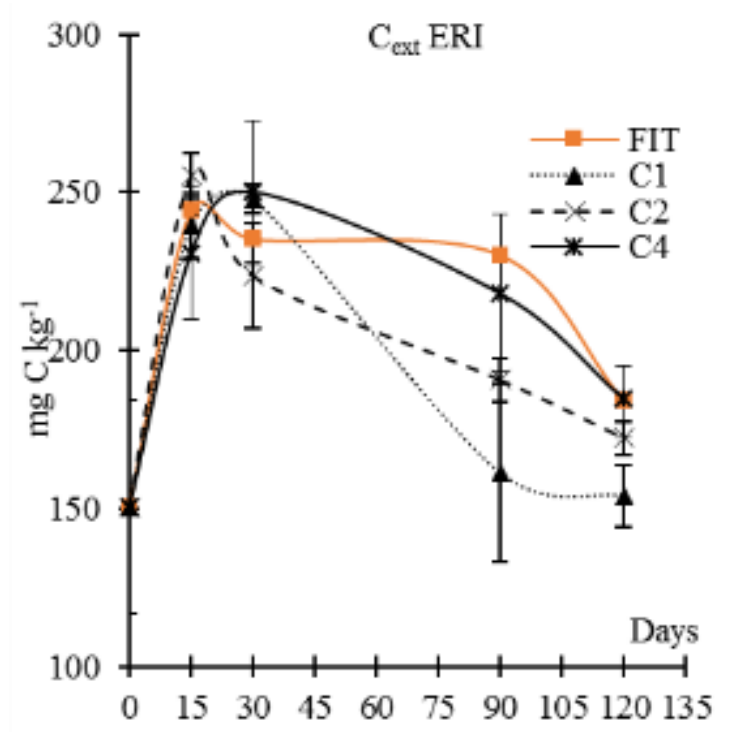

C

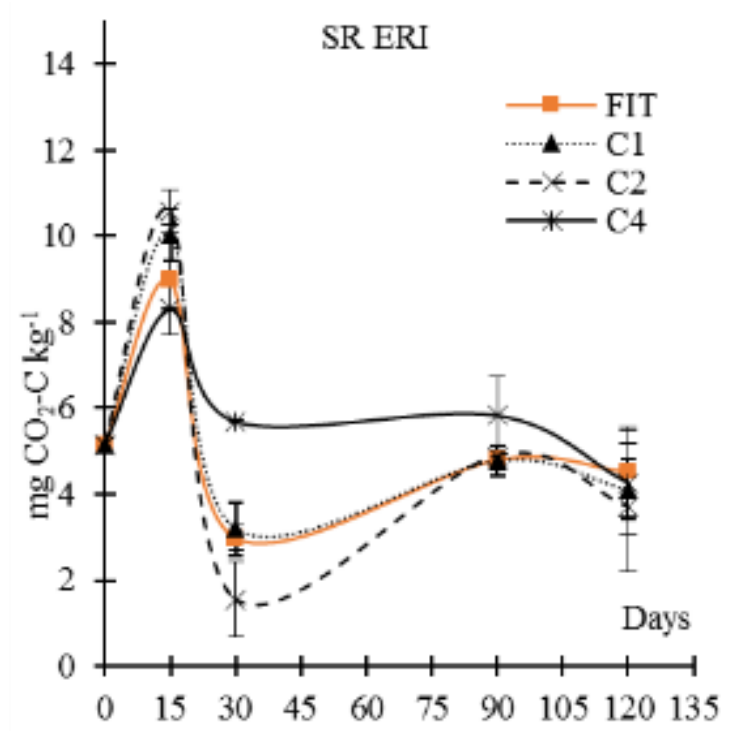

$\boldsymbol{B}$

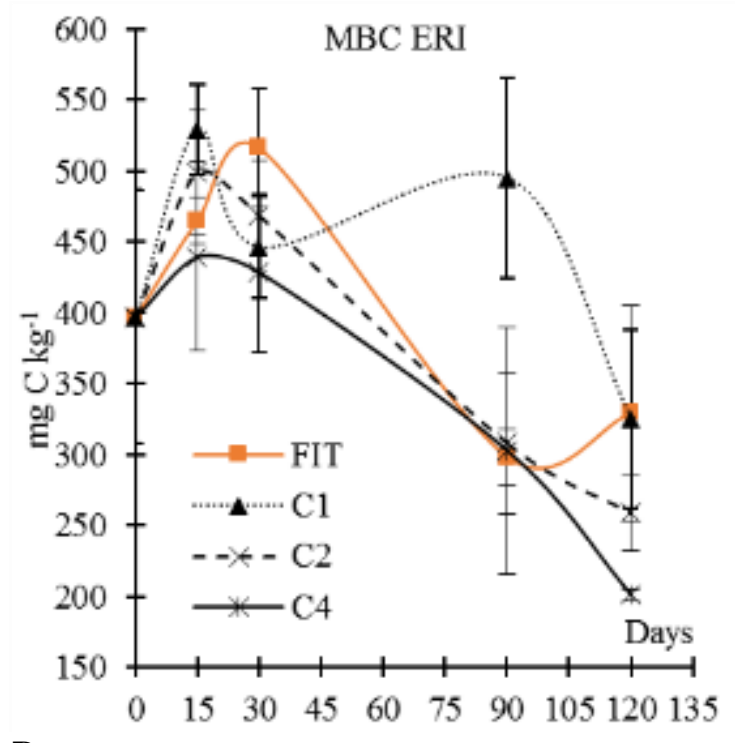

D

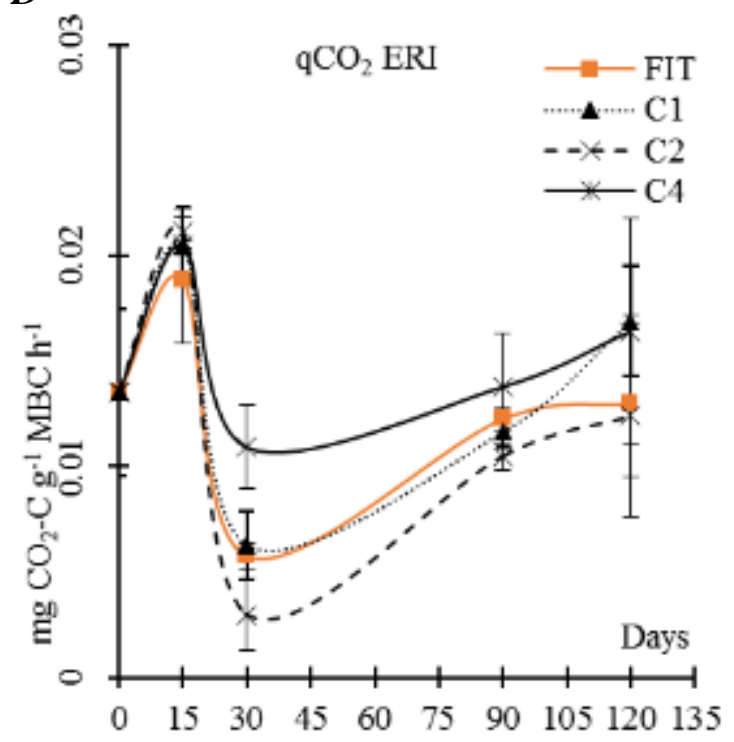

Figure 40: Biochemical soil variables determined at days 15, 30, 90 and 120 in the FIT (fitoil) and ERI (Eriocephalus africanus) treatments at different concentration (C1, C2 and C4 are, respectively, 1,2 and 4 $m L$ of essential oil per litre of water)

A) $C_{\text {ext }}$ extractable organic carbon; B) $M B C$, microbial biomass carbon; C) $S R$, soil respiration; D) $q C \mathrm{CO}_{2}$, metabolic quotient. Reported results are means of three samples, bars are standard deviations.

Unlike the case of Microbial Biomass Carbon, there is on day 15 a first impact in microbial FAs abundance, entailing the $\mathrm{C} 4$ treatment a decrease in detected FAs amount (table 22 figure 41). This result can be ascribed mainly to stronger effect of the higher concentration treatment against fungal biomass (figure 41 fun\%), while bacteria (both Gp and Gn, figures $41 \mathrm{~b}, \mathrm{c}, \mathrm{d}$ and i), on the contrary, were stimulated by ERI C4 treatment during one month after the treatments. Fun\% and F_B ratio continued to be lower than the other treatments on day 30, when no significant differences appeared in FAs amount. On 
day 90 FAs was higher in C2 compared to FIT and C1, as Fun\% and F_B comparing C2 to FIT.

After day 90 FAs content decreased in all ERI EO treated soils more than in Fitoil treated ones, consequently, on day 120 in Fitoil treated soils FAs amount was higher than in ERI EO treated ones. No inhibitory effect of C4 on fungi persisted until day 120 , rather a stimulatory one given by $\mathrm{C} 1$ and $\mathrm{C} 2$. About bacteria bioindicators, as previously told, the stimulatory effect vanished after 15 days after the treatments, while equilibria among Gram-positive and negative varied during time. Gram-positive bioindicators were significantly higher in C4 treated soils than all the other treatments only on day 15 , on day 90 another significant difference divides C2 from the other EO treatments. Gram-negative bioindicator showed more and much various reactions to EO subministration: $\mathrm{C} 4$ treatment entailed and maintained during the whole experimental period Gn\% values very near to the day 0 ones (19\%). On the contrary in $\mathrm{C} 1$ and $\mathrm{C} 2$ treated soil $\mathrm{Gn} \%$ bioindicator followed the same trend of the Fitoil treated ones until day 90, to suddenly decrease during the last 30 days and ending with significantly higher values in Fitoil treated soils.

Gram-positive to negative ratio reflects the higher stimulant effect of $\mathrm{C} 2$ treatment on Gram-negative bacteria if compared to the other ERI EO treatments. 
Oddo M. - Effects of different weed control practices on soil quality in mediterranean crops

Table 22: Significant ( $*, P<0.05 ; * *, P<0.01 ; * * *, P<0.001 ;$ n.s, not significant) mean differences of soil microbial community bioindicators among treatments concentrations determined after 15, 30, 90 and 120 days since FIT and ERI treatments application

\begin{tabular}{|c|c|c|c|c|c|}
\hline Dep. Var. & Ind. Var. & Day 15 & Day 30 & Day 90 & Day 120 \\
\hline \multirow[t]{6}{*}{ FAs } & $\mathrm{C} 1-\mathrm{FIT}$ & n.s. & n.s. & n.s. & $-109 * * *$ \\
\hline & C2 - FIT & n.s. & n.s. & $74.0 * *$ & $-56.0 * *$ \\
\hline & $\mathrm{C} 2-\mathrm{C} 1$ & n.s. & n.s. & $56.4^{*}$ & $53.3 * *$ \\
\hline & C4 - FIT & $-72.3^{*}$ & n.s. & n.s. & $-89.2 * * *$ \\
\hline & $\mathrm{C} 4-\mathrm{C} 1$ & $-86.3 *$ & n.s. & n.s. & n.s. \\
\hline & $\mathrm{C} 4-\mathrm{C} 2$ & $-95.5^{* *}$ & n.s. & n.s. & $-33.2 *$ \\
\hline \multirow[t]{3}{*}{ Вас\% } & C4 - FIT & $4.72 * * *$ & n.s. & n.s. & n.s. \\
\hline & $\mathrm{C} 4-\mathrm{C} 1$ & $4.73 * * *$ & n.s. & n.s. & n.s. \\
\hline & $\mathrm{C} 4$ - C2 & $5.77 * * *$ & n.s. & n.s. & n.s. \\
\hline \multirow[t]{4}{*}{ Gp\% } & C4 - FIT & $3.12 * *$ & n.s. & n.s. & n.s. \\
\hline & $\mathrm{C} 4-\mathrm{C} 1$ & $3.10 * *$ & n.s. & n.s. & n.s. \\
\hline & $\mathrm{C} 4-\mathrm{C} 2$ & $3.66^{* * *}$ & n.s. & $2.28 *$ & n.s. \\
\hline & $\mathrm{C} 1-\mathrm{C} 2$ & n.s. & n.s. & $3.16 * *$ & n.s. \\
\hline \multirow[t]{6}{*}{ Gn\% } & C4 - FIT & $1.08 * * *$ & $2.17 * *$ & n.s. & $-5.35 * * *$ \\
\hline & $\mathrm{C} 4-\mathrm{C} 1$ & $1.12 * * *$ & $1.74^{*}$ & $-0.88^{*}$ & n.s. \\
\hline & $\mathrm{C} 4-\mathrm{C} 2$ & $1.35 * * *$ & n.s. & $-4.16 * * *$ & $-2.04 * *$ \\
\hline & $\mathrm{C} 2-\mathrm{C} 1$ & n.s. & n.s. & $3.28 * * *$ & $2.45^{* * *}$ \\
\hline & C2 - FIT & n.s. & n.s. & $3.70 * * *$ & $-3.31 * * *$ \\
\hline & C1 - FIT & n.s. & n.s. & $0.00 * * *$ & $-5.76 * * *$ \\
\hline \multirow[t]{6}{*}{ Fun\% } & C4 - FIT & $-6.13 * * *$ & $-5.63 * * *$ & n.s. & n.s. \\
\hline & $\mathrm{C} 4-\mathrm{C} 1$ & $-5.52 * * *$ & $-4.87 * * *$ & n.s. & n.s. \\
\hline & $\mathrm{C} 4-\mathrm{C} 2$ & $-6.25 * * *$ & $-5.43 * * *$ & n.s. & n.s. \\
\hline & C2 - FIT & n.s. & n.s. & $-0.23 *$ & n.s. \\
\hline & $\mathrm{C} 2-\mathrm{C} 1$ & n.s. & n.s. & n.s. & $0.21 *$ \\
\hline & C1 - FIT & n.s. & n.s. & n.s. & $0.29 * *$ \\
\hline \multirow[t]{6}{*}{ F_B } & C4 - FIT & $-.160 * * *$ & $-.165 * * *$ & n.s. & n.s. \\
\hline & $\mathrm{C} 4-\mathrm{C} 1$ & $-.150 * * *$ & $-.133 * *$ & n.s. & n.s. \\
\hline & $\mathrm{C} 4-\mathrm{C} 2$ & $-.180 * * *$ & $-.173 * * *$ & n.s. & n.s. \\
\hline & C2 - FIT & n.s. & n.s. & $.005^{*}$ & n.s. \\
\hline & $\mathrm{C} 2-\mathrm{C} 1$ & n.s. & n.s. & n.s. & $-.004 *$ \\
\hline & C1 - FIT & n.s. & n.s. & n.s. & $.006 * *$ \\
\hline \multirow[t]{5}{*}{ Gp_Gn } & C1 - FIT & n.s. & n.s. & n.s. & $.624 * * *$ \\
\hline & C2 - FIT & n.s. & n.s. & $-.351 * * *$ & $.365 * *$ \\
\hline & $\mathrm{C} 2-\mathrm{C} 1$ & n.s. & n.s. & $-.374 * * *$ & n.s. \\
\hline & $\mathrm{C} 2-\mathrm{C} 4$ & $-.110 *$ & n.s. & $-.406 * * *$ & n.s. \\
\hline & C4 - FIT & n.s. & n.s. & n.s. & $.564 * * *$ \\
\hline Mes\% & ALL & n.s. & n.s. & n.s. & n.s. \\
\hline
\end{tabular}

Data obtained by Tukey post-hoc test $(n=3)$ performed for each sampling day (15, 30, 90 and 120) assuming concentration (FIT, C1, C2, C4) as independent variable. FIT, Fitoil treated soils. ERI, E. africanus EO emulsions treated soils; $C 1, C 2$ and C4, EO concentration in the emulsion, 1,2 and $4 \mathrm{mLEO} \mathrm{L} \mathrm{L}^{-1}$ water.

FAs, microbial fatty acids (nmol $g^{-1}$ soil); Bac\%, percentage of bacteria; Gp\%, percentage of Gram-positive bacteria; Gn\% percentage of Gram-negative bacteria; Gp_Gn, Gram-positive to Gram-negative ratio; Fun $\%$, percentage of fungi; $F \_B$, fungi to bacteria ratio; Mes\%, percentage of mesofauna. 
A

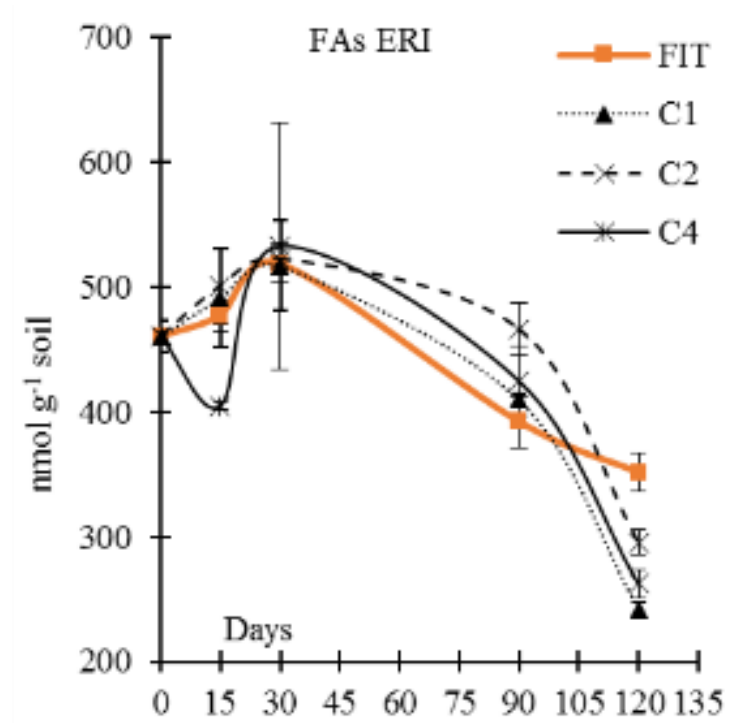

C

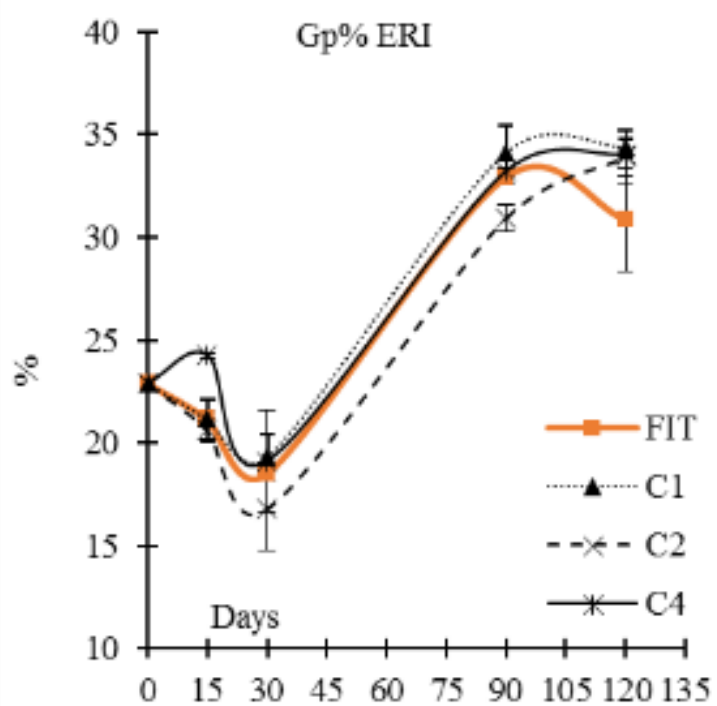

E

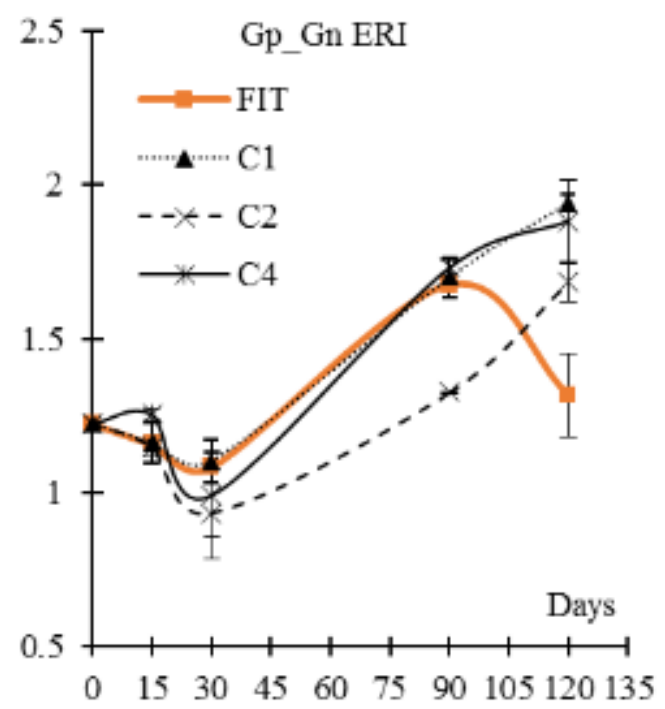

B

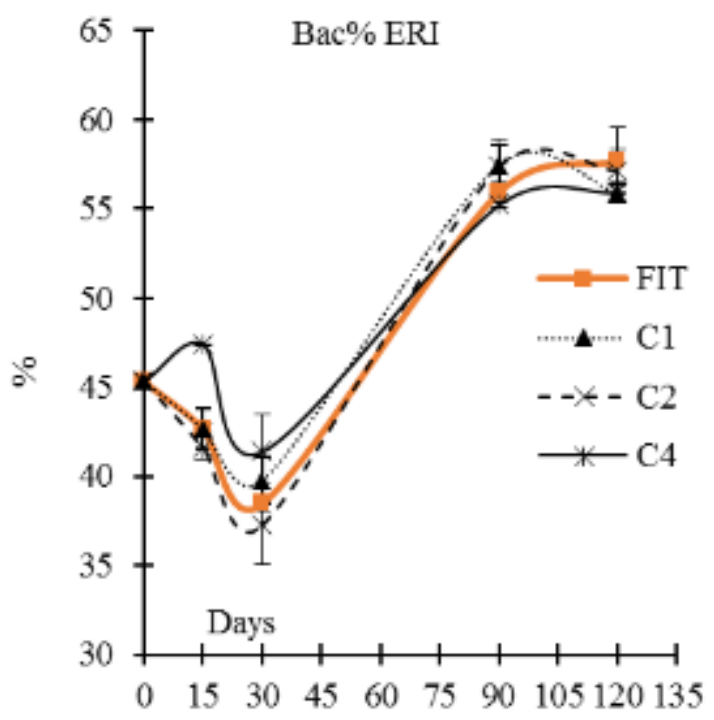

D

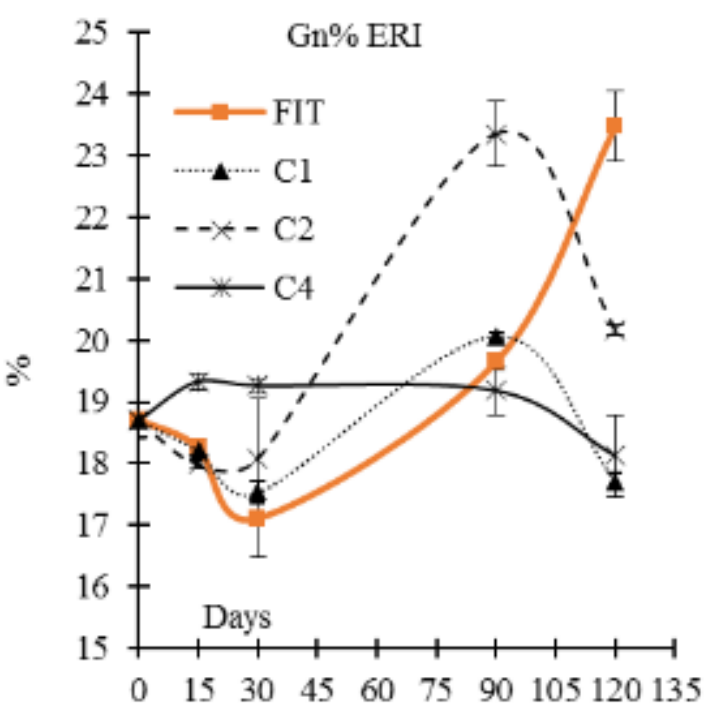

F

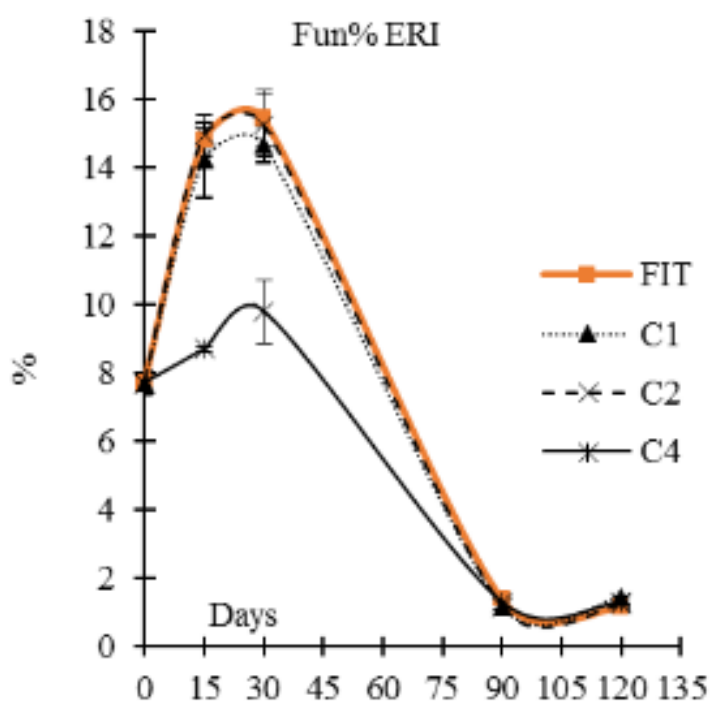


$\boldsymbol{G}$

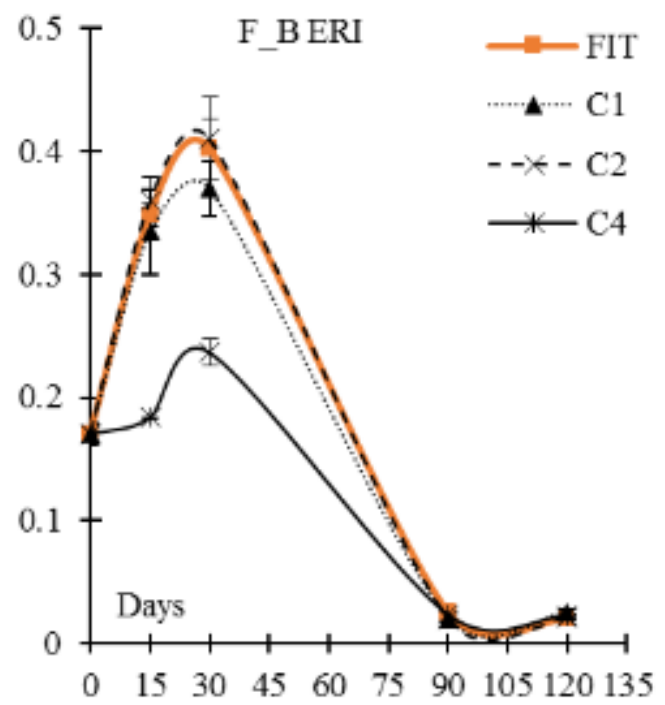

$\boldsymbol{H}$

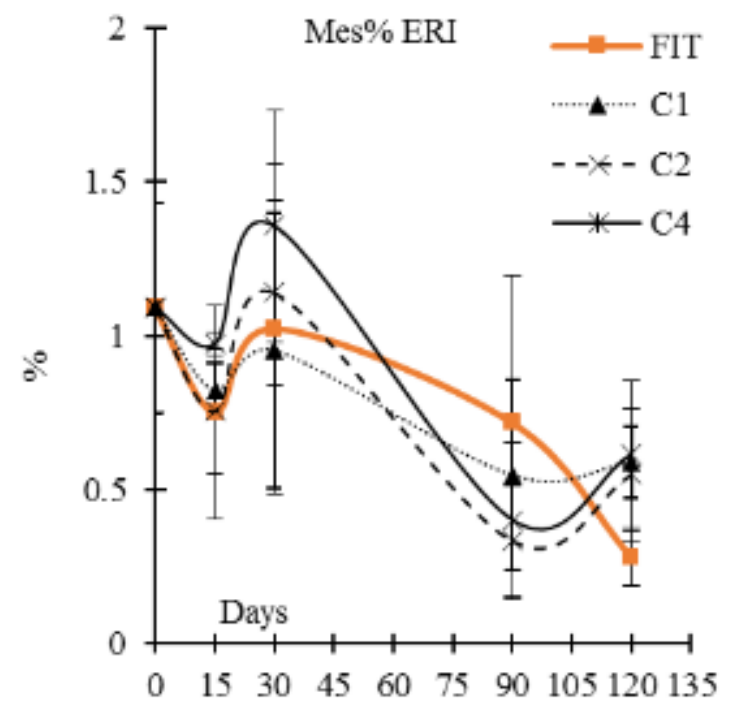

Figure 41: Microbial community structure determined at days 15, 30, 90 and 120 in the FIT (fitoil) and ERI (Eriocephalus africanus) treatments at different concentration (C1, C2 and C4 are, respectively, 1,2 and 4 $m L$ of essential oil per litre of water)

A) FAs, microbial fatty acids; B) Bac\%, percentage of bacteria; C) Gp\%, percentage of Gram-positive bacteria; D) Gn\% percentage of Gram-negative bacteria; $E$ ) $G p \_G n$, Gram-positive to Gram-negative ratio; $F$ ) $F u n \%$, percentage of fungi; $G) F \_B$, fungi to bacteria ratio; $\left.H\right)$ Mes $\%$, percentage of mesofauna. Showed values represents the mean values, bars are standard deviation $(n=3)$. 


\subsubsection{EUC}

Eucalyptus camaldulensis Dehnh. EO treatments affected $\mathrm{C}_{\mathrm{ext}}, \mathrm{SR}$ and $\mathrm{qCO}_{2}$ since the beginning of the experiment, while MBC starts to react on day 30. On day 120 no residual effects persisted (table 23).

$\mathrm{C}_{\mathrm{ext}}$ was the more influenced dependent variable during time, having $\mathrm{C} 1$ higher levels of extractable carbon during the first 30 days of greenhouse incubation if compared to $\mathrm{C} 2$ and C4 as well to FIT. C2 on day 90 contains significantly less $\mathrm{C}_{\mathrm{ext}}$ than C1 and FIT.

$\mathrm{SR}$, compared to FIT, increased after the $\mathrm{C} 1$ treatment only on day 15 , while decreased after the application of $\mathrm{C} 2$ and $\mathrm{C} 4$. Significant negative differences on day 30 are evidenced among $\mathrm{C} 4$ and the lower concentrations, but not with the Fitoil control. Soil respiration in EUC treated soils follows SR trends on the first sampling day, becoming insignificant later.

Microbial biomass carbon more slowly and scarcely reacts to the treatments. Significant differences appear on day 30 when $\mathrm{C} 1$ and $\mathrm{C} 2$ treated soils have lower values than $\mathrm{C} 4$ and FIT. MBC in C2 treated soil continues to drop till day 90, then grows again to reach the other treatments values.

Table 23: Significant (*, $P<0.05 ; * *, P<0.01 ; * * *, P<0.001$; n.s, not significant) mean differences of soil biochemical properties among treatments concentrations determined after 15, 30, 90 and 120 days since FIT and EUC treatments application

\begin{tabular}{lc|cccc}
\hline Dep. Var. & Ind. Var. & Day15 & Day30 & Day90 & Day 120 \\
\hline Cext & FIT - C1 & $-125.2^{* * *}$ & $-68.0^{* *}$ & n.s. & n.s. \\
& FIT - C2 & n.s. & n.s. & $35.1^{* * *}$ & n.s. \\
& C1 - C2 & $112.8^{* * *}$ & $40.9^{*}$ & $30.8^{* *}$ & n.s. \\
& C1 - C4 & $106.2^{* * *}$ & $77.7^{* *}$ & n.s. & n.s. \\
MBC & C4 - C2 & n.s. & n.s. & $30.4^{* *}$ & n.s. \\
& FIT - C1 & n.s. & $201^{* *}$ & n.s. & n.s. \\
& FIT - C2 & n.s. & $241^{* *}$ & n.s. & n.s. \\
SR & C1 - C2 & n.s. & n.s. & $-134^{*}$ & n.s. \\
& C4 - C2 & n.s. & $138^{*}$ & n.s. & n.s. \\
& FIT - C1 & n.s. & n.s. & $-1.96^{*}$ & n.s. \\
& FIT - C2 & $4.77^{* *}$ & n.s. & n.s. & n.s. \\
& FIT - C4 & $4.05^{* *}$ & n.s. & n.s. & n.s. \\
& C1 - C2 & $6.41^{* * *}$ & n.s. & n.s. & n.s. \\
& C1 - C4 & $5.70^{* * *}$ & $1.01^{*}$ & n.s. & n.s. \\
qCO2 & C4 - C2 & n.s. & $-1.11^{*}$ & n.s. & n.s. \\
& FIT - C2 & $0.01^{* *}$ & n.s. & n.s. & n.s. \\
& FIT - C4 & $0.01^{* *}$ & n.s. & n.s. & n.s. \\
& C1 - C2 & $0.20^{* * *}$ & n.s. & n.s. & n.s. \\
& C1 - C4 & $0.10^{* * *}$ & n.s. & n.s. & n.s. \\
\hline
\end{tabular}

Data obtained by Tukey post-hoc test ( $n=3)$ performed for each sampling day (15, 30, 90 and 120) assuming concentration (FIT, C1, C2, C4) as independent variable. FIT, Fitoil treated soils. EUC, E. camaldulensis EO emulsions treated soils; $C 1, C 2$ and C4, EO concentration in the emulsion, 1,2 and $4 \mathrm{mLEO} \mathrm{L^{-1 }}$ water. $C_{\text {ext }}$, extractable organic carbon; $M B C$, microbial biomass carbon; $S R$, soil respiration; $q \mathrm{CO}_{2}$, metabolic quotient. 
$\boldsymbol{A}$

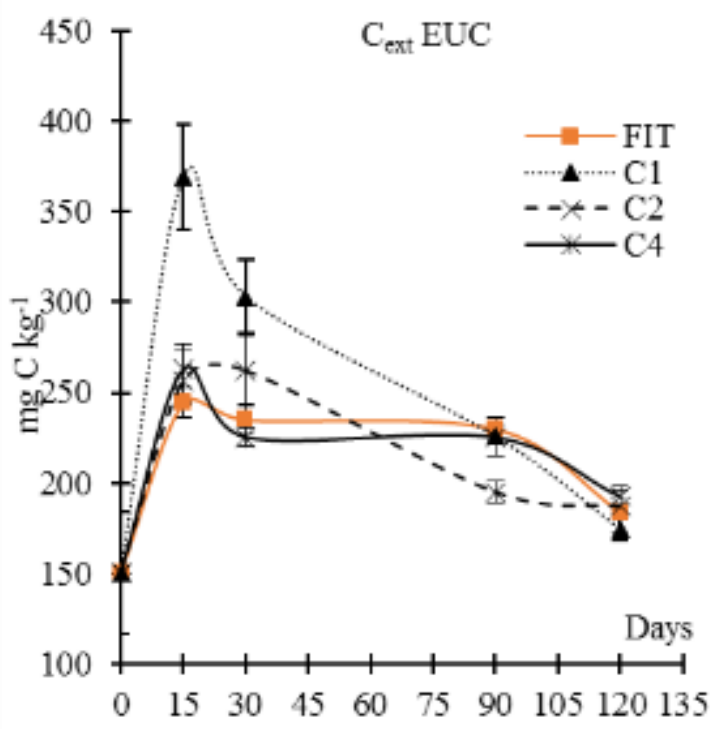

C

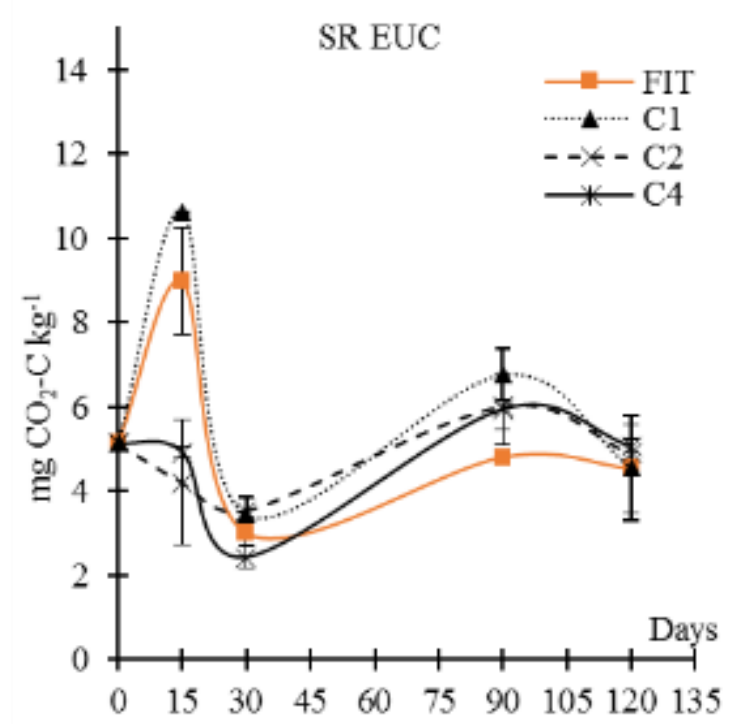

B

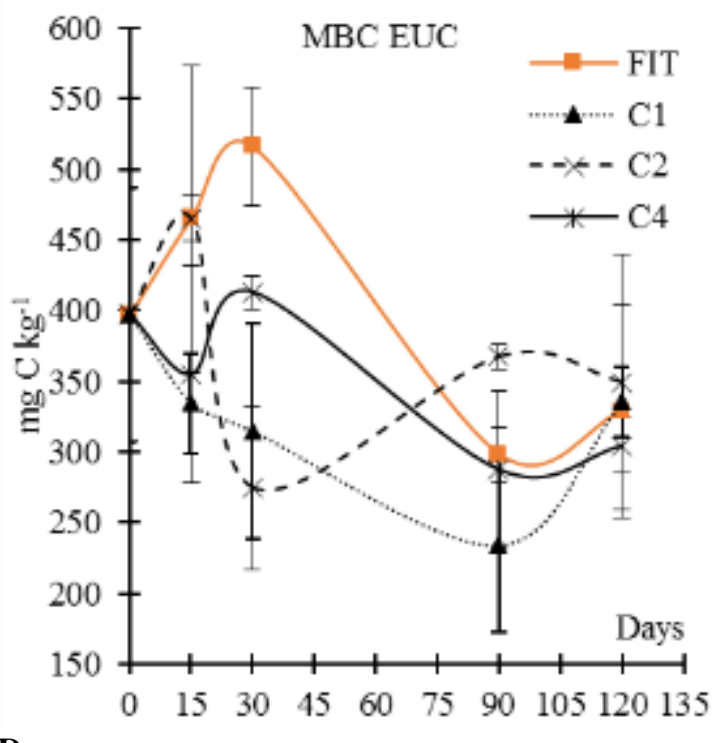

D

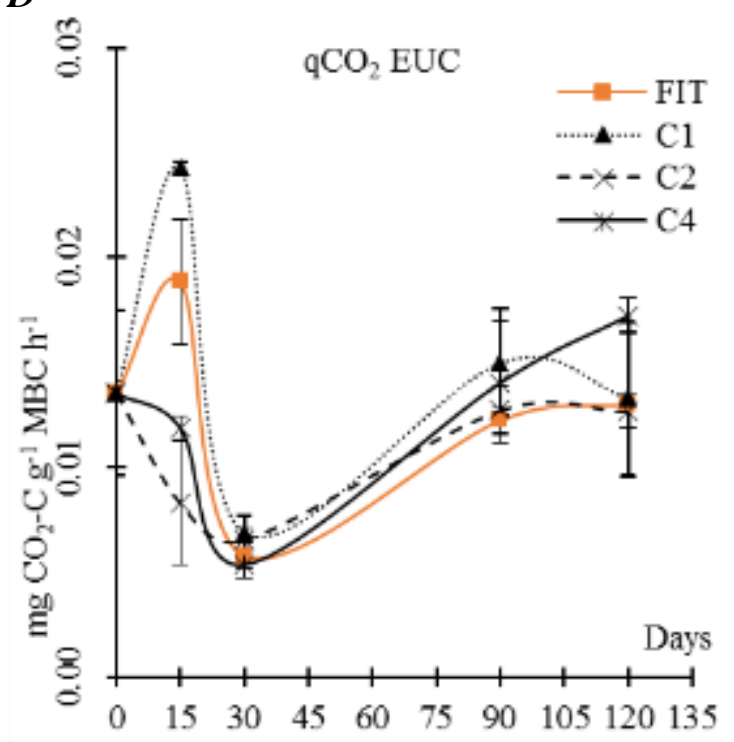

Figure 42: Biochemical soil variables determined at days 15, 30, 90 and 120 in the FIT (fitoil) and EUC (Eucalyptus camaldulensis) treatments at different concentration (C1, $C 2$ and $C 4$ are, respectively, 1,2 and $4 \mathrm{~mL}$ of essential oil per litre of water)

A) $C_{\text {ext }}$ extractable organic carbon; $B$ ) $M B C$, microbial biomass carbon; C) SR, soil respiration; D) $q C O_{2}$, metabolic quotient. Reported results are means of three samples, bars are standard deviations.

In figure $43 \mathrm{a}$, it is possible to observe the strong negative effect of EUC C4 and C1 treatment on FAs bioindicator, and the positive one caused by $\mathrm{C} 2$ treatment. After this first impact, in all treated soils FAs bioindicator reached the maximum values of the experimental period. After day 30 all the treated soils suffered the physiological decrease, that was more pendent in Fitoil treated soils than in the EO treated ones, while in C4 samples the bioindicator maintained values similar to the not treated one (day 0 ) on day 30 and 90. At the end of the experiment $\mathrm{C} 2$ treated soils values was significantly higher than 
the $\mathrm{C} 1$ and FIT ones, while on the contrary $\mathrm{C} 4$ was significantly lower than all the other EUC and the Fitoil treated ones.

Table 24: Significant (*, $P<0.05$; **, $P<0.01$; ***, $P<0.001$; n.s, not significant) mean differences of soil microbial community bioindicators among treatments concentrations determined after 15, 30, 90 and 120 days since FIT and EUC treatments application

\begin{tabular}{|c|c|c|c|c|c|}
\hline Dep. Var. & Ind. Var. & Day 15 & Day 60 & Day 90 & Day 120 \\
\hline \multirow[t]{5}{*}{ FAs } & $\mathrm{C} 4-\mathrm{FIT}$ & $-62.0 * *$ & $-67.0 * * *$ & n.s. & $-57.4 * *$ \\
\hline & $\mathrm{C} 4-\mathrm{C} 1$ & n.s. & $-50.3 * * *$ & n.s. & $-49.5 * *$ \\
\hline & $\mathrm{C} 4-\mathrm{C} 2$ & $-92.8 * *$ & $-91.6 * * *$ & n.s. & $-92.7 * * *$ \\
\hline & $\mathrm{C} 2-\mathrm{FIT}$ & n.s. & $24.7 *$ & n.s. & $35.4^{*}$ \\
\hline & $\mathrm{C} 2-\mathrm{C} 1$ & $70.2 * *$ & $41.3 * *$ & n.s. & $43.3 *$ \\
\hline \multirow[t]{4}{*}{ Вас\% } & FIT - C1 & n.s. & $-1.92 *$ & n.s. & n.s. \\
\hline & C4 - FIT & n.s. & $4.92 * * *$ & n.s. & n.s. \\
\hline & $\mathrm{C} 4-\mathrm{C} 1$ & n.s. & $3.01 * *$ & n.s. & n.s. \\
\hline & $\mathrm{C} 4-\mathrm{C} 2$ & n.s. & $4.06 * * *$ & n.s. & n.s. \\
\hline \multirow[t]{4}{*}{ Gp\% } & FIT - C1 & n.s. & $-0.86^{*}$ & n.s. & n.s. \\
\hline & C4 - FIT & n.s. & $2.90 * * *$ & n.s. & n.s. \\
\hline & $\mathrm{C} 4-\mathrm{C} 1$ & n.s. & $2.04 * * *$ & n.s. & n.s. \\
\hline & $\mathrm{C} 4-\mathrm{C} 2$ & n.s. & $2.36 * * *$ & $2.89 *$ & $3.46^{*}$ \\
\hline \multirow[t]{6}{*}{ Gn\% } & FIT - C1 & n.s. & $-1.19 *$ & n.s. & $1.42 *$ \\
\hline & FIT - C2 & n.s. & n.s. & $-2.94 * *$ & n.s. \\
\hline & $\mathrm{C} 1-\mathrm{C} 2$ & n.s. & n.s. & n.s. & $-1.67 * *$ \\
\hline & C4 - FIT & n.s. & $1.69 * *$ & n.s. & $-4.26 * * *$ \\
\hline & $\mathrm{C} 4-\mathrm{C} 1$ & n.s. & n.s. & $-2.68 * *$ & $-2.85 * * *$ \\
\hline & $\mathrm{C} 4-\mathrm{C} 2$ & n.s. & $1.59 *$ & $-3.94 * * *$ & $-4.51 * * *$ \\
\hline \multirow[t]{5}{*}{ Fun\% } & C1 - FIT & n.s. & n.s. & n.s. & $0.23 * * *$ \\
\hline & $\mathrm{C} 1-\mathrm{C} 2$ & n.s. & n.s. & n.s. & $0.31 * * *$ \\
\hline & C4 - FIT & $-9.36 * *$ & $-4.10 * *$ & n.s. & $0.24 * * *$ \\
\hline & $\mathrm{C} 4-\mathrm{C} 1$ & $-5.46^{*}$ & n.s. & n.s. & n.s. \\
\hline & $\mathrm{C} 4-\mathrm{C} 2$ & $-8.85^{* *}$ & $-2.73 *$ & n.s. & $0.32 * * *$ \\
\hline \multirow[t]{5}{*}{ F_B } & FIT - C1 & n.s. & $.083^{*}$ & n.s. & $-.004 * *$ \\
\hline & $\mathrm{C} 1-\mathrm{C} 2$ & n.s. & n.s. & n.s. & $.005 * * *$ \\
\hline & C4 - FIT & $-.230 * *$ & $-.139 * *$ & n.s. & $.005 * * *$ \\
\hline & $\mathrm{C} 4-\mathrm{C} 1$ & n.s. & n.s. & n.s. & n.s. \\
\hline & $\mathrm{C} 4-\mathrm{C} 2$ & $-.260 * *$ & $-.096^{*}$ & n.s. & $.006 * * *$ \\
\hline \multirow[t]{3}{*}{ Gp_Gn } & C4 - FIT & n.s. & n.s. & n.s. & $.416^{* * *}$ \\
\hline & $\mathrm{C} 4-\mathrm{C} 1$ & n.s. & $.081 *$ & $.351 *$ & $.290 * *$ \\
\hline & $\mathrm{C} 4-\mathrm{C} 2$ & n.s. & n.s. & $.459 * *$ & $.475^{* * *}$ \\
\hline Mes\% & ALL & n.s. & n.s. & n.s. & n.s. \\
\hline
\end{tabular}

Data obtained by Tukey post-hoc test $(n=3)$ performed for each sampling day $(15,30,90$ and 120$)$ assuming concentration (FIT, C1, C2, C4) as independent variable. FIT, Fitoil treated soils. EUC, E. camaldulensis

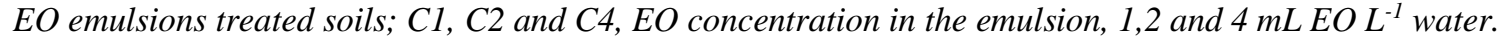
FAs, microbial fatty acids ( $\mathrm{nmol} \mathrm{g}^{-1}$ soil); Bac\%, percentage of bacteria; Gp\%, percentage of Gram-positive bacteria; Gn\% percentage of Gram-negative bacteria; Gp_Gn, Gram-positive to Gram-negative ratio; Fun $\%$, percentage of fungi; $F_{-} B$, fungi to bacteria ratio; Mes\%, percentage of mesofauna

The short-term negative impact of EUC C4 on FAs total amount is linked to the inhibitory effect on fungi and Gram-negative bacteria, while Gram-positive ones are stimulated by this treatment (figures $43 \mathrm{c}, \mathrm{d}$ and $\mathrm{h}$ ).

Bacterial community in general reacted slowly to EOs addiction in comparison to fungal one (table 24), in Gp the effect persisted until day 120 only after $\mathrm{C} 4$ treatment, Gn reacted differently to each concentration. In detail, C2 treated soils Gp values never significantly 
differed from FIT ones, while after C4 treatment Gp values remained higher than in the other treatments till the end of the experiment. All the EUC EO treatments inhibited (not significantly) Gn population initially, but on day $30 \mathrm{C} 4$ treatment effect becomes stimulatory, then Gn population returned to the not treated soil value (day 0) since day 30 until the end of the experiment. Stimulatory medium-term effect on Gram-negative bacteria also appeared in $\mathrm{C} 1$ and $\mathrm{C} 2$ treated soils (table 24, figure $42 \mathrm{~d}$ ). In figure 51 it is possible to observe that EUC EO treatments influenced Gram-positive to negative ratio on day 15 proportionately to treatment concentrations, and since day 30 the different effect of $\mathrm{C} 4$ treatment (stimulant for $\mathrm{Gp}$, bacteriostatic for $\mathrm{Gn}$ ) separated the $\mathrm{C} 4$ curve from the other treatments one.

As mentioned earlier, the $\mathrm{C} 4$ treatment inhibited fungal growth on day 15 and 30. As for $\mathrm{Gp}$, no significant differences were evidenced between C2 and FIT treated soil Fun\% bioindicator. There are no significant differences on day 90 and 120. Fungi to bacteria ratio bioindicator follows the same trend of the Fun\% one. 
A

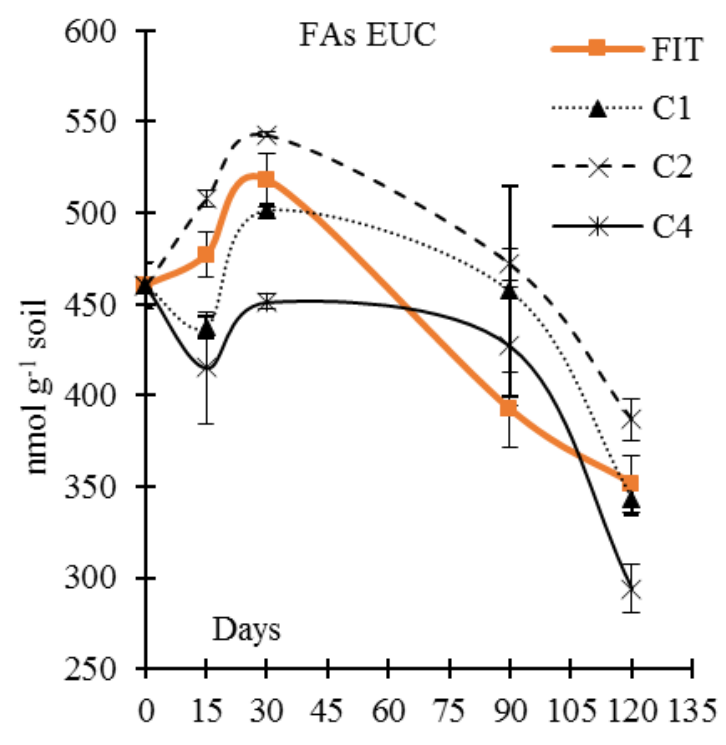

C

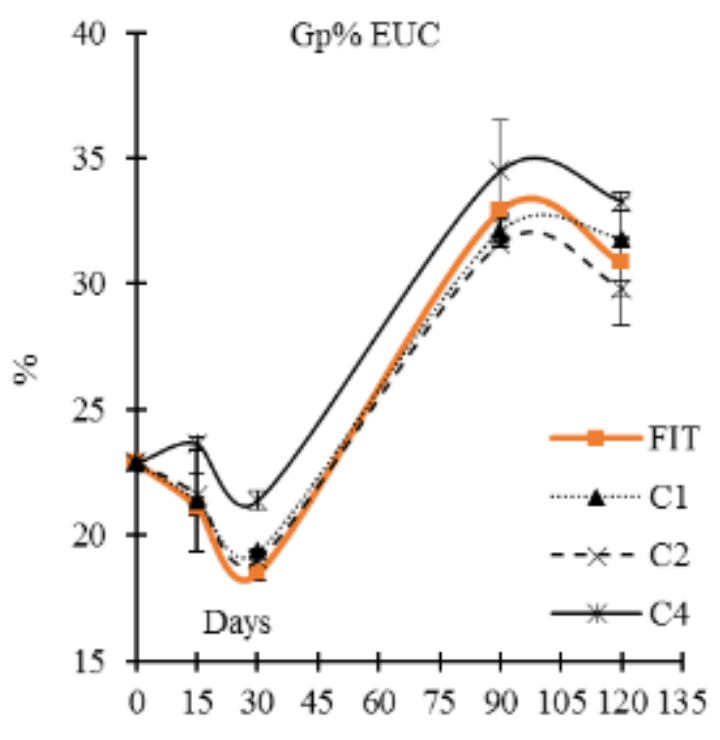

E

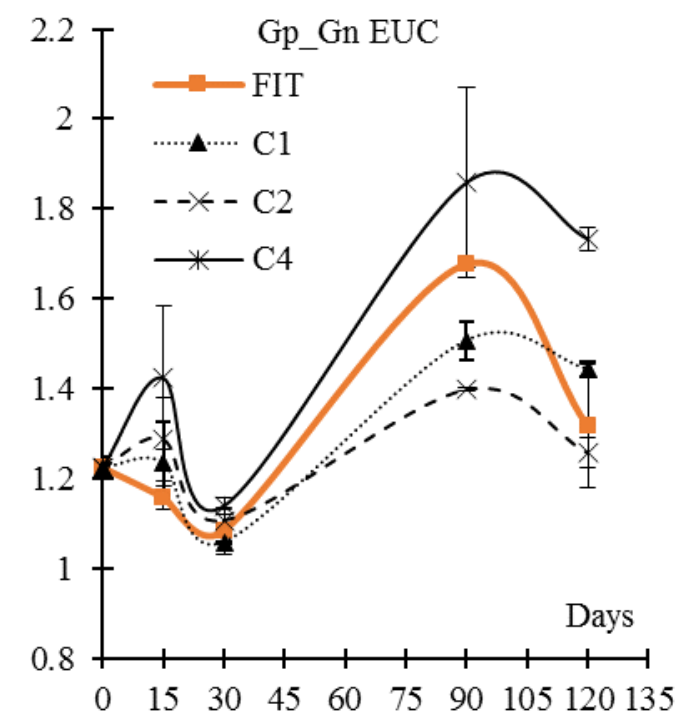

B

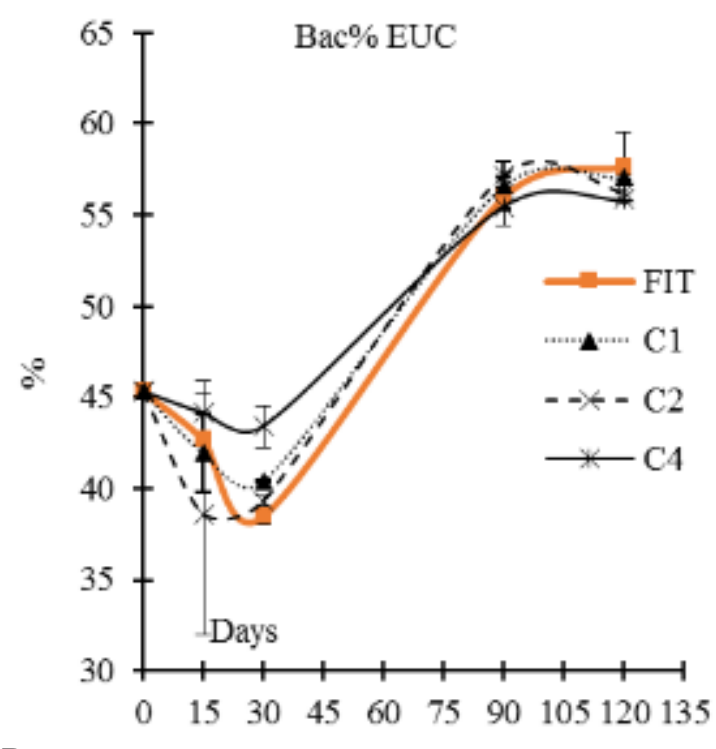

D

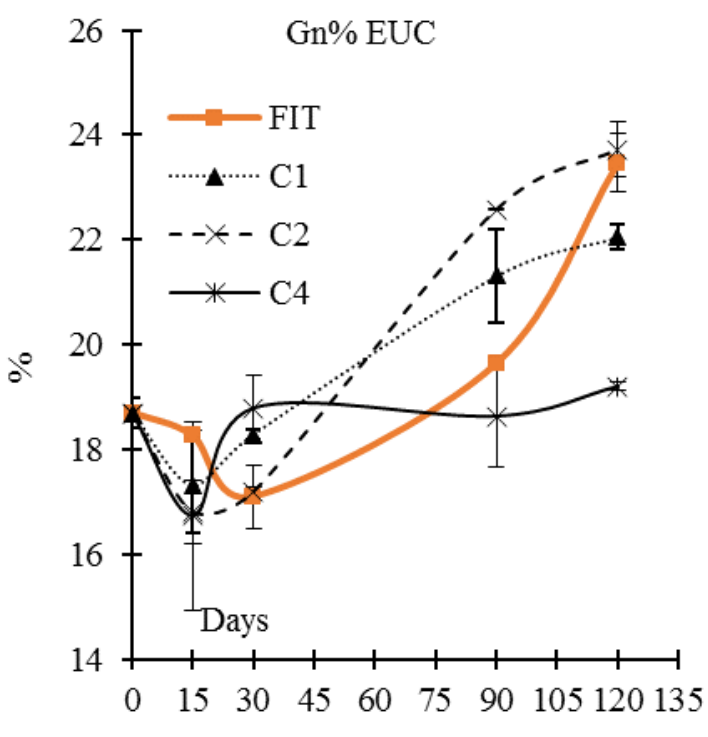

F

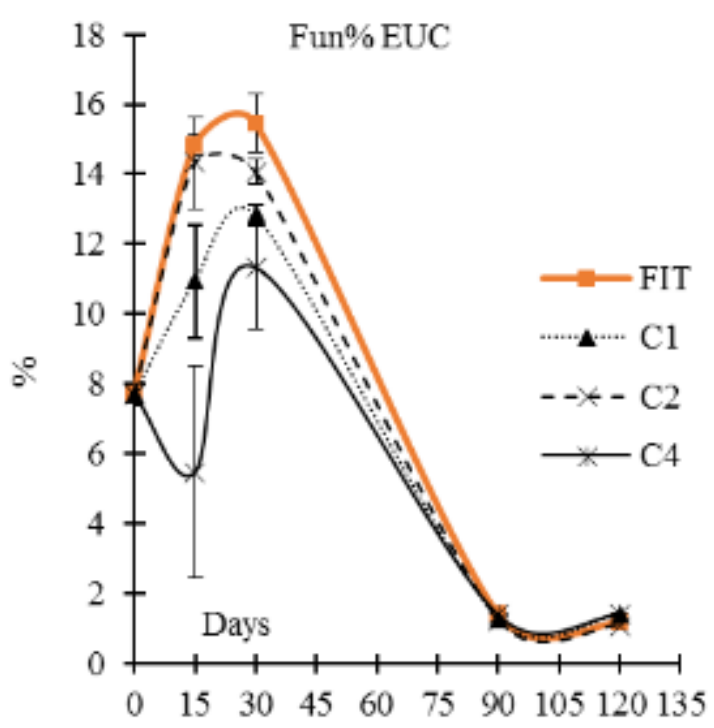


$\boldsymbol{G}$

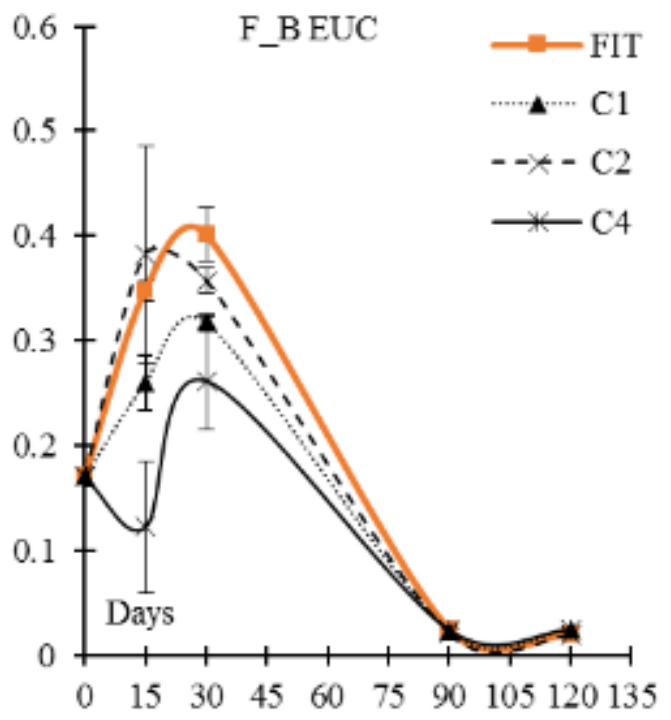

$\boldsymbol{H}$

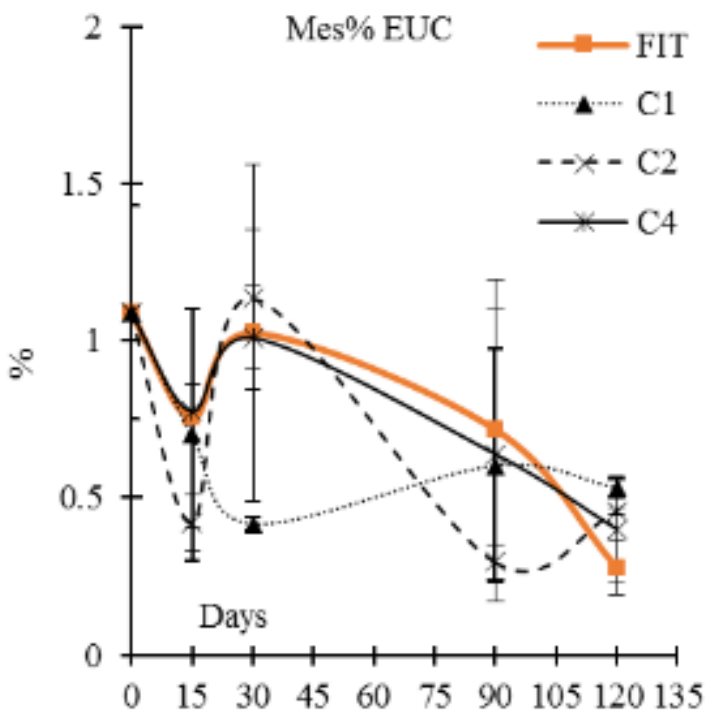

Figure 43: Microbial community structure determined at days 15, 30, 90 and 120 in the FIT (fitoil) and EUC (Eucalyptus camaldulensis) treatments at different concentration $(C 1, C 2$ and $C 4$ are, respectively, 1,2 and $4 \mathrm{~mL}$ of essential oil per litre of water)

A) FAs, microbial fatty acids; B) Bac\%, percentage of bacteria; C) Gp\%, percentage of Gram-positive bacteria; D) Gn\% percentage of Gram-negative bacteria; E) Gp_Gn, Gram-positive to Gram-negative ratio; $F$ ) $F u n \%$, percentage of fungi; $G) F \_B$, fungi to bacteria ratio; $\left.H\right)$ Mes\%, percentage of mesofauna. Showed values represents the mean values, bars are standard deviation $(n=3)$. 


\subsubsection{LEM}

Neither in soils treated with Citrus limon (L.) Osbeck EO biochemical soil properties suffered effects after 90 days since the treatments was applied. On the first sampling day after the treatments supply, MBC was the most affected biochemical soil property. In particular $\mathrm{C} 2$ concentration caused a fast and strong decrease of microbial biomass carbon if compared to the other LEM treatments and the Fitoil control, acting symmetrically on $\mathrm{C}_{\mathrm{ext}}$ values on the same day. After the first impact, treated soils MBC suffered a general decrease on day 30, due to all lemon EO treatments, such differences appear clearly related to treatment concentrations on day 90 , when the only significant difference was between C1 (lower than Fitoil) and C4 (higher), while C2 showed the same value of fitoil.

$\mathrm{C}_{\mathrm{ext}}$ and soil metabolism was not significantly affected by lemon EO treatment on day 30, but they do on day 90 . In figure 47 it is possible to observe that $\mathrm{C}_{\mathrm{ext}}$ in Fitoil treated pots maintained constant $\mathrm{C}_{\text {ext }}$ levels since day 30, then physiologically decreased on day 120 . Instead, after the short term-increment in lemon EO treated soil extractable carbon slightly decreased, and the stronger negative effect was caused by the higher EO concentration.

Table 25: Significant (*, $P<0.05 ; * *, P<0.01$; ***, $P<0.001$; n.s, not significant) mean differences of soil biochemical properties among treatments concentrations determined after 15, 30, 90 and 120 days since FIT and LEM treatments application

\begin{tabular}{|c|c|c|c|c|c|}
\hline Dep. Var. & Ind. Var. & Day 15 & Day 30 & Day 90 & Day 120 \\
\hline \multirow[t]{5}{*}{$\mathrm{C}_{\text {ext }}$} & $\mathrm{FIT}-\mathrm{C} 1$ & n.s. & n.s. & $27.67 *$ & n.s. \\
\hline & $\mathrm{FIT}-\mathrm{C} 2$ & $-67.7 * *$ & n.s. & n.s. & n.s. \\
\hline & $\mathrm{FIT}-\mathrm{C} 4$ & n.s. & n.s. & $39.0 * *$ & n.s. \\
\hline & $\mathrm{C} 2-\mathrm{C} 1$ & $77.7 * *$ & n.s. & n.s. & n.s. \\
\hline & $\mathrm{C} 2-\mathrm{C} 4$ & $49.0 *$ & n.s. & $26.5^{*}$ & n.s. \\
\hline \multirow[t]{6}{*}{ MBC } & $\mathrm{FIT}-\mathrm{C} 1$ & n.s. & $179 * *$ & n.s. & n.s. \\
\hline & $\mathrm{FIT}-\mathrm{C} 2$ & $194 * *$ & $169 * *$ & n.s. & n.s. \\
\hline & $\mathrm{FIT}-\mathrm{C} 4$ & n.s. & $211 * *$ & n.s. & n.s. \\
\hline & $\mathrm{C} 2-\mathrm{C} 1$ & $-204 * *$ & n.s. & n.s. & n.s. \\
\hline & $\mathrm{C} 2-\mathrm{C} 4$ & $-202 * *$ & n.s. & n.s. & n.s. \\
\hline & $\mathrm{C} 4-\mathrm{C} 1$ & n.s. & n.s. & $-101 *$ & n.s. \\
\hline \multirow[t]{3}{*}{ SR } & $\mathrm{FIT}-\mathrm{C} 1$ & $3.58 *$ & n.s. & n.s. & n.s. \\
\hline & $\mathrm{C} 4-\mathrm{C} 1$ & $6.66 * *$ & n.s. & n.s. & n.s. \\
\hline & $\mathrm{C} 4-\mathrm{C} 2$ & $5.18 * *$ & n.s. & n.s. & n.s. \\
\hline \multirow[t]{2}{*}{$\mathrm{qCO}_{2}$} & $\mathrm{C} 4-\mathrm{C} 1$ & $0.01 * *$ & n.s. & $-0.01 *$ & n.s. \\
\hline & $\mathrm{C} 4-\mathrm{C} 2$ & $0.01 *$ & n.s. & $-0.01 *$ & n.s. \\
\hline
\end{tabular}

Data obtained by Tukey post-hoc test ( $n=3)$ performed for each sampling day (15, 30, 90 and 120) assuming concentration (FIT, C1, C2, C4) as independent variable. FIT, Fitoil treated soils. LEM, C. limon EO emulsions treated soils; $C 1, C 2$ and C4, EO concentration in the emulsion, 1,2 and $4 \mathrm{mLEO} \mathrm{L} \mathrm{L}^{-1}$ water. $C_{\text {ext, }}$ extractable organic carbon; $M B C$, microbial biomass carbon; $S R$, soil respiration; $q \mathrm{CO}_{2}$, metabolic quotient. 
Soil respiration and $\mathrm{qCO}_{2}$ (figure $44 \mathrm{c}$ and $\mathrm{d}$ ) appears to have a similar short-term reaction to the treatment concentrations, while fitoil treatment is only occasionally significantly different. On the first sampling day, significant differences are evidenced among each lemon EO concentrations and only in SR data serie C1 is significantly lower than FIT. Another small significant reaction in metabolic quotient appears on day 90, due to the notable increment of MBC in $\mathrm{C} 4$ treatment.

$\boldsymbol{A}$

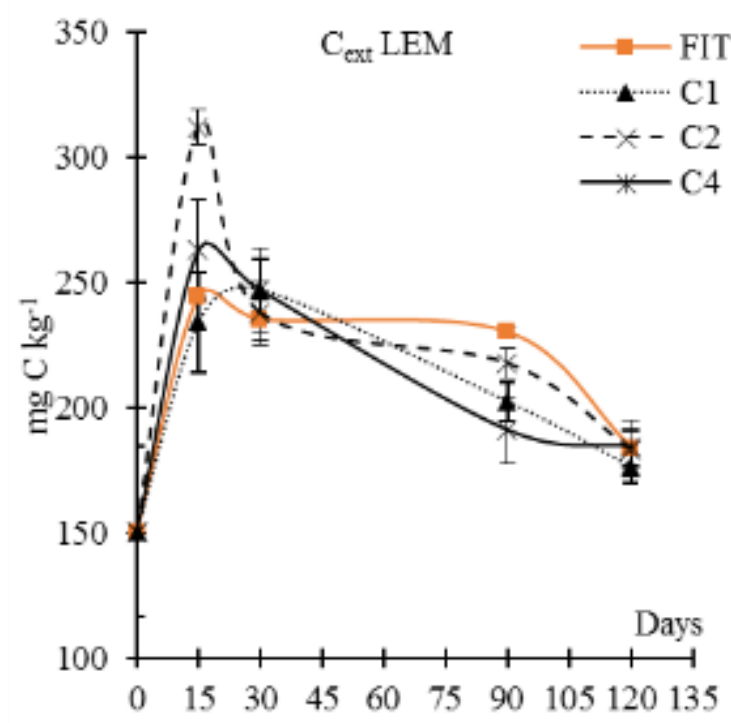

C

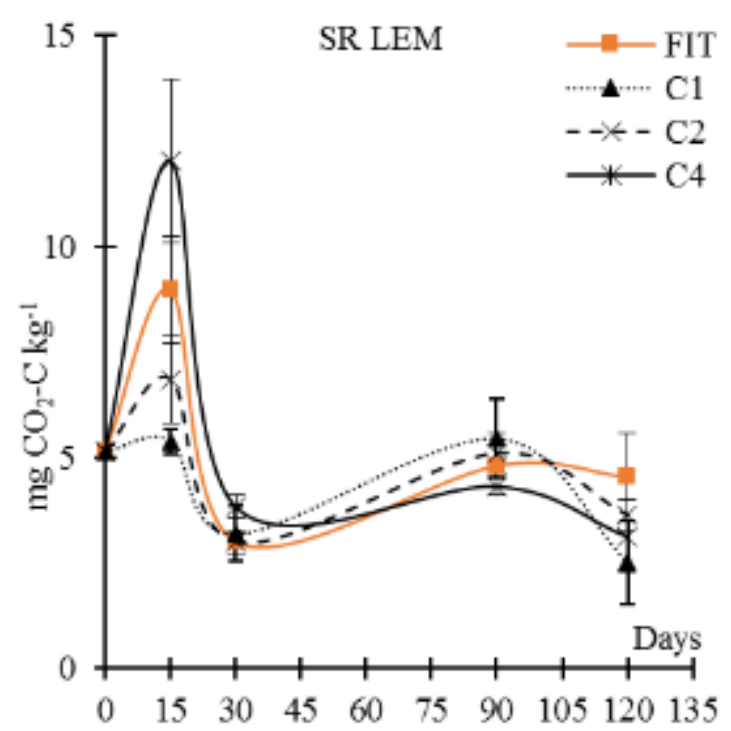

$\boldsymbol{B}$

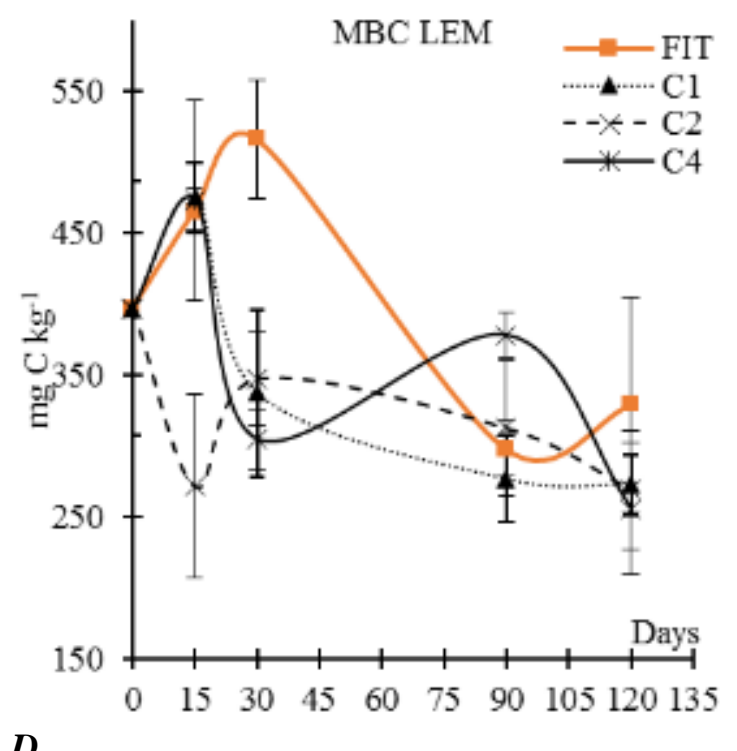

D

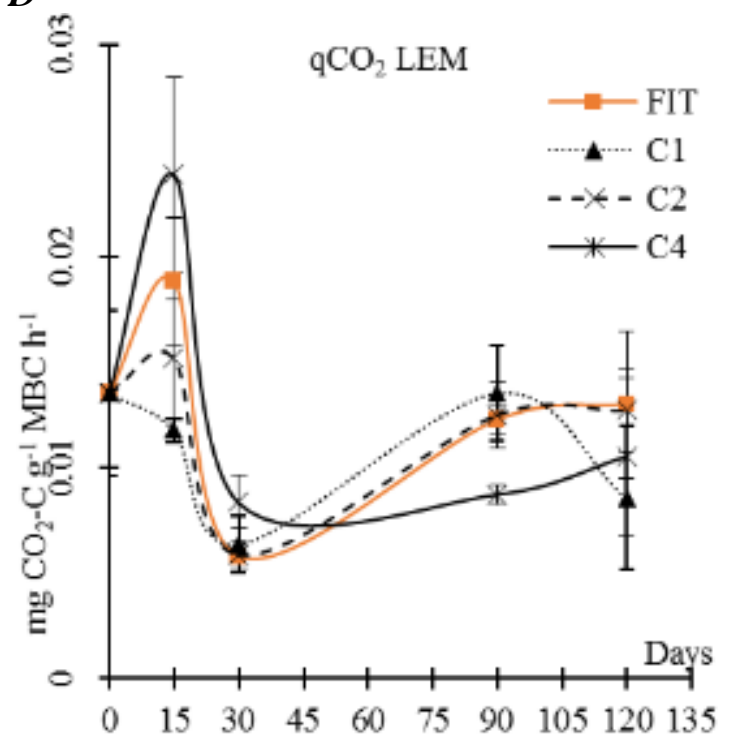

Figure 44: Biochemical soil variables determined at days 15, 30, 90 and 120 in the FIT (fitoil) and LEM (Citrus limon) treatments at different concentration (C1,C2 and C4 are, respectively, 1,2 and $4 \mathrm{~mL}$ of essential oil per litre of water)

A) $C_{\text {ext }}$ extractable organic carbon; B) $M B C$, microbial biomass carbon; C) SR, soil respiration; D) $q C O_{2}$, metabolic quotient. Reported results are means of three samples, bars are standard deviations. 
Even in the case of Citrus limon (L.) Osbeck essential oil treatments, the $4 \mathrm{mLL}^{-1}$ concentration played the bigger role in influencing variances (table 30). A short-term impact, on day 30, can be evidenced in the FAs and the Fun\% bioindicators (figures 45 a and f), while other variables will suffer EO treatments starting from day 90.

FAs was significantly higher after $\mathrm{C} 4$ treatment than the $\mathrm{C} 1$ and $\mathrm{C} 2$ one, to decrease on day 30, on the contrary in FIT, C1 and C2 a stimulatory effect springed between day 15 and 30. Such treatments followed a similar FAs bioindicator trend until day 90,

then in LEM EO treated soils FAs values drastically decreased becoming significantly lower than FIT ones. C4 treatment, on the other hand, allowed treated soils to store a bigger number of microbial FAs until day 90, when values collapsed reaching the other EO treatments ones.

Table 26: Significant (*, $P<0.05 ; * *, P<0.01 ; * * *, P<0.001 ;$ n.s, not significant) mean differences of soil microbial community bioindicators among treatments concentrations determined after 15, 30, 90 and 120 days since FIT and LEM treatments application

\begin{tabular}{lc|cccc}
\hline Dep. Var. & Ind. Var. & Day 15 & Day 30 & Day 90 & Day 120 \\
\hline FAs & C1 - FIT & n.s. & n.s. & n.s. & $-57.1^{*}$ \\
& C2 - FIT & n.s. & n.s. & n.s. & $-64.2^{* *}$ \\
& C4 - FIT & n.s. & n.s. & $103.4^{* * *}$ & $-48.8^{*}$ \\
Bac\% & C4 - C1 & $48.1^{*}$ & n.s. & $93.3^{* *}$ & n.s. \\
Gp\% & C4 - C2 & $52.6^{*}$ & n.s. & $86.2^{* *}$ & n.s. \\
& ALL & n.s. & n.s. & n.s. & n.s. \\
Gn\% & C4 - FIT & n.s. & n.s. & $-4.64^{* * *}$ & n.s. \\
& C4 - C1 & n.s. & n.s. & $-4.69^{* * *}$ & n.s. \\
& C4 - C2 & n.s. & n.s. & $-5.61^{* * *}$ & n.s. \\
& C1 - FIT & n.s. & n.s. & n.s. & $-3.24^{* *}$ \\
Fun\% & C2 - FIT & n.s. & $1.40^{*}$ & n.s. & $-3.74^{* *}$ \\
& C4 - FIT & n.s. & n.s. & $4.03^{* * *}$ & $-5.25^{* * *}$ \\
F_B & C4 - C1 & n.s. & n.s. & $4.24^{* * *}$ & n.s. \\
Gp_Gn & C4 - C2 & n.s. & n.s. & $4.09^{* * *}$ & n.s. \\
& FIT - C2 & $2.99 * *$ & n.s. & n.s. & n.s. \\
& FIT - C4 & $2.67 *$ & n.s. & n.s. & $-0.23^{* *}$ \\
Mes\% & FIT - C2 & $.074^{* *}$ & n.s. & n.s. & n.s. \\
& FIT - C4 & $.070^{*}$ & n.s. & n.s. & $-.005^{*}$ \\
& C4 - FIT & n.s. & n.s. & $-.479^{* * *}$ & $-.587^{*}$ \\
& C4 - C1 & n.s. & n.s. & $-.500^{* * *}$ & n.s. \\
C4 - C2 & n.s. & n.s. & $-.534^{* * *}$ & n.s. \\
C4 - FIT & n.s. & $-.862^{*}$ & n.s. & n.s. \\
C4 - C2 & n.s. & $-.951^{*}$ & n.s. & n.s. \\
C2 - C1 & n.s. & $.867 *$ & n.s. & n.s. \\
\hline
\end{tabular}

Data obtained by Tukey post-hoc test $(n=3)$ performed for each sampling day (15, 30, 90 and 120) assuming concentration (FIT, C1, C2, C4) as independent variable. FIT, Fitoil treated soils. LEM, C. limon EO emulsions treated soils; C1, C2 and C4, EO concentration in the emulsion, 1,2 and $4 \mathrm{mLEO} \mathrm{L}^{-1}$ water. FAs, microbial fatty acids (nmol $\mathrm{g}^{-1}$ soil); Bac\%, percentage of bacteria; Gp\%, percentage of Gram-positive bacteria; Gn\% percentage of Gram-negative bacteria; Gp_Gn, Gram-positive to Gram-negative ratio; Fun $\%$, percentage of fungi; $F \_B$, fungi to bacteria ratio; Mes\%, percentage of mesofauna

No significant differences in bacterial bioindicator emerged, while it is possible to underline (table 30 and figure $45 \mathrm{~b}$ and c) that on day 90 the $\mathrm{C} 4$ treated soils showed 
reversed reactions in Gram-positive and negative bioindicators. Gp was inhibited between day 30 and 90, while Gn was strongly stimulated until day 90 to reach the lower Gn\% level among LEM EO treated soils. This result is confirmed by the Gp_Gn bioindicator (figure $45 \mathrm{e})$.

Fungal community suffered a comparable inhibition after $\mathrm{C} 2$ and $\mathrm{C} 4$ treatments on day 15 only, as also the F_B bioindicator, and in neither of the two datasets C1 was different from FIT or the other concentrations.

The small animals living in soil (Mes\%) greatly diminished in abundance consequently to $\mathrm{C} 1$ and $\mathrm{C} 4$ treatments until day 30 , while $\mathrm{C} 2$ have an insignificant inhibitory effect only on day 90 .

A

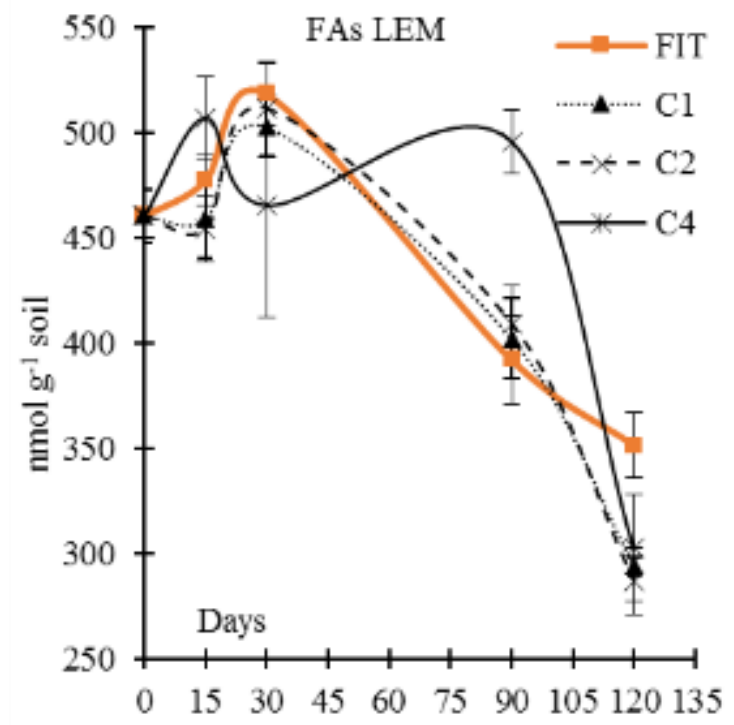

C

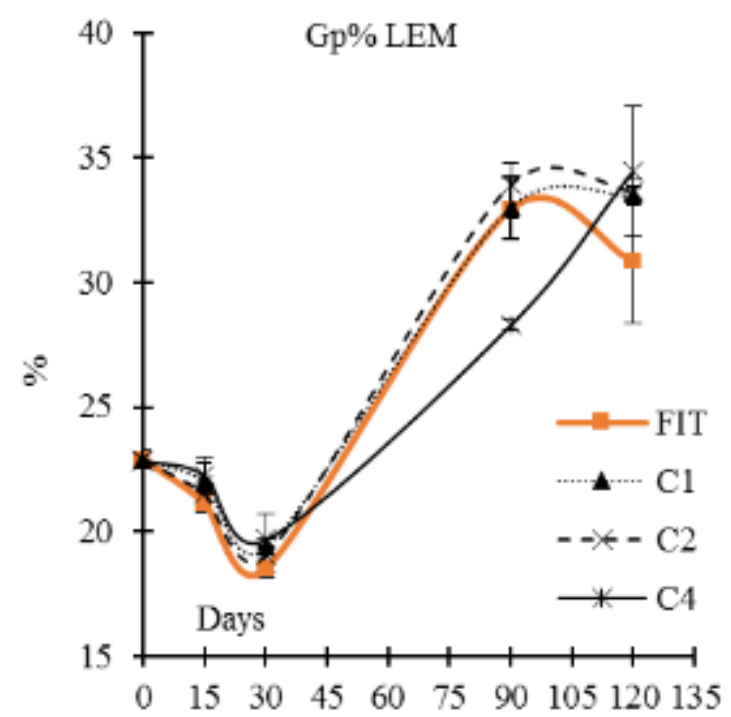

B

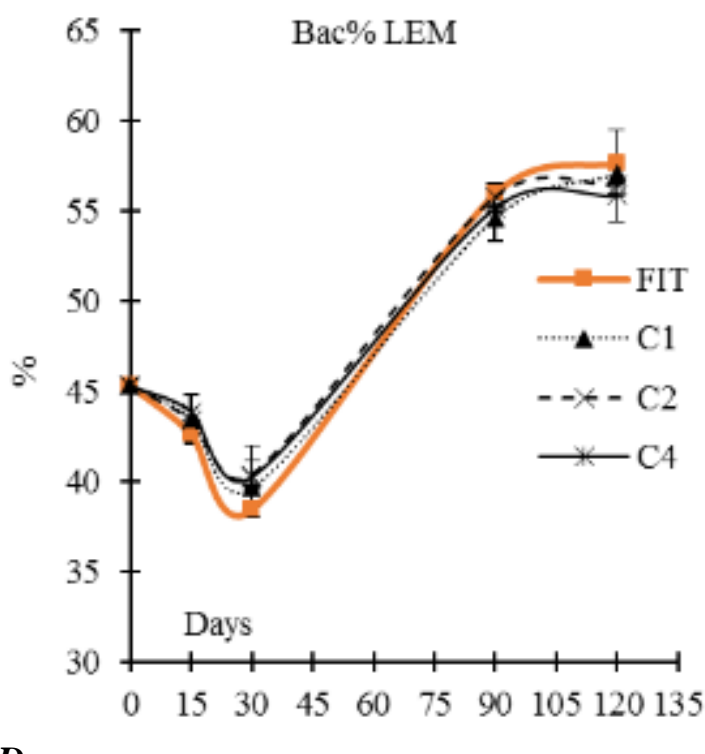

D

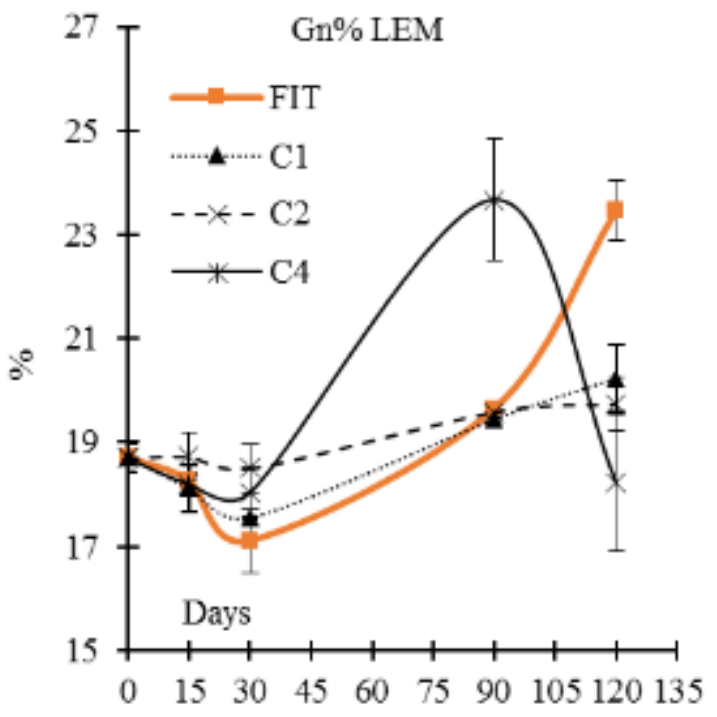


$\boldsymbol{E}$

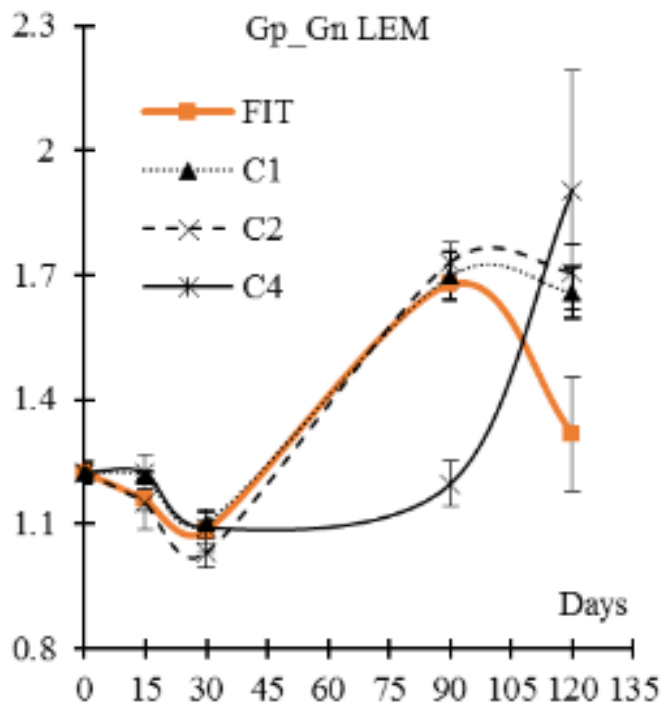

G

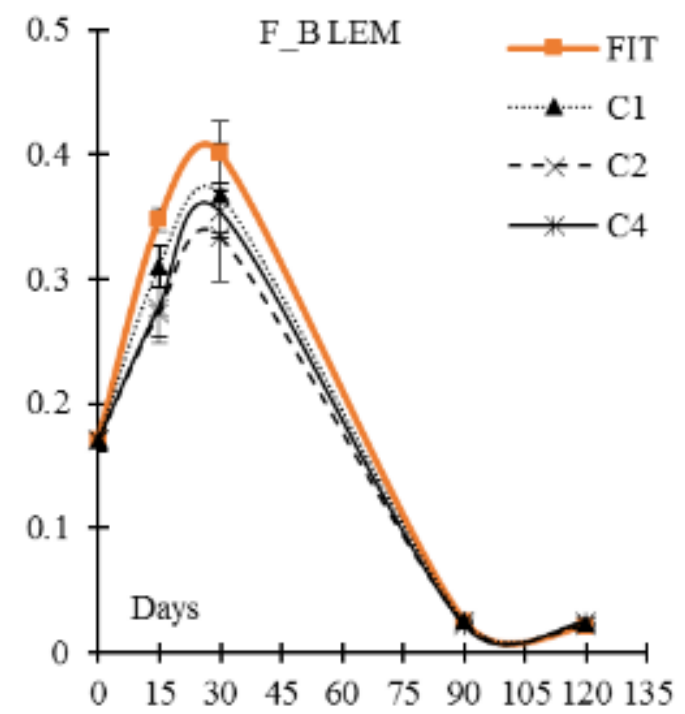

F

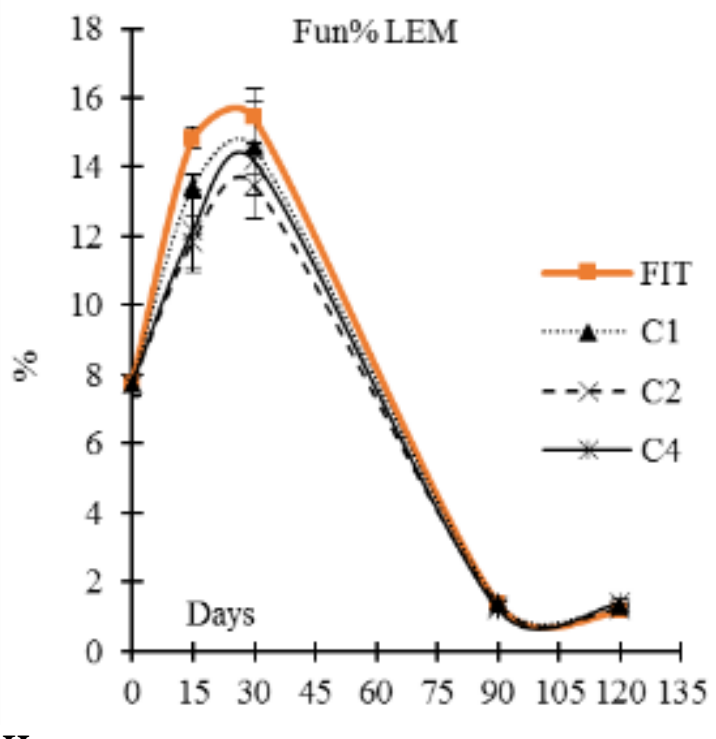

$\boldsymbol{H}$

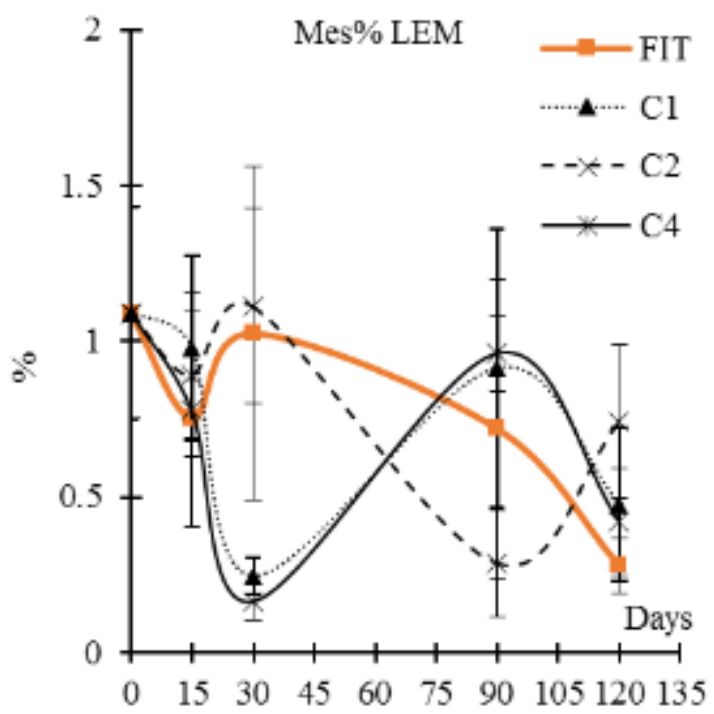

Figure 45: Microbial community structure determined at days 15, 30, 90 and 120 in the FIT (fitoil) and LEM (Citrus limon) treatments at different concentration (C1, C2 and C4 are, respectively, 1,2 and $4 \mathrm{~mL}$ of essential oil per litre of water)

A) FAs, microbial fatty acids; B) Bac\%, percentage of bacteria; C) Gp\%, percentage of Gram-positive bacteria; D) Gn\% percentage of Gram-negative bacteria; E) Gp_Gn, Gram-positive to Gram-negative ratio; $F$ ) $F u n \%$, percentage of fungi; $G) F_{-} B$, fungi to bacteria ratio; $\left.H\right)$ Mes $\%$, percentage of mesofauna. Showed values represents the mean values, bars are standard deviation $(n=3)$. 


\subsubsection{TAN}

It is interesting to evidence that according to ANOVA post-hoc test, the dependent variables MBC and SR are not significantly different comparing TAN C4 and Fitoil treatments. MBC of the $\mathrm{C} 2$ treated soils reached significantly lower values than the $\mathrm{C} 1$ and Fitoil treated samples on day 90 only. Consequently, also soil respiration mean difference between $\mathrm{C} 2$ and $\mathrm{C} 1$ was significant on day 90. It is also significant on day 15 among Fitoil and $\mathrm{C} 2$.

Soil respiration was significantly more efficient in all EO treated soils than in the Fitoil control on day 15 only.

Fitoil treatment and the tangerine EO ones followed a very different $\mathrm{C}_{\mathrm{ext}}$ trend. Fitoil treated soils maintained $\mathrm{C}_{\text {ext }}$ constant values during the first 3 sampling days and dropped on day 120, on the contrary extractable carbon in Citrus reticulata Blanco EO treated samples growth on day 15 and 30 and then drops near the day 0 value.

Table 27: Significant (*, $P<0.05$; **, $P<0.01$; ***, $P<0.001$; n.s, not significant) mean differences of soil biochemical properties among treatments concentrations determined after 15, 30, 90 and 120 days since FIT and TCP treatments application

\begin{tabular}{|c|c|c|c|c|c|}
\hline Dep. Var. & Ind. Var. & Day 15 & Day 30 & Day 90 & Day 120 \\
\hline \multirow[t]{5}{*}{ Cext } & FIT - C1 & n.s. & n.s. & $82.4 * * *$ & n.s. \\
\hline & $\mathrm{FIT}-\mathrm{C} 2$ & n.s. & n.s. & $65.0 * * *$ & n.s. \\
\hline & $\mathrm{FIT}-\mathrm{C} 4$ & n.s. & n.s. & $65.4 * * *$ & n.s. \\
\hline & $\mathrm{C} 4-\mathrm{C} 1$ & $33.5 *$ & n.s. & n.s. & n.s. \\
\hline & $\mathrm{C} 4-\mathrm{C} 2$ & $29.6^{*}$ & n.s. & n.s. & n.s. \\
\hline \multirow[t]{2}{*}{ MBC } & $\mathrm{FIT}-\mathrm{C} 2$ & n.s. & n.s. & $-1.90 * *$ & n.s. \\
\hline & $\mathrm{C} 1-\mathrm{C} 2$ & n.s. & n.s. & $-1.30 *$ & n.s. \\
\hline \multirow[t]{2}{*}{ SR } & $\mathrm{C} 1-\mathrm{C} 2$ & n.s. & n.s. & $-1.29 *$ & n.s. \\
\hline & $\mathrm{FIT}-\mathrm{C} 2$ & $3.37 *$ & n.s. & n.s. & n.s. \\
\hline \multirow[t]{3}{*}{$\mathrm{qCO}_{2}$} & $\mathrm{FIT}-\mathrm{C} 1$ & $0.01 *$ & n.s. & n.s. & n.s. \\
\hline & $\mathrm{FIT}-\mathrm{C} 2$ & $0.01 *$ & n.s. & n.s. & n.s. \\
\hline & $\mathrm{FIT}-\mathrm{C} 4$ & $0.01 *$ & n.s. & n.s. & n.s. \\
\hline
\end{tabular}

Data obtained by Tukey post-hoc test ( $n=3)$ performed for each sampling day (15, 30, 90 and 120) assuming concentration (FIT, C1, C2, C4) as independent variable. FIT, Fitoil treated soils. TAN, C. reticulata EO emulsions treated soils; $C 1, C 2$ and C4, EO concentration in the emulsion, 1,2 and $4 \mathrm{~mL} E O \mathrm{~L}^{-1}$ water. $C_{\text {ext, }}$ extractable organic carbon; $M B C$, microbial biomass carbon; $S R$, soil respiration; $q C_{2}$, metabolic quotient.

In figure $46 \mathrm{a}$, it is possible to observe two different reaction rhythms in FAs amount. In every Citrus reticulata Blanco essential oil treated soil such bioindicator reached higher values than in Fitoil samples, on day 15 for $\mathrm{C} 1$ and on day 30 for $\mathrm{C} 2$ and $\mathrm{C} 4$. At the end of the experiment in $\mathrm{C} 2$ treated soil FAs content was higher than in $\mathrm{C} 1$ and $\mathrm{C} 4$.

C2 treatment has a different effect also on bacteria, as both Gp and Gn was stimulated by this treatment on day 15. Gp population suffered other slight EO influences on day 120. In C4 treated soils Gn was always lower than FIT, while in C2 and C4 ones. Significantly 
higher values were detected on day 90. All the Gn values was lower in tangerine EO treated soils than in the Fitoil ones on day 120. In table 28 the Gram-positive to negative ration confirms that differences between Gp and Gn abundances appeared on medium-long term, since day 90.

In figure $47 \mathrm{f}$ and $\mathrm{g}$ and in table 31 it is possible to observe again a similar trend of $\mathrm{C} 1$ and 4 treatments compared to $\mathrm{C} 2$, the only inhibiting fungal development on day 15 and 30. Very smaller was the significant differences on day 120.

$\boldsymbol{A}$

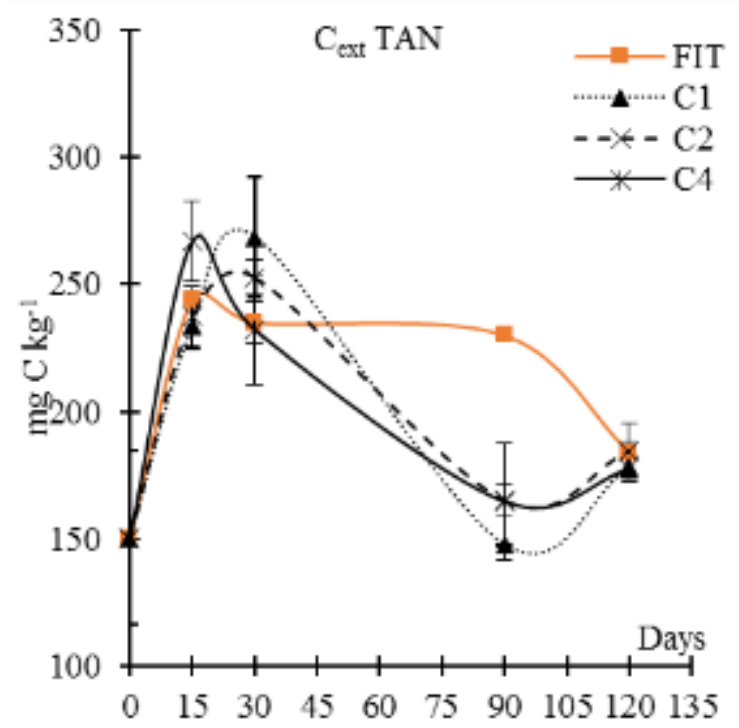

$\boldsymbol{B}$

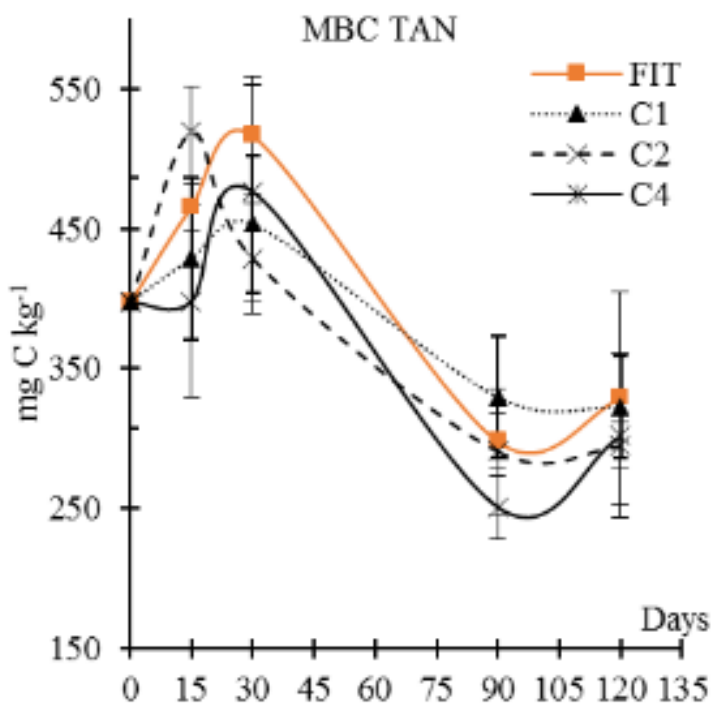

D

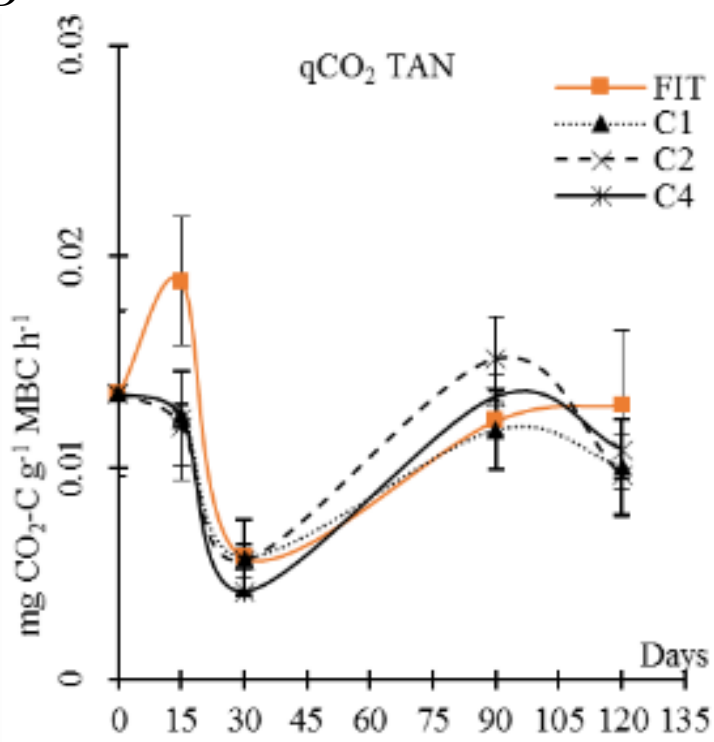

Figure 46: Biochemical soil variables determined at days 15, 30, 90 and 120 in the FIT (fitoil) and TAN (Citrus reticulata) treatments at different concentration (C1,C2 and C4 are, respectively, 1,2 and $4 \mathrm{~mL}$ of essential oil per litre of water)

A) $C_{\text {ext }}$, extractable organic carbon; B) $M B C$, microbial biomass carbon; $\left.C\right) S R$, soil respiration; D) $q C O_{2}$, metabolic quotient. Reported results are means of three samples, bars are standard deviations. 
Oddo M. - Effects of different weed control practices on soil quality in mediterranean crops

Table 28: Significant (*, $P<0.05 ; * *, P<0.01$; ***, $P<0.001 ;$ n.s, not significant) mean differences of soil microbial community bioindicators among treatments concentrations determined after 15, 30, 90 and 120 days since FIT and TAN treatments application

\begin{tabular}{|c|c|c|c|c|c|}
\hline Dep. Var. & Ind. Var. & Day 15 & Day 30 & Day 90 & Day 120 \\
\hline \multirow[t]{4}{*}{ FAs } & FIT - C1 & $-81.4^{*}$ & n.s. & n.s. & n.s. \\
\hline & FIT - C4 & $-89.1 *$ & n.s. & n.s. & n.s. \\
\hline & $\mathrm{C} 2-\mathrm{C} 1$ & $-87.3^{*}$ & n.s. & n.s. & n.s. \\
\hline & $\mathrm{C} 2$ - C4 & $-95.0 *$ & n.s. & n.s. & $113^{*}$ \\
\hline \multirow[t]{5}{*}{ Вас\% } & C1 - FIT & $-3.42 * * *$ & n.s. & n.s. & n.s. \\
\hline & $\mathrm{C} 1-\mathrm{C} 2$ & $-6.67 * * *$ & n.s. & n.s. & n.s. \\
\hline & C1 - C4 & $-2.54 * *$ & n.s. & n.s. & n.s. \\
\hline & C2 - FIT & $3.25 * * *$ & n.s. & n.s. & n.s. \\
\hline & $\mathrm{C} 2-\mathrm{C} 4$ & $4.13 * * *$ & n.s. & n.s. & n.s. \\
\hline \multirow[t]{5}{*}{ Gp\% } & C1 - FIT & $-1.66^{* *}$ & n.s. & n.s. & n.s. \\
\hline & $\mathrm{C} 1-\mathrm{C} 2$ & $-3.46 * * *$ & n.s. & n.s. & n.s. \\
\hline & $\mathrm{C} 1-\mathrm{C} 4$ & $-1.54 * *$ & n.s. & $-2.17 *$ & n.s. \\
\hline & C2 - FIT & $1.80 * *$ & n.s. & n.s. & n.s. \\
\hline & $\mathrm{C} 2-\mathrm{C} 4$ & $1.92 * * *$ & n.s. & n.s. & n.s. \\
\hline \multirow[t]{6}{*}{ Gn\% } & C1 - FIT & $-1.51 * *$ & n.s. & $3.69 * * *$ & $-2.90 * *$ \\
\hline & $\mathrm{C} 1-\mathrm{C} 2$ & $-2.78 * * *$ & n.s. & n.s. & $-2.03 *$ \\
\hline & $\mathrm{C} 1-\mathrm{C} 4$ & $-0.85^{*}$ & n.s. & $3.11 * * *$ & $1.84^{*}$ \\
\hline & C2 - FIT & $1.28 * *$ & n.s. & $2.55 * * *$ & n.s. \\
\hline & $\mathrm{C} 2-\mathrm{C} 4$ & $1.93 * * *$ & n.s. & $1.97 * *$ & $3.87 * * *$ \\
\hline & FIT - C4 & n.s. & n.s. & n.s. & $4.74 * * *$ \\
\hline \multirow[t]{5}{*}{ Fun\% } & C2 - FIT & $-3.25 * * *$ & n.s. & n.s. & n.s. \\
\hline & $\mathrm{C} 2-\mathrm{C} 1$ & $-4.21 * * *$ & n.s. & n.s. & n.s. \\
\hline & $\mathrm{C} 2-\mathrm{C} 4$ & $-3.04 * * *$ & $-5.75 * *$ & n.s. & $-0.29 *$ \\
\hline & $\mathrm{C} 1-\mathrm{C} 4$ & $1.17 *$ & $-4.30 * *$ & n.s. & n.s. \\
\hline & FIT - C4 & n.s. & $-4.90 * *$ & n.s. & $-0.27 *$ \\
\hline \multirow[t]{6}{*}{ F_B } & C1 - FIT & $.055^{* *}$ & n.s. & n.s. & n.s. \\
\hline & $\mathrm{C} 1-\mathrm{C} 2$ & $.150 * * *$ & n.s. & n.s. & n.s. \\
\hline & $\mathrm{C} 1-\mathrm{C} 4$ & $.052 * *$ & $-.177 *$ & n.s. & n.s. \\
\hline & C2 - FIT & $-.095 * * *$ & n.s. & n.s. & n.s. \\
\hline & $\mathrm{C} 2-\mathrm{C} 4$ & $-.098 * * *$ & $-.213^{*}$ & n.s. & $-.006^{*}$ \\
\hline & FIT - C4 & n.s. & $-.214^{*}$ & n.s. & $-.005^{*}$ \\
\hline \multirow[t]{6}{*}{ Gp_Gn } & C1 - FIT & n.s. & n.s. & $-.319 * * *$ & $.301 *$ \\
\hline & $\mathrm{C} 1-\mathrm{C} 2$ & n.s. & n.s. & $-.112 *$ & n.s. \\
\hline & $\mathrm{C} 1-\mathrm{C} 4$ & n.s. & n.s. & $-.316 * * *$ & n.s. \\
\hline & C2 - FIT & n.s. & n.s. & $-.207 * * *$ & n.s. \\
\hline & $\mathrm{C} 2-\mathrm{C} 4$ & n.s. & n.s. & $-.204 * * *$ & $-.403 * *$ \\
\hline & FIT - C4 & n.s. & n.s. & n.s. & $-.508 * * *$ \\
\hline Mes\% & ALL & n.s. & n.s. & n.s. & n.s. \\
\hline
\end{tabular}

Data obtained by Tukey post-hoc test $(n=3)$ performed for each sampling day (15, 30, 90 and 120) assuming concentration (FIT, C1, C2, C4) as independent variable. FIT, Fitoil treated soils. TAN, C. reticulata EO

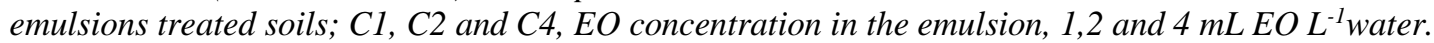
FAs, microbial fatty acids ( $n$ mol $g^{-1}$ soil); Bac\%, percentage of bacteria; $\mathrm{G} p \%$, percentage of Gram-positive bacteria; Gn\% percentage of Gram-negative bacteria; Gp_Gn, Gram-positive to Gram-negative ratio; Fun $\%$, percentage of fungi; $F \_B$, fungi to bacteria ratio; Mes $\%$, percentage of mesofauna. 
A

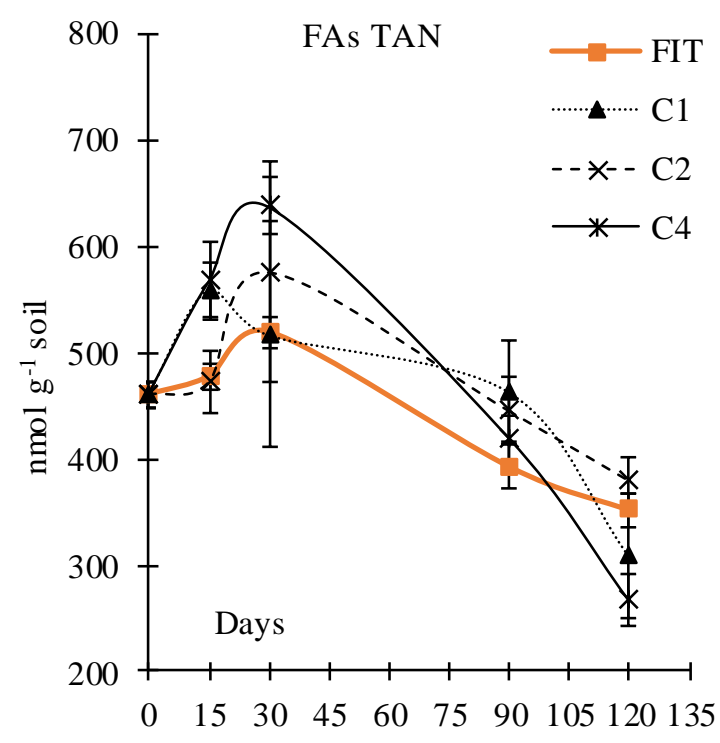

C

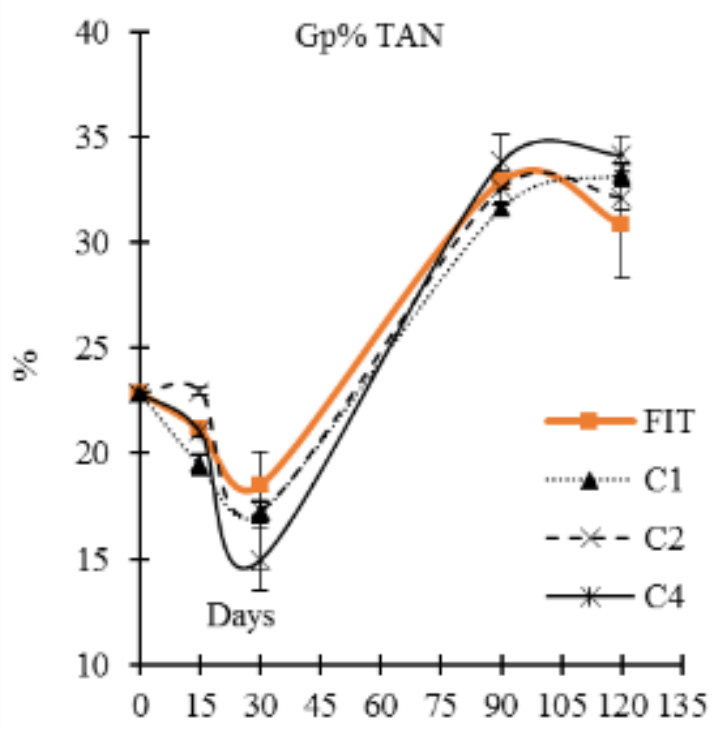

E

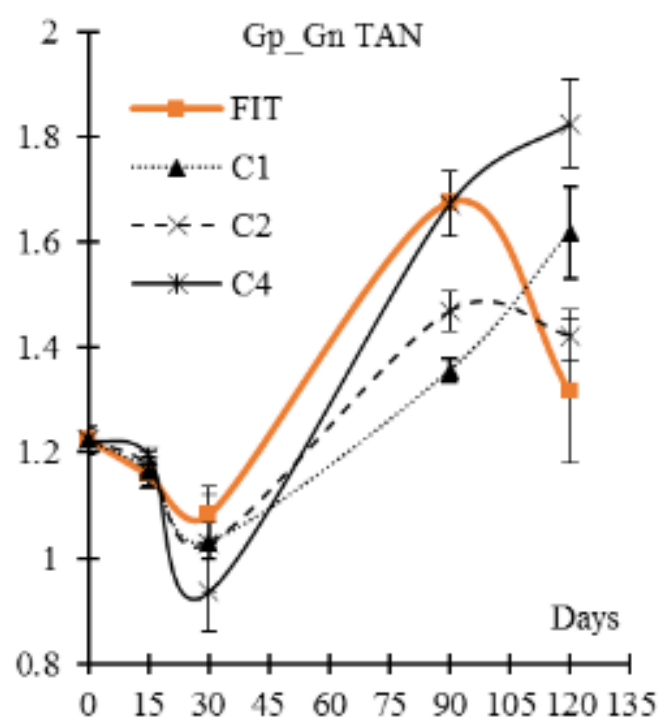

B

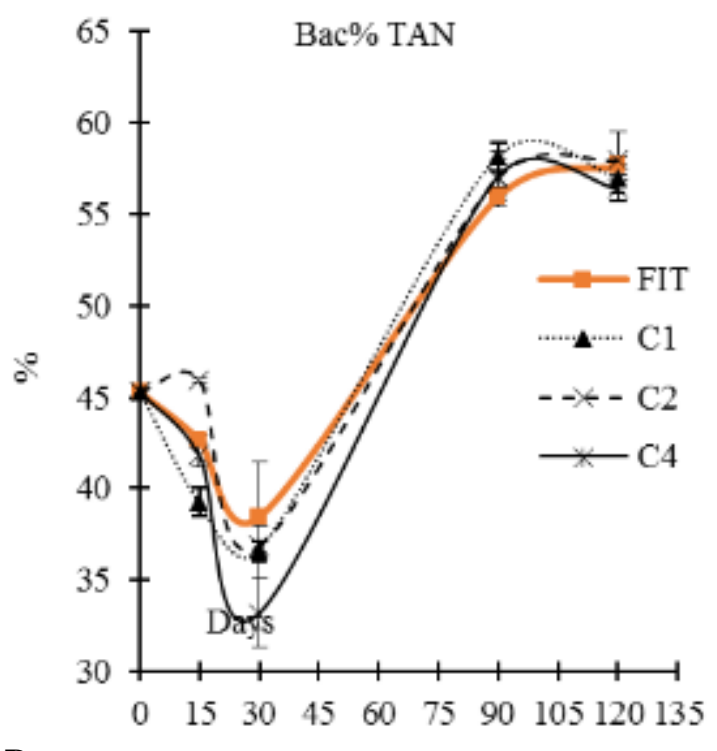

D

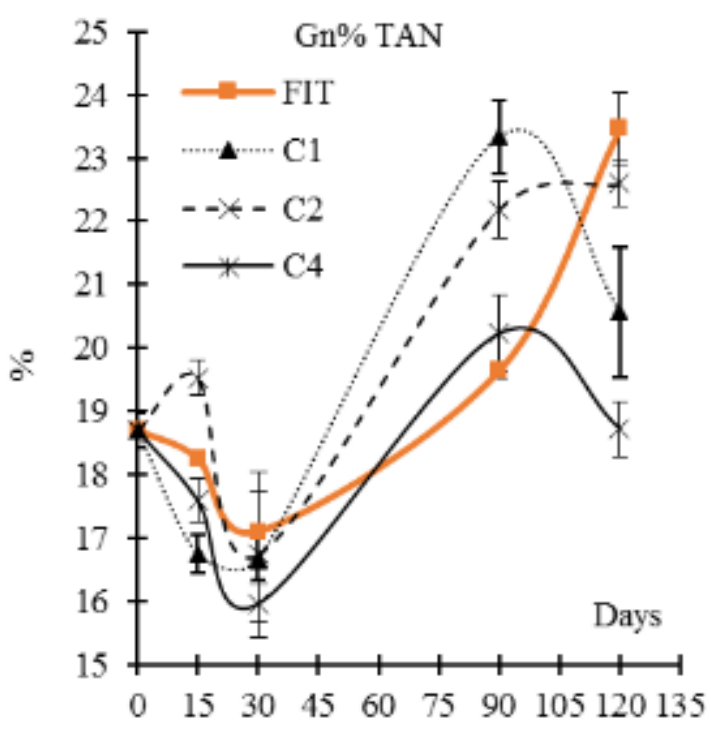

F

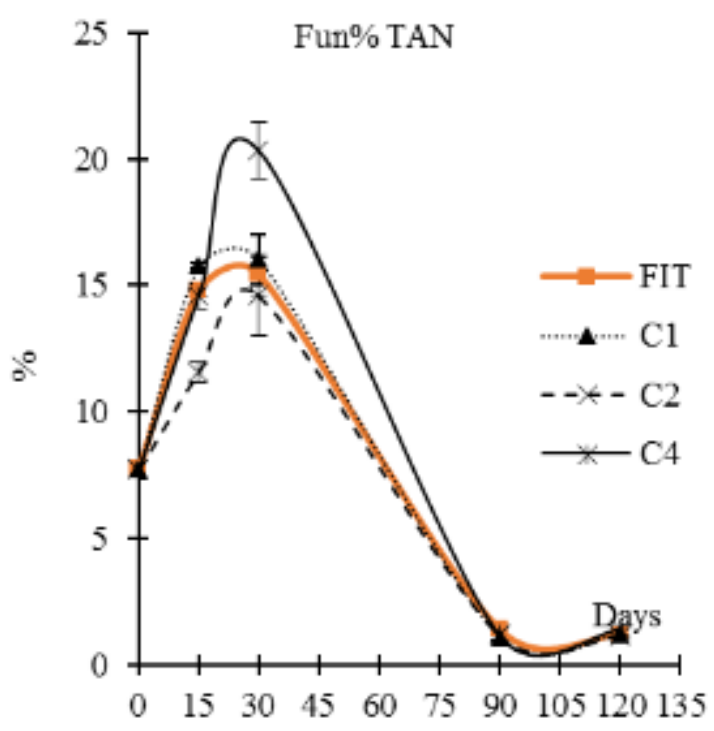


$\boldsymbol{G}$

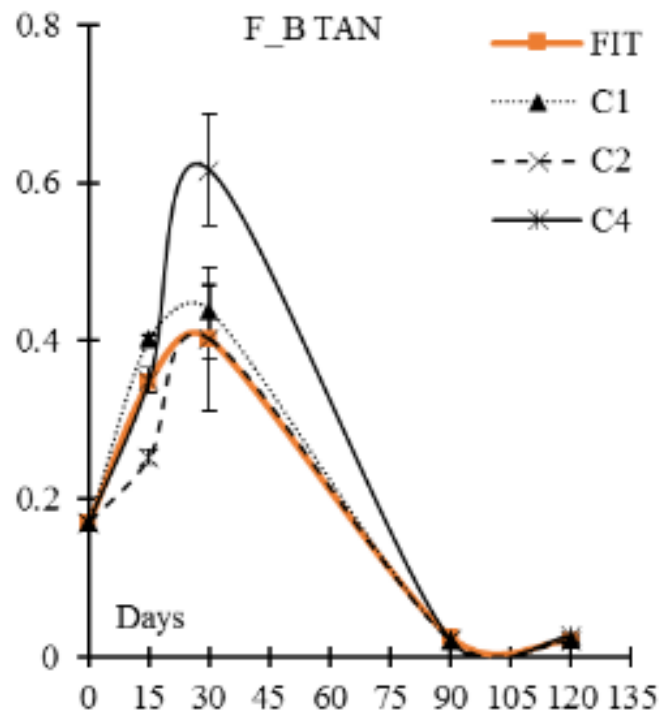

$\boldsymbol{H}$

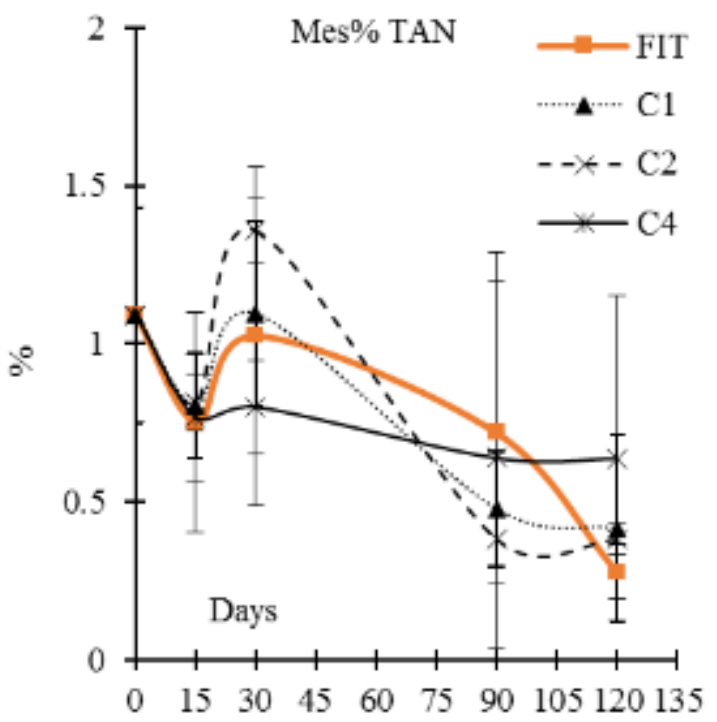

Figure 47: Microbial community structure determined at days 15, 30, 90 and 120 in the FIT (fitoil) and TAN (Citrus reticulata) treatments at different concentration (C1, C2 and C4 are, respectively, 1,2 and $4 \mathrm{~mL}$ of essential oil per litre of water)

A) FAs, microbial fatty acids; B) Bac\%, percentage of bacteria; C) Gp\%, percentage of Gram-positive bacteria; D) Gn\% percentage of Gram-negative bacteria; E) Gp_Gn, Gram-positive to Gram-negative ratio; $F$ ) $F u n \%$, percentage of fungi; $G) F \_B$, fungi to bacteria ratio; $\left.H\right)$ Mes\%, percentage of mesofauna. Showed values represents the mean values, bars are standard deviation $(n=3)$. 


\subsubsection{5 $\underline{T C P}$}

Changes in $\mathrm{C}_{\mathrm{ext}}$ content starts on day 30 , when to the decrease of MBC due to $\mathrm{C} 4$ treatments, it corresponds a significant increase of $\mathrm{C}_{\mathrm{ext}}$ compared to the other treatments. In all the thyme $\mathrm{EO}$ treated soils $\mathrm{C}_{\text {ext }}$ decreased since day 30 till day 90 , to have a small reprise on day 120, when no significant differences persisted.

Soil respiration amount and efficiency data on first sampling day disagrees with evidences just explained on carbon content, as to the microbiocidal effect of $\mathrm{C} 4$ treatment.

Thymbra capitata (L.) Cav. EO have not had a strong short-term effect on biochemical soil variables, while significant effects emerged in medium-term reaction. Only in MBC data, there are differences among $\mathrm{C} 1$ and the greater concentrations and not with Fitoil.

Table 29: Significant (*, $P<0.05 ; * *, P<0.01 ; * * *, P<0.001 ;$ n.s, not significant) mean differences of soil biochemical properties among treatments concentrations determined after 15, 30, 90 and 120 days since FIT and TCP treatments application

\begin{tabular}{|c|c|c|c|c|c|}
\hline Dep. Var. & Ind. Var. & Day 15 & Day 30 & Day 90 & Day 120 \\
\hline \multirow[t]{5}{*}{$\mathrm{C}_{\text {ext }}$} & $\mathrm{FIT}-\mathrm{C} 1$ & n.s. & n.s. & 86.0 *** & n.s. \\
\hline & $\mathrm{FIT}-\mathrm{C} 2$ & n.s. & n.s. & $59.4 * * *$ & n.s. \\
\hline & C4 - FIT & n.s. & $44.4^{* *}$ & $-75.0 * * *$ & n.s. \\
\hline & $\mathrm{C} 4-\mathrm{C} 1$ & n.s. & $61.3 * * *$ & n.s. & n.s. \\
\hline & $\mathrm{C} 4-\mathrm{C} 2$ & n.s. & $50.6^{* *}$ & n.s. & n.s. \\
\hline \multirow[t]{5}{*}{ MBC } & $\mathrm{FIT}-\mathrm{C} 2$ & n.s. & n.s. & $98.9 *$ & n.s. \\
\hline & $\mathrm{FIT}-\mathrm{C} 4$ & n.s. & $233.3^{* *}$ & n.s. & n.s. \\
\hline & $\mathrm{C} 1-\mathrm{C} 2$ & $178.8^{*}$ & n.s. & n.s. & n.s. \\
\hline & $\mathrm{C} 1-\mathrm{C} 4$ & $167.1^{*}$ & $218.9 * *$ & n.s. & n.s. \\
\hline & $\mathrm{C} 2-\mathrm{C} 4$ & n.s. & $160.6^{*}$ & n.s. & n.s. \\
\hline \multirow[t]{2}{*}{ SR } & $\mathrm{FIT}-\mathrm{C} 1$ & n.s. & $-2.8 * *$ & n.s. & n.s. \\
\hline & $\mathrm{C} 1-\mathrm{C} 4$ & n.s. & $3.1 * *$ & $-1.61 *$ & n.s. \\
\hline \multirow[t]{3}{*}{$\mathrm{qCO}_{2}$} & $\mathrm{FIT}-\mathrm{C} 1$ & n.s. & $-0.01 * *$ & n.s. & n.s. \\
\hline & $\mathrm{C} 1-\mathrm{C} 2$ & n.s. & $0.01 *$ & n.s. & n.s. \\
\hline & $\mathrm{C} 1-\mathrm{C} 4$ & n.s. & $0.01 * *$ & n.s. & $-0.01 *$ \\
\hline
\end{tabular}

Data obtained by tukey post-hoc test $(n=3)$ performed for each sampling day (15, 30, 90 and 120) assuming concentration (FIT, C1, C2, C4) as independent variable. FIT, Fitoil treated soils. TCP, T. capitata EO

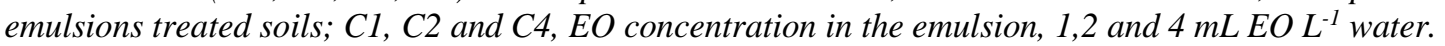

$C_{\text {ext }}$, extractable organic carbon; $M B C$, microbial biomass carbon; $S R$, soil respiration; $q C_{2}$, metabolic quotient.

In figure $48 \mathrm{~b}$ it is possible to visualize how $\mathrm{MBC}$ trends during the experimental period are dependent by the emulsion concentration. $\mathrm{MBC}$ in soils treated with the smallest concentration of Thymbra capitata (L.) Cav. EO shows a very similar trend with Fitoil treatment during all the 120 days. On the contrary C2 and C4 treated soil have had an opposite reaction to $T$. capitata EO, decreasing 15 days after treatments pulverization instead to increase as in $\mathrm{C} 1$ and Fitoil treated soils.

C4 continued to negatively influence soil MBC till day 90 to have a small regain on day 20 , while the microbiocidal effects of $\mathrm{C} 2$ is statistically insignificant on day 30 and 120 .on 
day 15, it corresponds an increase of both $\mathrm{SR}$ and $\mathrm{qCO}_{2}$ (graphics $49 \mathrm{c}$ and d), and on day 30 these variables are equivalent in $\mathrm{C} 4$ and Fitoil treatments.

$\mathrm{C} 1$ was the treatment which caused the most different soil respiration trend compared to the others (tab 29), having SR a slower decrease between day 15 and 30, and continued decreasing until the end of the experiment. Another slight significant difference in metabolic quotient emerged on day 120, with higher values in $\mathrm{C} 4$ treated soils than in $\mathrm{C} 1$.

$\boldsymbol{A}$

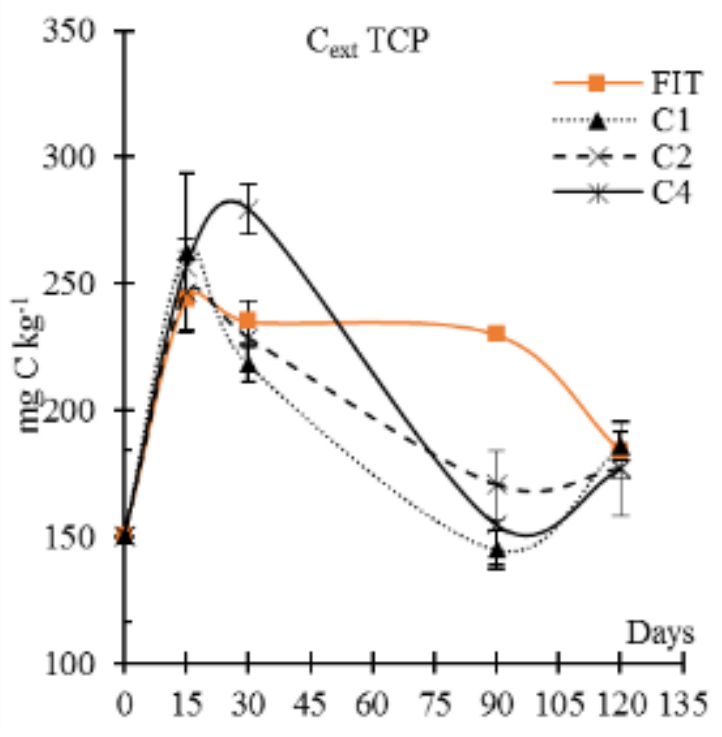

$C$

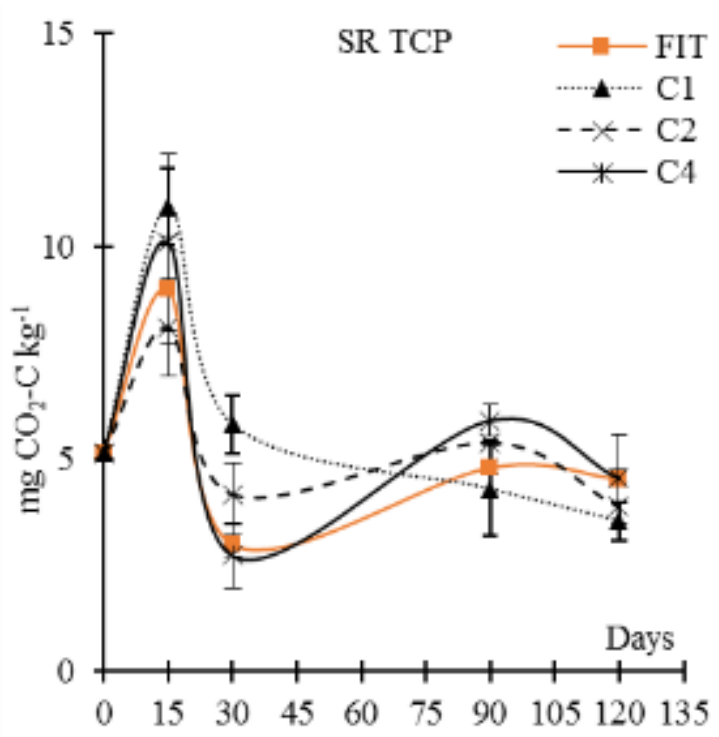

B

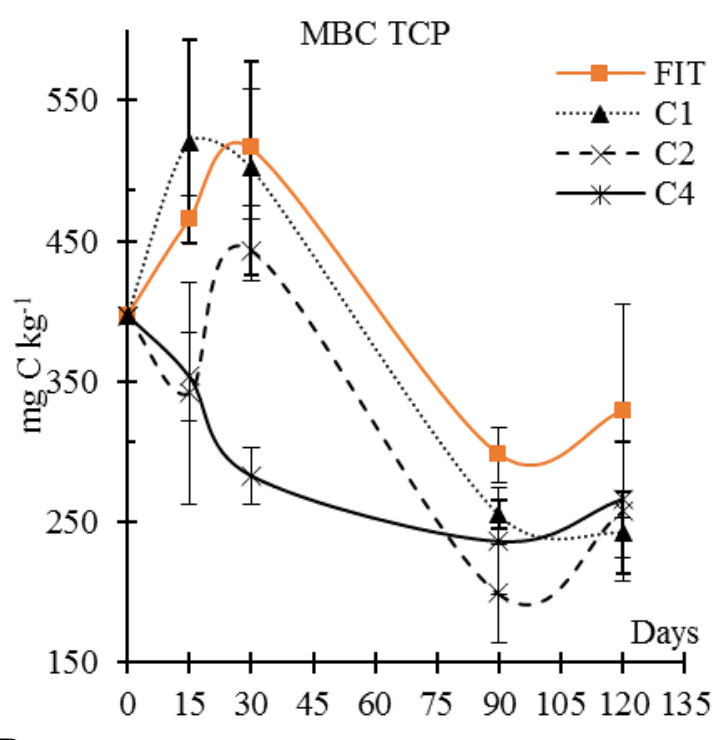

$D$

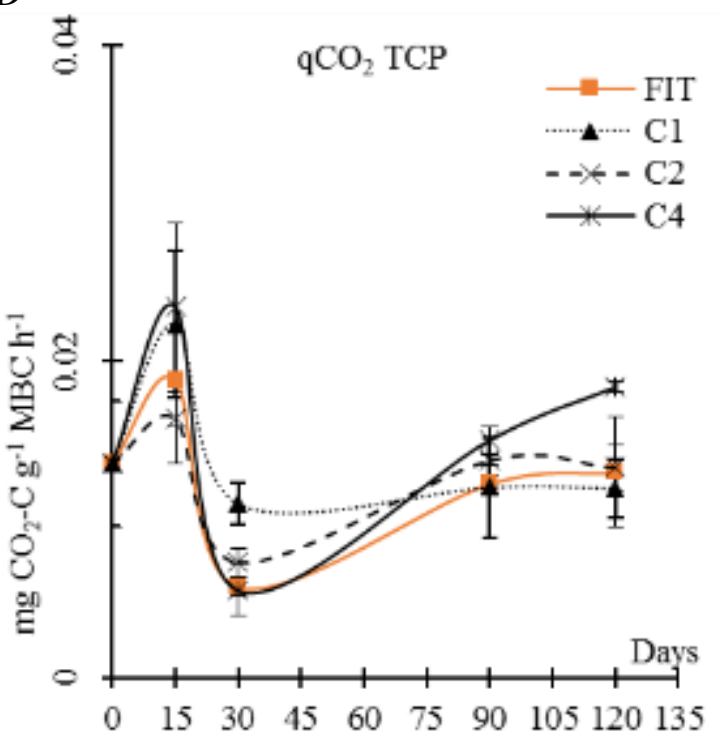

Figure 48: Biochemical soil variables determined at days 15, 30, 90 and 120 in the FIT (fitoil) and TCP (Thymbra capitata) treatments at different concentration (C1, C2 and C4 are, respectively, 1,2 and $4 \mathrm{~mL}$ of essential oil per litre of water)

A) $C_{\text {ext }}$ extractable organic carbon; $\left.B\right) M B C$, microbial biomass carbon; C) SR, soil respiration; D) $q C O_{2}$, metabolic quotient. Reported results are means of three samples, bars are standard deviations. 
Thymbra capitata (L.) Cav. essential oil treatments caused the smaller significant influence on microbial community structure, affecting only bacteria. On day 15 , only in the C2 treated soils, Gp\% bioindicator was significantly higher than the Fitoil ones, as also Gn\% on day 30. Added together the increase of bacteria makes significant the increase of total FAs amount on day 30 comparing $\mathrm{C} 2$ treated soils to the $\mathrm{C} 4$ ones.

Since day 30 and until day 90 in $\mathrm{C} 4$ treated soil Gn population growth much more than in the other samples, dragging up also the Bac\% bioindicator. On the other hand, in $\mathrm{C} 1$ treated soils total FAs amount drastically decreased reaching significantly lower values than the other treatments. On day 120 only a residual activity of C4 treatment negatively affects FAs bioindicator. In $\mathrm{C} 1$ treated soils $\mathrm{Gp} \%$ growth more than in the Fitoil ones, on the contrary in Gn\% ending values in EO treated soils was all lower than the Fitoil control, and the differences are strictly driven by the treatment concentration.

Table 30: Significant (*, $P<0.05$; **, $P<0.01 ; * * *, P<0.001$; n.s, not significant) mean differences of soil microbial community bioindicators among treatments concentrations determined after 15, 30, 90 and 120 days since FIT and TCP treatments application

\begin{tabular}{lc|cccc}
\hline Dep. Var. & Ind. Var. & Day 15 & Day 30 & Day 90 & Day 120 \\
\hline FAs & C2 - C4 & n.s. & $76.2^{*}$ & n.s. & n.s. \\
& C1 - FIT & n.s. & n.s. & $-35.5^{*}$ & n.s. \\
& C1 - C2 & n.s. & n.s. & $-34.9^{*}$ & n.s. \\
Bac\% & C1 - C4 & n.s. & n.s. & $-36.0^{*}$ & n.s. \\
& FIT - C4 & n.s. & n.s. & n.s. & $104.6^{*}$ \\
Gp\% & C4 - FIT & n.s. & n.s. & $1.79^{*}$ & n.s. \\
& C4 - C1 & n.s. & n.s. & $2.00^{* *}$ & n.s. \\
Gn\% & C2 - C1 & n.s. & n.s. & $1.40^{*}$ & n.s. \\
& FIT - C2 & $-1.36^{*}$ & n.s. & n.s. & n.s. \\
& FIT - C1 & n.s. & n.s. & n.s. & $-8.83^{*}$ \\
FIT - C1 & n.s. & n.s. & n.s. & $7.65^{* * *}$ \\
Fun\% & FIT - C2 & n.s. & $-1.74 * *$ & n.s. & $7.01^{* * *}$ \\
F_B & C4 - FIT & n.s. & n.s. & $2.08^{* * *}$ & $-3.69^{* *}$ \\
Gp_Gn & C4 - C1 & n.s. & n.s. & $2.10^{* * *}$ & $3.95^{* *}$ \\
& C4 - C2 & n.s. & n.s. & $1.31^{* *}$ & $3.32^{*}$ \\
& ALL & n.s. & n.s. & n.s. & n.s. \\
ALL & n.s. & n.s. & n.s. & n.s. \\
Mes\% & FIT - C1 & n.s. & n.s. & n.s. & $-1.22^{* *}$ \\
\hline Fata - C2 & n.s. & n.s. & n.s. & $-.894^{*}$
\end{tabular}

Data obtained by Tukey post-hoc test $(n=3)$ performed for each sampling day $(15,30,90$ and 120$)$ assuming concentration (FIT, C1, C2, C4) as independent variable. FIT, Fitoil treated soils. TCP, T. capitata EO

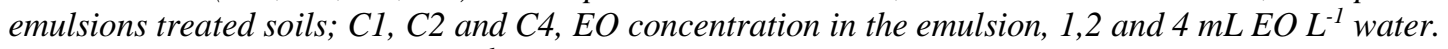
FAs, microbial fatty acids ( $\mathrm{nmol}^{-1}$ soil); Bac\%, percentage of bacteria; Gp\%, percentage of Gram-positive bacteria; Gn\% percentage of Gram-negative bacteria; Gp_Gn, Gram-positive to Gram-negative ratio; Fun $\%$, percentage of fungi; $F_{-} B$, fungi to bacteria ratio; Mes\%, percentage of mesofauna. 
Oddo M. - Effects of different weed control practices on soil quality in mediterranean crops

A

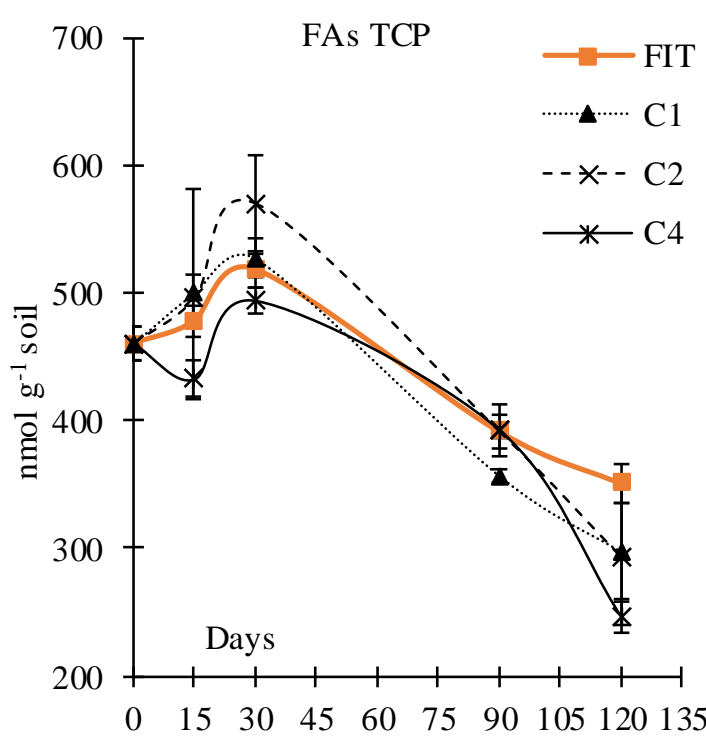

C

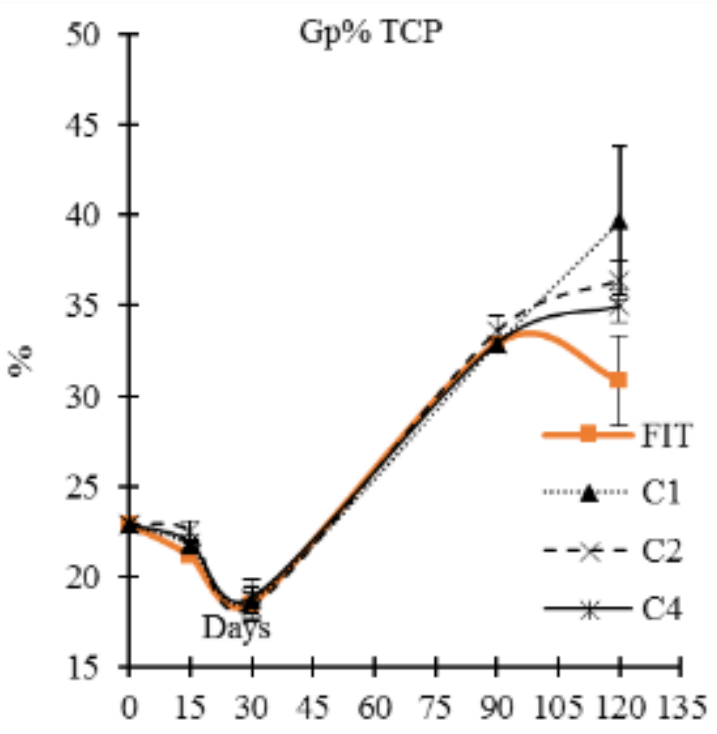

E

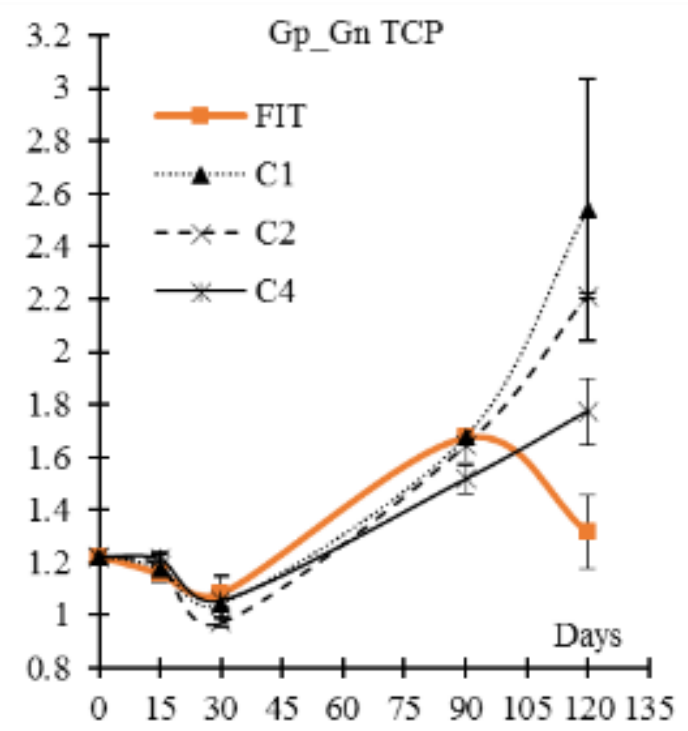

B

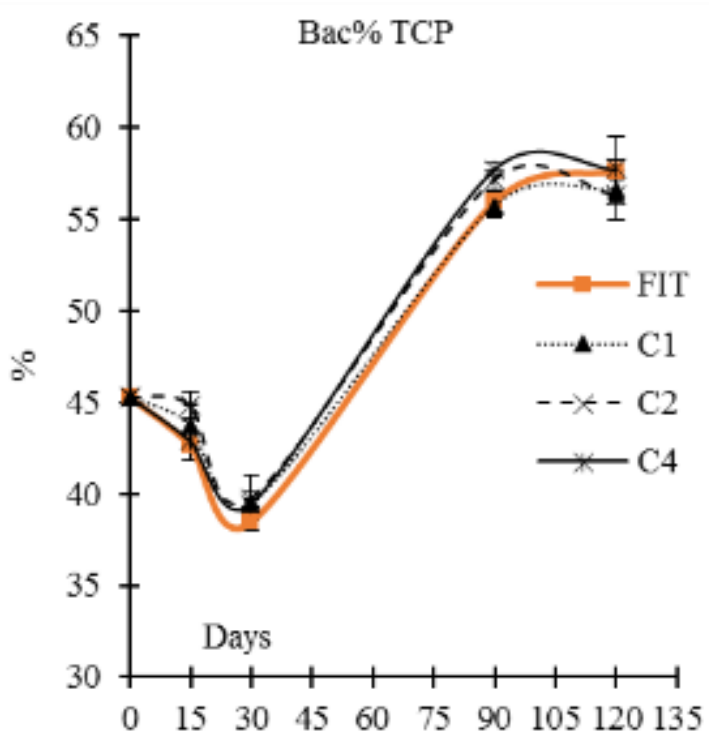

D

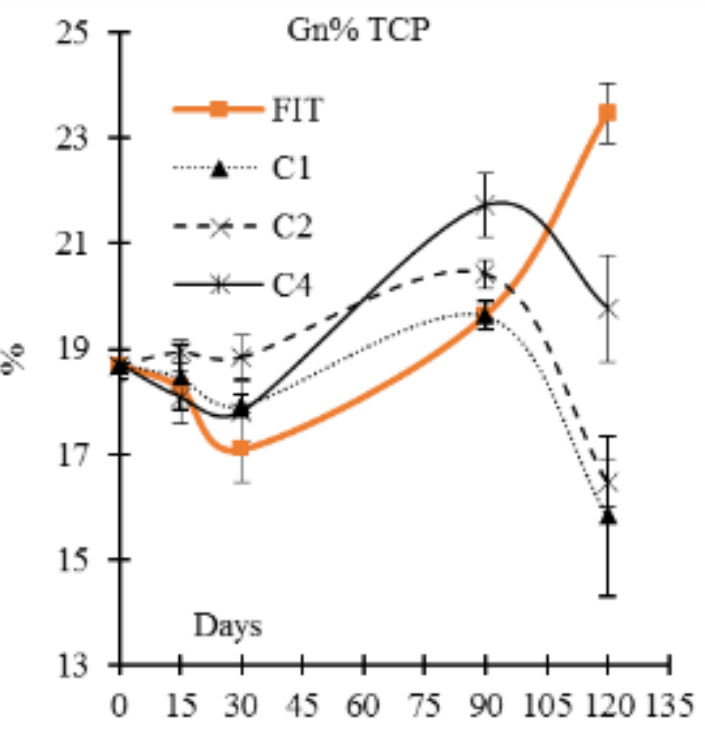

F

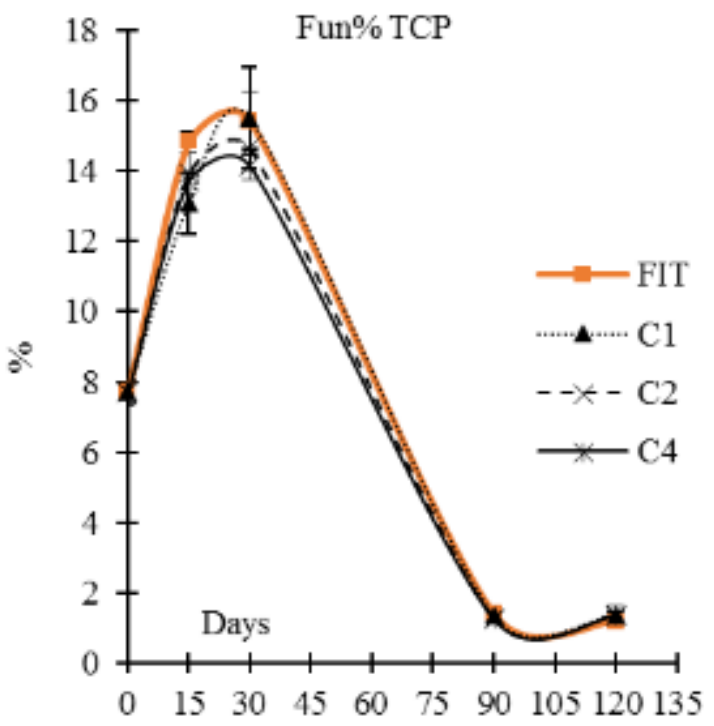


$\boldsymbol{G}$

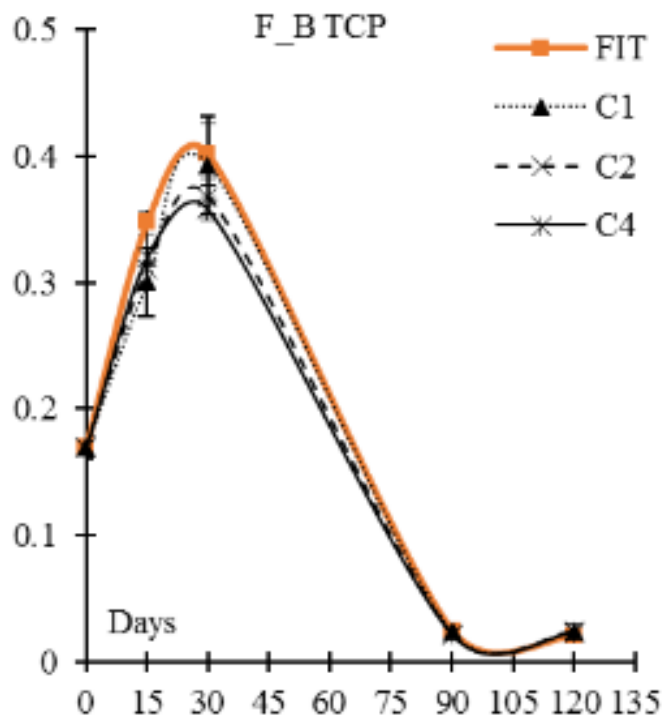

$\boldsymbol{H}$

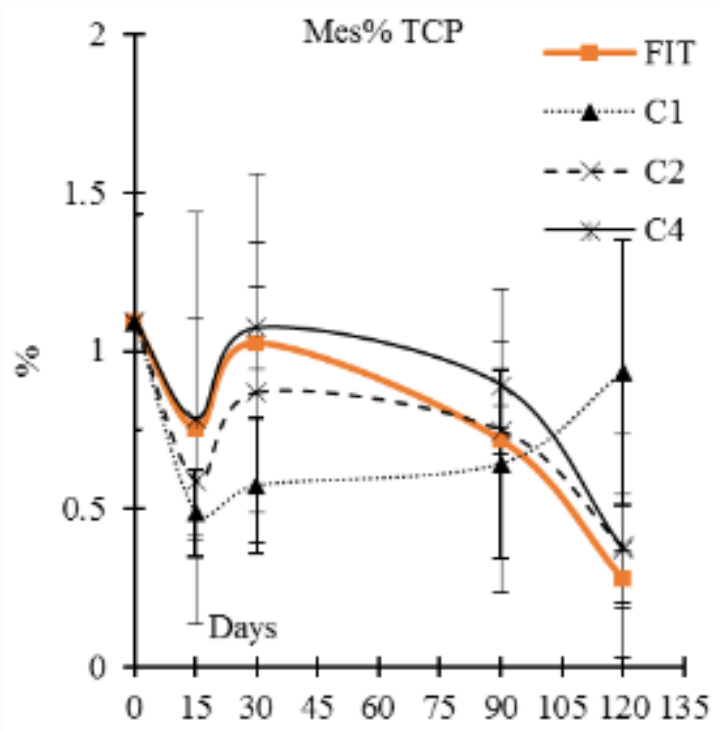

Figure 49: Microbial community structure determined at days 15, 30, 90 and 120 in the FIT (fitoil) and TCP (Thymbra capitata) treatments at different concentration (C1,C2 and C4 are, respectively, 1,2 and $4 \mathrm{~mL}$ of essential oil per litre of water)

A) FAs, microbial fatty acids; B) Bac\%, percentage of bacteria; C) Gp\%, percentage of Gram-positive bacteria; D) Gn\% percentage of Gram-negative bacteria; E) Gp_Gn, Gram-positive to Gram-negative ratio; $F$ ) $F$ un $\%$, percentage of fungi; $G) F_{-} B$, fungi to bacteria ratio; $\left.H\right)$ Mes $\%$, percentage of mesofauna. Showed values represents the mean values, bars are standard deviation $(n=3)$. 


\subsection{Experiment two: medium-term response of soil microorganisms to aqueous extracts with phytotoxic potential extracted from mediterranean plants}

Data subsets for the dependent variables pH, E.C., TOC and $\mathrm{N}_{\text {tot }}$ cannot be computed by the statics software because of the dataset homogeneity.

Results of chemical analyses carried out on the artificial substrate treated with aqueous extracts are showed in table 31 .

Table 31: Chemical variables of experiment two substrate after the aqueous extracts treatments.

\begin{tabular}{lcccccc}
\hline & UNS & CTR & ART & CUP & EUC & SAN \\
\hline pH & 6.00 & 5.80 & 6.90 & 3.45 & 6.90 & 6.90 \\
E.C. $\left[\mathbf{d S ~ m}^{-1}\right.$ ] & 0.38 & 0.37 & 0.37 & 0.30 & 0.25 & 0.38 \\
T.O.C. $\left[\mathbf{g K g}^{-1}\right.$ ] & 1.58 & 1.03 & 1.15 & 1.55 & 1.30 & 1.48 \\
$\mathbf{N}_{\text {tot }}\left[\mathbf{g ~ K g}^{-1}\right]$ & 0.014 & 0.000 & 0.028 & 0.042 & 0.014 & 0.000 \\
\hline
\end{tabular}

Variables measured (means, $n=3$ ) 120 days after the treatments. UNS, unsown and treated with water; CTR, sawn and treated with water; ART, A. absinthium AE treatment; CUP, C. sempervirens AE treatment; EUC, E. camaldulensis AE treatment; SAN, S. chamaecyparissus AE treatment. In red are evidenced the values higher than the mean, in blue the values lower than the mean.

After the CUP treatment, the substrate resulted acid ( $\mathrm{pH} 3.45)$ compared with the seeded control ( $\mathrm{pH}$ 5.80); no other treatments showed differences in soil reaction.

Electrical conductivity varied between the $0.25 \mathrm{dS} \mathrm{m}^{-1}$ of the EUC treated substrate and the 0.38 of UNS and SAN ones, but no meaningful differences can be identified among treated substrates.

Neither total organic carbon was affected by one treatment in particular, having the bigger difference between the two water treatments UNS $\left(1.03 \mathrm{~g} \mathrm{Kg}^{-1}\right)$ and CTR $\left(1.58 \mathrm{~g} \mathrm{Kg}^{-1}\right)$. Total nitrogen detected was very low, under detection limits for CTR and SAN, reaching $0.042 \mathrm{~g} \mathrm{Kg}^{-1}$ in CUP.

Test of between-subjects effects (table 32) performed on the whole dataset showed significant effects on $\mathrm{MBC}(\mathrm{F}=3.163 ; \mathrm{P}=0.047), \mathrm{Gp} \%(\mathrm{~F}=8.41 ; \mathrm{P}=0.001), \mathrm{Gp} \_\mathrm{Gn}$ $(\mathrm{F}=13.86 ; \mathrm{P}=0.000), \mathrm{Fun} \%(\mathrm{~F}=10.1, \mathrm{P}=0.001)$ and $\mathrm{F} \_\mathrm{B}(\mathrm{F}=8.3 ; \mathrm{P}=0.001)$.

Performing the same test excluding CSS treatment data, differences becomes significantly high between the CTR and all the AEs treatments for only 3 dependent variables: FAs $\left(3.58^{*}\right), \mathrm{Gp} \%(14 * * *), \mathrm{Gp} \_\mathrm{Gn}(24 * * *)$. This results evidences how the effects of Poa аппиа roots exudates drastically influences the mycotic fraction of microbial community in unsown samples. 
Table 32: Fisher's F values of the substrate chemical, biochemical and microbiological variables calculated by one-way ANOVA after (aqueous extract treatment as factors) determined 120 days after AEs application

\begin{tabular}{|c|c|c|}
\hline Dependent variable & With UNS & Without UNS \\
\hline $\mathrm{C}_{\mathrm{ext}}$ & n.s. & n.s. \\
\hline $\mathrm{MBC}$ & $3.2 *$ & n.s. \\
\hline SR & n.s. & n.s. \\
\hline $\mathrm{qCO}_{2}$ & n.s. & n.s. \\
\hline FAs & n.s. & $3.6^{*}$ \\
\hline $\mathrm{Bac} \%$ & n.s. & n.s. \\
\hline Fun $\%$ & $10.1 * * *$ & n.s. \\
\hline $\mathrm{Gp} \%$ & $8.4 * *$ & $14.5^{* * *}$ \\
\hline $\mathrm{Gn} \%$ & n.s. & n.s. \\
\hline Gp_Gn & $13.9 * * *$ & $24.6^{* * *}$ \\
\hline F_B & $8.3 * *$ & n.s. \\
\hline Mes $\%$ & n.s. & n.s. \\
\hline \multicolumn{3}{|c|}{ 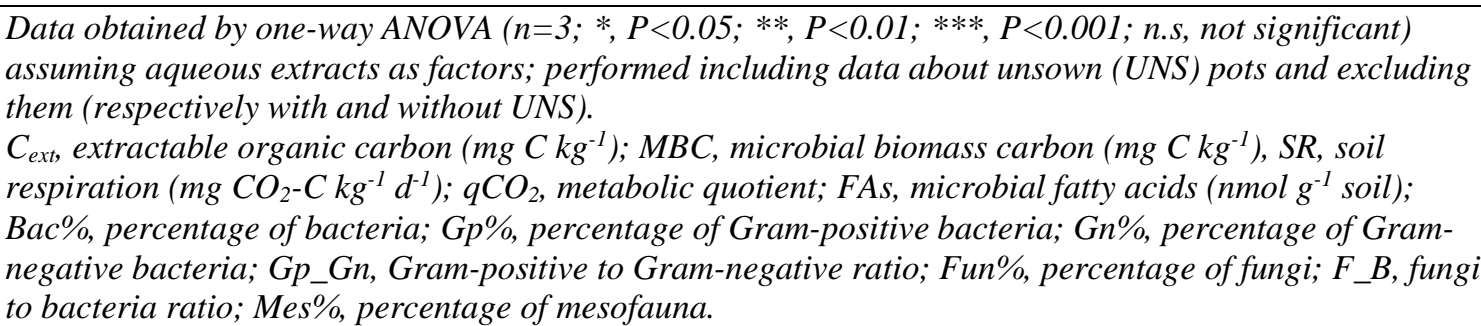 } \\
\hline
\end{tabular}

Even if the first test of between-subjects effects on $\mathbf{M B C}$ was significant, none of the two post-hoc tests evidenced important differences among the treatments effects on microbial biomass carbon (table 32). The bigger mean difference and evidenced in the first statistical analysis was among CTR and UNS, as showed in figure $50 \mathrm{~A}$. Microbial biomass Carbon maintained the lower level in CTR (398+/- $\left.68.23 \mathrm{mg} \mathrm{Kg}^{-1}\right)$. SAN and CUP showed a higher amount of MBC (499 +/- $44.07 \mathrm{mg} \mathrm{Kg}^{-1}$ and $\left.519+/-58.04 \mathrm{mg} \mathrm{Kg}^{-1}\right)$ compared with CTR, but not with UNS $\left(529+/-32.09 \mathrm{mg} \mathrm{Kg}^{-1}\right)$.

The second analysis post-hoc (without UNS), instead, showed a significant $(\mathrm{P}<0.05)$ negative effect of EUC A.E. on the FAs bioindicators (figure $50 \mathrm{~B}$ ).

Fungal bioindicators (figure $50 \mathrm{C}$ ) showed differences only among the UNS treatment and all the other treatment ( $\mathrm{P}<0.01$ only in the first analysis), having the UNS treatment doubled the fungi amount in treated substrate. The scatterplot in figure $50 \mathrm{D}$ shows how all the aqueous extracts treatments holds less fungal and bacterial FAs compared both with CTR and UNS, also can be evidenced that UNS is separated from the other treatments because of the higher fungi content, suggesting the rhizosphere influences this equilibrium more than the aqueous extracts treatments.

Regarding the distribution between Gram-positive and negative bacteria, in CTR the Gram-positive bacteria reached more than the double of the aqueous extracts treatments and also of UNS treatment (figure $50 \mathrm{E}$ ). Gram-negative bacteria, instead, uniformly 
reacted to all treatments. The difference in Gram-positive content is the main factor separating the CTR from the other treatments in the scatterplot in figure $50 \mathrm{~F}$.

The multiple comparisons post hoc tests (tab 33) confirm the decrease in Gram-positive bacteria, and consequently Gp_Gn, in soil treated with aqueous extracts. All the AEs treatments similarly influences $\mathrm{Gp}$ and $\mathrm{Gp}$ Gn with at least $\mathrm{P}<0.0 .01$.

Table 33: Significant (*, $P<0.05 ; * *, P<0.01 ; * * *, P<0.001 ;$ n.s, not significant) mean differences of chemical, biochemical and microbiological variables among aqueous extracts treatments determined 120 days after AEs application

\begin{tabular}{|c|c|c|c|}
\hline Dep. Var. & Ind. Var. & With UNS & Without UNS \\
\hline \multirow[t]{4}{*}{ FAs } & CTR - ART & & n.s. \\
\hline & CTR - CUP & & n.s. \\
\hline & CTR - EUC & & $43.80 *$ \\
\hline & CTR - SAN & & n.s. \\
\hline \multirow[t]{5}{*}{ Fun $\%$} & UNS - ART & $8.56^{* *}$ & \\
\hline & UNS - CTR & $8.09 * *$ & \\
\hline & UNS - CUP & $8.82 * *$ & \\
\hline & UNS - EUC & $9.08 * * *$ & \\
\hline & UNS - SAN & $7.99 * *$ & \\
\hline \multirow[t]{5}{*}{ F_B } & UNS - ART & $.138 * *$ & \\
\hline & UNS - CTR & $.123 * *$ & \\
\hline & UNS - CUP & $.129 * *$ & \\
\hline & UNS - EUC & $.143 * *$ & \\
\hline & UNS - SAN & $.123 * *$ & \\
\hline \multirow[t]{5}{*}{ Gp\% } & CTR - ART & $3.89 * *$ & $3.89 * *$ \\
\hline & CTR - CUP & $4.69 * *$ & $4.69 * * *$ \\
\hline & CTR - EUC & $3.54 *$ & $3.54 * *$ \\
\hline & CTR - SAN & $4.31 * *$ & $4.31 * * *$ \\
\hline & CTR - UNS & $4.44^{* *}$ & \\
\hline \multirow[t]{5}{*}{ Gp_Gn } & CTR - ART & $.0867 * * *$ & $.0867 * * *$ \\
\hline & CTR - CUP & $.0905^{* * *}$ & $.0905 * * *$ \\
\hline & CTR - EUC & $.0796 * * *$ & $.0796 * * *$ \\
\hline & CTR - SAN & $.0834 * * *$ & $.0834 * * *$ \\
\hline & CTR - UNS & $.0853 * * *$ & \\
\hline
\end{tabular}

Data obtained by Tukey post-hoc test ( $n=3)$ performed including data about unsown (UNS) pots and excluding them (respectively with and without UNS), assuming aqueous extracts treatment (CTR, UNS, $A R T, C U P, E U C$ and SAN) as independent variable. CTR, sawn and treated with water; UNS, unsown and treated with water, ART, A. absinthium AE treatment; CUP, C. sempervirens AE treatment; EUC, E. camaldulensis AE treatment; SAN, S. chamaecyparissus AE treatment.

FAs, microbial fatty acids ( $n$ mol $g^{-1}$ soil); Fun $\%$, percentage of fungi; $F_{-}$B, fungi to bacteria ratio; Gp\%, percentage of Gram-positive bacteria; Gp_Gn, Gram-positive to Gram-negative ratio. 
A

MBC

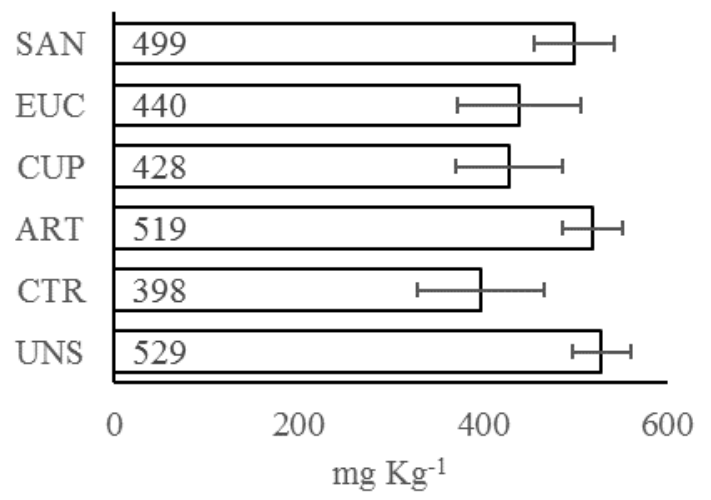

C

Fun $\%$

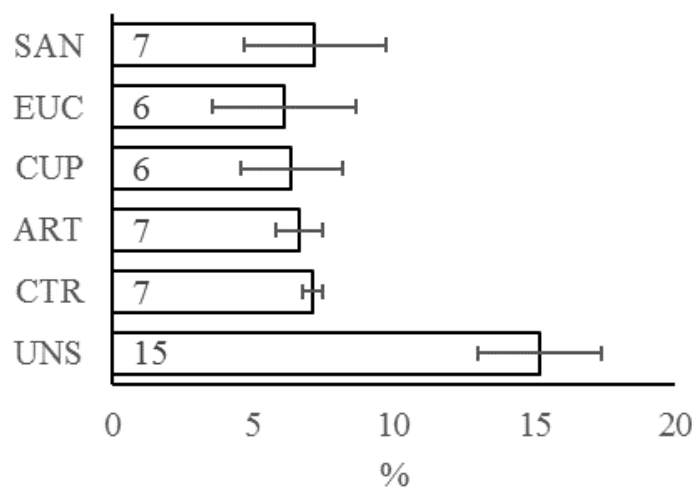

$\boldsymbol{E}$

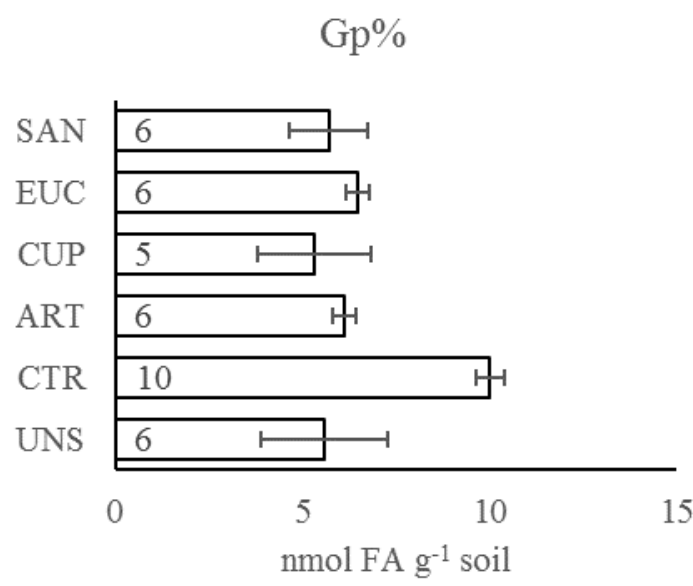

$\boldsymbol{B}$

FAs

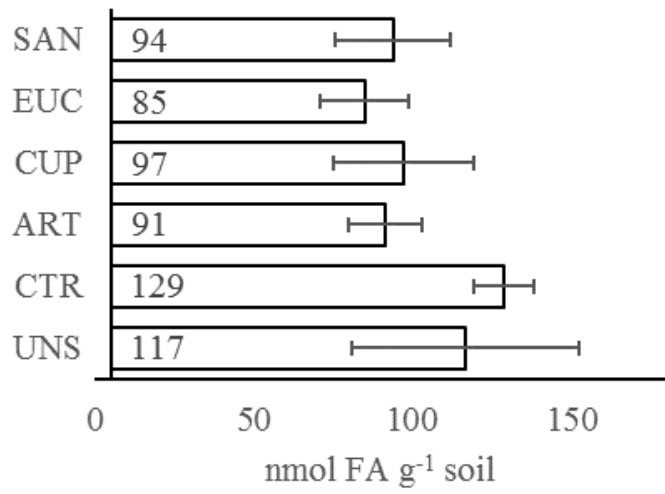

$\boldsymbol{D}$

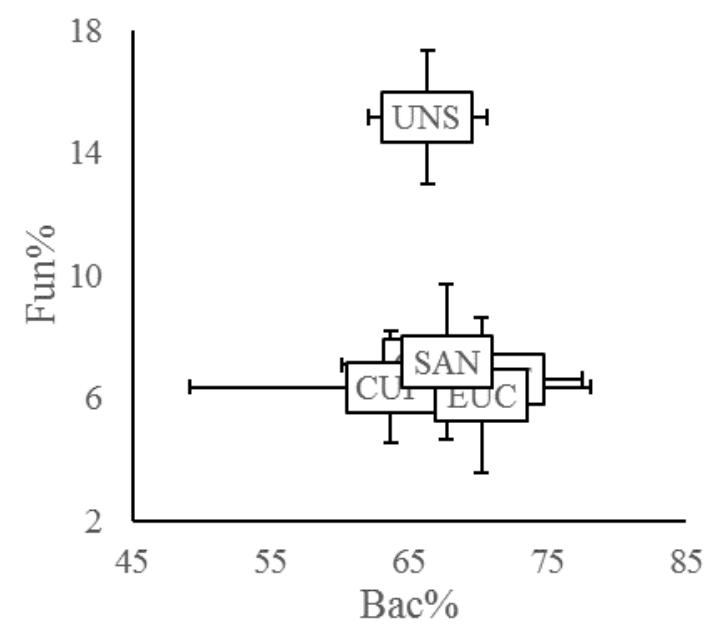

$\boldsymbol{F}$

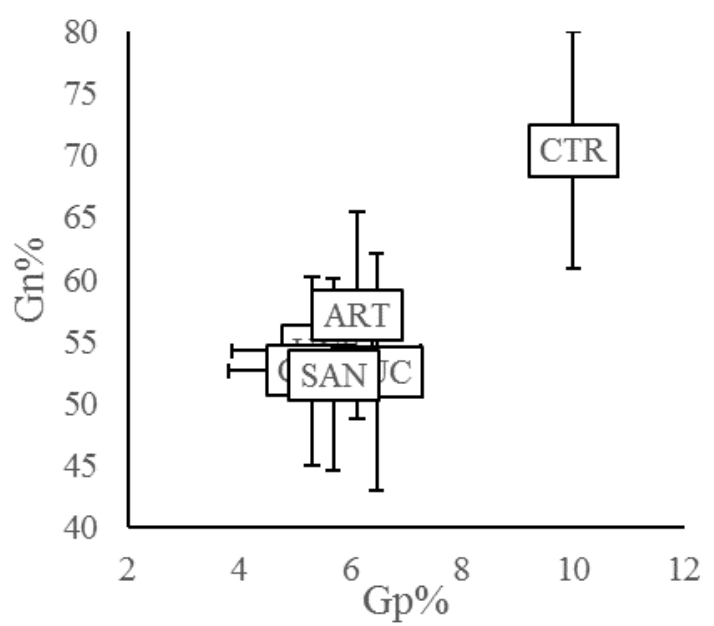

Figure 50: Soil variables determined 120 days after aqueous extracts (AE) treatments.

A) MBC, microbial biomass carbon; B) FAs, microbial fatty acids bioindicator; C) Fun\%, fungal fatty acids bioindicator; D) Scatterplot of the bacterial and the fungal FAs bioindicators; E) Gp\%, Gram-positive fatty acids bioindicator; F) Scatterplot of the Gram-positive and negative fatty acids bioindicators.

UNS, unsown pot treated with water; CTR, sown pot treated with water; ART, A. absinthium AE treatment; CUP, C. sempervirens AE treatment; EUC, E. camaldulensis AE treatment; SAN, S. chamaecyparissus AE treatment.

Only the variables significantly affected by treatments reported. Showed values represents the mean values, bars are standard deviation $(n=3)$. 


\subsection{Experiment three: short, medium and long-term response of soil microorganisms to natural and synthetic herbicides}

\subsubsection{Water and Fitoil}

Both for WAT and FIT extractable carbon weaved initially to reach the minimal value on day 60. Since day 120 values remained similar to day zero ones. Neither the variable MBC suffered particular influences after Fitoil application, both WAT and FIT values constantly increase since day 30 to 180 .

$\boldsymbol{A}$

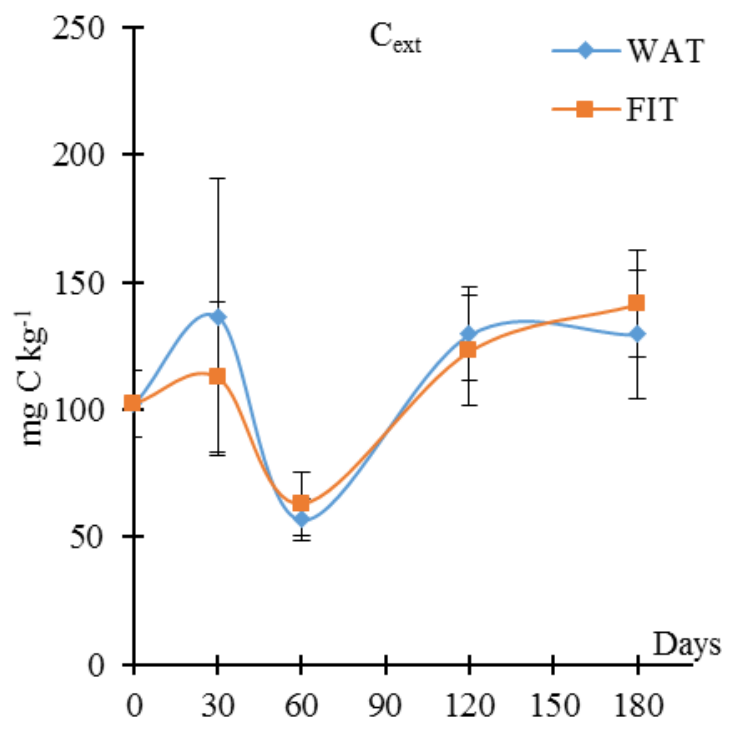

C

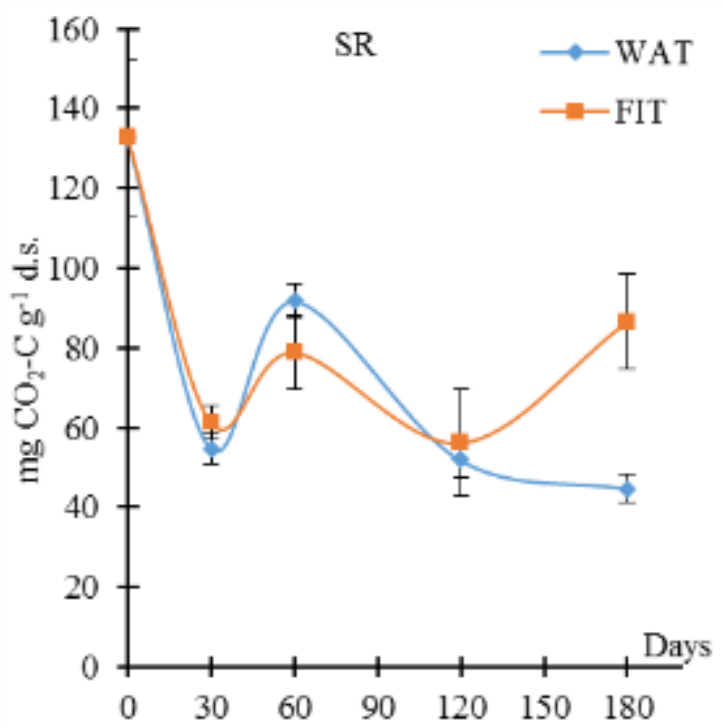

$\boldsymbol{B}$

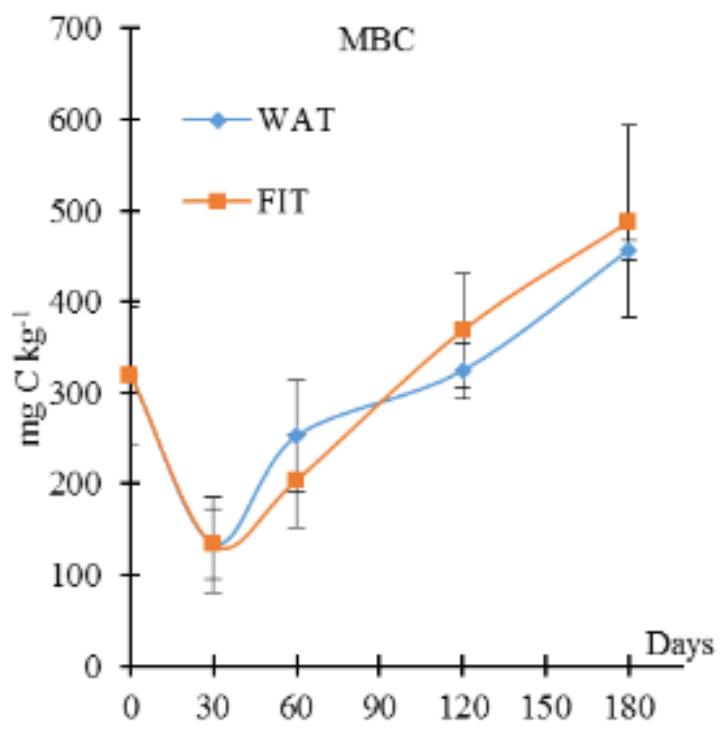

D

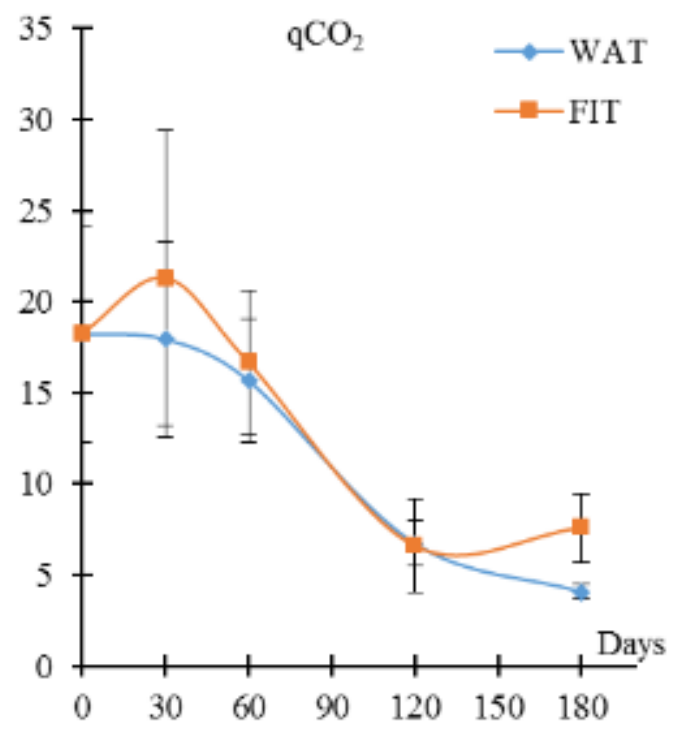

Figure 51: Biochemical soil variables determined at days 30,60,120 and 180 in the fitoil (FIT) and water (WAT) treatments

A) $C_{\text {ext }}$ extractable organic carbon; $\left.B\right) M B C$, microbial biomass carbon; C) SR, soil respiration; $\left.D\right) q C O_{2}$, metabolic quotient. Reported results are means of three samples, bars are standard deviations. 
Soil respiration and metabolic quotient differs between the two treatments on day 180 only. In Fitoil treated samples soil respiration is higher and more efficient $\left(\right.$ lower $\left.\mathrm{qCO}_{2}\right)$, metabolism is shifted if compared to the equilibrium reached in WAT samples.

No significant differences emerged in the microbial community structure evolution of the samples treated with water and with fitoil (figures $52 \mathrm{a}-\mathrm{f}$ ).

Fitoil treatment causes significant differences in fresh weight (figure 53,10.3g compared to $12.5 \mathrm{~g}$ of WAT) only on the 30 day). After this first negative impact of fitoil, both treatments show a similar trend, with an increase over the first 60 days and assuming slightly lower values until the experiment end. Fresh weight highest values on day 60 mean that the plants had not yet begun to lignify their drums or to dry their fruits.

Dry weight trend clearly shows how biomass grows during the experiment first two months and stays between $3.35 \mathrm{~g}$ and $4.17 \mathrm{~g}$ up to 180 days.

The standard deviation of all count values is so high that a true trend of the number of counted plants cannot be defined. 
Oddo M. - Effects of different weed control practices on soil quality in mediterranean crops
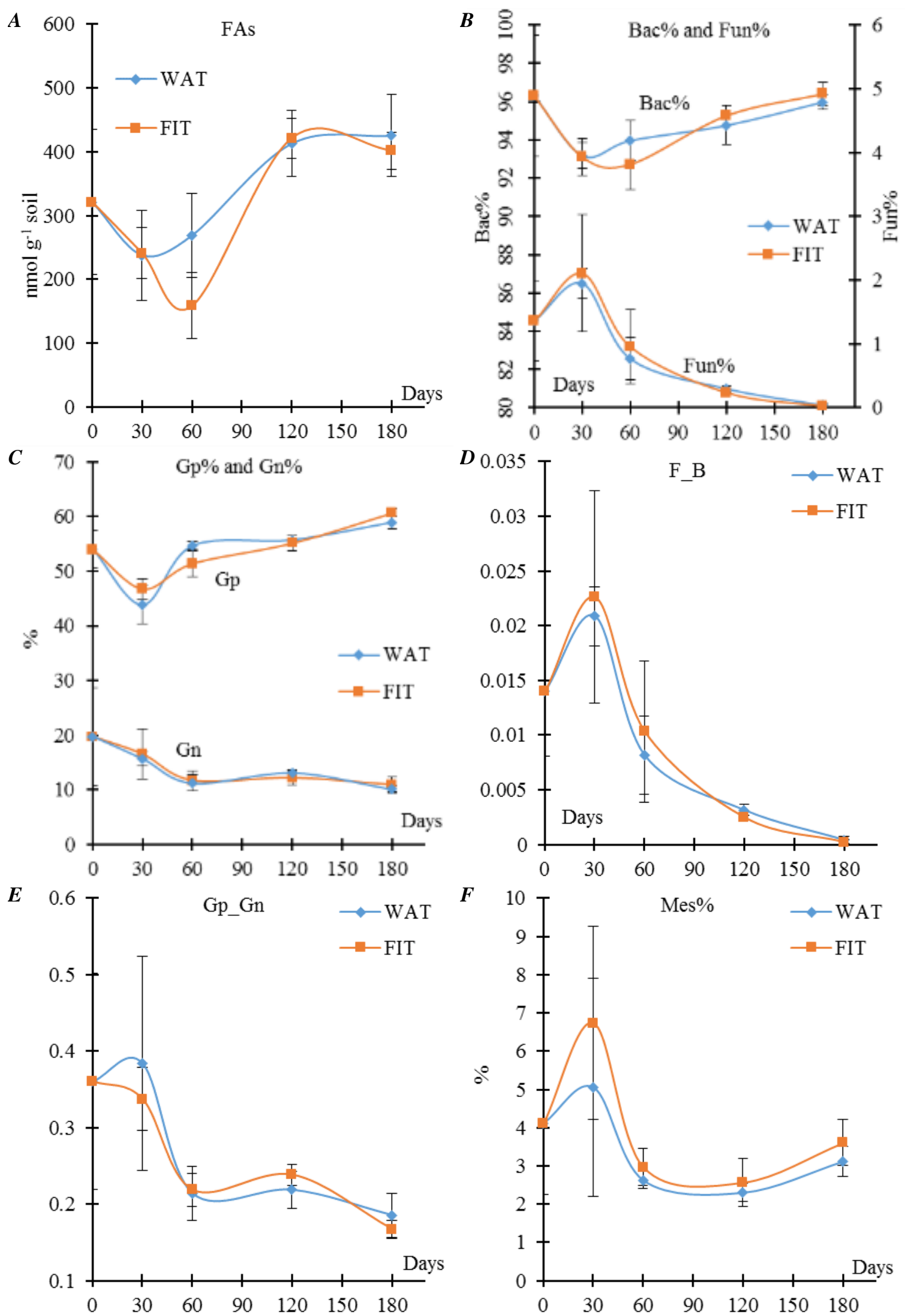

Figure 52: Microbial community structure determined at days determined at days 30, 60, 120 and 180 in the fitoil (FIT) and water (WAT) treatments

A) FAs, microbial fatty acids; B) Bac\% and Fun\%, percentage of bacteria and fungi; C) Gp\% and Gn\%, percentage of Gram-positive and negative bacteria; D); $F \_B$, fungi to bacteria ratio; $E$ ) Gp_Gn, Grampositive to Gram-negative ratio; $F$ ) Mes\%, percentage of mesofauna. Showed values represents the mean values, bars are standard deviation $(n=3)$. 
$\boldsymbol{A}$

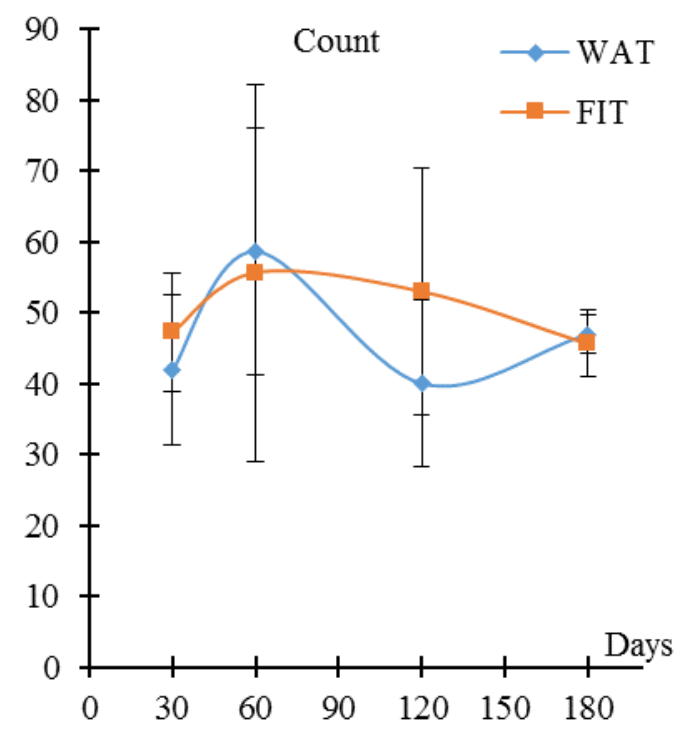

C

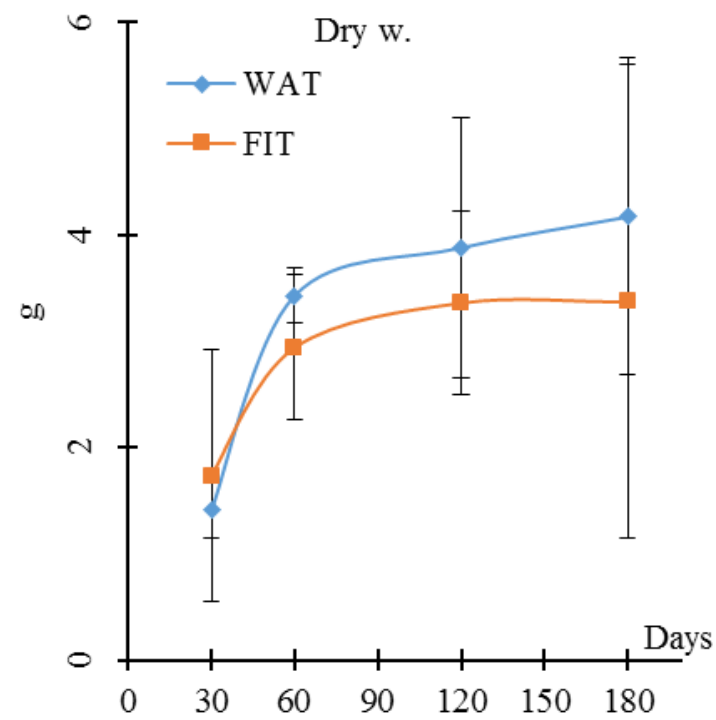

B

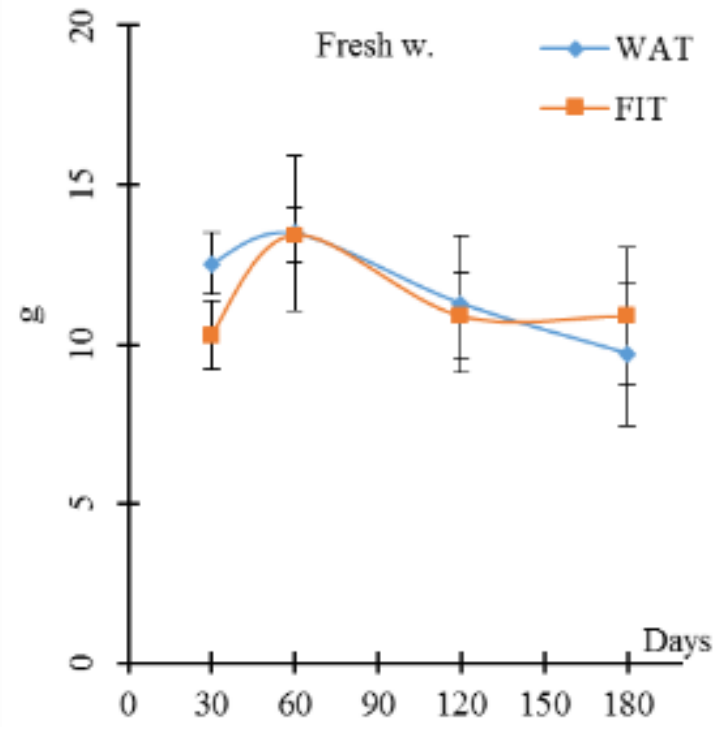

Figure 53: Weeds variables determined at days 30, 60, 120 and 180 in the fitoil (FIT) and water (WAT) treatments

A) Count, number of counted plants; B) Fresh w., fresh weight; C) Dry w., dry weight. Reported results are means of three samples, bars are standard deviations. 


\subsubsection{Water and Oxyfluorfen}

The treatment with synthetic oxyfluorfen-based herbicide did not affected 5 of 14 soil variables and, among the affected ones, none were for the whole experimental period.

The days when soil variables are most affected are 60 and 120.60 is also the day when there was the higher difference between respective dry weight.

Table 34: Pairwise mean comparison between the chemical, biochemical and microbiological parameters at the same sampling day after 30,60,120 and 180 days since WAT and OXY treatments application

\begin{tabular}{|c|c|c|c|c|}
\hline & Day 30 & Day 60 & Day 120 & Day 180 \\
\hline $\mathrm{C}_{\mathrm{ext}}$ & n.s. & n.s. & n.s. & n.s. \\
\hline $\mathrm{MBC}$ & n.s. & $8.17 *$ & n.s. & n.s. \\
\hline SR & n.s. & $140.0 * * *$ & n.s. & $86.8 * * *$ \\
\hline $\mathrm{qCO}_{2}$ & n.s. & $15.49 *$ & n.s. & $7.87 *$ \\
\hline FAs & n.s. & n.s. & n.s. & n.s. \\
\hline $\mathrm{Bac} \%$ & n.s. & n.s. & n.s. & n.s. \\
\hline $\mathrm{Gp} \%$ & n.s. & n.s. & n.s. & n.s. \\
\hline $\mathrm{Gn} \%$ & n.s. & $32.1 * *$ & $16.2 *$ & n.s. \\
\hline Gp_Gn & n.s. & n.s. & n.s. & n.s. \\
\hline Fun $\%$ & $18.9^{*}$ & n.s. & n.s. & n.s. \\
\hline F_B & $21.3 * *$ & n.s. & n.s. & n.s. \\
\hline Mes \% & n.s. & n.s. & $8.08 *$ & n.s. \\
\hline Count & $40.29 * *$ & $19.92 *$ & n.s. & n.s. \\
\hline Fresh w. & $432.9 * * *$ & $50.7 * *$ & $10.5^{*}$ & n.s. \\
\hline Dry w. & $79.8 * * *$ & $79.9 * * *$ & $10.6^{*}$ & n.s. \\
\hline
\end{tabular}

Data obtained by student $t$-test $(n=3 ; *, P<0.05 ; * *, P<0.01 ; * * *, P<0.001 ; n$. , not significant) performed for each sampling day, WAT, (water treatment) and $O X Y$ (synthetic herbicide treatment) as independent variables.

$C_{\text {ext }}$, extractable organic carbon $\left(m g C \mathrm{~kg}^{-1}\right) ; \mathrm{MBC}$, microbial biomass carbon (mg $\left.\mathrm{C} \mathrm{kg}^{-1}\right)$, SR, soil respiration ( $\mathrm{mg} \mathrm{CO}_{2}-\mathrm{C} \mathrm{kg}^{-1} \mathrm{~d}^{-1}$ ); FAs, microbial fatty acids (nmol $\mathrm{g}^{-1}$ soil); Bac\%, percentage of bacteria; $G p \%$ percentage of Gram-positive bacteria; Gn\% percentage of Gram-negative bacteria; Gp_Gn, Grampositive to Gram-negative ratio; Fun\%, percentage of fungi; $F \_B$, fungi to bacteria ratio; Mes\%, percentage of mesofauna; Count, number of plants in the sample; Fresh w., collected plants fresh weight; Dry w, collected plants dry weight.

The maximum effect on plant biomass is short-term, on day 30, in which $\mathrm{F}$ of fresh weight is the highest of both the variables and the sampling days (432***). That day, all variables linked to aerial plant biomass are strongly influenced by oxyfluorfene, highlighting the efficiency of synthetic herbicide. A side effect of this treatment is, however, the increase of fungi and F_B percentage in microbial soil community (from $2 \%$ to $3.5 \%$ in OXY).

The next sampling day (day 60) no significant differences in Fun\% values between OXY and WAT, nor in soil metabolism indicators and microbial biomass carbon. MBC remains at the lowest levels in OXY treatment, while in WAT it increases between days 30 and 60 . This biomass metabolizes carbon in smaller amounts and with less efficacy than day 30, such behaviour may be due to the drastic decline in fungi and its increase of Gn\% (whose metabolism is slower and does not exploit all substrates). SR reaches and keeps the balance 
around value 80 , more than WAT that keeps it at $50 . \mathrm{qCO}_{2}$, also affected by $\mathrm{MBC}$, from day 60 onward increases slowly and steadily, significantly exceeding control values on day 180. Mesofauna varied over time in the same way in both treatments, only $120 \mathrm{Mes} \%$ in OXY was significantly greater than in WAT.

Oxyfluorfen continues to inhibit plant growth even in day 60, but less intensely. Graphs show that the number of plants (counts) is much lower in OXY and rises between 30 and 60 days, with higher gradient in WAT and OXY. Subsequently, the synthetic herbicide effect on the number of germinated plants disappears, the local seedbank of the treated soils is reactivated, the gradient of the graph changes (there is a flattening point between day 60 and 120), and the number of plants in the oxyfluorfene treated vessels grow to reach WAT values. Instead, both fresh weight and dry weight of the plants grown in oxyfluorfen treated containers remain under control even on day 120, with higher differences in dry weight than in freshness. The fresh weight grows very rapidly between day 60 and 120, supporting the hypothesis of the endemic seedbank vegetative recovery: after 60 days seeds begin to germinate, then increases the number of plantules, which are affected by a significant loss of weight when dried because of having few lignified tissues, therefore dry weight behaves differently than fresh one.

$\boldsymbol{A}$

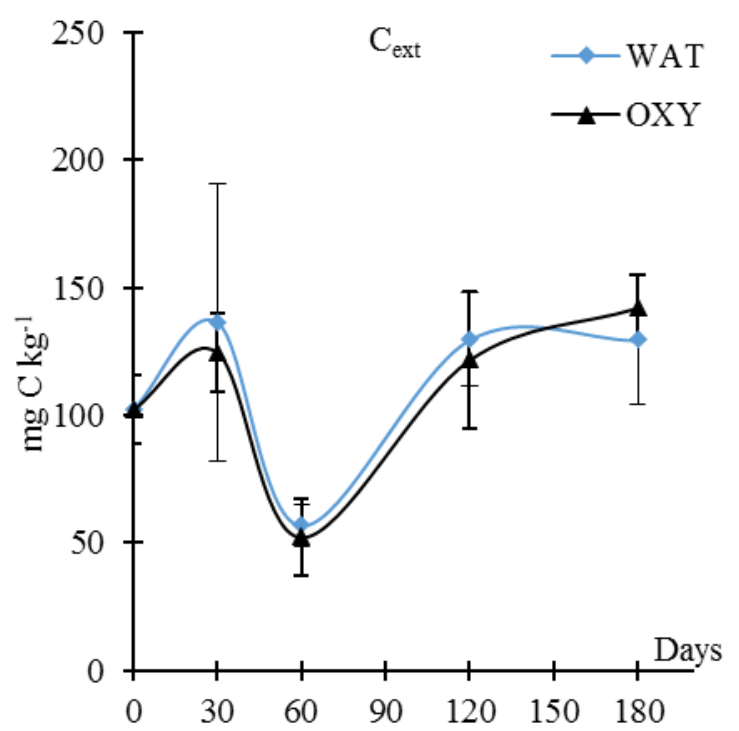

$\boldsymbol{B}$

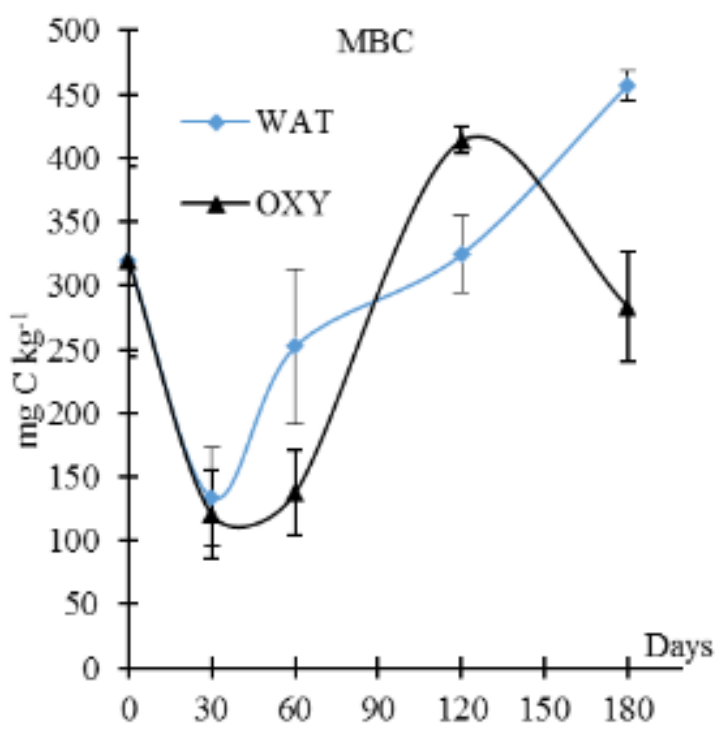


Oddo M. - Effects of different weed control practices on soil quality in mediterranean crops

C

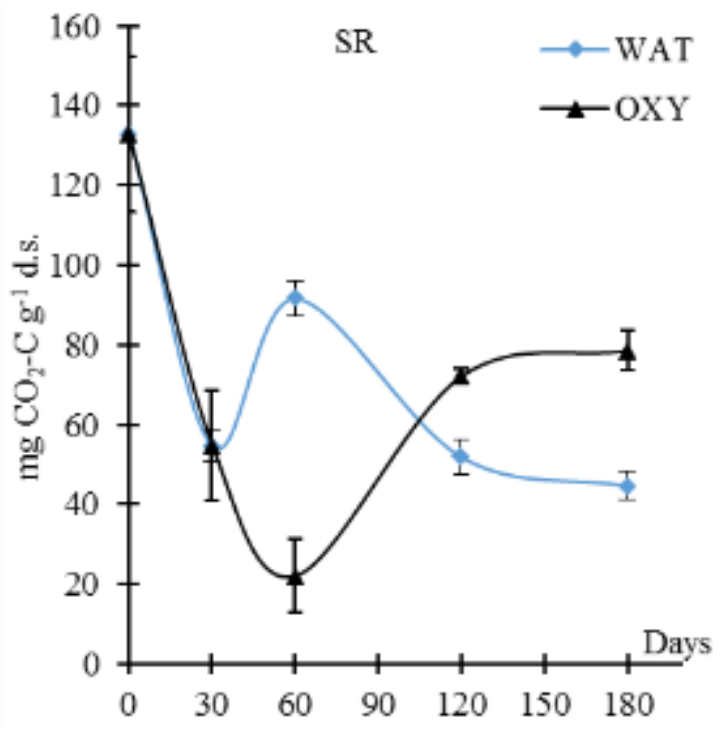

E

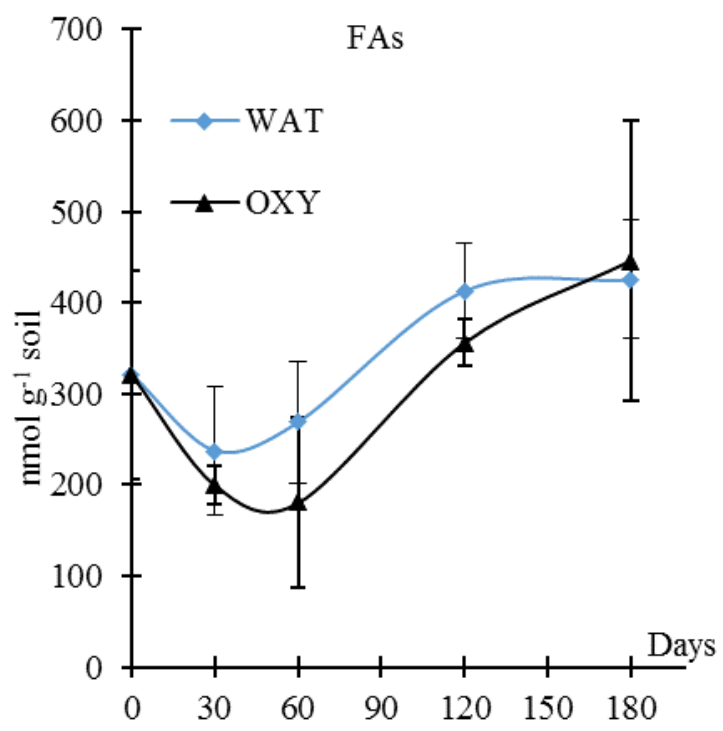

G

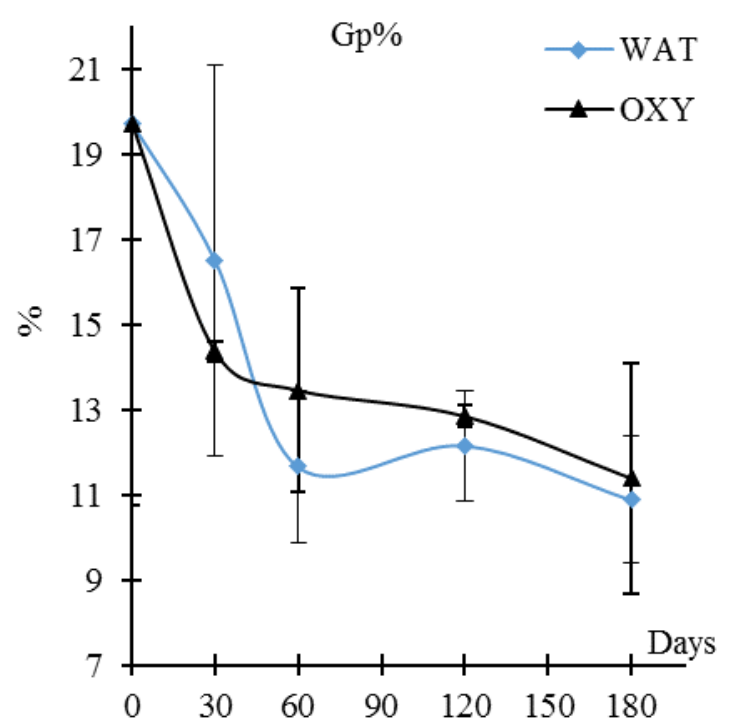

D

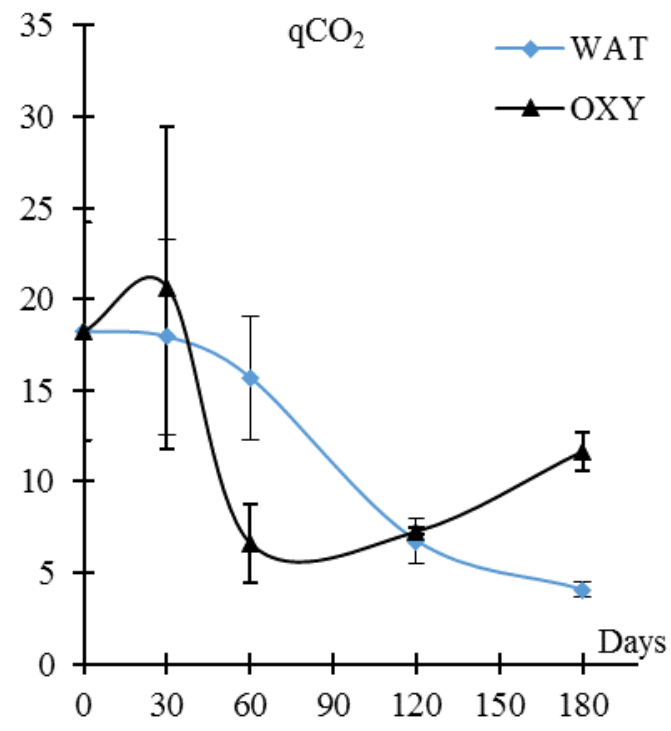

$\boldsymbol{F}$

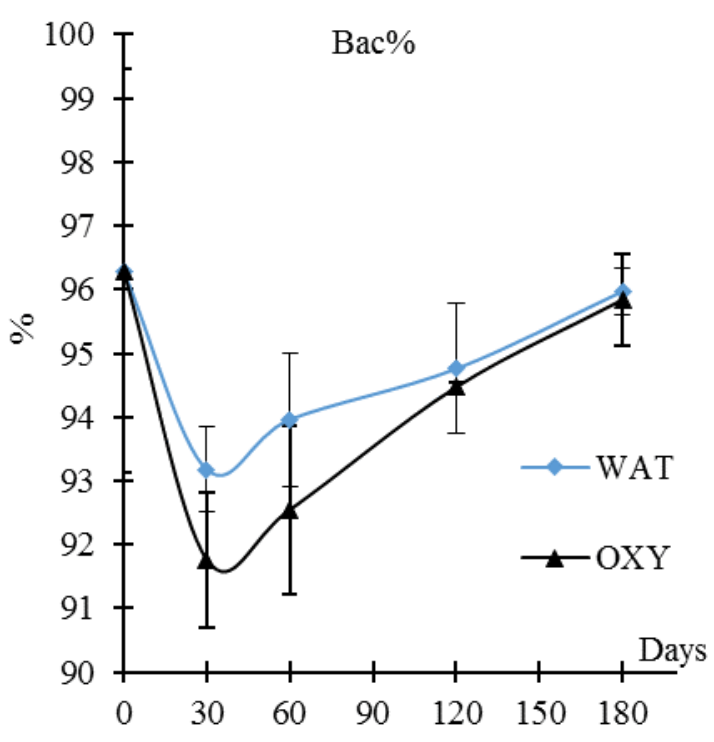

H

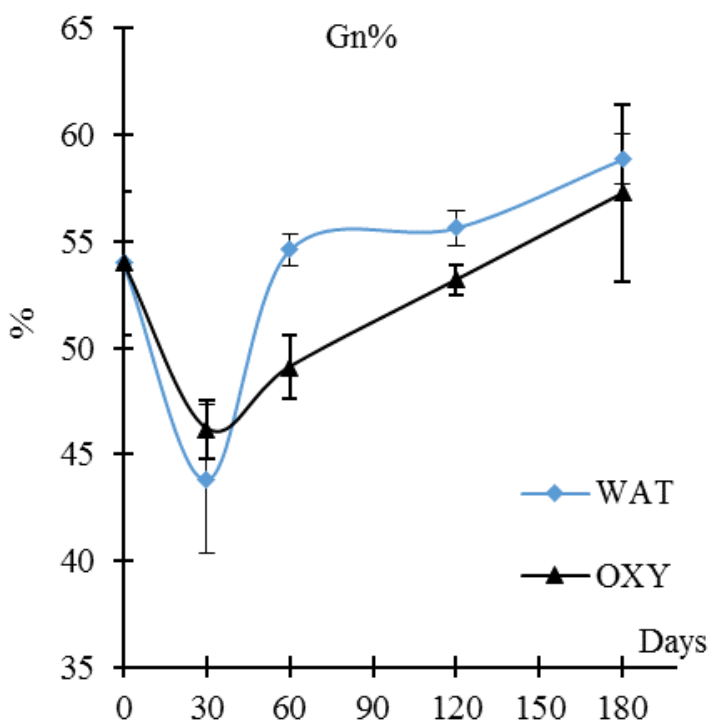




\section{$\boldsymbol{I}$}

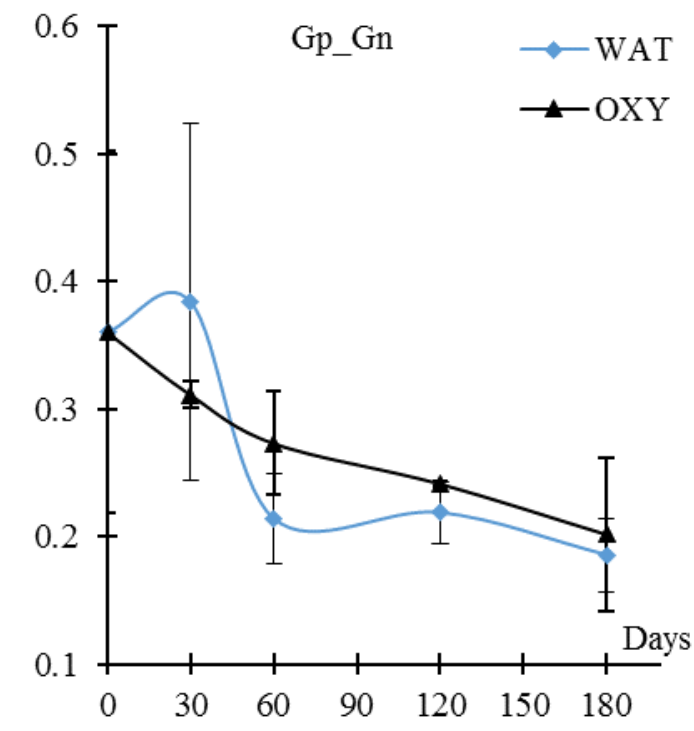

$\boldsymbol{L}$

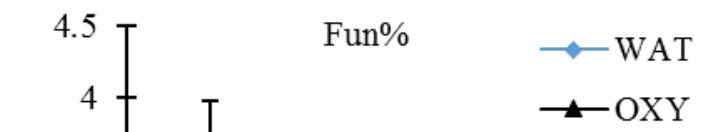

$N$
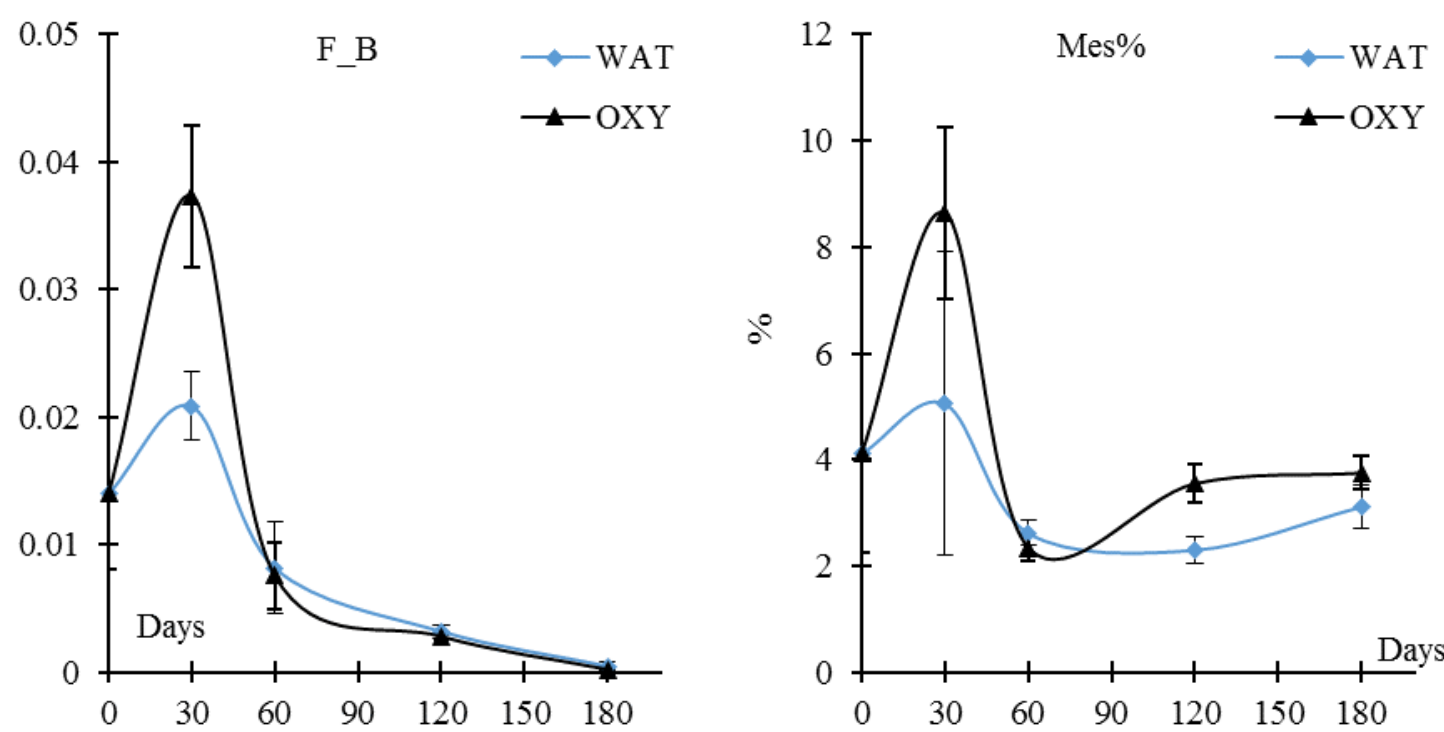

Figure 54: Biochemical soil variables and microbial community structure determined at days 30, 60, 120 and 180 in the oxyfluorfen $(O X Y)$ and water (WAT) treatments.

A) $C_{\text {ext }}$ extractable organic carbon; B) $M B C$, microbial biomass carbon; $\left.C\right) S R$, soil respiration; D) $q C O_{2}$, metabolic quotient, E) FAs, microbial fatty acids; F) Bac\%, percentage of bacteria; $G$ ) Gp\%, percentage of Gram-positive bacteria; H) Gn\% percentage of Gram-negative bacteria; I) Gp_Gn, Gram-positive to Gramnegative ratio; $L) F u n \%$, percentage of fungi; $M) F_{-} B$, fungi to bacteria ratio; $N$ ) Mes\%, percentage of mesofauna. Showed values represents the mean values, bars are standard deviation ( $n=3)$. 
Oddo M. - Effects of different weed control practices on soil quality in mediterranean crops

$\boldsymbol{A}$

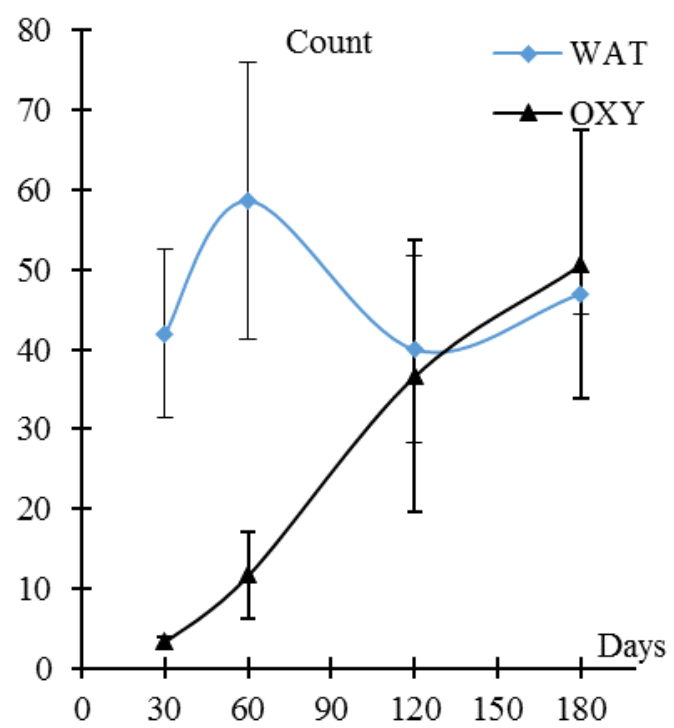

C

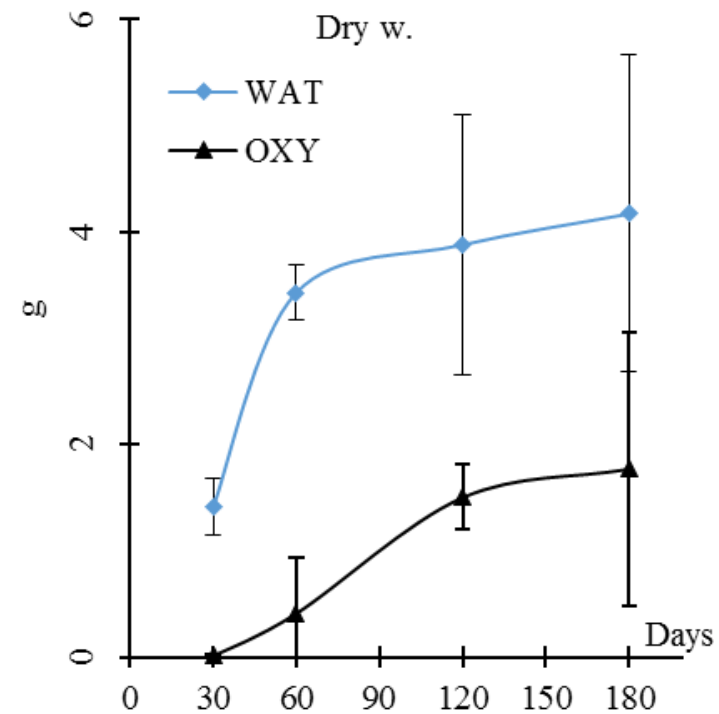

$\boldsymbol{B}$

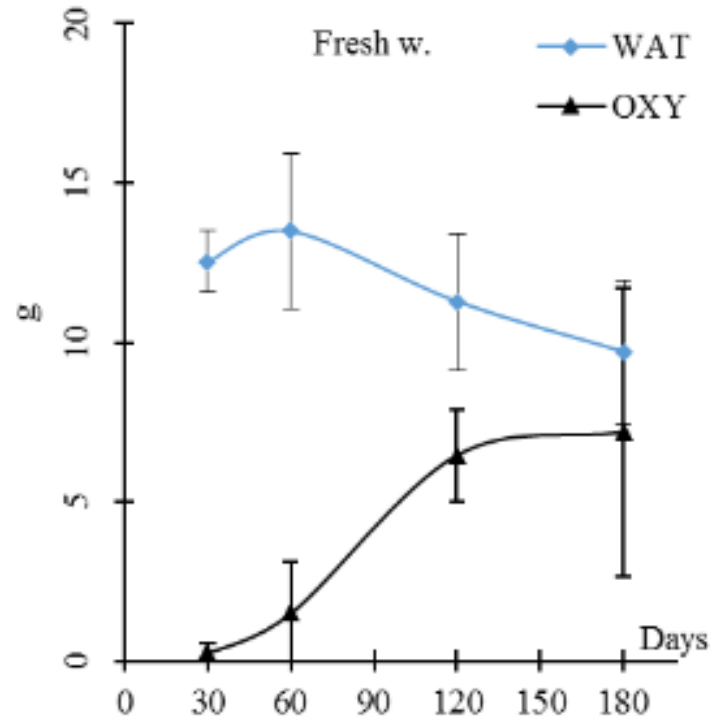

Figure 55: Weeds variables determined at days 30, 60, 120 and 180 in the oxyfluorfen (OXY) and water (WAT) treatments.

A) Count, number of counted plants; B) Fresh w., fresh weight; C) Dry w., dry weight. Reported results are means of three samples, bars are standard deviations. 


\subsubsection{Essential Oils and Pure Compound}

Principal components analysis extracted 3 factors from the 17 investigated dependent variables (table 35). PC1 explained $37.7 \%$ of the total variance, and was linked to, at decreasing order, Gn\%, Gp_Gn, FAs, Bac\%, Gp\%, Fun\%, F_B, MBC and Cext. PC2 explained the $13.8 \%$ of total variance and was linked to weeds variables and $\mathrm{qCO}_{2}$. The $10.2 \%$ of the variance was explained by PC3 whom distinguish in order: Mes\% and SR. As in experiment one, PC1 separates sampling days in the scatterplot (figure 56 a). Drawing the PC3 on the vertical axe (figure 56 b) division between day 30 and the others sampling day results amplified.

Table 35: Principal Component Matrix

\begin{tabular}{lccc}
\hline & PC1 (37.7\%) & PC2 (13.8\%) & PC3 (10.2\%) \\
\hline C $_{\text {ext }}$ & $\mathbf{0 . 6 2 2}$ & 0.403 & -0.063 \\
MBC & $\mathbf{0 . 7 0 2}$ & 0.386 & -0.150 \\
$\mathrm{SR}$ & 0.200 & 0.201 & $\mathbf{0 . 2 4 2}$ \\
$\mathrm{qCO}{ }_{2}$ & -0.322 & $\mathbf{- 0 . 3 8 7}$ & 0.238 \\
$\mathrm{FAs}$ & $\mathbf{0 . 8 3 5}$ & 0.192 & 0.075 \\
$\mathrm{Bac \%}$ & $\mathbf{0 . 8 0 2}$ & 0.028 & 0.070 \\
$\mathrm{Gp \%}$ & $\mathbf{- 0 . 7 4 0}$ & -0.082 & -0.227 \\
$\mathrm{Gn} \%$ & $\mathbf{0 . 9 5 4}$ & 0.032 & 0.056 \\
$\mathrm{Gp}$ Gn & $\mathbf{- 0 . 8 5 5}$ & -0.038 & -0.170 \\
Fun\% & $\mathbf{- 0 . 7 2 5}$ & 0.383 & 0.491 \\
F_B & $\mathbf{- 0 . 7 2 3}$ & 0.382 & 0.487 \\
Mes\% & -0.322 & 0.498 & $\mathbf{0 . 5 3 5}$ \\
Count & -0.098 & $\mathbf{- 0 . 3 4 0}$ & 0.287 \\
Fresh w. & 0.162 & $\mathbf{- 0 . 6 7 3}$ & 0.466 \\
Dry w. & 0.529 & $\mathbf{- 0 . 5 7 5}$ & 0.325 \\
\hline
\end{tabular}
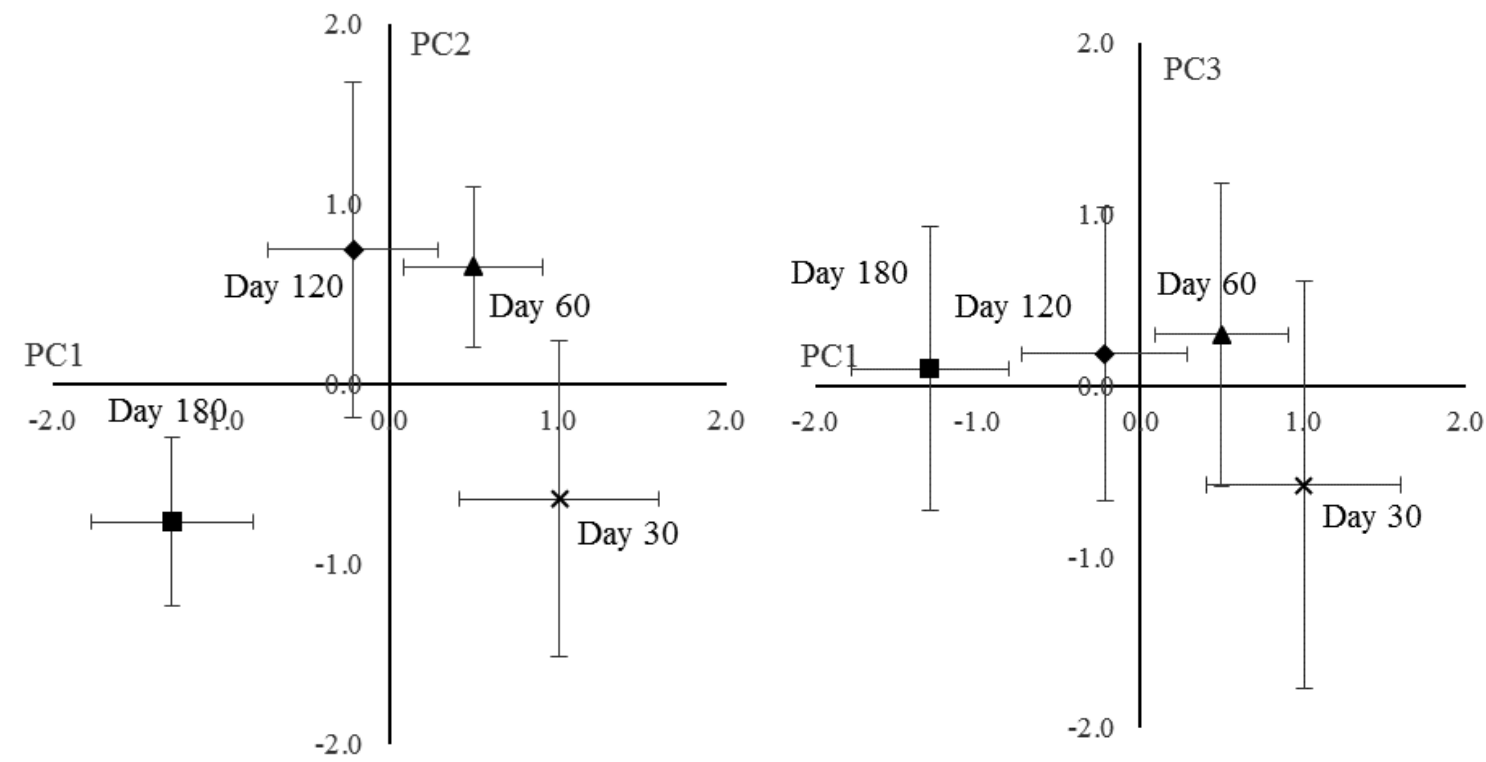

Figure 56: Principal Components scatterplots 


\subsubsection{Thymbra capitata (L.) Cav EO and Carvacrol}

In table 36 the results of student t-test pairwise mean comparison among the two treatments at equivalent concentrations are exposed.

Table 36: Significant ( $*, P<0.05$; **, $P<0.01$; ***, $P<0.001$; n.s, not significant) Fisher's $F$ values of the chemical, biochemical and microbiological parameters calculated by one-way ANOVA (concentration of essential oil as factors) after 30, 60,120 and 180 days since TCP and CAR treatments application

\begin{tabular}{|c|c|c|c|c|c|}
\hline Dep. Var. & Ind. Var. & Day 30 & Day 60 & Day 120 & Day 180 \\
\hline \multirow[t]{2}{*}{$\mathbf{C}_{\text {ext }}$} & $\mathrm{C} 2$ & $13.12 *$ & $18.75^{*}$ & $40.9 * *$ & $10.94 *$ \\
\hline & $\mathrm{C} 4$ & n.s. & $10.23 *$ & $59.1 * *$ & n.s. \\
\hline \multirow[t]{3}{*}{ MBC } & $\mathrm{C} 2$ & n.s. & n.s. & $26.0 * *$ & n.s. \\
\hline & $\mathrm{C} 4$ & n.s. & n.s. & $9.39 *$ & n.s. \\
\hline & $\mathrm{C} 8$ & $24.0 * *$ & n.s. & $143.8 * * *$ & n.s. \\
\hline \multirow[t]{3}{*}{ SR } & $\mathrm{C} 2$ & n.s. & $275.7 * * *$ & $45.9 * *$ & n.s. \\
\hline & $\mathrm{C} 4$ & n.s. & $166.8 * * *$ & $33.2 * *$ & n.s. \\
\hline & $\mathrm{C} 8$ & $36.7 * *$ & n.s. & $2592 * * *$ & n.s. \\
\hline \multirow[t]{3}{*}{$\mathrm{qCO}_{2}$} & $\mathrm{C} 2$ & n.s. & $11.5^{*}$ & n.s. & $9.84 *$ \\
\hline & $\mathrm{C} 4$ & n.s. & $582 * * *$ & n.s. & n.s. \\
\hline & $\mathrm{C} 8$ & $241 * * *$ & n.s. & $170 * * *$ & n.s. \\
\hline FAs & $\mathrm{C} 8$ & $30.6^{* *}$ & n.s. & n.s. & $17.2 *$ \\
\hline \multirow{3}{*}{ Вас\% } & $\mathrm{C} 2$ & n.s. & n.s. & $8.70^{*}$ & n.s. \\
\hline & $\mathrm{C} 4$ & n.s. & $19.22 *$ & n.s. & n.s. \\
\hline & $\mathrm{C} 8$ & $7.93 *$ & n.s. & n.s. & n.s. \\
\hline Gp\% & $\mathrm{C} 2$ & n.s. & n.s. & $20.13^{*}$ & n.s. \\
\hline \multirow[t]{3}{*}{ Gn\% } & $\mathrm{C} 2$ & n.s. & n.s. & $8.87 *$ & n.s. \\
\hline & $\mathrm{C} 4$ & n.s. & $12.62 *$ & n.s. & n.s. \\
\hline & $\mathrm{C} 8$ & $23.5 * *$ & n.s. & n.s. & n.s. \\
\hline \multirow[t]{2}{*}{ Gp_Gn } & $\mathrm{C} 2$ & n.s. & n.s. & $18.90 *$ & n.s. \\
\hline & $\mathrm{C} 4$ & n.s. & n.s. & n.s. & $13.1 *$ \\
\hline \multirow[t]{3}{*}{ Fun \% } & $\mathrm{C} 2$ & n.s. & n.s. & $40.43 * *$ & n.s. \\
\hline & $\mathrm{C} 4$ & $13.7 *$ & $31.5^{* *}$ & n.s. & n.s. \\
\hline & $\mathrm{C} 8$ & $16.0 *$ & n.s. & n.s. & n.s. \\
\hline \multirow[t]{3}{*}{ F_B } & $\mathrm{C} 2$ & n.s. & n.s. & $38.6^{* *}$ & n.s. \\
\hline & $\mathrm{C} 4$ & $13.1 *$ & $28.2 * *$ & n.s. & n.s. \\
\hline & $\mathrm{C} 8$ & $19.5^{*}$ & n.s. & n.s. & n.s. \\
\hline \multirow[t]{2}{*}{ Mes\% } & $\mathrm{C} 4$ & $13.5^{*}$ & $630.7 * * *$ & n.s. & n.s. \\
\hline & $\mathrm{C} 8$ & $8.83 *$ & $19.8 *$ & n.s. & n.s. \\
\hline Count & All & n.s. & n.s. & n.s. & n.s. \\
\hline Fresh w. & All & n.s. & n.s. & n.s. & n.s. \\
\hline Dry w. & All & n.s. & n.s. & n.s. & n.s. \\
\hline
\end{tabular}

Data obtained by one-way ANOVA $(n=3 ;)$ performed for each sampling day assuming concentrations as independent variable.

TCP, T. capitata essential oil; CAR, carvacrol; $C 2, C 4$ and C8, EO concentration in the emulsion, 2,4 and

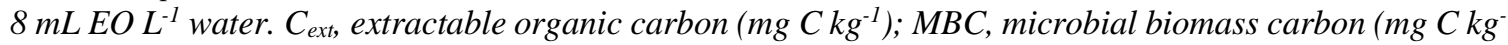
${ }^{1}$ ), $\mathrm{SR}$, soil respiration ( $\left.\mathrm{mg} \mathrm{CO}_{2}-\mathrm{C} \mathrm{kg}^{-1} \mathrm{~d}^{-1}\right) ; \quad q \mathrm{CO}_{2}$, metabolic quotient; FAs, microbial fatty acids (nmol $\mathrm{g}^{-1}$ soil); Bac\%, percentage of bacteria; Gp\%, percentage of Gram-positive bacteria; Gn\% percentage of Gramnegative bacteria; $G p_{-} G n$, Gram-positive to Gram-negative ratio; Fun\%, percentage of fungi; $F \_B$, fungi to bacteria ratio; Mes\%, percentage of mesofauna; Count, number of plants in the sample; Fresh w., collected plants fresh weight; Dry w, collected plants dry weight.

On day 120 significant TCP and CAR at equivalent concentration caused significant effects on 16 of 15 studied variables, on day 30 and 60 significant interactions was evidenced respectively on 13 and 12 dependant variables. On day 180 only four variables 
vas affected by treatments with low $\mathrm{P}$ values. Weeds variables reacted similarly to both treatments.

Significant effects on dependent variables was evidenced comparing TCP C2 and CAR C2 were 16, 14 comparing concentration C8 and 11 between CAR C4 and TCP C4.

Table 37: Significant (*, $P<0.05 ; * *, P<0.01 ; * * *, P<0.001 ;$ n.s, not significant) mean differences of biochemical variables among concentrations determined at each repetition 30, 60, 120 and 180 days after TCP and CAR treatments application.

\begin{tabular}{|c|c|c|c|c|c|c|c|c|c|}
\hline \multirow{2}{*}{$\begin{array}{l}\text { Dep. } \\
\text { Var. }\end{array}$} & \multirow{2}{*}{$\begin{array}{l}\text { Ind. } \\
\text { Var. }\end{array}$} & \multicolumn{4}{|c|}{ TCP } & \multicolumn{4}{|c|}{ CAR } \\
\hline & & Day 30 & Day 60 & Day 120 & Day 180 & Day 30 & Day 60 & Day 120 & Day 180 \\
\hline \multirow[t]{4}{*}{$\mathrm{C}_{\text {ext }}$} & FIT - C2 & n.s. & $-47.4 *$ & n.s. & $-108.2 * *$ & n.s. & n.s. & n.s. & $-80.2 * *$ \\
\hline & FIT - C4 & n.s. & $-36.7 *$ & n.s. & $-112.6 * *$ & n.s. & n.s. & n.s. & $-93.4 * * *$ \\
\hline & FIT - C8 & n.s. & n.s. & n.s. & $-120.6 * *$ & n.s. & n.s. & n.s. & $-109 * * *$ \\
\hline & $\mathrm{C} 2-\mathrm{C} 8$ & n.s. & n.s. & n.s. & n.s. & $-78.3 * *$ & n.s. & n.s. & n.s. \\
\hline \multirow[t]{5}{*}{ MBC } & $\mathrm{FIT}-\mathrm{C} 2$ & n.s. & n.s. & $233 * * *$ & n.s. & n.s. & n.s. & $284 * * *$ & n.s. \\
\hline & FIT - C4 & n.s. & n.s. & $308 * * *$ & n.s. & n.s. & n.s. & $338 * * *$ & n.s. \\
\hline & FIT - C8 & n.s. & n.s. & $138.7 * *$ & n.s. & n.s. & n.s. & $327 * * *$ & n.s. \\
\hline & $\mathrm{C} 4-\mathrm{C} 8$ & n.s. & n.s. & $-169.4 * *$ & n.s. & n.s. & n.s. & n.s. & n.s. \\
\hline & $\mathrm{C} 2-\mathrm{C} 8$ & n.s. & n.s. & $-94.9 *$ & n.s. & n.s. & n.s. & n.s. & n.s. \\
\hline \multirow[t]{6}{*}{ SR } & C2 - FIT & n.s. & $-54.9 * * *$ & n.s. & n.s. & n.s. & n.s. & n.s. & n.s. \\
\hline & C4 - FIT & n.s. & $-44.2 * * *$ & n.s. & n.s. & n.s. & n.s. & $-25.2 *$ & n.s. \\
\hline & C8 - FIT & n.s. & $-31.4 * *$ & n.s. & n.s. & $45.8 * *$ & $-31.8 *$ & $-21.8^{*}$ & n.s. \\
\hline & $\mathrm{C} 8-\mathrm{C} 2$ & n.s. & $23.5^{*}$ & n.s. & n.s. & $37.8 * *$ & $-52.4 * *$ & n.s. & n.s. \\
\hline & $\mathrm{C} 8-\mathrm{C} 4$ & n.s. & n.s. & n.s. & n.s. & $38.0 * *$ & n.s. & n.s. & n.s. \\
\hline & $\mathrm{C} 2-\mathrm{C} 4$ & n.s. & n.s. & n.s. & n.s. & n.s. & $35.5 *$ & n.s. & n.s. \\
\hline \multirow[t]{6}{*}{$\mathrm{qCO}_{2}$} & C2 - FIT & n.s. & $-10.6^{*}$ & $15.3 * *$ & n.s. & n.s. & n.s. & $17.0 * *$ & n.s. \\
\hline & $\mathrm{C} 2-\mathrm{C} 4$ & n.s. & n.s. & $-26.6 * * *$ & n.s. & n.s. & n.s. & $-18.3 * *$ & n.s. \\
\hline & C4 - FIT & n.s. & $-11.6^{*}$ & $41.9 * * *$ & n.s. & n.s. & n.s. & $35.3 * * *$ & n.s. \\
\hline & C8 - FIT & n.s. & n.s. & n.s. & n.s. & $28.5 * * *$ & $-8.4^{*}$ & $27.3 * * *$ & n.s. \\
\hline & $\mathrm{C} 8-\mathrm{C} 2$ & n.s. & n.s. & $-9.5^{*}$ & n.s. & $29.1 * * *$ & n.s. & $10.4^{*}$ & n.s. \\
\hline & $\mathrm{C} 8-\mathrm{C} 4$ & n.s. & n.s. & $-36.1 * * *$ & n.s. & $33.6 * * *$ & n.s. & n.s. & n.s. \\
\hline
\end{tabular}

Data obtained by Tukey post-hoc test $(n=3)$ performed for each sampling day (30, 60, 120 and 180) assuming concentration (FIT, C1, C2, C4) as independent variable. FIT, Fitoil only treatment; TCP, T. capitata EO emulsion; CAR, carvacrol emulsion; $C 2, C 4$ and $C 8$, treatment concentration in the emulsion, 2,4 and $8 \mathrm{~mL} E O$ (or the corresponding percentage of carvacrol) $L^{-1}$ water.

$C_{\text {ext }}$, extractable organic carbon $\left(m g C \mathrm{~kg}^{-1}\right) ; M B C$, microbial biomass carbon $\left(m g \mathrm{Cg}^{-1}\right), S R$, soil respiration ( $\mathrm{mg} \mathrm{CO}_{2}-\mathrm{C} \mathrm{kg}^{-1} \mathrm{~d}^{-1}$ ); $q \mathrm{CO}_{2}$, metabolic quotient.

\section{Cext}

In CAR C2 treated soils was measured higher $\mathrm{C}_{\mathrm{ext}}$ values if compared to TCP C2 during all the experiment, among C4 concentrations such difference has the opposite sign on day 60 and the same on day 180. C8 treatments showed no differences in $\mathrm{C}_{\mathrm{ext}}$ (table 36 and 37).

Comparing the natural products effects among concentrations and with the Fitoil by the one-way ANOVA (table 38, figures $57 \mathrm{a}$ and b), the most evident natural products effect is on day 180, with a drastic increase of extractable carbon in TCP and CAR treated soils.

Thymbra capitata (L.) Cav. EO treatments showed a concentration effect on day 60 and 180, differences with Fitoil was significant only on day 60 and for the concentrations C2 and $\mathrm{C} 4$. 
Carvacrol treatments compared to the Fitoil control, except for the last sampling day, caused no significant effect on $\mathrm{C}_{\text {ext }}$. One significant difference between CAR C2 and CAR C8 was also evidenced by the ANOVA.

\section{MBC}

The significant result on day 30 in table 37 is due to the higher inhibitory effect of CAR C8 compared to FIT C8. On day 120 all the concentrations showed differences between the natural products treatments, having each CAR concentration lower values tan the corresponding TCP one. Day 120 is also the only one on which differences among the natural herbicides was significant as all the treatments, compared to the Fitoil control, inhibit microbial biomass development. There is no concentration effect in CAR samples, while in TCP ones the effects are apparently not related to the concentration.

\section{SR}

Differences among equivalent concentrations was evidenced by the student t-test during the first 120 sampling day (table 36), also the two natural herbicides effects trends appear different (figure 57 e and f). The first difference was due to a temporary increment of soil respiration in CAR C8 treated soils, whom value was significantly higher than all the other treatments (tables 36 and 37). On the second sampling day, the difference among corresponding concentrations was significant for the C2 and C4, SR values measured in TCP treated soils was significantly lower than in FIT and CAR C2 ones, and the lower concentration caused higher decrease. SR in CAR C2 treated soils, since day 60, followed a more similar trend to FIT samples than the other CAR and FIT treated ones. After that date, TCP treated soils SR values obscilled near the control ones, while in CAR C4 and C8 treated soil SR remained lower than FIT and all TCP treatments, showing a longer persistence.

\section{$\mathrm{qCO}_{2}$}

Observing $\mathrm{qCO}_{2}$ graphics in figure $57 \mathrm{~g}$ and $\mathrm{h}$ it is possible to affirm that natural products effects persisted until day 120, and that the significant differences described about MBC and SR appears amplified. The strong differences between TCP C8 and CAR C8 in MBC and SR are composed in the variable $\mathrm{qCO}_{2}$ values on days 30 and 120 (table 36), as well visible in graphs $\mathrm{g}$ and $\mathrm{h}$ and in table 37. In TCP C8 treated soils metabolic quotient remained similar to FIT ones, while in CAR C8 samples $\mathrm{qCO}_{2}$ amply weaved.

CAR C8 treatment first impact was negative for soil microbial respiration efficiency, with $\mathrm{qCO}_{2}$ values doubled if compared to all the others CAR, TCP and FIT samples. Following (day 60) values decreased under those measured in FIT samples, then growth again on day 
120 (also compared to CAR C2) and returned to the FIT levels on the last sampling day. Oscillation amplitude appears even smaller during time. TCP and CAR C4 treatments showed comparable trends: enhanced soil respiration efficiency along the first two months but caused a drastic increase of $\mathrm{qCO}_{2}$ values (at least triplicated) on day 120 . The t-test significant result on day 60 is due to the stronger TCP C4 effect, that during all the experiment caused more ample swings in $\mathrm{qCO}_{2}$ trend than $\mathrm{CAR} \mathrm{C} 4$.

A similar discussion can be done about $\mathrm{C} 2$ treatments, with less wide $\mathrm{qCO}_{2}$ oscillations compared to the corresponding $\mathrm{C} 4$ trends, lower short-term (day 30 and 60) impact in TCP samples and significantly lower values in CAR than TCP samples on day 180.

$\boldsymbol{A}$

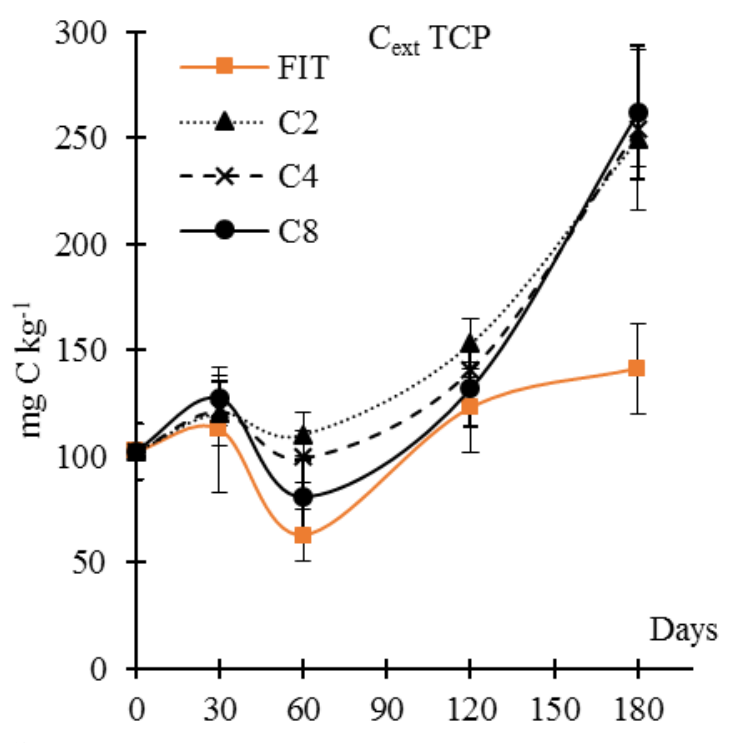

C

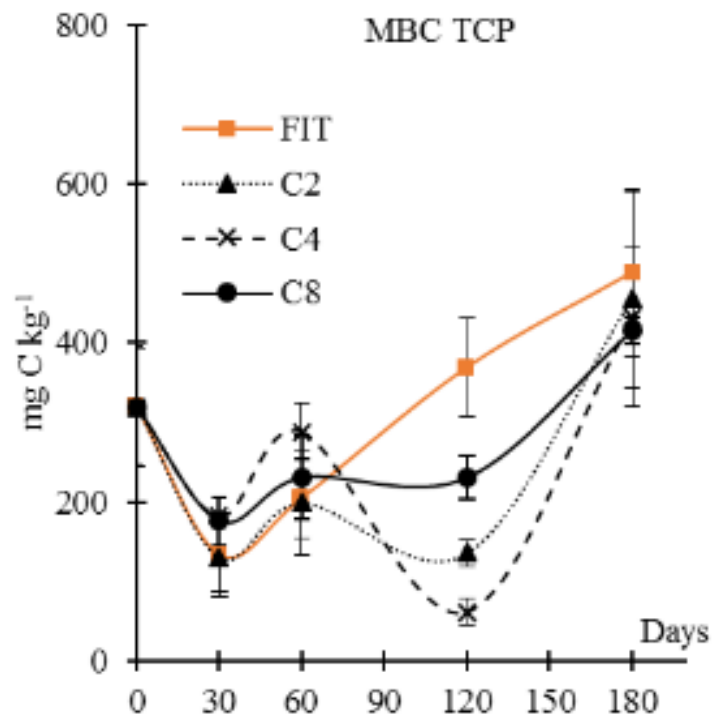

B
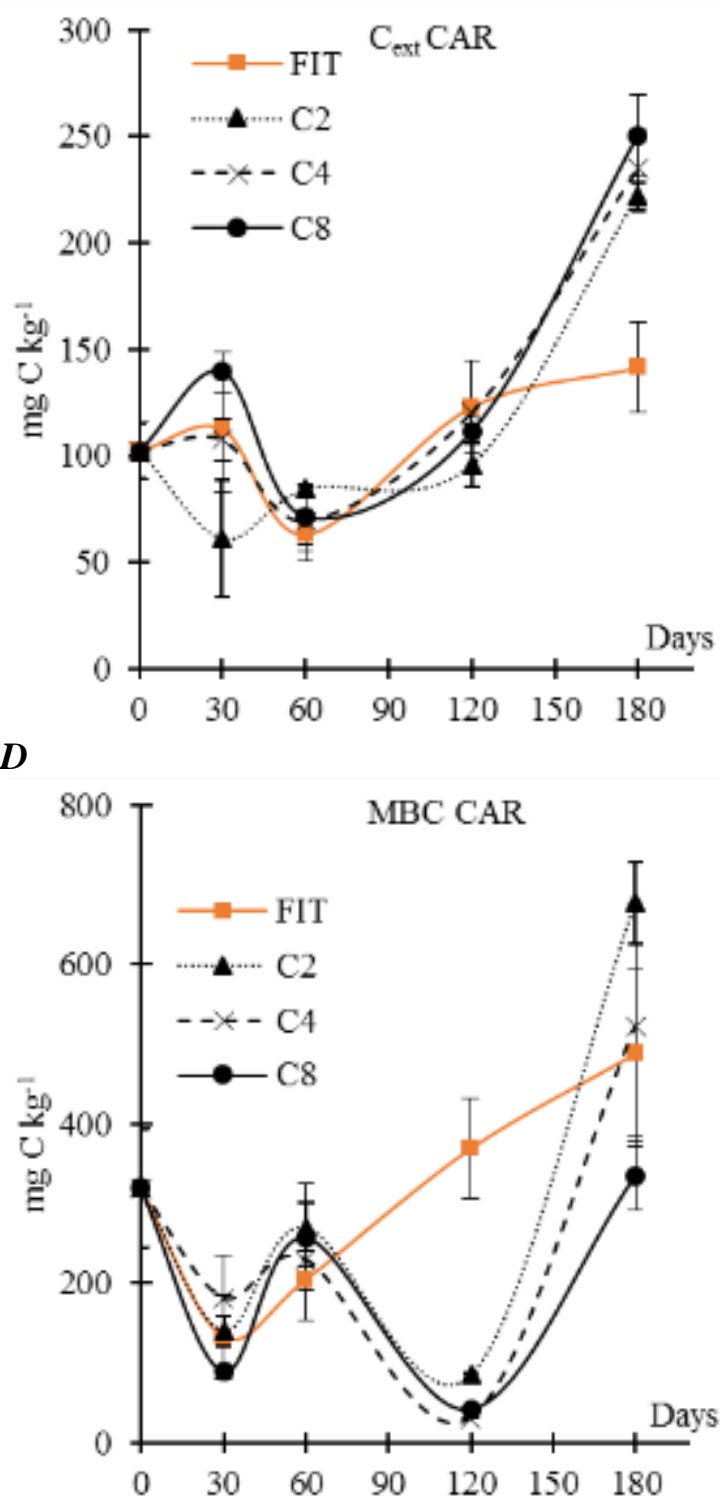

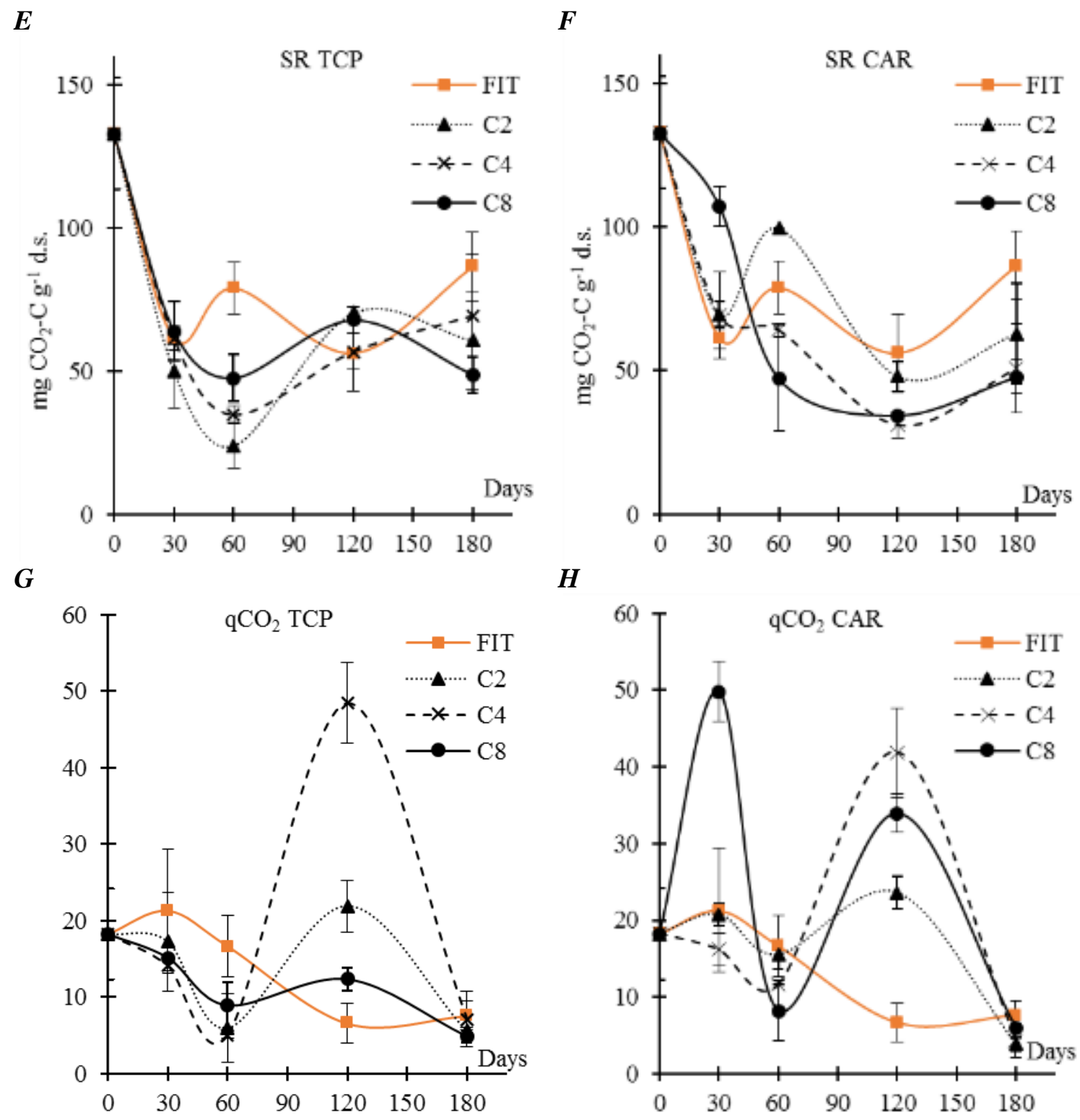

Figure 57: Biochemical soil variables determined at days 30, 60, 120 and 180 in the TCP (Thymbra capitata $E O)$ and CAR (carvacrol) treatments at different concentration (C2, C4 and C8 are, respectively, 2, 4 and 8 $m L$ of essential oil per litre of water)

$A$ and B) $C_{\text {ext, }}$ extractable organic carbon; $C$ and D) $M B C$, microbial biomass carbon; $E$ and F) SR, soil respiration; $\mathrm{G}$ and $\mathrm{H}) q \mathrm{CO}_{2}$, metabolic quotient. Reported results are means of three samples, bars are standard deviations.

\section{FAs}

As for MBC, natural products treatments negatively influenced microbial fatty acids measured in treated soil compared to the control only on medium-term (day 60 and 120, figure 58 table 38). Student t-test evidenced significant differences among C8 treatments on day 30 and 180 (table 38), comparing figures 58 a and b C8 trends appear very different along all the experimental time. The higher concentration caused medium-term significant differences to the fitoil treatment only in CAR samples. 
TCP EO concentration trends can be divided in two groups (figure $58 \mathrm{a}$ and $\mathrm{b}$ ). In the first one, composed by $\mathrm{C} 2$ and C4, microbial fatty acids amount remained around 250-300 nmol $\mathrm{g}^{-1}$ soil at short and medium term and was similar to the other treatments on day 180. In the second group C8 reached a minimal value of FAs, comparable to the one measured in FIT samples on day 60, then constantly growth until the last sampling day.

All the CAR treatments, on the contrary, showed similar trends. CAR treated soils FAs values was higher than in control soils on days 30 and 60, remained constant until day 120 and then growth reaching the fitoil values.

\section{Bacteria}

Student t-test evidenced significant differences in Bac\% and Gn\% bioindicators on day 30 (TCP C8 < CAR C8), 60 (CAR C4 < TCP C4) and 180 (TCP C2 < CAR C2). Grampositive bioindicator scored only one significant difference on day 180 , because in TCP C2 treated soils Gp\% remained similar to day 120 instead to decrease as all the other samples have done. Gram-positive to negative ratio differently reacted to $\mathrm{C} 2$ on day 120 and $\mathrm{C} 4$ on day 180, with higher values in TCP treated soils.

In figure $58 \mathrm{~d}$ and in table 38 , it is possible to observe that CAR treatments have not influenced bacteria populations if compared to the control soils. On the other hand (figure 58 c) only TCP C8 treatment influenced detected bacterial FAs amount, in particular with a negative short-term impact.

Gram-positive populations in treated soils not significantly varied comparing TCP and FIT treated pots, while a clear concentration effect can be evidenced for CAR treatments on day 60 (figures $58 \mathrm{e}$ and f). In general, it is possible to observe that CAR treated soils maintained constant values on the first 3 sampling days, while in the other samples Gp\% bioindicator suffers more variations during time and depending by treatments and concentrations.

Gn\% bioindicator, oppositely to Gp\%, according to ANOVA results, suffered some effects due to TCP and not to CAR treatments (table 38, figures $58 \mathrm{~h}$ and i). Significant inhibitory effects against Gram-negative bacteria was detected in TCP treated samples among C8 and C2 on day 30 and among all the concentrations and Fitoil on day 180.

Gram-positive to negative ratio reflected CAR treatments stimulation on $\mathrm{Gp} \%$ occurred on day 60. TCP C8 values was significantly higher than FIT on day 60, on day 180 C4 reached the lower values of the graph, significantly lower than the other TCP treatments.

\section{Fungi}


Significant difference among all the concentrations was detected by the student t-test during the first 120 experimental days (table 38). During time significant differences was among the higher concentrations at the beginning, between $\mathrm{C} 4$ on day 60 , and $\mathrm{C} 2$ on day 120.

Comparing ANOVA results, (table 38), only CAR treatments caused significant variations in fungal biomass if compared to the FIT ones, while in TCP treated soils significant differences occurred only on day 30 among the treatments concentrations. How it is possible to observe in figure $58 \mathrm{k}$, TCP treatments acted proportionally to the concentration of EO contained in the emulsions, having $\mathrm{C} 8$ and $\mathrm{C} 4$ a relative stimulant effect, and maintaing $\mathrm{C} 2$ the same values of day zero. Later the fungal population physiologically decreased as in control samples, but the decrease was slower in C2 if compared to C8 and C4. Physiological decrease in CAR treated soils ends on day 120 (when before mentioned differences was detected), with a statistically total extinction of detectable fungi.

\section{Fungi to bacteria ratio}

The same evidences among concentrations effects described for the Fun\% bioindicator was evidenced by student-t-test for the F_B bioindicator. Also, the statistical extinction of detectable fungi (on day 120 in all the CAR treated pots) is visible in graph $68 \mathrm{n}$ and significant in table 38. Bacterial population inhibition caused by TCP C8 treatment on day 30 is reflected in fungi to bacteria ratio, as on the same day C8 values was significantly higher than FIT and C2 ones. C8 scored higher values than C2 also on day 120.

\section{Mesofauna}

Different reactions to CAR and TCP treatments was detected among C4 and C8 on the first 3 sampling days, while on day 180 differences among treatments disappeared (table 38). Comparing graphics o and $\mathrm{p}$, in figure 58, it is possible to observe that CAR C4 and C8 inhibited mesofauna on day 30, TCP C4 stimulated it, while the same amount of mesofauna FAs was detected in FIT, TCP C2, TCP C8 and CAR C2.

No significant effects were detected by ANOVA in TCP treated soils. On day 60 it was evidenced a significant inhibitory effect of all CAR treated pots if compared to the control. 
Table 38: Significant (*, $P<0.05$; **, $P<0.01$; ***, $P<0.001$; n.s, not significant) mean differences of fatty acids bioindicators among concentrations determined at each repetition 30, 60, 120 and 180 days after TCP and CAR treatments application

\begin{tabular}{|c|c|c|c|c|c|c|c|c|c|}
\hline \multirow{2}{*}{$\begin{array}{l}\text { Dep. } \\
\text { Var. }\end{array}$} & \multirow{2}{*}{$\begin{array}{l}\text { Ind. } \\
\text { Var. }\end{array}$} & \multicolumn{4}{|c|}{ TCP } & \multicolumn{4}{|c|}{ CAR } \\
\hline & & Day30 & Day60 & Day120 & Day 180 & Day30 & Day60 & Day120 & Day 180 \\
\hline \multirow[t]{3}{*}{ FAs } & FIT - C2 & n.s. & $-160 *$ & n.s. & n.s. & n.s. & $-105.4 * *$ & $171.5 * *$ & n.s. \\
\hline & FIT - C4 & n.s. & n.s. & $162 *$ & n.s. & n.s. & n.s. & $144.4 * *$ & n.s. \\
\hline & FIT - C8 & n.s. & n.s. & n.s. & n.s. & n.s. & $-88.1^{*}$ & $163.4 * *$ & n.s. \\
\hline \multirow[t]{2}{*}{ Вас\% } & C8 - FIT & n.s. & n.s. & n.s. & $1.23 *$ & n.s. & n.s. & n.s. & n.s. \\
\hline & $\mathrm{C} 8-\mathrm{C} 4$ & $-4.81 *$ & n.s. & n.s. & n.s. & n.s. & n.s. & n.s. & n.s. \\
\hline \multirow[t]{5}{*}{ Gp\% } & FIT - C2 & n.s. & n.s. & n.s. & n.s. & n.s. & $-3.95 * *$ & n.s. & n.s. \\
\hline & FIT - C4 & n.s. & n.s. & n.s. & n.s. & n.s. & $-3.01 *$ & n.s. & n.s. \\
\hline & FIT - C8 & n.s. & n.s. & n.s. & n.s. & n.s. & $-2.93 *$ & n.s. & n.s. \\
\hline & $\mathrm{C} 4-\mathrm{C} 8$ & n.s. & n.s. & n.s. & $-2.64 *$ & n.s. & n.s. & n.s. & n.s. \\
\hline & $\mathrm{C} 4-\mathrm{C} 2$ & n.s. & n.s. & n.s. & $-3.21 * *$ & n.s. & n.s. & n.s. & n.s. \\
\hline \multirow[t]{3}{*}{ Gn\% } & C2 - FIT & n.s. & n.s. & n.s. & $-3.83 *$ & n.s. & n.s. & n.s. & n.s. \\
\hline & C8 - FIT & n.s. & n.s. & n.s. & $-4.09 *$ & n.s. & n.s. & n.s. & n.s. \\
\hline & $\mathrm{C} 8-\mathrm{C} 2$ & -5.46 n.s. & n.s. & n.s. & n.s. & n.s. & n.s. & n.s. & n.s. \\
\hline \multirow[t]{5}{*}{ Gp_Gn } & FIT - C2 & n.s. & n.s. & n.s. & $-0.051 *$ & n.s. & $-.0822 * *$ & n.s. & n.s. \\
\hline & FIT - C4 & n.s. & n.s. & n.s. & n.s. & n.s. & $-.0717^{*}$ & n.s. & n.s. \\
\hline & FIT - C8 & n.s. & $-4.121 *$ & n.s. & n.s. & n.s. & $-.0678 *$ & n.s. & n.s. \\
\hline & $\mathrm{C} 2-\mathrm{C} 4$ & n.s. & n.s. & n.s. & $0.064 *$ & n.s. & n.s. & n.s. & n.s. \\
\hline & $\mathrm{C} 8-\mathrm{C} 4$ & n.s. & n.s. & n.s. & $0.054 *$ & n.s. & n.s. & n.s. & n.s. \\
\hline \multirow[t]{5}{*}{ Fun\% } & FIT - C2 & n.s. & n.s. & n.s. & n.s. & n.s. & n.s. & $.230 * * *$ & n.s. \\
\hline & FIT - C4 & n.s. & n.s. & n.s. & n.s. & n.s. & n.s. & $.227 * * *$ & n.s. \\
\hline & FIT - C8 & n.s. & n.s. & n.s. & n.s. & n.s. & n.s. & $.208 * * *$ & n.s. \\
\hline & $\mathrm{C} 4-\mathrm{C} 2$ & n.s. & n.s. & $-0.198 *$ & n.s. & n.s. & n.s. & n.s. & n.s. \\
\hline & $\mathrm{C} 8-\mathrm{C} 2$ & $2.896^{*}$ & n.s. & $-0.248 *$ & n.s. & n.s. & n.s. & n.s. & n.s. \\
\hline \multirow[t]{4}{*}{ F_B } & FIT - C2 & n.s. & n.s. & n.s. & n.s. & n.s. & n.s. & $.002 * * *$ & n.s. \\
\hline & FIT - C4 & n.s. & n.s. & n.s. & n.s. & n.s. & n.s. & $.002 * * *$ & n.s. \\
\hline & FIT - C8 & $-.026^{*}$ & n.s. & n.s. & n.s. & n.s. & n.s. & $.002 * * *$ & n.s. \\
\hline & $\mathrm{C} 2-\mathrm{C} 8$ & $-2.896 *$ & n.s. & $0.248 *$ & n.s. & n.s. & n.s. & n.s. & n.s. \\
\hline \multirow[t]{3}{*}{ Mes\% } & FIT - C2 & n.s. & n.s. & 142n.s. & n.s. & n.s. & $0.90 *$ & n.s. & n.s. \\
\hline & FIT - C4 & n.s. & n.s. & n.s. & n.s. & n.s. & $1.35 * *$ & n.s. & n.s. \\
\hline & FIT - C8 & n.s. & n.s. & n.s. & n.s. & n.s. & $1.05 *$ & n.s. & n.s. \\
\hline
\end{tabular}

Data obtained by Tukey post-hoc test $(n=3)$ performed for each sampling day (30, 60, 120 and 180) assuming concentration (FIT, C2, C4, C8) as independent variable.

FIT, Fitoil; TCP, T. capitata EO emulsion; CAR, carvacrol emulsion; $C 2, C 4$ and $C 8, E O$ concentration in the emulsion, 2,4 and $8 \mathrm{~mL} E O$ (or the corresponding percentage of carvacrol) $L^{-1}$ water.

FAs, microbial fatty acids ( mol $^{-1}$ soil); Bac\%, percentage of bacteria; Gp\%, percentage of Gram-positive bacteria; Gn\% percentage of Gram-negative bacteria; Gp_Gn, Gram-positive to Gram-negative ratio; Fun\%, percentage of fungi; $F \_B$, fungi to bacteria ratio; Mes\%, percentage of mesofauna. 
A

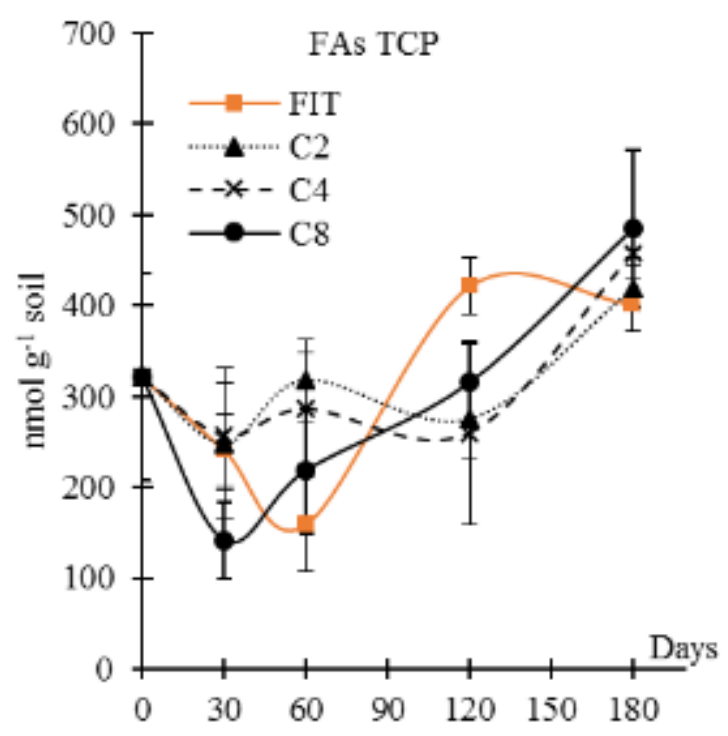

C

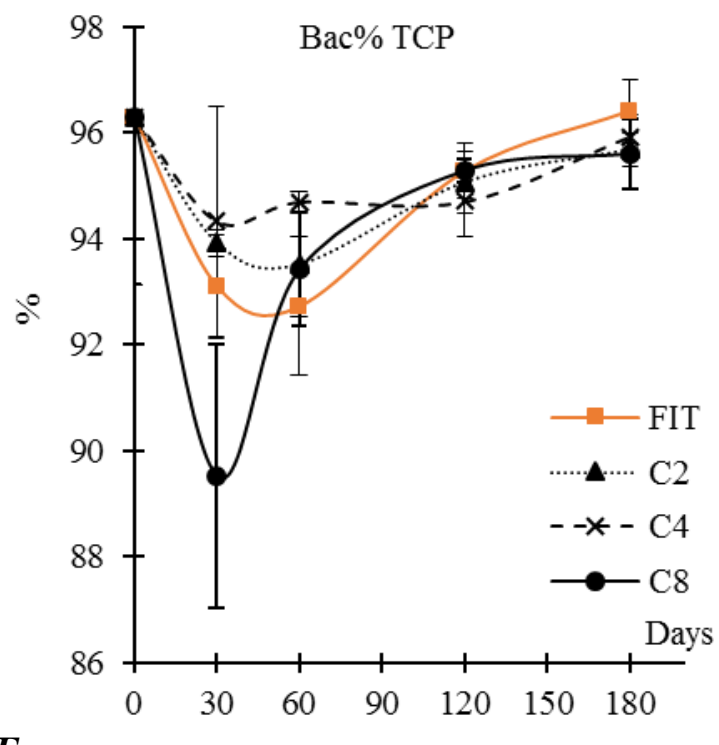

B

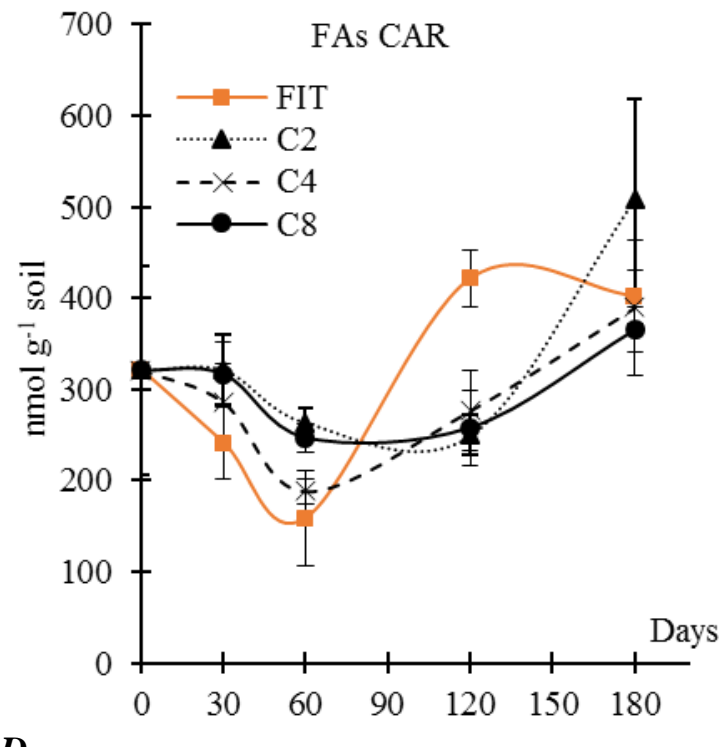

D
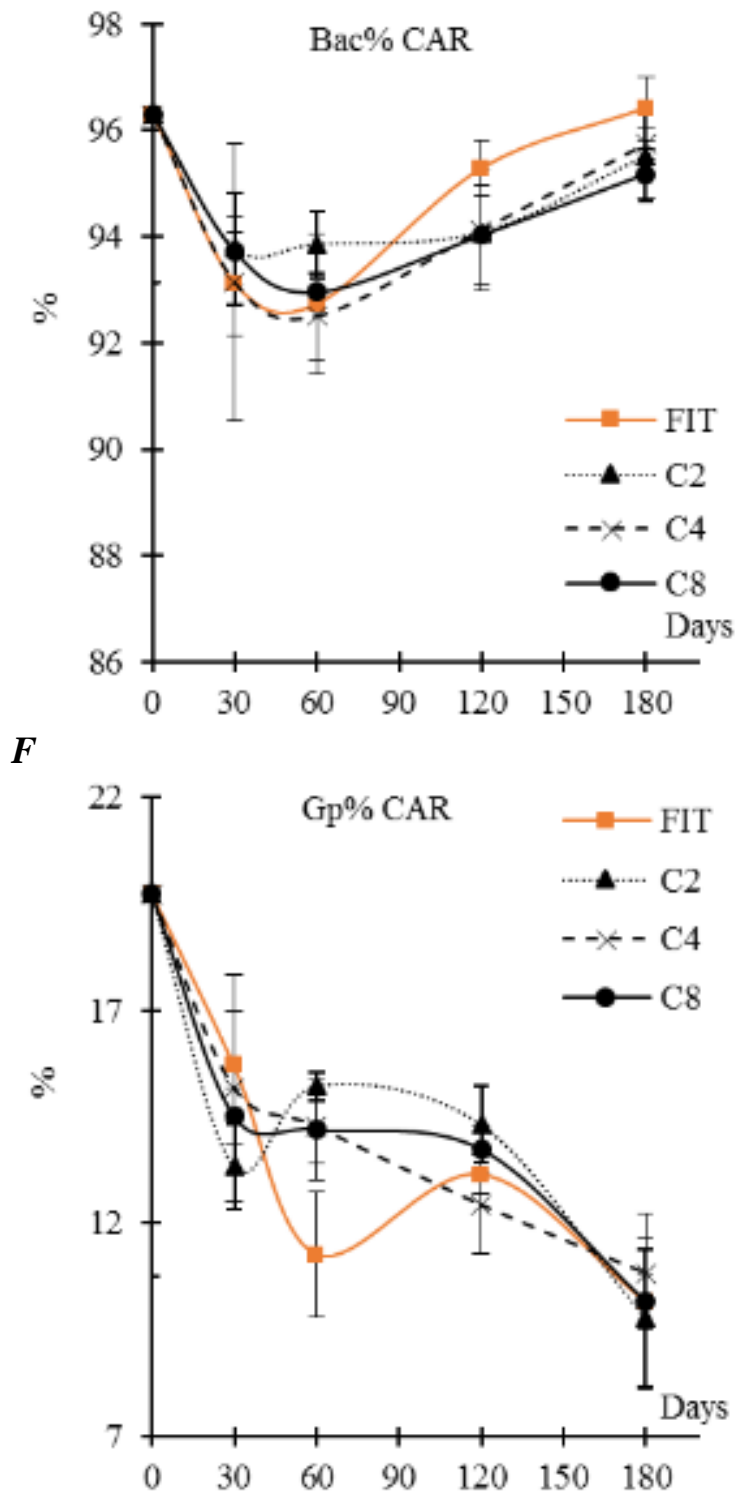
G

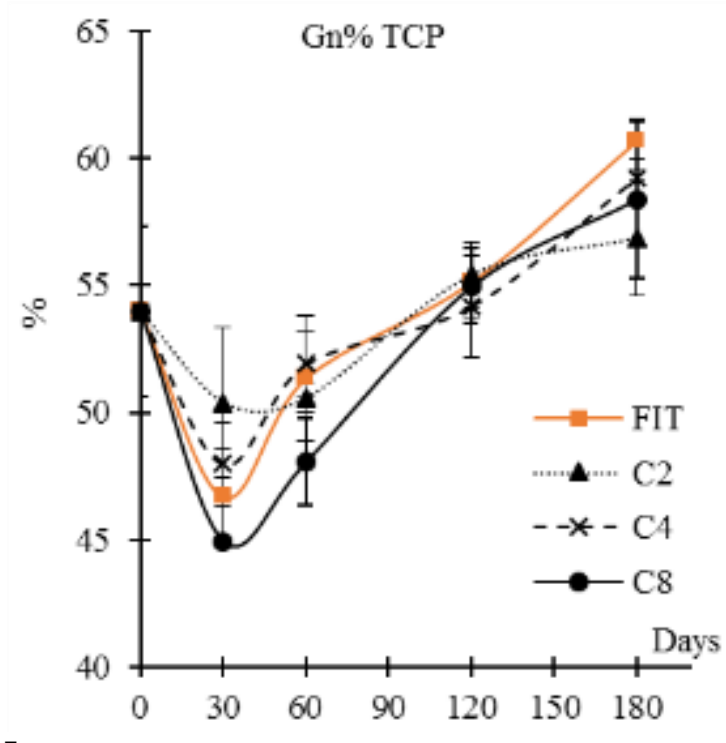

I

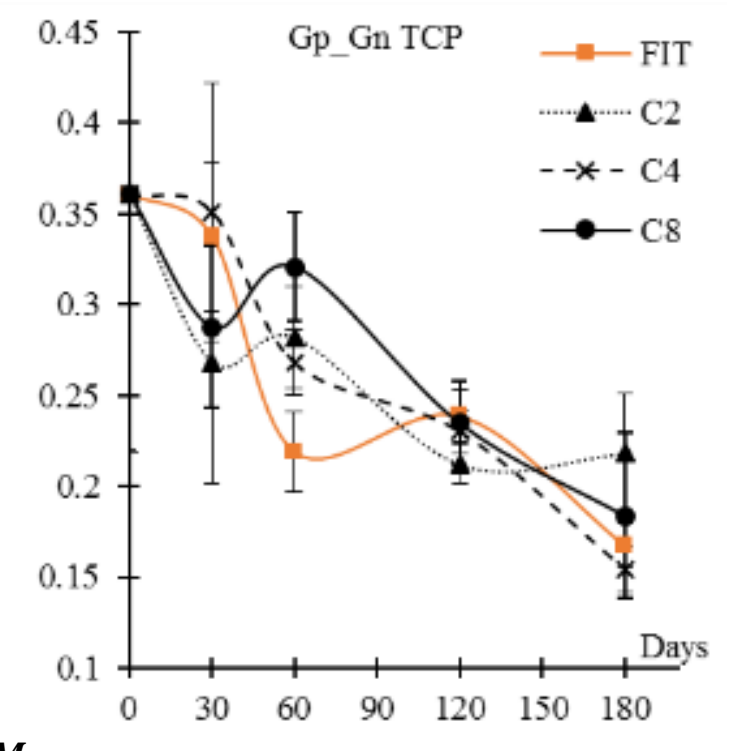

$\boldsymbol{H}$

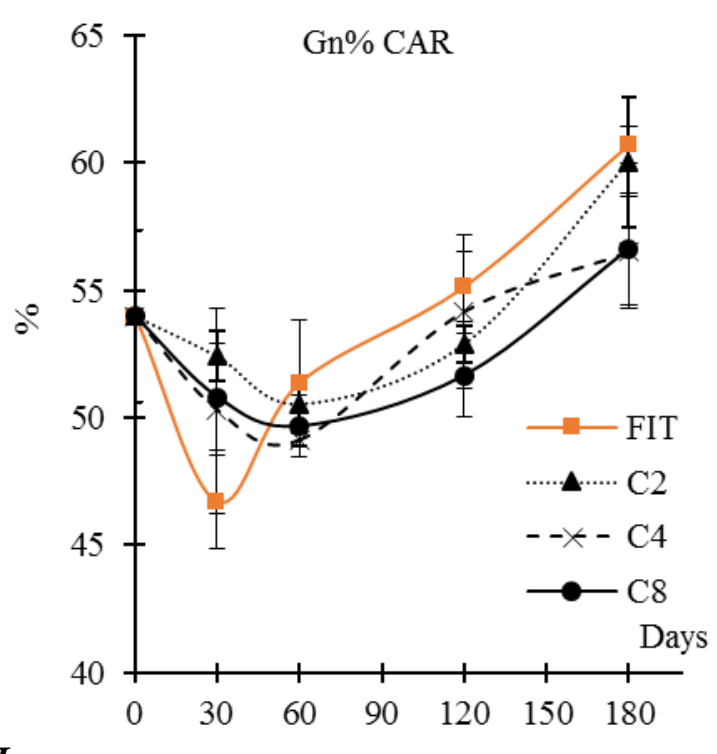

$L$

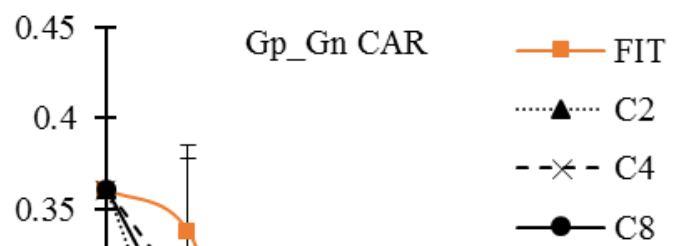

M

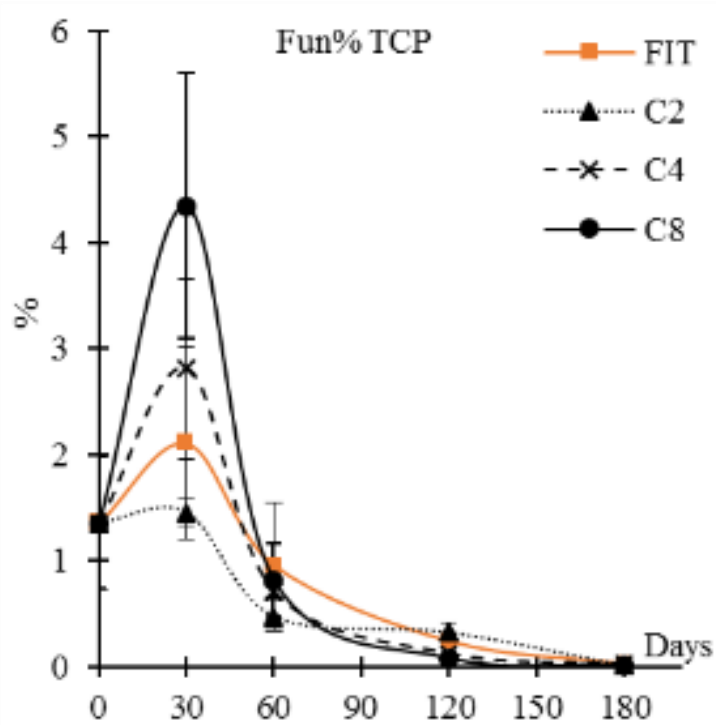

$N$

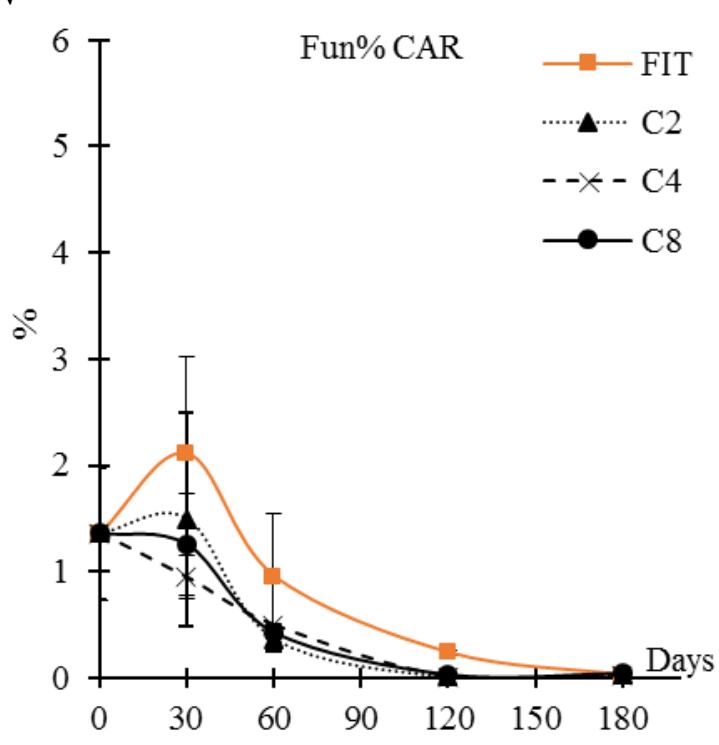


Oddo M. - Effects of different weed control practices on soil quality in mediterranean crops
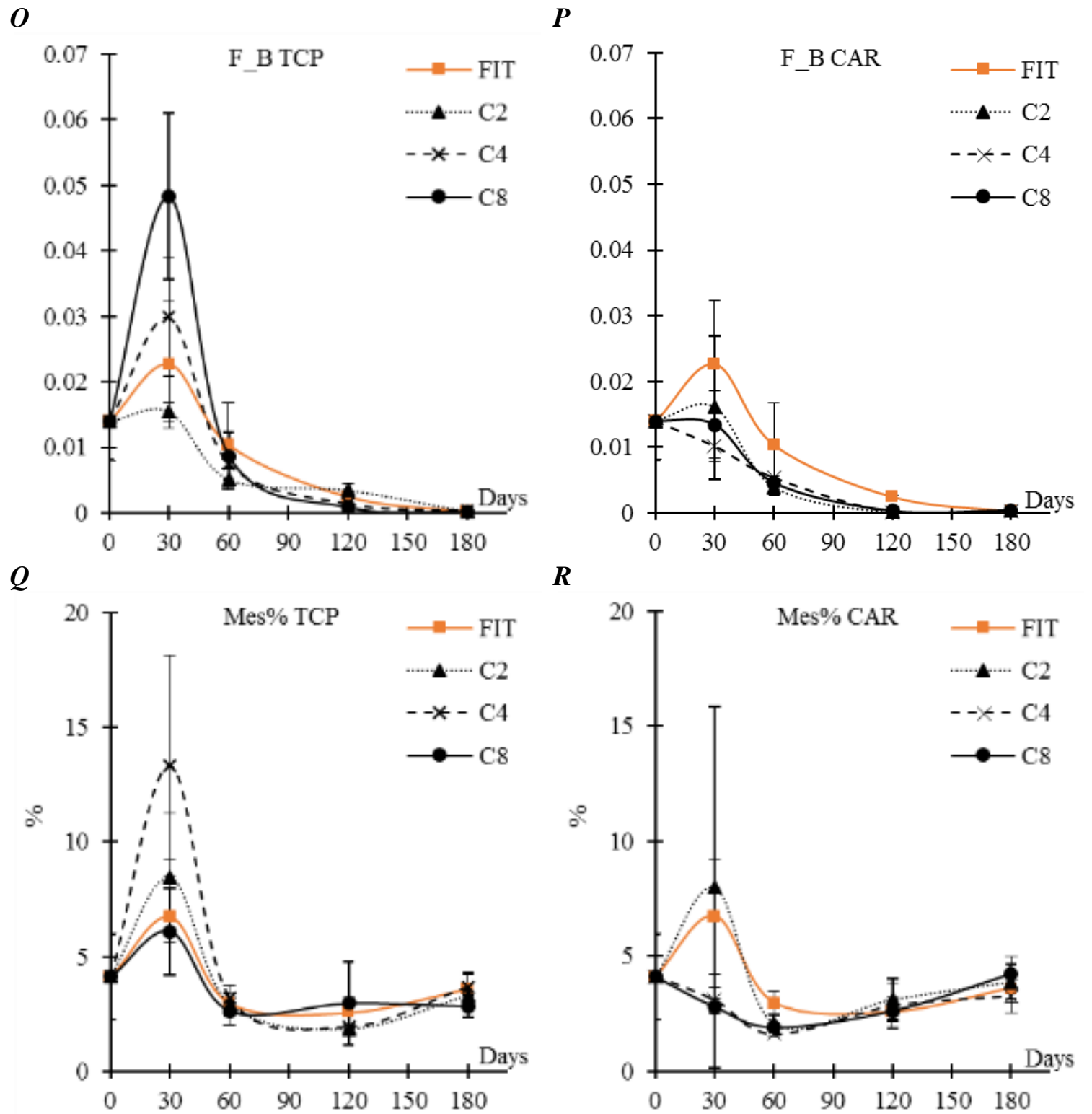

Figure 58: Microbial community structure determined at days 30, 60, 120 and 180 in the TCP (Thymbra capitata $E O)$ and CAR (carvacrol) treatments at different concentration $(C 2, C 4$ and $C 8$ are, respectively, 2,4 and $8 \mathrm{~mL}$ of essential oil per litre of water)

$A$ and B) FAs, microbial fatty acids; $C$ and D) Bac\%, percentage of bacteria; $E$ and $F$ ) Gp\%, percentage of Gram-positive bacteria; $G$ and $H$ ) Gn\% percentage of Gram-negative bacteria; I and L) Gp_Gn, Grampositive to Gram-negative ratio; $M$ and $N) F u n \%$, percentage of fungi; $O$ and $P) F$ B , fungi to bacteria ratio; $Q$ and $R$ ) Mes\%, percentage of mesofauna.

Showed values represents the mean values, bars are standard deviation $(n=3)$. 


\section{Weeds variables}

No differences in the effects of CAR and TCP treatments were detected by Student t-test on weeds variables. In all treatments, the effects were proportional to the concentration (figure 59 a-f).

Weed germination was initially stimulated by TCP C4 treated pots, where the plant number, fresh and dry weight are significantly higher if compared to $\mathrm{C} 2$ on the first sampling day only. Fresh weight measured on day 30 was also significantly higher in C4 if compared to Fitoil treated samples.

Table 39: Significant ( $*, P<0.05 ; * *, P<0.01 ; * * *, P<0.001 ;$ n.s, not significant) mean differences of weeds variables among concentrations determined at each repetition 30, 60, 120 and 180 days after TCP and CAR treatments application.

\begin{tabular}{lc|cccc|cccc}
\hline Dep. Var. & Ind. Var. & \multicolumn{4}{|c|}{ TCP } & \multicolumn{4}{c}{ CAR } \\
& & Day 30 & Day 60 & Day 120 & Day 180 & Day 30 & Day 60 & Day 120 & Day 180 \\
\hline Count & C2 - C4 & $-54.6^{*}$ & n.s. & n.s. & n.s. & n.s. & n.s. & n.s. & n.s. \\
Fresh w. & FIT - C4 & $-7.36^{*}$ & n.s. & n.s. & n.s. & n.s. & $3.50^{*}$ & n.s. & n.s. \\
& C2 - C4 & $-11.07^{* *}$ & n.s. & n.s. & n.s. & n.s. & n.s. & n.s. & n.s. \\
& C2 - C 8 & $-8.95^{*}$ & n.s. & n.s. & n.s. & n.s. & n.s. & n.s. & n.s. \\
Dry w. & FIT - C2 & n.s. & n.s. & n.s. & n.s. & $-1.10^{*}$ & n.s. & n.s. & n.s. \\
& FIT - C4 & $-1.03^{*}$ & n.s. & n.s. & n.s. & n.s. & n.s. & n.s. & n.s. \\
& C2 - C4 & $-1.33^{* *}$ & n.s. & n.s. & n.s. & n.s. & n.s. & n.s. & n.s. \\
\hline
\end{tabular}

Data obtained by Tukey post-hoc test ( $n=3)$ performed for each sampling day (30, 60, 120 and 180) assuming concentration (FIT, C2, C4, C8) as independent variable.

FIT, Fitoil; TCP, T. capitata EO emulsion; CAR, carvacrol emulsion; C2, C4 and C8, EO concentration in the emulsion, 2,4 and $8 \mathrm{~mL} E O$ (or the corresponding percentage of carvacrol) $L^{-1}$ water. Count, number of plants in the sample; Fresh w., collected plants fresh weight; Dry w, collected plants dry weight. 
$\boldsymbol{A}$

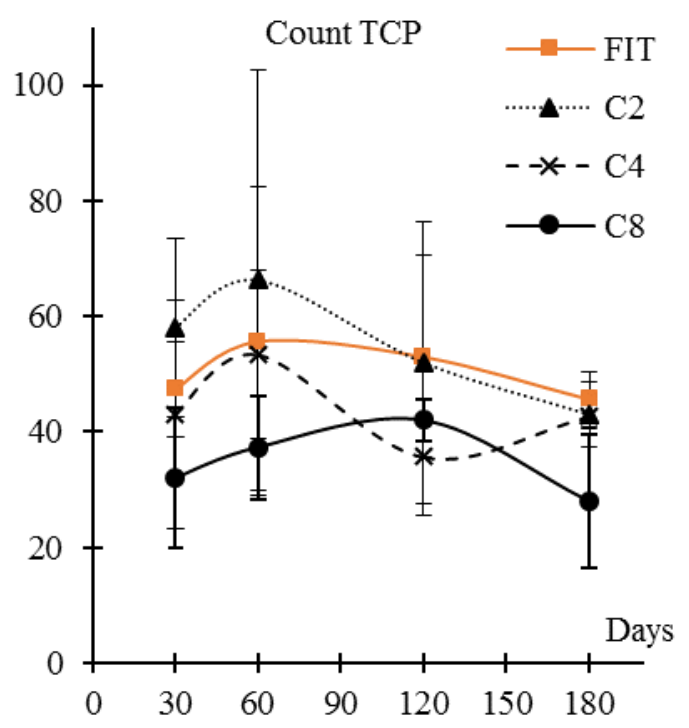

$C$

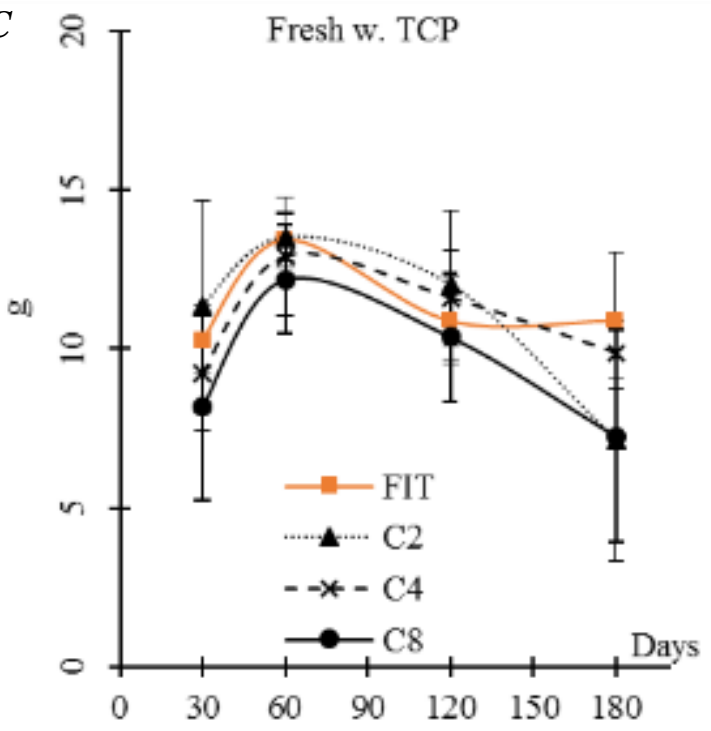

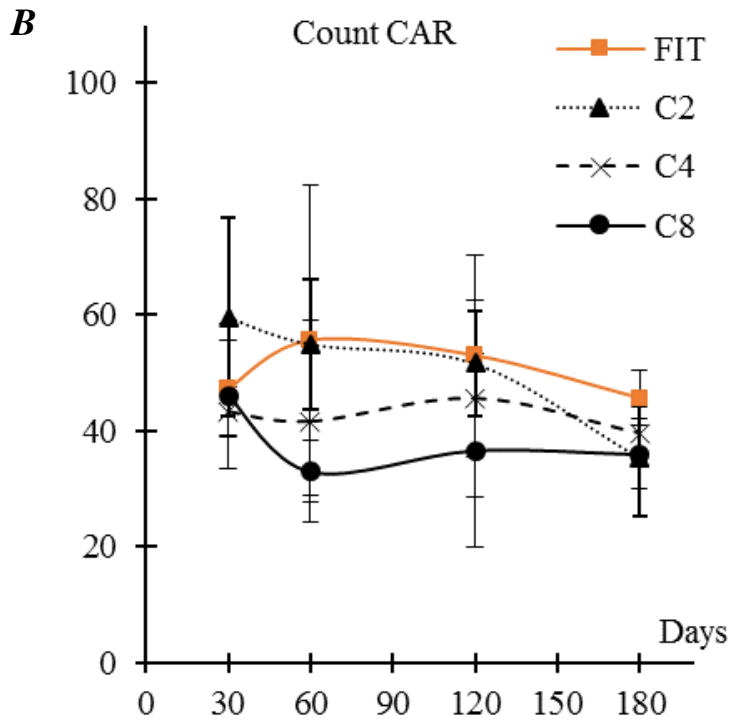

D 으 T Fresh w. CAR
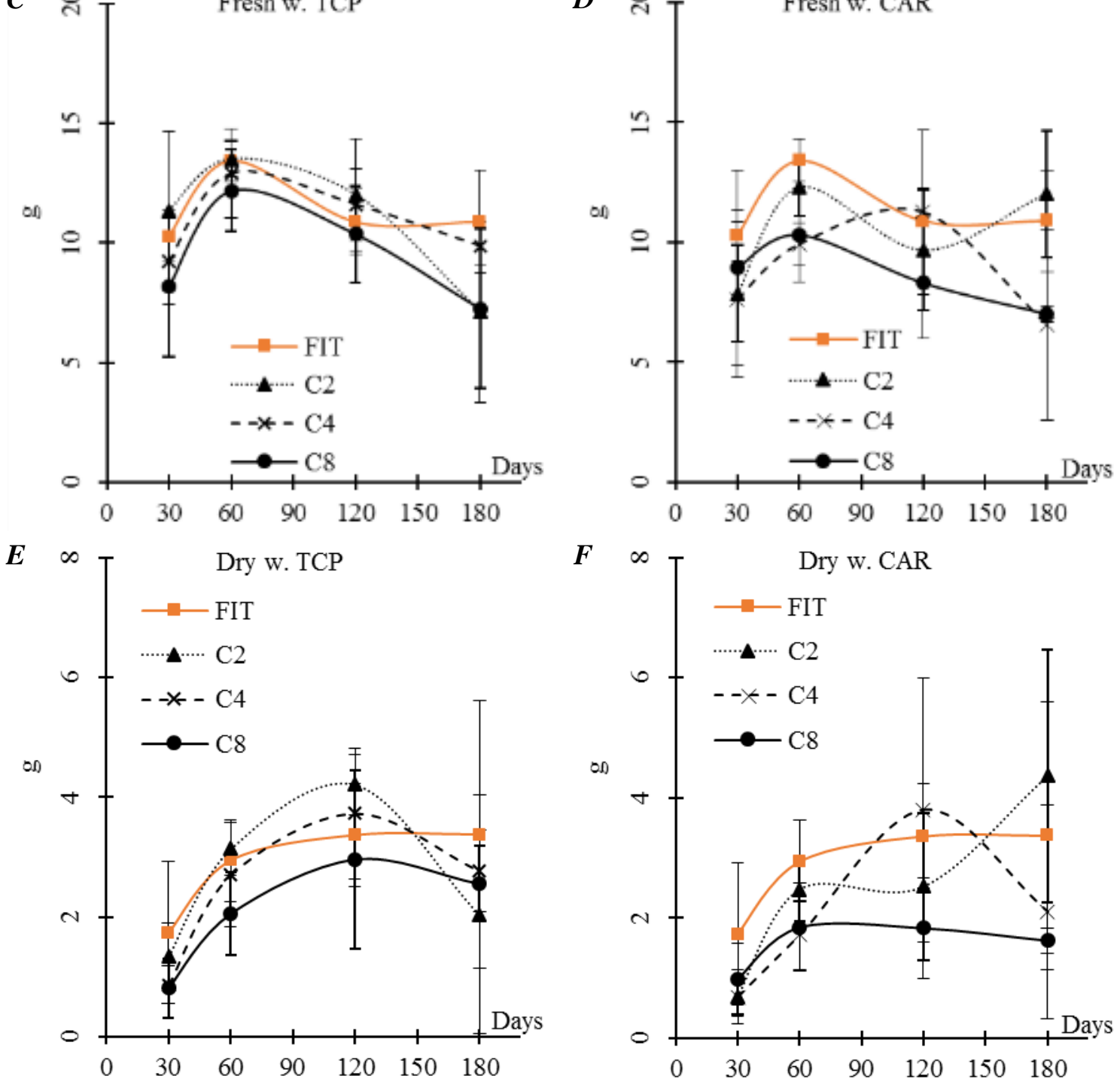

$\boldsymbol{F} \infty \quad$ Dry w. CAR

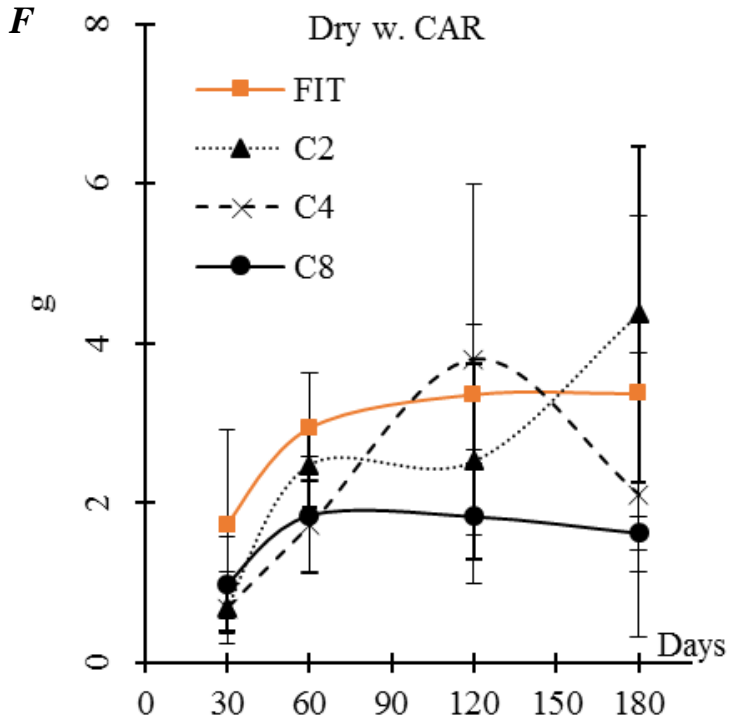

Figure 59: Weeds variables determined at days 30, 60, 120 and 180 in the TCP (Thymbra capitata EO) and CAR (carvacrol) treatments at different concentration $(C 2, C 4$ and $C 8$ are, respectively, 2, 4 and $8 \mathrm{~mL}$ of essential oil per litre of water)

$A$ and B) Count, number of counted plants; C and D) Fresh w., fresh weight; $E$ and F) Dry w., dry weight. Reported results are means of three samples, bars are standard deviations. 


\subsubsection{Eriocephalus africanus L. EO}

Eriocephalus africanus L. EO treatments have not significantly influenced any soil variables on day 30 and 120; the bioindicators Fun\%, F_B Gp_Gn and Mes\% was not influenced at all (table 40).

Table 40: Significant (*, $P<0.05 ; * *, P<0.01 ; * * *, P<0.001$; n.s, not significant) mean differences of soil variables among concentrations determined at each repetition 30, 60, 120 and 180 days after FIT and ERI treatments application.

\begin{tabular}{|c|c|c|c|c|c|}
\hline Dep. Var. & Ind. Var. & Day30 & Day60 & Day120 & Day 180 \\
\hline $\mathrm{C}_{\text {ext }}$ & C8 - FIT & n.s. & $-28.8^{*}$ & n.s. & n.s. \\
\hline \multirow[t]{2}{*}{ MBC } & $\mathrm{C} 4-\mathrm{C} 2$ & n.s. & $-119 *$ & n.s. & n.s. \\
\hline & $\mathrm{C} 4-\mathrm{C} 8$ & n.s. & $-190 * *$ & n.s. & n.s. \\
\hline \multirow[t]{4}{*}{ SR } & FIT - C4 & n.s. & $47.5^{* *}$ & n.s. & n.s. \\
\hline & FIT - C8 & n.s. & $58.4 * * *$ & n.s. & n.s. \\
\hline & $\mathrm{C} 2-\mathrm{C} 4$ & n.s. & $27.1 *$ & n.s. & n.s. \\
\hline & $\mathrm{C} 2-\mathrm{C} 8$ & n.s. & $36.0 * *$ & n.s. & n.s. \\
\hline $\mathrm{qCO}_{2}$ & C8 - FIT & n.s. & $-13.8^{*}$ & n.s. & n.s. \\
\hline \multirow[t]{3}{*}{ FAs } & C2 - FIT & n.s. & $166^{* *}$ & n.s. & n.s. \\
\hline & $\mathrm{C} 2-\mathrm{C} 4$ & n.s. & $154^{*}$ & n.s. & n.s. \\
\hline & $\mathrm{C} 2-\mathrm{C} 8$ & n.s. & $137 *$ & n.s. & n.s. \\
\hline \multirow[t]{2}{*}{ Вас\% } & FIT - C8 & n.s. & n.s. & n.s. & $1.27 * *$ \\
\hline & $\mathrm{C} 2-\mathrm{C} 8$ & n.s. & n.s. & n.s. & $1.26 * *$ \\
\hline Gp\% & ALL & n.s. & n.s. & n.s. & n.s. \\
\hline \multirow[t]{3}{*}{ Gn\% } & $\mathrm{C} 2-\mathrm{C} 4$ & n.s. & $4.87 *$ & n.s. & n.s. \\
\hline & $\mathrm{C} 2-\mathrm{C} 8$ & n.s. & $6.51 * *$ & n.s. & $3.96 *$ \\
\hline & FIT - C8 & n.s. & n.s. & n.s. & $4.14^{*}$ \\
\hline Fun \% & ALL & n.s. & n.s. & n.s. & n.s. \\
\hline F_B & ALL & n.s. & n.s. & n.s. & n.s. \\
\hline Gp_Gn & ALL & n.s. & n.s. & n.s. & n.s. \\
\hline Mes\% & ALL & n.s. & n.s. & n.s. & n.s. \\
\hline Count & ALL & n.s. & n.s. & n.s. & n.s. \\
\hline \multirow[t]{2}{*}{ Fresh w. } & $\mathrm{C} 8-\mathrm{C} 2$ & n.s. & n.s. & n.s. & $-7.22 *$ \\
\hline & $\mathrm{C} 8-\mathrm{C} 4$ & n.s. & n.s. & n.s. & $-5.61 *$ \\
\hline Dry w. & ALL & n.s. & n.s. & n.s. & n.s. \\
\hline
\end{tabular}

Data obtained by Tukey post-hoc test $(n=3)$ performed for each sampling day (30, 60, 120 and 180) assuming concentration (FIT, C2, C4, C8) as independent variable. FIT, Fitoil treated soils. ERI, E. africanus EO emulsion; $C 2, C 4$ and C8, EO concentration in the emulsion, 2, 4 and $8 \mathrm{mLEO} \mathrm{L} \mathrm{L}^{-1}$ water.

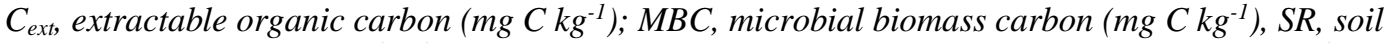
respiration ( $\mathrm{mg} \mathrm{CO}_{2}-\mathrm{C} \mathrm{kg}^{-1} \mathrm{~d}^{-1}$ ); qCO , metabolic quotient; FAs, microbial fatty acids ( $\mathrm{nmol} \mathrm{g}^{-1}$ soil); Bac\%, percentage of bacteria; Gp\%, percentage of Gram-positive bacteria; Gn\% percentage of Gramnegative bacteria; $G p_{-} G n$, Gram-positive to Gram-negative ratio; Fun\%, percentage of fungi; $F \_B$, fungi to bacteria ratio; Mes\%, percentage of mesofauna.

Biochemical soil properties suffered treatment influence on day 60 only (figures 60 a-d). $\mathrm{C}_{\text {ext }}$ and $\mathrm{qCO}_{2}$ was lower in $\mathrm{C} 4$ treated soils than in the Fitoil samples. $\mathrm{MBC}$ was differently influenced by each EO concentration, having $\mathrm{C} 4$ samples the lower and $\mathrm{C} 8$ the higher values. Soil respiration in EO treated soils was inhibited in relation with the EO concentration (higher concentration, more inhibition). 
Even FAs total amount suffered treatments effects only on day 60, and followed a different trend from the $\mathrm{MBC}$ one, resulting $\mathrm{C} 2$ treated soils values higher than all the other treatments ones. Such increase is due mainly to the significant Gn population growth occurred on the same sampling day in C2 treated soils. On day 180, it appeared another significant effect: the $\mathrm{C} 8$ treatment inhibited both $\mathrm{Gn} \%$ and $\mathrm{Bac} \%$ if compared with $\mathrm{C} 2$ and FIT (figure 61).

Among weeds variables (figure 62), fresh weight was the only significantly influenced by the higher concentration of ERI EO (table 40). Nevertheless, in figures 62 a-c it is possible to observe that EO treatments follows different trends if compared to the Fitoil control, and that $\mathrm{C} 8$ concentration inhibited weed growth more than $\mathrm{C} 2$ and $\mathrm{C} 4$ until day 120 at least. A minor number of weed was counted in in $\mathrm{C} 8$ treated pots compared to the Fitoil control during all the experimental period; it was true also in $\mathrm{C} 4$ treated ones, with lower differences. $\mathrm{C} 2$ trend is similar to the $\mathrm{C} 4$ and $\mathrm{C} 8$ ones, but the short-term effect (day 30 and 60 ) of such concentration stimulated weed growth compared to the control, while on day 120 also C2 caused weed inhibition. On day 180 all the pots were containing 40-45 plants, the same amount counted in the control pots on the first sampling day.

In fresh and dry weight trends, it is possible to identify the stronger phytotoxic effect of the higher concentration of E. africanus EO (figures $62 \mathrm{~b}$ and c), being C8 the most effective and persistent treatment. 

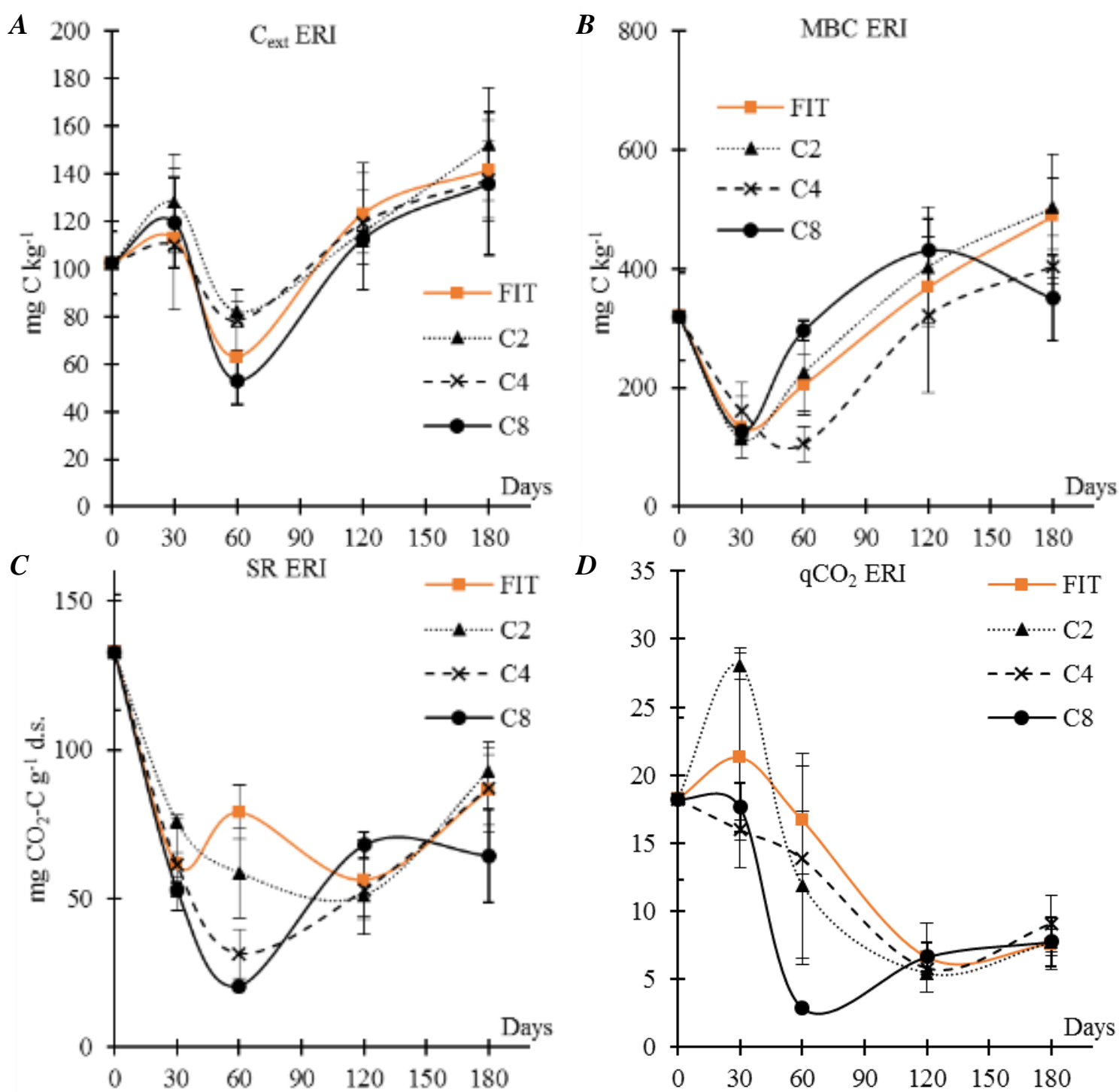

Figure 60: Biochemical soil variables determined at days 30, 60, 120 and 180 in the FIT (fitoil) and ERI (Eriocephalus africanus) treatments at different concentration (C2, C4 and C8 are, respectively, 2, 4 and 8 $m L$ of essential oil per litre of water)

A) $C_{\text {ext }}$, extractable organic carbon; B) $M B C$, microbial biomass carbon; C) $S R$, soil respiration; D) $q \mathrm{CO}_{2}$, metabolic quotient. Reported results are means of three samples, bars are standard deviations.
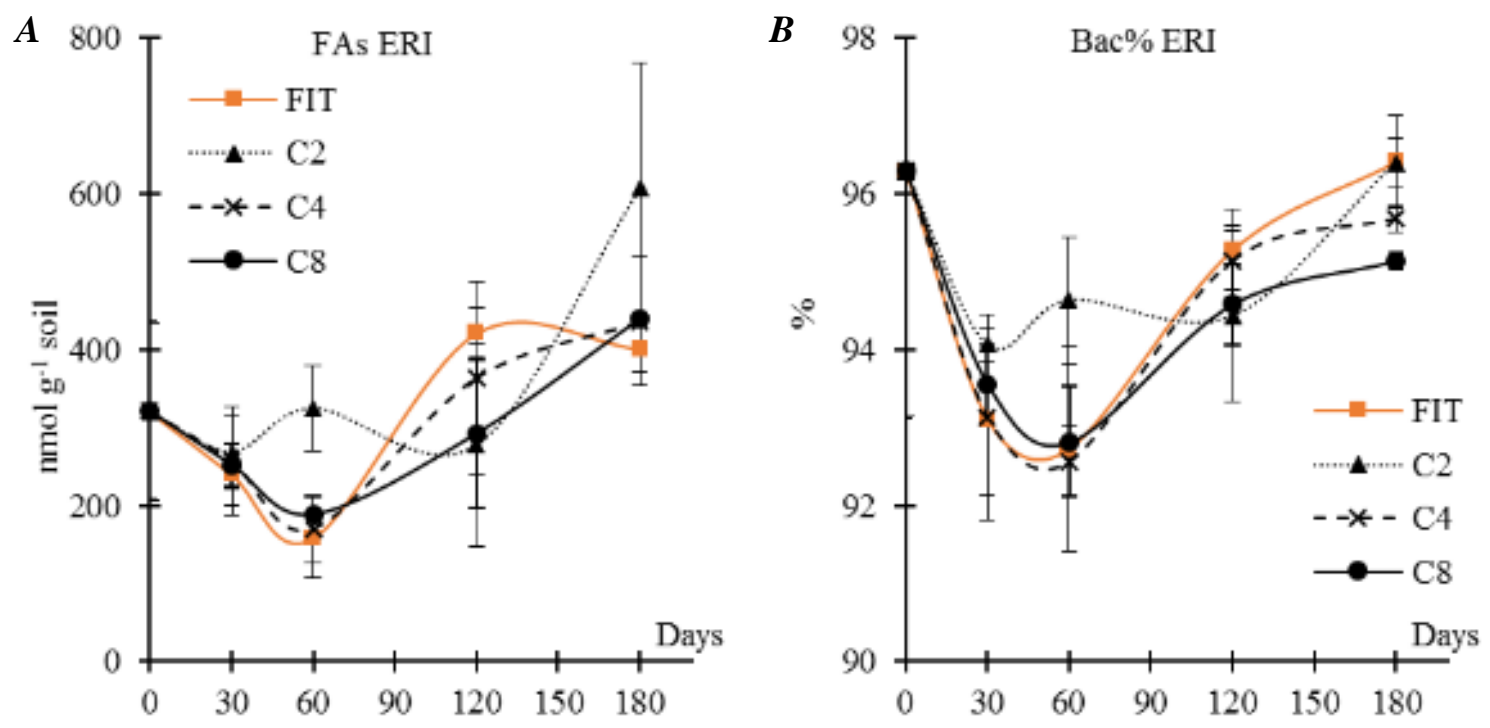

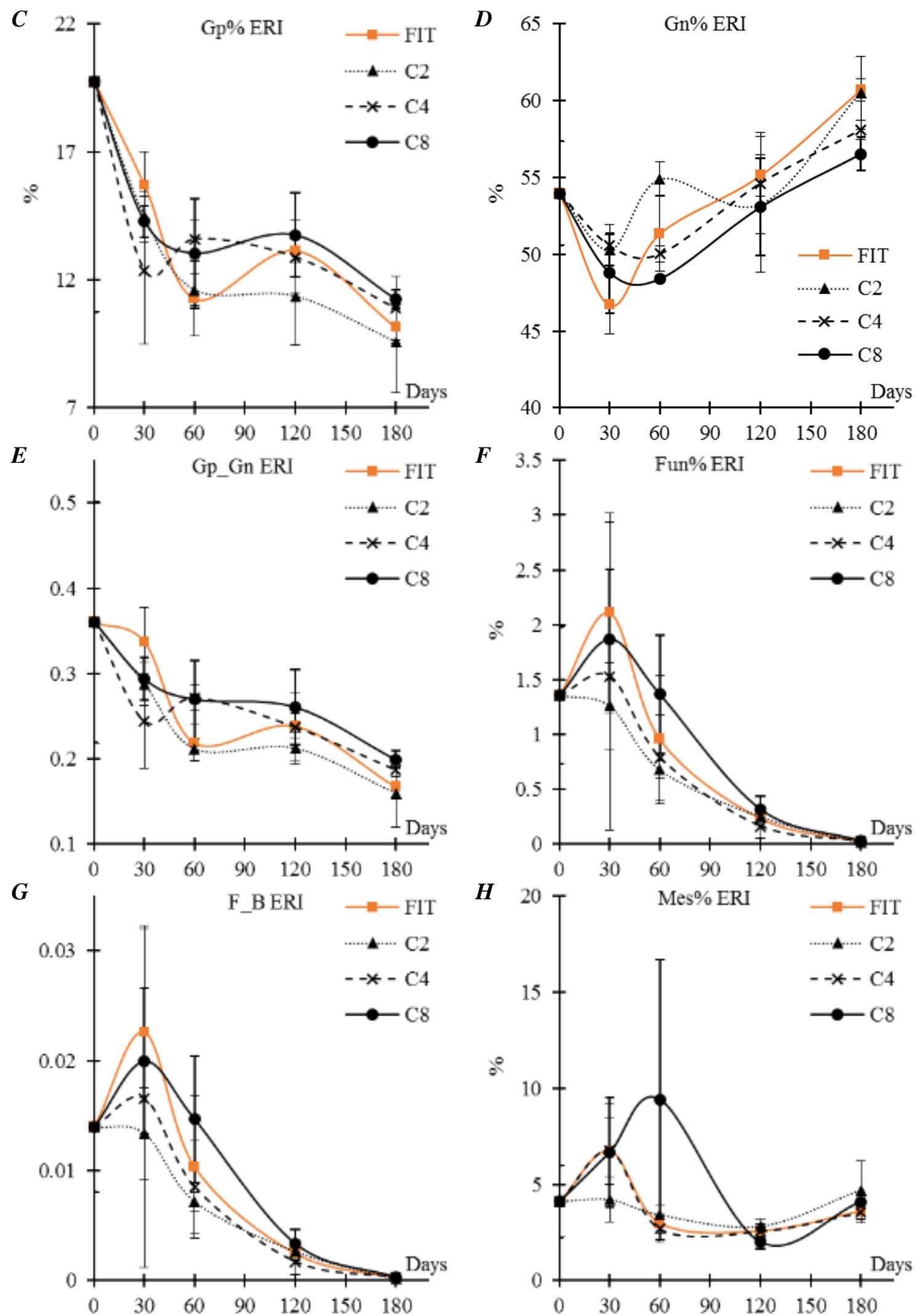

Figure 61: Microbial community structure determined at days 30, 60, 120 and 180 in the FIT (fitoil) and ERI (Eriocephalus africanus) treatments at different concentration (C2, C4 and C8 are, respectively, 2,4 and $8 \mathrm{~mL}$ of essential oil per litre of water)

A) FAs, microbial fatty acids; B) Bac\%, percentage of bacteria; C) Gp\%, percentage of Gram-positive bacteria; D) Gn\% percentage of Gram-negative bacteria; E) Gp_Gn, Gram-positive to Gram-negative ratio; F) Fun \%, percentage of fungi; $G) F_{-} B$, fungi to bacteria ratio; $\left.H\right)$ Mes $\%$, percentage of mesofauna. Showed values represents the mean values, bars are standard deviation $(n=3)$. 
$\boldsymbol{A}$

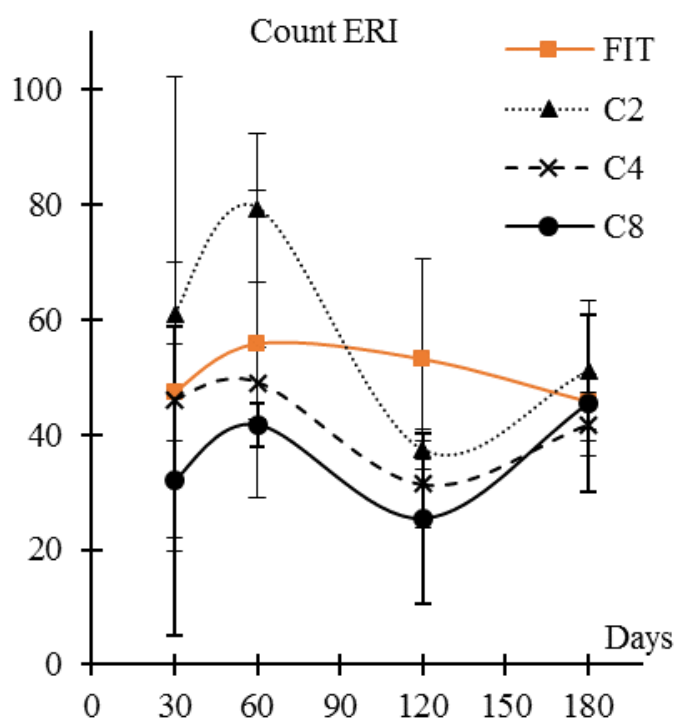

C

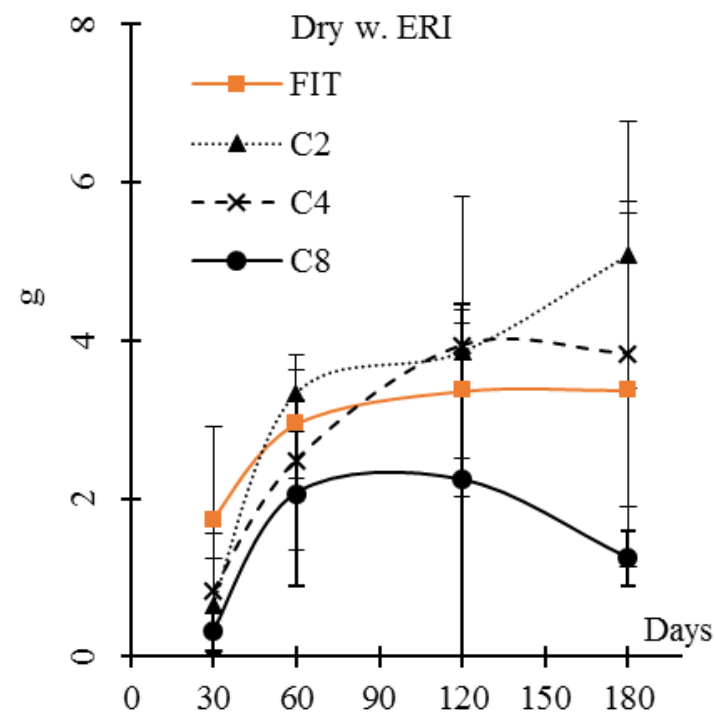

$\boldsymbol{B}$

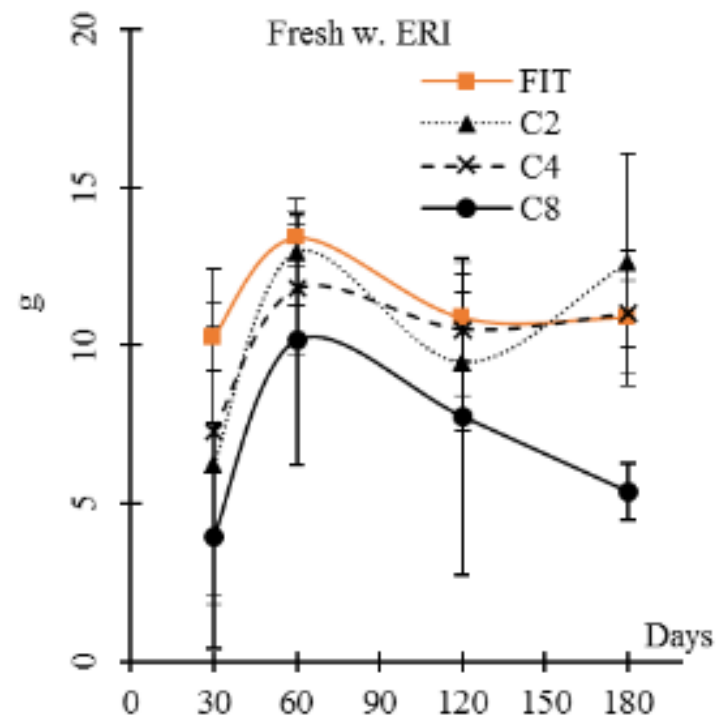

Figure 62: Weeds variables determined at days 30, 60, 120 and 180 in the FIT (fitoil) and ERI (Eriocephalus africanus) treatments at different concentration (C2,C4 and C8 are, respectively, 2,4 and $8 \mathrm{~mL}$ of essential oil per litre of water)

A) Count, number of counted plants; B) Fresh w., fresh weight; C) Dry w., dry weight. Reported results are means of three samples, bars are standard deviations. 


\subsection{Experiment four: long-term comparison between tillage and mulching effects on soil biological properties}

Results showed the more intense effect of tested practices on the superficial $(0-20 \mathrm{~cm})$ soil layer than on the deeper one (20-40), with $\mathrm{P}<0.05$ for all dependent variables, while in the deeper layer ten of the fourteen variables are significantly affected by the treatments (tab 41). The four not affected variables were: $\mathrm{MBC}_{2} \mathrm{qCO}_{2}, \mathrm{~F} \_\mathrm{B}$ and $\mathrm{Mes} \%$ (figure 63).

Table 41: Fisher's $F$ values of the chemical, biochemical and microbiological parameters calculated by one-way ANOVA (physical practice as factors) at the two sampling depths (0-20 and 20-40 cm) in the four experimental plots.

\begin{tabular}{|c|c|c|}
\hline & $0-20 \mathrm{~cm}$ & $20-40 \mathrm{~cm}$ \\
\hline TOC & $678.0 * * *$ & $295.3 * * *$ \\
\hline $\mathrm{MBC}$ & $6.4^{*}$ & n.s. \\
\hline $\mathrm{C}_{\mathrm{ext}}$ & $8.3^{* *}$ & $5.2 *$ \\
\hline SR & $62.2 * * *$ & $6.6^{*}$ \\
\hline $\mathrm{qCO}_{2}$ & $18.6^{* *}$ & n.s. \\
\hline FAs & $475.6 * * *$ & $15.3 * *$ \\
\hline Вас\% & $172.5 * * *$ & $7.2 *$ \\
\hline $\mathrm{Gp} \%$ & $154.7 * * *$ & $5.9 *$ \\
\hline $\mathrm{Gn} \%$ & $179.6^{* * *}$ & $7.4^{*}$ \\
\hline Gp_Gn & $58.0 * * *$ & $20.7 * * *$ \\
\hline Fun $\%$ & $64.7 * * *$ & $4.4^{*}$ \\
\hline F_B & $7.0 *$ & n.s. \\
\hline Mes\% & $19.9 * * *$ & n.s. \\
\hline
\end{tabular}

Data obtained by one-way ANOVA ( $n=3)$ performed for each sampling depth assuming physical practices (T15, M15, T7M8 and M8T7) as independent variable; *, $P<0.05 ; * *, P<0.01 ; * * *, P<0.001 ;$ n.s, not significant. T15, tillage during 15 years; M15, mulching during 15 years; T7M8, tillage for 7 years followed by 8 years of mulching; M7T8, 7 years of mulching followed by 8 of tillage.

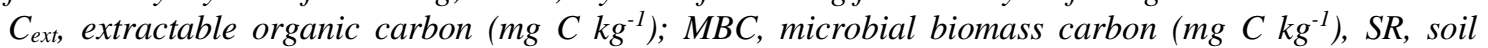
respiration (mg $\mathrm{CO}_{2}-\mathrm{C} \mathrm{kg}^{-1} \mathrm{~d}^{-1}$ ); $q \mathrm{CO}_{2}$, metabolic quotient; FAs, microbial fatty acids (nmol $\mathrm{g}^{-1}$ soil); Bac\%, percentage of bacteria; Gp\%, percentage of Gram-positive bacteria; Gn\% percentage of Gramnegative bacteria; $G p \_G n$, Gram-positive to Gram-negative ratio; Fun\%, percentage of fungi; $F \_B$, fungi to bacteria ratio; Mes\%, percentage of mesofauna.

In M15 treatment, the superficial soil layer (0-20) showed the higher levels of TOC, MBC, $\mathrm{C}_{\mathrm{ext}}, \mathrm{SR}, \mathrm{qCO}_{2}$ and FAs of the whole dataset. Post-hoc test evidenced significant differences with the other superficial samples for all these dependent variables ( $\mathrm{P}$ at least $<0.05$ ), except for MBC, being the difference between M15 0-20 and T15 0-20 not significant. The lower level (M15 20-40) showed a similar behaviour to the superficial one, having significantly higher values for TOC, $\mathrm{C}_{\mathrm{ext}}$, SR and FAs, if compared with the other 20-40 samples (table 42).

In T15 0-20 all measured soil variables except mesofauna, Gp_Gn and F_B rata are lower than all the other 0-20 samples (post-hoc $\mathrm{P}<0.01$ at least). On the other hand, mesofauna in permanently tilled soil can occupy a bigger ecological niche than microbial community, showing in T15 0-20 and 20-40 the higher values of the series. On the contrary, mesofauna 
have his minimum values in T7M8 at the two deepness, suggesting that changing the management method from tillage to mulching can negatively interfere with population growth of the small animals constituting mesofauna.

Fungi to bacteria ratio drastically separates T7M8 0-20 from M7T8 20-40, having respectively the lower and the higher value of this bioindicator.

Table 42: Mean differences and significance chemical, biochemical and microbiological parameters determined at the two sampling depths $(0-20$ and $20-40 \mathrm{~cm})$ in the four experimental plots.

\begin{tabular}{|c|c|c|c|c|c|c|c|c|}
\hline $\begin{array}{l}\text { Dep. } \\
\text { Var. }\end{array}$ & $\begin{array}{l}\text { Ind. } \\
\text { Var. }\end{array}$ & $\begin{array}{l}\text { T15 - } \\
\text { M15 }\end{array}$ & M7T8 & T7M8 & $\begin{array}{l}\text { M15 - } \\
\text { M7T8 }\end{array}$ & T15 & T7M8 & $\begin{array}{r}\text { T7M8 - } \\
\text { M7T8 }\end{array}$ \\
\hline \multirow[t]{2}{*}{ TOC } & $0-20$ & $-30.3 * * *$ & $-7.0 * * *$ & $-5.1 * *$ & $23.3 * * *$ & $30.3 * * *$ & $25.2 * * *$ & n.s. \\
\hline & $20-40$ & $-8.6^{* * *}$ & $-1.2 *$ & $-1.2 *$ & $7.4 * * *$ & $8.6 * * *$ & $7.4 * * *$ & n.s. \\
\hline \multirow[t]{2}{*}{ MBC } & $0-20$ & n.s. & n.s. & n.s. & $98.9 *$ & n.s. & $120.2 *$ & n.s. \\
\hline & $20-40$ & n.s. & n.s. & n.s. & n.s. & n.s. & n.s. & n.s. \\
\hline \multirow[t]{2}{*}{$\mathrm{C}_{\text {ext }}$} & $0-20$ & $-112.6^{* *}$ & n.s. & n.s. & $86.0 *$ & $112.6^{* *}$ & $102.0 *$ & n.s. \\
\hline & $20-40$ & $-84.5^{*}$ & n.s. & n.s. & n.s. & $84.5^{*}$ & n.s. & n.s. \\
\hline \multirow[t]{2}{*}{$\mathrm{CO}_{2}$} & $0-20$ & $-17.7 * * *$ & n.s. & n.s. & $13.9 * * *$ & $17.7 * * *$ & $22.0 * * *$ & $-8.2 * *$ \\
\hline & $20-40$ & n.s. & n.s. & n.s. & $5.6 *$ & n.s. & $4.7^{*}$ & n.s. \\
\hline \multirow[t]{2}{*}{$\mathrm{qCO}_{2}$} & $0-20$ & $-1.42 * *$ & n.s. & n.s. & $0.85 *$ & $1.42 * *$ & $1.74 * *$ & $-0.89 *$ \\
\hline & $20-40$ & n.s. & n.s. & n.s. & n.s. & n.s. & n.s. & n.s. \\
\hline \multirow[t]{2}{*}{ FAs } & $0-20$ & $-311 * * *$ & $130 * * *$ & $-132 * * *$ & $442 * * *$ & $311 * * *$ & $179 * * *$ & $262 * * *$ \\
\hline & $20-40$ & $-130.3 * *$ & n.s. & n.s. & $173.1 * *$ & $130.3 * *$ & $140.1 * *$ & n.s. \\
\hline \multirow[t]{2}{*}{ Вас\% } & $0-20$ & $-12.5 * *$ & $-57.1 * * *$ & n.s. & $-44.5^{* * * *}$ & $12.5^{* *}$ & n.s. & $-51.7 * * *$ \\
\hline & $20-40$ & n.s. & $-19.7 *$ & $-16.2 *$ & n.s. & n.s. & n.s. & n.s. \\
\hline \multirow[t]{2}{*}{ Gp\% } & $0-20$ & $-8.6^{*}$ & $-46.4 * * *$ & n.s. & $37.8 * * *$ & $8.6 *$ & n.s. & $-42.7 * * *$ \\
\hline & $20-40$ & n.s. & $-14.3^{*}$ & n.s. & n.s. & n.s. & n.s. & n.s. \\
\hline \multirow[t]{2}{*}{ Gn\% } & $0-20$ & $-2.8 * * *$ & $-5.6 * * *$ & $-0.9 *$ & $-2.8 * * *$ & $2.8 * * *$ & $2.0 * * *$ & $-4.7 * * *$ \\
\hline & $20-40$ & $-5.4 * *$ & n.s. & n.s. & n.s. & $5.4 * *$ & n.s. & n.s. \\
\hline \multirow[t]{2}{*}{ Gp_Gn } & $0-20$ & $1.3 * *$ & $-1.7 * * *$ & n.s. & $-3.0 * * *$ & $-1.3 * *$ & $-1.0 *$ & $-2.1 * * *$ \\
\hline & $20-40$ & $4.0 * * *$ & n.s. & n.s. & $-2.4 * *$ & $-4.0 * * *$ & $-2.6 * *$ & n.s. \\
\hline \multirow[t]{2}{*}{ Fun\% } & $0-20$ & $-4.8^{*}$ & $-13.4 * * *$ & n.s. & $-8.6 * * *$ & $4.8 *$ & $5.0 * *$ & $-13.5 * * *$ \\
\hline & $20-40$ & n.s. & $-7.6^{*}$ & n.s. & n.s. & n.s. & n.s. & n.s. \\
\hline \multirow[t]{2}{*}{ F_B } & $0-20$ & n.s. & n.s. & n.s. & n.s. & n.s. & $0.1^{*}$ & n.s. \\
\hline & $20-40$ & n.s. & n.s. & n.s. & n.s. & n.s. & n.s. & n.s. \\
\hline \multirow[t]{2}{*}{ Mes\% } & $0-20$ & $0.010 * *$ & n.s. & $0.011 * *$ & $-0.011 * *$ & $-0.010 * *$ & n.s. & $-0.012 * *$ \\
\hline & $20-40$ & n.s. & n.s. & n.s. & n.s. & n.s. & n.s. & n.s. \\
\hline
\end{tabular}

Data obtained by Tukey post-hoc test $(n=3)$ performed for each sampling deepness $(0-20 \mathrm{~cm}$ and 20-40 $\mathrm{cm})$ assuming treatment physical practices (T15, M15, T7M8 and M8T7) as independent variable;

*, $P<0.05$; **, $P<0.01$; ***, $P<0.001 ;$ n.s, not significant.

T15, tillage during 15 years; M15, mulching (with geotextiles) during 15 years; T7M8, tillage for 7 years followed by 8 years of mulching; M7T8, 7 years of mulching followed by 8 of tillage. $C_{\text {ext }}$, extractable organic carbon ( $\left.\mathrm{mg} \mathrm{C} \mathrm{kg}^{-1}\right)$; $\mathrm{MBC}$, microbial biomass carbon $(\mathrm{mg} \mathrm{C} \mathrm{kg-1})$, SR, soil respiration ( $\mathrm{mg} \mathrm{CO}_{2}-\mathrm{C}$ $\left.\mathrm{kg}^{-1} \mathrm{~d}^{-1}\right) ; q \mathrm{CO}_{2}$, metabolic quotient; FAs, microbial fatty acids (nmol $\mathrm{g}^{-1}$ soil); Bac\%, percentage of bacteria; Gp\%, percentage of Gram-positive bacteria; Gn\% percentage of Gram-negative bacteria; $G p \_G n$, Gram-positive to Gram-negative ratio; Fun\%, percentage of fungi; $F \_B$, fungi to bacteria ratio; Mes\%, percentage of mesofauna. 
Oddo M. - Effects of different weed control practices on soil quality in mediterranean crops

A

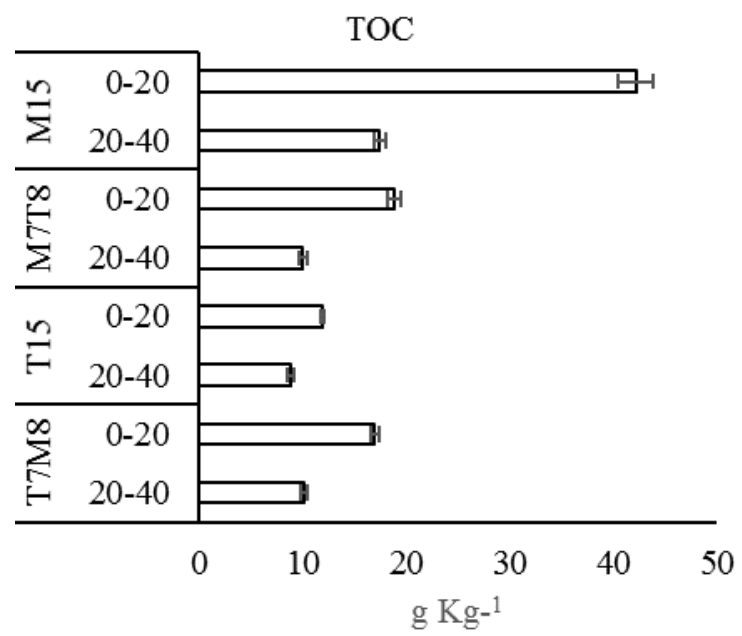

C

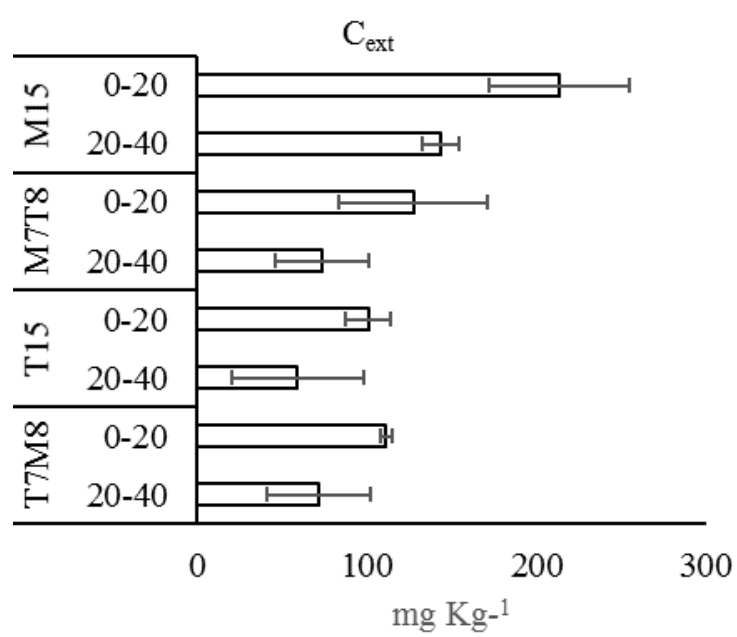

$\boldsymbol{E}$

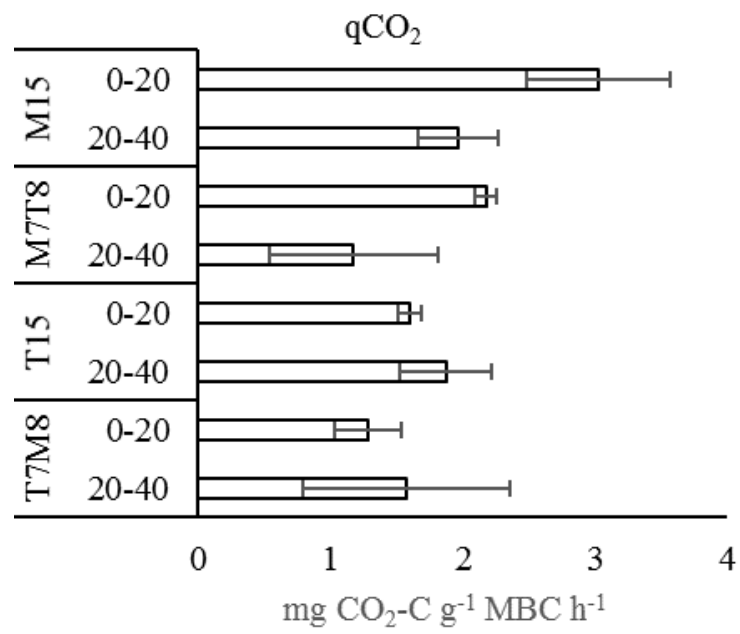

B

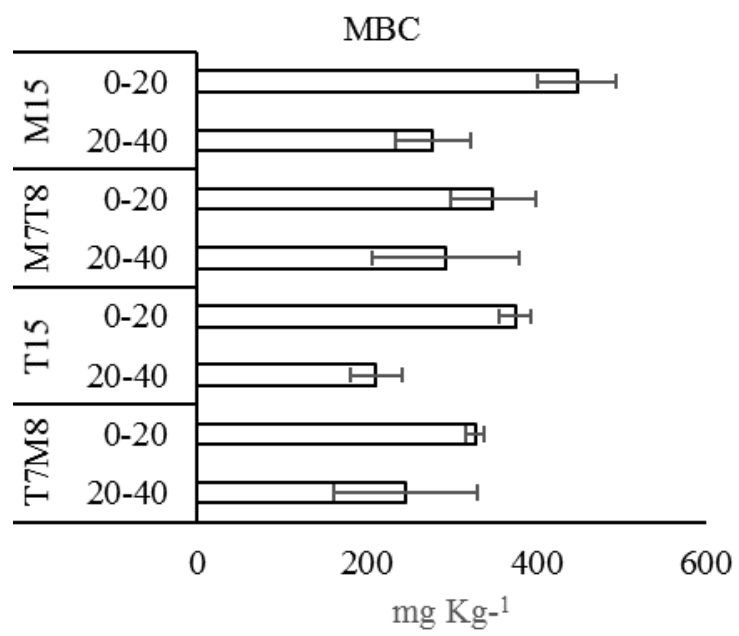

D

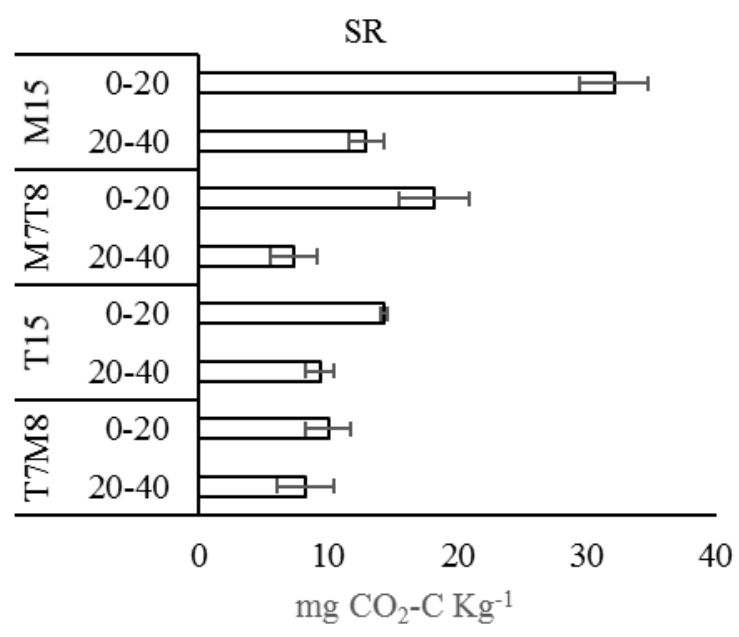

F

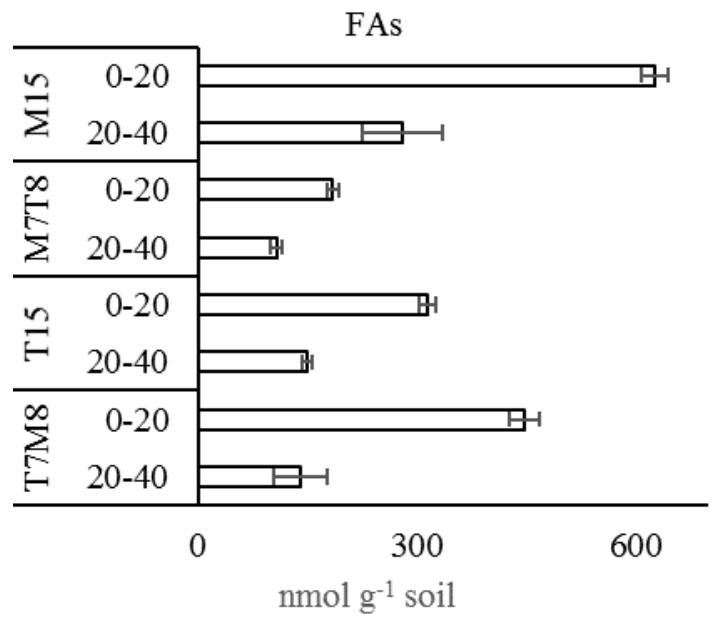


G

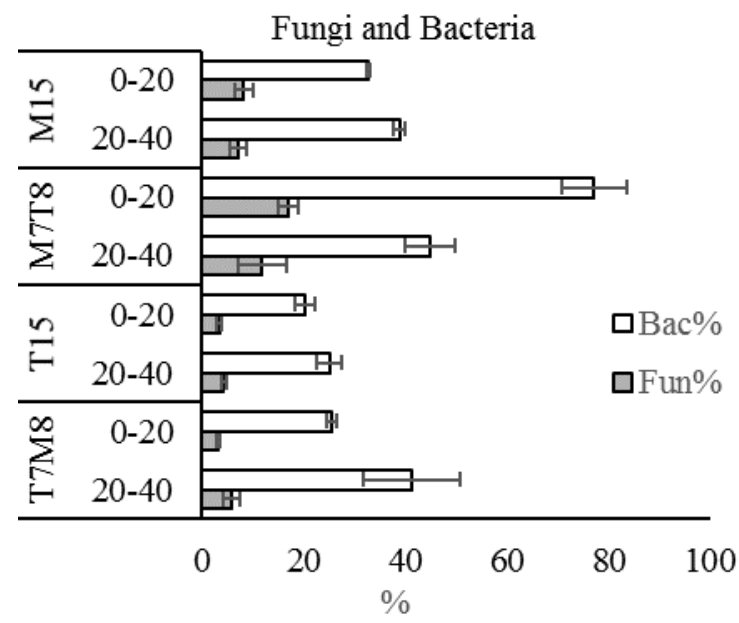

I

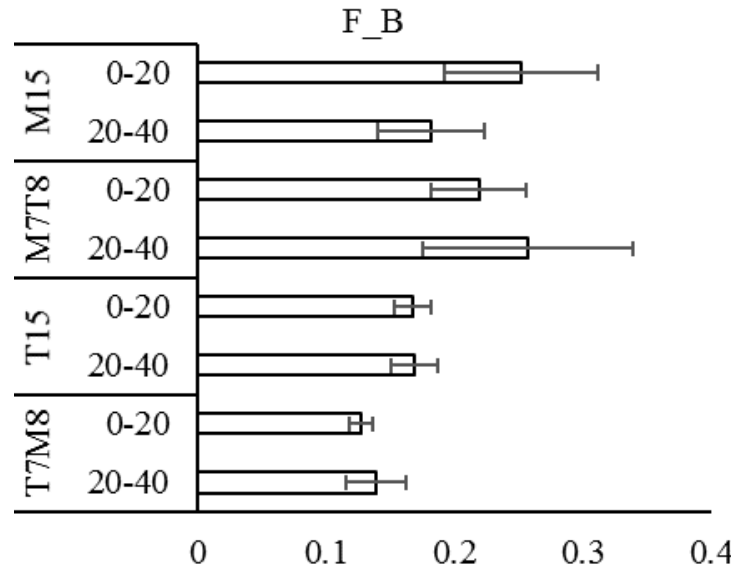

M

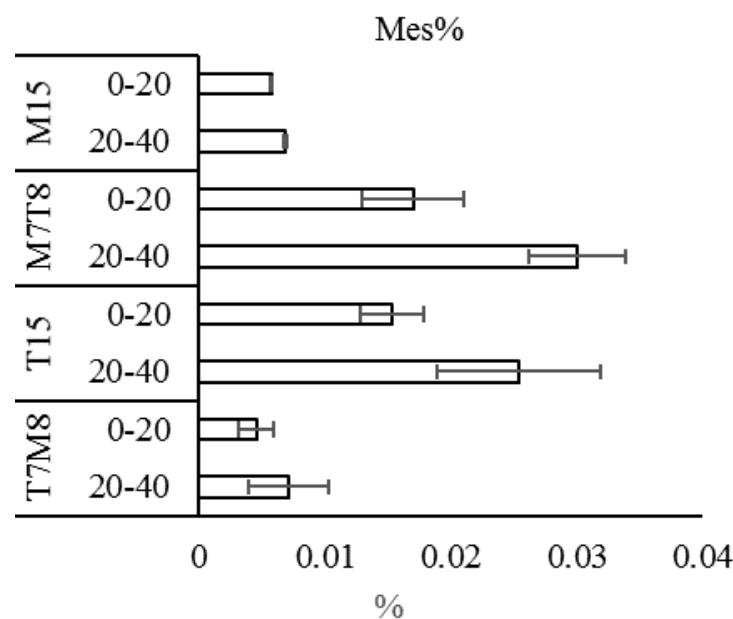

H

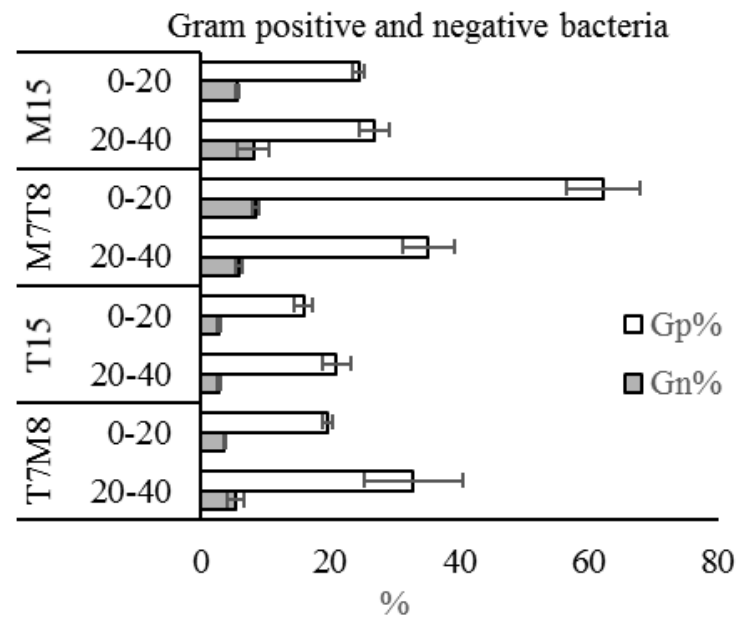

L

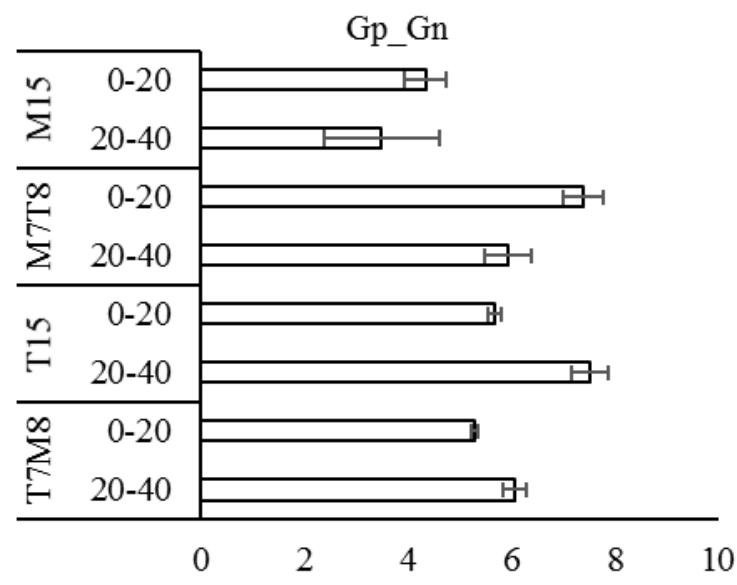

Figure 63: Soil properties measured at the two sampling depths in the four experimental plots.

A) TOC, total organic carbon; B) MBC, Microbial biomass Carbon; C) $C_{\text {ext }}$ extractable organic carbon; D) $S R$, soil respiration; E) $q \mathrm{CO}_{2}$, metabolic quotient; F) FAs, Fatty acids microbial bioindicator; G) Fun\% and $\mathrm{Bac} \%$, fungal and bacterial fatty acids bioindicators; $\mathrm{H}) \mathrm{Gp} \%$ and $\mathrm{Gn} \%$, Gram-positive and negative fatty acids bioindicators; I) $F \_B$, fungi to bacteria ratio; L) Gp_Gn, Gram-positive to negative ratio; $M$ ) Mes\%, mesofauna fatty acid bioindicator. Experimental plots are T15, tillage during 15 years; M15, mulching (with geotextiles) during 15 years; T7M8, tillage for 7 years followed by 8 years of mulching; M7T8, 7 years of mulching followed by 8 of tillage. Showed values represents the mean values, bars are standard deviation $(n=3)$. 


\section{Conclusions}

\subsection{Experiment one}

Our results demonstrated that the five tested essential oils could be sustainable for weed management. In fact, although was affected by EOs Used EOs concentrations, which are those usually adopted to test the efficiency of essential oils as herbicides, had not significant effects on soil biological activity, thus higher concentrations should be tested.

Further studies are needed to understand if the observed shift in microbial community structure may alter other soil processes such as nitrogen turnover.

Citrus EOs are active against many groups of microbes and have been used for pest management and food preservation (Palazzolo et al. 2013). Studies carried out on EOs extracted from different citrus cultivars indicate that they are very effective against the Gram-positive bacteria, being Citrus limon (L.) Osbeck cultivars more efficient than Citrus reticulata Blanco ones (Settanni et al. 2012). Despite these in vitro results, tangerine and lemon treatments showed in our experiment relatively few effects on soil bioindicators and microbial community. This evidence is reasonable as the used soil was covered by tangerine trees and likely soil microorganisms since long time were exposed to allelochemicals coming from tangerine, thus acquiring an adaptation.

The effects of EOs extracted from TCP disagrees with several microbiological studies reporting the antimicrobial effects of EOs from Thymbra capitata on phytopathogens (Behdani et al. 2012; Tabti et al. 2014);and of EOs contain thymol on human pathogens (Dutta et al. 2007) and on foodborne microbes (Cosentino et al. 1999). From the other hand Vokou et al. (2006), found that soil respiration is stimulated by essential oils of aromatic plants rich in carvacrol and/or thymol as the one used in this experiment. Our results evidenced an increase of the specific respiration $\left(\mathrm{qCO}_{2}\right)$ in TCP treatment, results of previous research (Vokou et al. 1984, 2002) showed that soil respiration was activated in the presence of Thymbra capitata and Satureja thymbra essential oils. The increase of soil respiration was found to be a primary rather than secondary effect. The essential oils from these plants did not kill some soil microorganisms, thereby providing substrate easily decomposable to others but directly activated soil bacteria.

It has been already found that, although their volatile oils are generally used in the therapeutics as antimicrobial agents, when applied to soil samples from the site where the aromatic plants grow they did promote soil respiration; it was further shown that this 
promotion is mainly due to soil bacteria which are able to catabolize them (Vokou \& Margaris 1986).

Although essential oils are well known antimicrobial agents, some microorganisms are activated by them and can use them as a carbon and energy source; this is the case for soil bacteria from Mediterranean ecosystems (Vokou \& Liotiri 1999).

\subsection{Experiment two}

All tested aqueous extracts showed biocide effects on soil bacteria, fungi and mesofauna.

Comparing seeded and unseeded controls, target weed ( $P$. апnиa) rhizosphere affected four soil variables (TOC, fun\%, Gp\% and Mes\%) more than the AEs treatments.

\subsection{Experiment three}

The commercial synthetic herbicide showed the minimal influence on soil microbial community and the more homogeneous dataset. It is a probe about the importance of the formulation of a stabile product acting only on the target pest and not influencing soil ecosystem.

Further studies, improved with more concentrations and more frequent samplings should allow to understand if a synergistic effect among essential oils constituents stimulates or inhibits weeds germination.

\subsection{Experiment four}

Our results confirms previous studies (Laudicina et al. 2011) evidencing that tillage mechanically suppress fungal hyphae inhibiting fungal community. Also, differences in $\mathrm{qCO}_{2}$ can depend on the fungal/bacterial biomass ratio with fungi respiring less than bacteria per unit of biomass. Mulching with allelopathic plants will be more effective than the single techniques (Hatcher \& Melander 2003). 


\subsection{Final remarks}

Results of previous research showed that soil respiration was activated in the presence of Thymbra capitata and Satureja thymbra essential oils. The increase of soil respiration was found to be a primary rather than secondary effect. The essential oils from these plants did not kill some soil microorganisms, thereby providing substrate easily decomposable to others (Vokou et al. 1984) but directly activated soil bacteria (Vokou et al. 2002). It has been already found that, although their volatile oils are generally used in the therapeutics as antimicrobial agents, when applied to soil samples from the site where the aromatic plants grow they did promote soil respiration; it was further shown that this promotion is mainly due to soil bacteria which are able to catabolize them (Vokou \& Margaris 1986).

Although essential oils are well known antimicrobial agents, some microorganisms are activated by them and can use them as a carbon and energy source; this is the case for soil bacteria from Mediterranean ecosystems (Vokou \& Liotiri 1999).

Our results suggested that essential oils with allelopathic potential extracted from mediterranean plants could be sustainable for weed management as they have a small and short-time effect on soil microorganisms. In fact, although soil microbial community structure was affected by EOs, total microbial biomass as well as the overall metabolic capacity of soil was not.

Nevertheless, as essential oils affect soil microorganisms structure at short and medium timescale, their repeated use as herbicides should consider these findings.in many graphics could be observed that high concentrations are more effectives on the short-period (15-30 days), subsequently their effects become less significant than the lower concentration. On the contrary, lower concentration showed long lasting effectiveness. It is possible to suppose that high concentration causes a strong reaction in soil ecosystem that rapidly neutralizes the phytotoxic effects. 


\section{Bibliography}

Abdul, M. \& Grohmann, E. (2012) Environmental Protection Strategies for Sustainable Development (A Malik and E Grohmann, Eds.). Dordrecht: Springer Netherlands.

Aliloo, A. A. (2012) Allelopathic potentials of Cupressus arizonica leaves extracts on seed germination and seedling growth of Lolium perenne and Poa pratensis. International Journal of Agriculture and Crop Sciences 4: 1371-1375.

Amabeoku, G. J. et al. (2000) Effects of Tarchonanthus camphoratus and Eriocephalus africanus on nociception in mice and pyrexia in rats. Phytomedicine: international journal of phytotherapy and phytopharmacology 7: 517-522.

Anderson, T. H. \& Domsch, K. H. (2010) Soil microbial biomass: The eco-physiological approach. Soil Biology and Biochemistry 42: 2039-2043.

Andrén, O. et al. (1999) Soil organism influence on ecosystem-level processes - bypassing the ecological hierarchy? Applied Soil Ecology 11: 177-188.

Aryakia, E. et al. (2015) Evaluating allelopathic effects of some plant species in tissue culture media as an accurate method for selection of tolerant plant and screening of bioherbicides. J. Agr. Sci. Tech 17: 1011-1023.

El Asbahani, A. et al. (2015) Essential oils: from extraction to encapsulation. International journal of pharmaceutics 483: 220-43.

Asita, A. O. \& Mokhobo, M. M. (2013) Clastogenic and cytotoxic effects of four pesticides used to control insect pests of stored products on root meristems of Allium cepa. Environment and Natural Resources Research 3: 133-145.

Badalucco, L. et al. (2010) Reversing agriculture from intensive to sustainable improves soil quality in a semiarid South Italian soil. Biology and Fertility of Soils 46: 481489.

Behdani, M. et al. (2012) Evaluation of antifungal activity of some medicinal plants essential oils against Botrytis cinerea, causal agent of postharvest apple rot, in vitro. International Journal of Agriculture and Crop Sciences. 4: 1012-1016.

Berger, S. et al. (2013) Plastic mulching in agriculture-Friend or foe of $\mathrm{N}_{2} \mathrm{O}$ emissions? Agriculture, Ecosystems \& Environment 167: 43-51.

Bhadoria, P. B. S. (2011) Allelopathy: a natural way towards weed management. American Journal of Experimental Agriculture 1: 7-20.

Blázquez, M. A. (2014) Role of natural essential oils in sustainable agriculture and food preservation. Journal of Scientific Research and Reports 3: 1843-1860. 
Bond, W. (2002) Chapter 13 Non-chemical weed management. Weed Management Handbook (R. E. L. Naylor, ed): pp. 280-301.

Bradford, M. A. et al. (2002) Microbiota, fauna, and mesh size interactions in litter decomposition. Oikos 99: 317-323.

Brookes, P. C. C. et al. (1985) Chloroform fumigation and the release of soil nitrogen: A rapid direct extraction method to measure microbial biomass nitrogen in soil. Soil Biology and Biochemistry 17: 837-842.

Cantrell, C. L. \& Klun, J. A. (2011) Callicarpenal and Intermedeol: two natural arthropod feeding deterrent and repellent compounds identified from the suthern folk remedy plant, Callicarpa americana. ACS Symposium Series pp. 47-58.

Catarino, M. D. et al. (2015) Characterization of phenolic constituents and evaluation of antioxidant properties of leaves and stems of Eriocephalus africanus. Arabian Journal of Chemistry.

Cavalier-Smith, T. (1987) The origin of eukaryote and archaebacterial cells. Annals of the New York Academy of Sciences 503: 17-54.

Cavalier-Smith, T. (2002) The phagotrophic origin of eukaryotes and phylogenetic classification of Protozoa. International Journal of Systematic and Evolutionary Microbiology 52: 297-354.

Chen, J. et al. (2008) Repellency of callicarpenal and intermedeol against workers of imported fire ants (Hymenoptera: Formicidae). Journal of economic entomology 101: 265-71.

Cheng, F. \& Cheng, Z. (2015) Research progress on the use of plant allelopathy in agriculture and the physiological and ecological mechanisms of allelopathy. Frontiers in plant science 6: 1020.

Chinchilla Albundio, P. (2015) Estudio de la aplicación del aceite esencial de Thymus capitatus (L.) Hoffmanns. \& Link como alternativa para el control de arvenses y la enfermedad del moteado en el cultivo del níspero.

Chu, C. et al. (2014) Allelopathic effects of Eucalyptus on native and introduced tree species. Forest Ecology and Management 323: 79-84.

Coleman, D. C. \& Whitman, W. B. (2005) Linking species richness, biodiversity and ecosystem function in soil systems. Pedobiologia pp. 479-497.

Cosentino, S. et al. (1999) In-vitro antimicrobial activity and chemical composition of Sardinian Thymus essential oils. Letters in Applied Microbiology 29: 130-135.

Dance, A. (2008) Soil ecology: What lies beneath. Nature 455: 724-725 
Van Diepeningen, A. D. et al. (2006) Effects of organic versus conventional management on chemical and biological parameters in agricultural soils. Applied Soil Ecology 31: $120-135$.

Dirilgen, T. et al. (2016) Mite community composition across a European transect and its relationships to variation in other components of soil biodiversity. Applied Soil Ecology 97: 86-97.

Doran, J. W. \& Zeiss, M. R. (2000) Soil health and sustainability: Managing the biotic component of soil quality. Applied Soil Ecology 15: 3-11.

Doran, J. W. et al. (1996) Soil Health and Sustainability. Advances in Agronomy pp. 1-54.

Dudai, N. et al. (1999) Essential Oils As Allelochemicals and Their Potential Use As Bioherbicides. Journal of Chemical Ecology 25: 1079-1089.

Dutta, B. K. et al. (2007) Anticandidial activity of some essential oils of a mega biodiversity hotspot in India. Mycoses 50: 121-124.

EEA, European Environment Agency, https://www.eea.europa.eu/.

European Commission (2016) Commission Implementing Regulation (EU) 2016/1313 of 1 August 2016 amending Implementation Regulation (EU) No 540/2011 as regards the conditions of approval of the active substance glyphosate (Text with EEA relevance). Official Journal of the European Union 208.

European Commission (2017) EU Pesticides database - European Commission, http://ec.europa.eu/food/plant/pesticides/eu-pesticidesdatabase/public/?event=homepage\&language $=E N$.

European Food Safety Authority (EFSA) (2014) The 2013 European Union Report on pesticide residues in food. EFSA Journal 12: 3942.

Feng, X. \& Simpson, M. J. (2009) Temperature and substrate controls on microbial phospholipid fatty acid composition during incubation of grassland soils contrasting in organic matter quality. Soil Biology and Biochemistry 41: 804-812.

Flamini, G. (2012) Natural herbicides as a safer and more environmentally friendly approach to weed control: a review of the literature since 2000. Studies in Natural Products Chemistry. pp. 353-396. Elsevier.

Fontaine, S. et al. (2003) The priming effect of organic matter: a question of microbial competition? Soil Biology and Biochemistry 35: 837-843.

Foster, R. C. (1988) Microenvironments of soil microorganisms. Biology and Fertility of Soils 6: 189-203.

De Freitas Duarte, N. et al. (2012) Tolerance of anadenanthera peregrina to Eucalyptus 
camaldulensis and Eucalyptus grandis essential oil as condition for mixed plantation. Brazilian Archives of Biology and Technology 55: 417-424.

García Plasencia, S. (2014) Actividad herbicida del aceite esencial de Thymus capitatus (L.) Hoffmanns. et Link. y su efectividad en función de distintos métodos de aplicación.

Gardner, T. et al. (2011) Soil rhizosphere microbial communities and enzyme activities under organic farming in alabama. Diversity 3: 308-328.

Gee, G. W. \& Or, D. (2002) Particle-size Analysis. Methods of Soils Analysis pp. 255-293.

Graña, E. (2015) Mode of action and herbicide potential of the terpenoids farnesene and citral on Arabidopsis thaliana metabolism.

Griffiths, B. S. \& Philippot, L. (2013) Insights into the resistance and resilience of the soil microbial community. FEMS Microbiology Reviews 37: 112-129.

Guenet, B. et al. (2010) Is there a linear relationship between priming effect intensity and the amount of organic matter input? Applied Soil Ecology 46: 436-442.

Hatcher, P. E. \& Melander, B. (2003) Combining physical, cultural and biological methods: Prospects for integrated non-chemical weed management strategies. Weed Research 43: 303-322.

Hazelton, P. \& Murphy, B. (2007) Soil test results: What do all the numbers mean?

He, H. et al. (2014) Phytotoxic effects of volatile organic compounds in soil water taken from a Eucalyptus urophylla plantation. Plant and Soil 377: 203-215.

Heap, I. (2017) International Survey of Herbicide Resistant Weeds, http://www.weedscience.org/

Herranz, J. M. et al. (2006) Effect of allelopathic compounds produced by Cistus ladanifer on germination of 20 Mediterranean taxa. Plant Ecology 184: 259-272.

Hinojosa, M. B. et al. (2016) Post-fire soil functionality and microbial community structure in a Mediterranean shrubland subjected to experimental drought. Science of The Total Environment 573: 1178-1189.

Huising, J. et al. (2016) Plan of Action for Pillar One of the Global Soil Partnership Promote sustainable management of soil resources for soil protection, conservation and sustainable productivity Pillar One -Promote sustainable management of soil resources for soil protection (FAO, Ed.). FAO.

Inderjit et al. (2011) The ecosystem and evolutionary contexts of allelopathy. Trends in Ecology and Evolution 26: 655-662.

Jabran, K. et al. (2015) Allelopathy for weed control in agricultural systems. Crop 
Protection 72: 57-65.

Jeong, S.-H. et al. (2002) Intermedeol isolated from the leaves of Ligularia fischeri var. spiciformis induces the differentiation of human acute promyeocytic leukemia HL-60 cells. Planta Medica 68: 881-885.

Kadoglidou, K. et al. (2011) Inhibitory and stimulatory effects of essential oils and individual monoterpenoids on growth and sporulation of four soil-borne fungal isolates of Aspergillus terreus, Fusarium oxysporum, Penicillium expansum, and Verticillium dahliae. European Journal of Plant Pathology 130: 297-309.

Kalemba, D. \& Kunicka, A. (2003) Antibacterial and antifungal properties of essential oils. Current medicinal chemistry 10: 813-29.

Karlen, D. L. et al. (1997) Soil quality: a concept, definition, and framework for evaluation (a guest editorial). Soil Science Society of America Journal 61: 4.

Karp, F. \& Croteau, R. (1982) Evidence that sabinene is an essential precursor of C(3)oxygenated thujane monoterpenes. Archives of Biochemistry and Biophysics 216: 616-624.

Kim, S. et al. (2016) PubChem substance and compound databases. Nucleic Acids Research 44: D1202-D1213.

Knudsmark Jessing, K. et al. (2014) Potential ecological roles of artemisinin produced by Artemisia annua L. Journal of chemical ecology 40: 100-17.

Koul, O. et al. (2008) Essential oils as green pesticides: Potential and constraints. Biopesticides International 4: 63-84.

Langeveld, W. T. et al. (2014) Synergy between essential oil components and antibiotics: a review. Critical reviews in microbiology 40: 76-94.

Laudicina, V. A. et al. (2009) Soil chemical and biochemical properties of a salt-marsh alluvial Spanish area after long-term reclamation. Biology and Fertility of Soils 45: $691-700$

Laudicina, V. A. et al. (2011) Effects of compost input and tillage intensity on soil microbial biomass and activity under Mediterranean conditions. Biology and Fertility of Soils 47: 63-70.

Laudicina, V. A. et al. (2012) Key biochemical attributes to assess soil ecosystem sustainability. Environmental Protection Strategies for Sustainable Development (A. Malik \& (E. Grohmann, eds): pp. 193-227. Dordrecht: Springer Netherlands.

Laudicina, V. A. et al. (2013) Natural organic compounds in soil solution: potential role as soil quality indicators. Current Organic Chemistry 17: 2991-2997. 
Laudicina, V. A. et al. (2014) Soil carbon dynamics as affected by long-term contrasting cropping systems and tillages under semiarid Mediterranean climate. Applied Soil Ecology 73: 140-147.

Laudicina, V. A. et al. (2015) Long-term tillage and cropping system effects on chemical and Biochemical characteristics of soil organic matter in Mediterranean semiarid environment. Land Degradation \& Development 26: 45-53.

LI, Z.-G. et al. (2011) Carbon dioxide fluxes and concentrations in a cotton field in northwestern China: effects of plastic mulching and drip irrigation. Pedosphere 21: $178-185$.

Liakos, I. et al. (2014) All-natural composite wound dressing films of essential oils encapsulated in sodium alginate with antimicrobial properties. International Journal of Pharmaceutics 463: 137-145.

Luo, Z. et al. (2010) Can no-tillage stimulate carbon sequestration in agricultural soils? A meta-analysis of paired experiments. Agriculture, Ecosystems and Environment 139: 224-231.

Lynch, J. M. (1987) Allelopathy involving microorganisms. Allelochemicals: Role in Agriculture and Forestry pp. 44-52.

M'barek, K. (2016) Chemical composition and phytotoxicity of Cupressus sempervirens leaves against crops. Journal of Essential Oil Bearing Plants 19: 1582-1599.

Maffei, M. E. (2010) Sites of synthesis, biochemistry and functional role of plant volatiles. South African Journal of Botany 76: 612-631.

Mann, J. (2012) Bioactive Natural Products. Studies in natural products chemistry (Attaur-Rahman, ed): p. 544. Elsevier.

Manzoni, S. et al. (2012) Environmental and stoichiometric controls on microbial carbonuse efficiency in soils. New Phytologist 196: 79-91.

De Martino, L. et al. (2010) The antigerminative activity of twenty-seven monoterpenes. Molecules 15: 6630-6637.

McGuire, K. L. \& Treseder, K. K. (2010) Microbial communities and their relevance for ecosystem models: Decomposition as a case study. Soil Biology and Biochemistry 42: $529-535$.

McIntosh, R. P. (1981) Succession and ecological theory. pp. 10-23. Springer, New York, NY.

Merle, H. et al. (2004) Taxonomical contribution of essential oils in mandarins cultivars. Biochemical Systematics and Ecology 32: 491-497. 
Merle, H. et al. (2007) Chemical composition of the essential oils from Eriocephalus africanus L. var. africanus populations growing in Spain. Flavour and Fragrance Journal 22: 461-464.

MiPAF (1999) Ministero per le politiche agricole e forestali. Metodi di analisi fisica del suolo.

MiPAF (1999) Ministero per le politiche agricole e forestali. Metodi ufficiali di analisi chimica del suolo.

MiPAF (2002) Ministero per le politiche agricole e forestali. Metodi ufficiali di analisi microbiologica dei suoli.

MiPAF (2004) Ministero per le politiche agricole e forestali. Metodi ufficiali di analisi biochimica del suolo.

Monaco, Thomas J , Weller, Sthephen C, Ashton, F. M. (2002) WEED SCIENCE Principles and Practices. Wiley \& Sons, INC.

Moss, S. R. (2010) Non-chemical methods of weed control: benefits and limitations. 17th Australasian weeds conference. New frontiers in New Zealand: together we can beat the weeds. 26-30 September, 2010. pp. 14-19. Christchurch, New Zealand: Zydenbos, S. M.

Muscolo, A. et al. (2015) Early warning indicators of changes in soil ecosystem functioning. Ecological Indicators 48: 542-549.

Muzell Trezzi, M. et al. (2016) Allelopathy: driving mechanisms governing its activity in agriculture. Journal of Plant Interactions 11: 53-60.

Nakatsu, T. et al. (2000) Biological activity of essential oils and their constituents. Studies in Natural Products Chemistry pp. 571-631.

Nannipieri, P. et al. (2003) Microbial diversity and soil functions. European Journal of Soil Science 54: 655-670.

Njenga, E. W. (2005) The chemotaxonomy, phylogeny and biological activity of the genus Eriocephalus L. (Asteraceae).

Novara, A. et al. (2014) Dynamics of soil organic carbon pools after agricultural abandonment. Geoderma 235-236: 191-198.

Ocheng, F. et al. (2015) Essential oils from ugandan aromatic medicinal plants: chemical composition and growth inhibitory effects on oral pathogens. Evidence-based Complementary and Alternative Medicine 2015: 230832.

Oerke, E.-C. \& Dehne, H.-W. (2004) Safeguarding production-losses in major crops and the role of crop protection. Crop Protection 23: 275-285. 
Oerke, E. C. (2006) Crop losses to pests. The Journal of Agricultural Science 144: 31.

Olsson, P. A. (1999) Signature fatty acids provide tools for determination of the distribution and interactions of mycorrhizal fungi in soil. FEMS Microbiology Ecology 29: 303-310.

Paavolainen, L. et al. (1998) Inhibition of nitrification in forest soil by monoterpenes. Plant and Soil 205: 147-154.

Palazzolo, E. et al. (2013) Current and potential use of citrus essential oils. Current Organic Chemistry 17: 3042-3049.

Pankhurst, C. E. (1997) Biodiversity of soil organisms as an indicator of soil health.

Papatheodorou, E. M. et al. (2002) Biological and biochemical parameters distinguishing soil microsites under different mediterranean shrub species. 7. International meeting on Soils with Mediterranean Type of Climate (selected papers) (K. S. (ed. ). Zdruli P. (ed.), Steduto P. (ed.), ed): pp. 37-44.

Paz-Ferreiro, J. \& Fu, S. (2016) Biological indices for soil quality evaluation: perspectives and limitations. Land Degradation \& Development 27: 14-25.

Pickett, S. T. A. et al. (1989) The ecological concept of disturbance and its expression at various hierarchical levels. Oikos 54: 129.

Ponce, A. G. et al. (2003) Antimicrobial activity of essential oils on the native microflora of organic Swiss chard. LWT - Food Science and Technology 36: 679-684.

Projar (2015), agricultural furniture. https://www.projar.es/.

Rahman, A. et al. (2016) In vitro antibacterial properties of essential oil and organic extracts of Premna integrifolia Linn. Arabian Journal of Chemistry 9: S475-S479.

Rasooli, I. et al. (2003) Microbial sensitivity to and chemical properties of the essential oil of Artemisia annua L. Journal of Essential Oil Research 15: 59-62.

Raut, J. S. \& Karuppayil, S. M. (2014) A status review on the medicinal properties of essential oils. Industrial Crops and Products 62: 250-264.

Regnault-Roger, C. et al. (2012) Essential oils in insect control: low-risk products in a highstakes world. Annual Review of Entomology 57: 405-424.

Reigosa-Roger, M. J. \& Sánchez-Moreiras, A. M. (2009) Role of phenolics in allelopathy in the soil. Soil Phenols pp. 87-115. Nova Science Publishers, Inc.

Reigosa, M. J. \& Pazos-Malvido, E. (2007) Phytotoxic effects of 21 plant secondary metabolites on Arabidopsis thaliana germination and root growth. Journal of Chemical Ecology 33: 1456-1466.

Reigosa, M. J. et al. (2006) Allelopathy: A physiological process with ecological 
implications (MJ Reigosa, N Pedrol, and L González, Eds.). Dordrecht: Kluwer Academic Publishers.

Salie, F. et al. (1996) Preliminary antimicrobial screening of four South African Asteraceae species. Journal of ethnopharmacology 52: 27-33.

Sanyal, D. \& Shrestha, A. (2008) Direct effect of herbicides on plant pathogens and disease development in various cropping systems. Weed Science 56: 155-160.

Savary, S. et al. (2012) Crop losses due to diseases and their implications for global food production losses and food security. Food Security 4: 519-537.

Schloter, M. et al. (2003) Indicators for evaluating soil quality. Agriculture, Ecosystems and Environment 98: 255-262.

Scognamiglio, M. et al. (2013) Plant growth inhibitors: allelopathic role or phytotoxic effects? Focus on Mediterranean biomes. Phytochemistry Reviews 12: 803-830.

Seo, S.-M. et al. (2014) Fumigant toxicity and acetylcholinesterase inhibitory activity of 4 Asteraceae plant essential oils and their constituents against Japanese termite (Reticulitermes speratus Kolbe). Pesticide biochemistry and physiology 113: 55-61.

Settanni, L. et al. (2012) Inhibition of foodborne pathogen bacteria by essential oils extracted from citrus fruits cultivated in Sicily. Food Control 26: 326-330.

Da Silva, J. A. T. et al. (2005) Important secondary metabolites and essential oils of species within the Anthemideae (Asteraceae). Journal of Herbs, Spices \& Medicinal Plants 11: $1-46$.

Sliti, S. et al. (2015) Leaf essential oils chemical composition, antibacterial and antioxidant activities of Eucalyptus camaldulensis and E. rudis from korbous (Tunisia). Journal of Materials and Environmental Science 6: 743-748.

Smith, T. M. \& Smith, R. L. (2009) Elements of Ecology.

Soares, S. F. et al. (2010) Repellent activity of plant-derived compounds against Amblyomma cajennense (Acari: Ixodidae) nymphs. Veterinary Parasitology 167: 6773.

Solórzano-Santos, F. \& Miranda-Novales, M. G. (2012) Essential oils from aromatic herbs as antimicrobial agents. Current Opinion in Biotechnology 23: 136-141.

Sparling, G. (1997) Soil microbial biomass, activity and nutrient cycling as indicators of soil health. Biological Indicators of Soil Health pp. 97-119. CAB International.

Synowiec, A. et al. (2017) Phytotoxic potential of essential oils from temperate climate plants against the germination of selected weeds and crops. Journal of Pest Science 90: 407-419. 
Tabassum, N. \& Vidyasagar, G. M. (2013) Antifungal investigations on plant essential oils. A review. International Journal of Pharmacy and Pharmaceutical Sciences 5: 19-28.

Tabti, L. et al. (2014) Antioxidant and antifungal activity of extracts of the aerial parts of Thymus capitatus (L.) Hoffmanns against four phytopathogenic fungi of citrus sinensis. Jundishapur Journal of Natural Pharmaceutical Products 9: 49-54.

Vance, E. D. D. et al. (1987) An extraction method for measuring soil microbial biomass C. Soil Biology and Biochemistry 19: 703-707.

Verdeguer, M. (2011) Fitotoxicidad de aceites esenciales y extractos acuosos de las plantas mediterráneas para el control de arvenses.

Verdeguer, M. et al. (2009) Phytotoxic effects of Lantana camara, Eucalyptus camaldulensis and Eriocephalus africanus essential oils in weeds of Mediterranean summer crops. Biochemical Systematics and Ecology 37: 362-369.

Viljoen, A. M. et al. (2006) Essential oil composition and in vitro biological activities of seven Namibian species of Eriocephalus L. (Asteraceae). Journal of essential oil research 18: $124-128$.

Vokou, D. \& Liotiri, S. (1999) Stimulation of soil microbial activity by essential oils. Chemoecology 9: 41-45.

Vokou, D. \& Margaris, N. S. (1986) Variation of volatile oil concentration of Mediterranean aromatic shrubs Thymus capitatus hoffmag et link, Satureja thymbra L., Teucrium polium L. and Rosmarinus officinalis. International Journal of Biometeorology 30: 147-155.

Vokou, D. et al. (1984) Effects of volatile oils from aromatic shrubs on soil microorganisms. Soil Biology and Biochemistry 16: 509-513.

Vokou, D. et al. (2002) Activation of soil respiration and shift of the microbial population balance in soil as a response to Lavandula stoechas essential oil. Journal of chemical ecology 28: 755-68.

Walkley, A. \& Black, I. A. (1934) An examination of the Degtjareff methd for determining soil organic matter, and a proposed modification of the chromic acid titration method. Soil Science 37: 4-5.

Wang, C. et al. (2011) Review on allelopathy of exotic invasive plants. Procedia Engineering 18: 240-246.

Weston, L. A. \& Mathesius, U. (2013) Flavonoids: their structure, biosynthesis and role in the rhizosphere, including allelopathy. Journal of chemical ecology 39: 283-97.

Williams, D. E. (1949) A rapid manometric method for the determination of carbonate in 
soils. Soil Science Society of America Journal 13: 127.

Wixon, D. L. \& Balser, T. C. (2013) Toward conceptual clarity: PLFA in warmed soils. Soil Biology and Biochemistry 57: 769-774.

Wu, Y. et al. (2009) Effects of different soil weights, storage times and extraction methods on soil phospholipid fatty acid analyses. Geoderma 150: 171-178.

Yang, Q. et al. (2012) Modelling the effects of plastic mulch on water, heat and $\mathrm{CO}_{2}$ fluxes over cropland in an arid region. Journal of Hydrology 452-453: 102-118.

Zeng, R. et al. (2008) Allelopathy in Sustainable Agriculture and Forestry (R Sen Zeng, AU Mallik, and SM Luo, Eds.). New York, NY: Springer New York.

Zhang, J. et al. (2014) Phytotoxic activity and chemical composition of aqueous volatile fractions from Eucalyptus species. (J Chamani, Ed.). PloS one 9: e93189. 